\title{
DISSERTATION
}

\section{REDUCING CARBON DIOXIDE EMISSIONS IN THE ELECTRICITY SECTOR USING DEMAND SIDE MANAGEMENT}

\author{
Submitted by \\ Sulaiman Almohaimeed \\ Department of Electrical and Computer Engineering \\ In partial fulfillment of the requirements \\ For the Degree of Doctor of Philosophy \\ Colorado State University \\ Fort Collins, Colorado
}

Summer 2019

Doctoral Committee:

Advisor: Siddharth Suryanarayanan

George J Collins

Daniel Zimmerle

Patricia Aloise-Young

Peter O’Neill 
Copyright by Sulaiman Almohaimeed 2019

All Rights Reserved 
ABSTRACT

\section{REDUCING CARBON DIOXIDE EMISSIONS IN THE ELECTRICITY SECTOR USING DEMAND SIDE MANAGEMENT}

Increasing demand for energy consumption leads to concerns of global Greenhouse Gas (GHG) emissions. Most of the supplied energy comes from dirty generating units. Since there are no regulations to limit emissions of $\mathrm{CO}_{2}$ from electricity generation, power plants can emit unlimited amount of $\mathrm{CO}_{2}$. This dissertation, first, aims to explain some government directed plans to reduce GHG emissions. It gives an overview about the Clean Power Plan (CPP) and its benefits and challenges. Further, it explains several options of CPP in reducing emissions and its repeal. Further, this dissertation, discusses the Climate Action Plan (CAP) corresponding to Fort Collins, Colorado, U.S. and its timeline targets.

Demand side management (DSM) is discussed as a solution from engineering practices to affect GHG. Several options from DSM are investigated to reduce emissions. In fact, reducing energy consumption through DSM leads to a reduction in harmful emissions to the environment. This dissertation aims to identify the best available DSM options that will make the biggest difference for GHG reductions.

A framework is created to examine several options of DSM in reducing carbon footprints. The framework states that affecting GHG in electric power system is the main goal. The goal can be achieved by implementing DSM technologies in distribution systems. The framework proposes criteria such as cost, power quality, reliability, environmental collateral, and socioeconomic equity to examine the effectiveness of several alternatives: energy management, communication and intelligence, electrification of heating and transportation, and distributed generation.

Multi-Criteria Decision Making (MCDM) algorithms have been proposed to prioritize alternatives and select the ones that achieve suitable emissions reduction. Analytic Hierarchy Process (AHP) is one of the most common tools to perform decision-making analysis. The findings from AHP show that the "communication and intelligence" option is the potential optimal alternative in achieving the goal. Analytic Network Process 
(ANP) is another method for making decisions. It provides feedback and interdependence relationships between all nodes of the problem. It is more realistic and accurate than AHP. The results obtained from ANP suggest that "communication and intelligence" is the optimum technology to reach the target. By using ANP, the overall priority ranking has changed and the difference in priorities has reduced.

Institute of Electrical and Electronics Engineers (IEEE) 13-node test feeder is used, through Open Distribution System Simulator (OpenDSS), to perform power flow analysis on yearly load profile corresponding to Fort Collins, Colorado, U.S. The analysis includes simulation for several scenarios from the MCDM alternatives, either individual alternatives or mixed alternatives. The obtained results for the base case show the emissions decreased by $16.26 \%$ from 2005 level which comply with the results from emissions indicator released by the city. Integrating the MCDM alternatives indicates $\mathrm{CO}_{2}$ emissions change as a result of variation in supply and demand curve. The findings for 2017 load profile demonstrated that "electric stationary storage" is the best option, environmentally, since it contributes in more than $18 \%$ emissions reduction from 2005 level. The second alternative is "energy conservation" by achieving a $20.39 \%$ reduction in emissions, merging both alternatives in one scenario could increase the emissions mitigation up to $22.17 \%$. By simulation the residential sector, "communication and intelligence" shows about 14\% reduction in emissions from 2005 level. A scenario that combines "electric stationary storage" with "communication and intelligence" diminishes the emissions by more than $15 \%$. Indeed, combining "communication and intelligence" with "energy conservation" can decrease the environmental footprint by $18.04 \%$. Last scenario examined combining all MCDM alternatives in one option. The result finds that this option can reach $19.72 \%$ emissions reduction.

Since the simulation part investigates the system from environmental perspective, this work deploys a Cost Benefit Analysis (CBA) to assess economic, technical, and environmental cost and benefits associated with each alternative. The economic evaluation shows that "electric stationary storage" is the potential best option. This is reasonable since ESS charges during lower electricity price and discharge during peaking demand. Thus, the customers can avoid the high electricity charges, and the utility is not required to run more generating units. "communication and intelligence" combined with "electric stationary storage" is the second option due to its flexibility in shifting the loads to off-peak periods is. The scenario that includes all MCDM options came in the 
third place since it provides almost 20\% emissions reduction and its economic evaluation is beneficial. While "energy conservation" project and "electric stationary storage" with "energy conservation" project provide less economic impact than "communication and intelligence", those alternatives hold the fourth and fifth place, respectively, due to their environmental impact. The penultimate alternative is "communication and intelligence" because the Demand Response (DR) is designed to shift the peak load, and it has socioeconomic cost. Last alternative is combining "communication and intelligence" with "energy conservation". Although “energy conservation" performs environmentally better than "communication and intelligence", its socioeconomic cost plays a major role in selecting such alternative. However, the ranking might change according to the participants' choice. One can prefer environmental impact over economic output and vice versa. Therefore, this work presents a trade-off chart, so the decision maker can select the alternative based on their preference.

All analysis, simulation, and results in this work are particularly based on Fort Collins distribution system data and is not a general assessment. There are several factors might affect the result such as the location, the data, or the distribution system structure. 


\section{ACKNOWLEDGMENTS}

I would like, first, to thank all people who helped me in accomplishing this work. I would like to thank my advisor, Prof. Siddharth Suryanarayanan, for his guidance, encouragement, and support in doing this work. My thanks go my committee members Prof. George J Collins, Prof. Daniel Zimmerle, Prof. Patricia AloiseYoung, and Peter O’Neill for their advice and support. Additionally, I would like to thank Peter O’Neill, for his work on the surveys related to prioritizing demand side management technologies.

I must extend my gratitude to my mother and all my family members for their encouragements and motivations. Special mention goes to my supportive wife, and my wonderful son, Azzam, for their help and patience during doing this work.

I hugely acknowledge the Saudi Arabian Cultural Mission and Qassim University, Qassim Province, Saudi Arabia for their financial support for pursuing a Ph.D. in Electrical and Computer Engineering at Colorado State University. My colleagues at Advanced Power Engineering Laboratory also deserve many thanks for their help and support. 


\section{TABLE OF CONTENTS}

ABSTRACT

\section{CHAPTER 1}

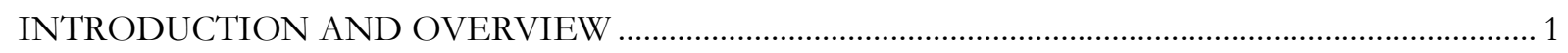

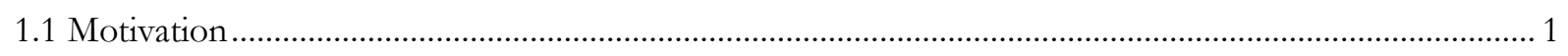

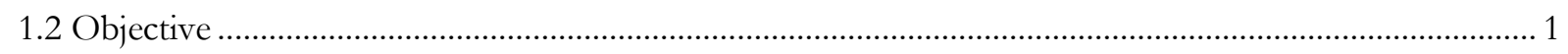

1.3 Scope

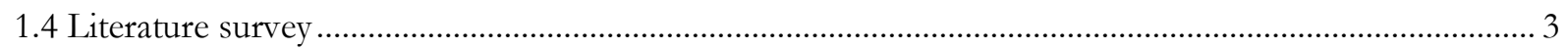

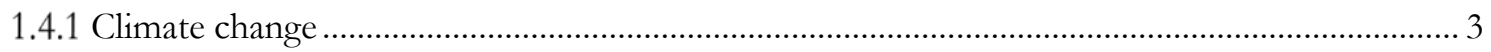

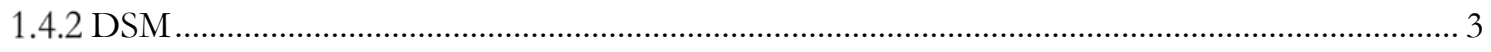

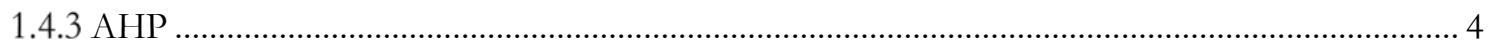

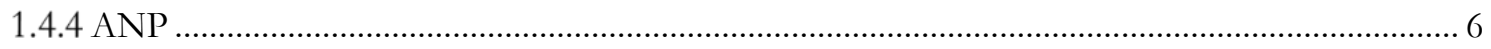

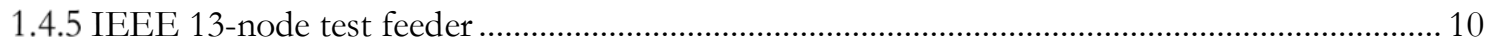

1.4.6 CBA

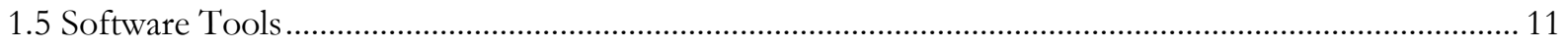

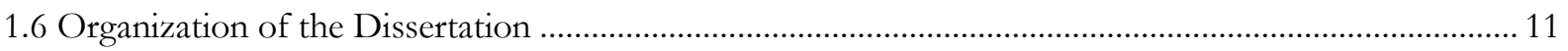

\section{CHAPTER 2}

GOVERNMENT DIRECTED PLANS TO REDUCE GHG EMISSIONS ........................................... 12

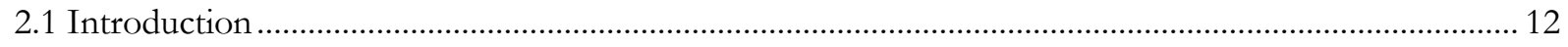

2.2 Clean Power Plan .................................................................................................................. 12

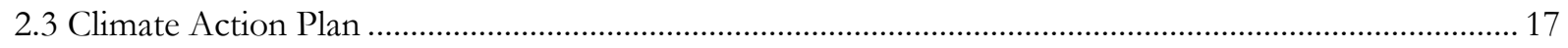




\section{CHAPTER 3}

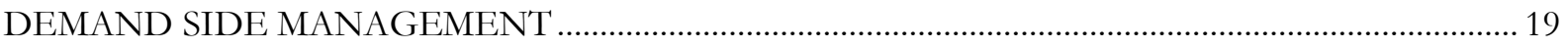

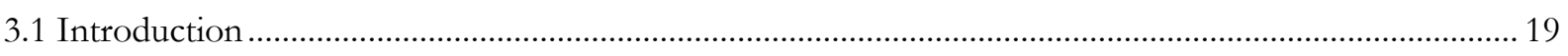

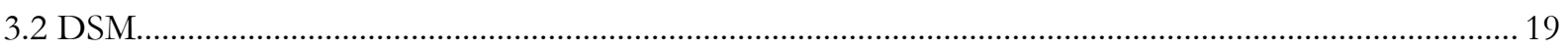

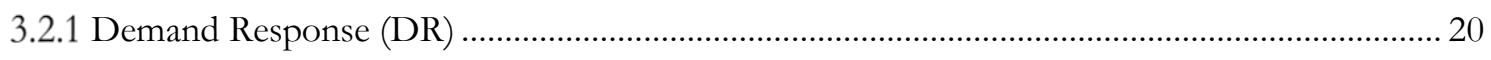

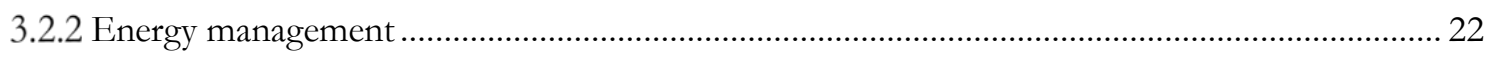

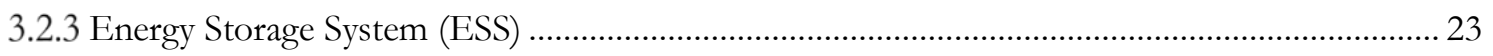

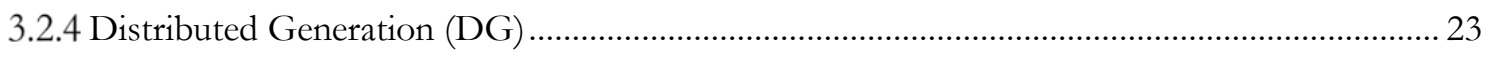

\section{CHAPTER 4}

ANALYTIC HIERARCHY PROCESS ALGORITHM TO PRIORITIZE DEMAND SIDE

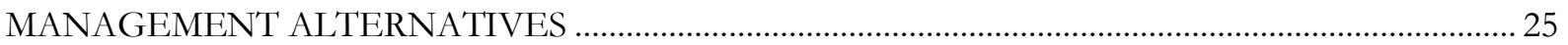

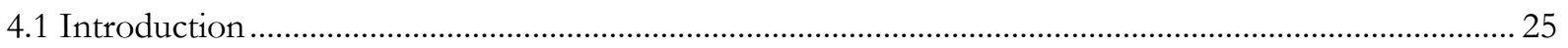

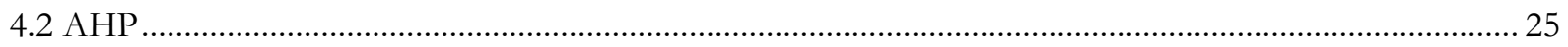

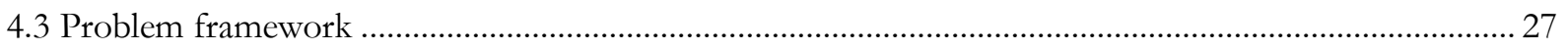

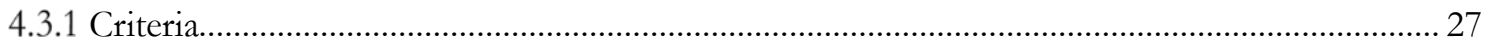

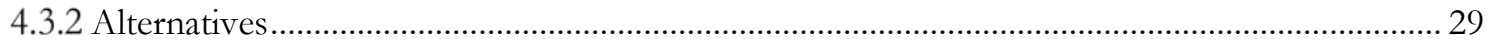

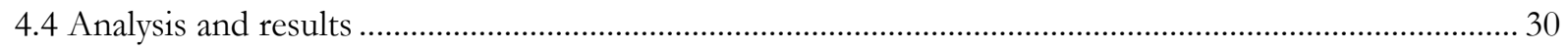

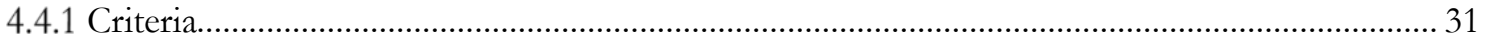

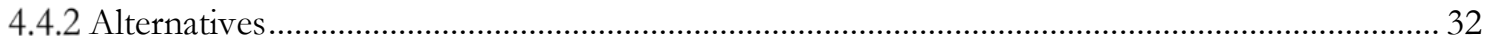

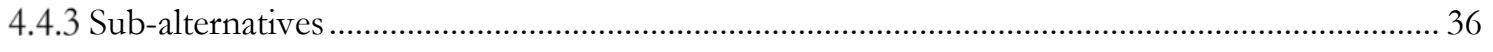

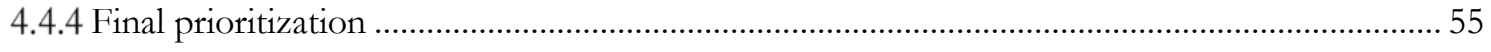

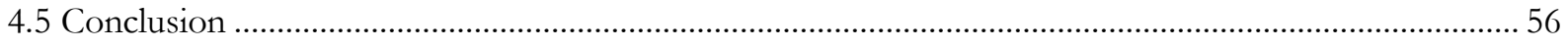

\section{CHAPTER 5}

ANALYTIC NETWORK PROCESS ALGORITHM TO PRIORITIZE DEMAND SIDE

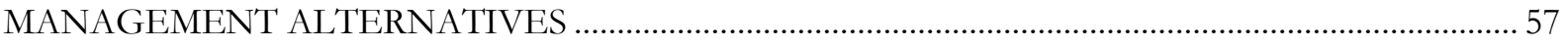

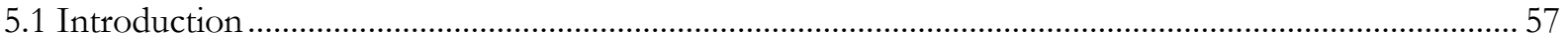




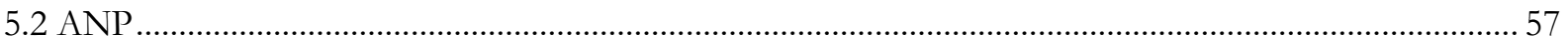

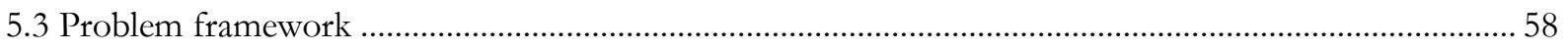

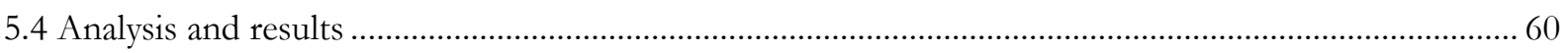

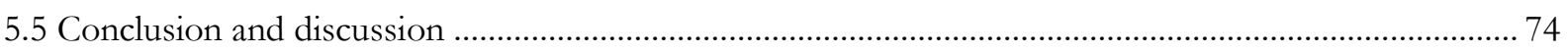

\section{CHAPTER 6}

MODELING AND SIMULATION OF THE DISTRIBUTION SYSTEM …........................................ 76

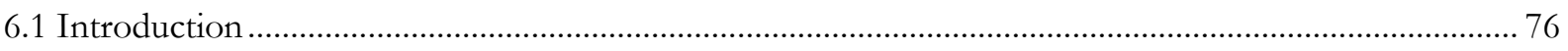

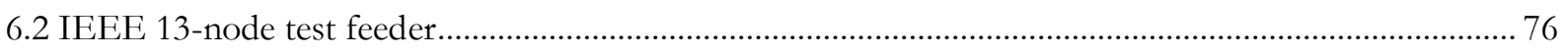

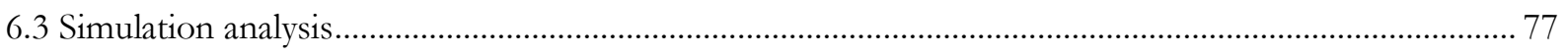

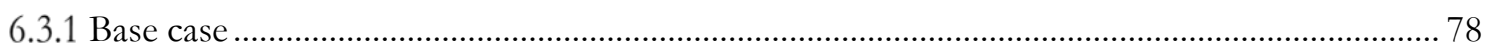

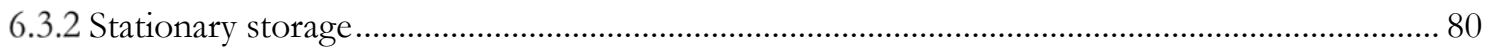

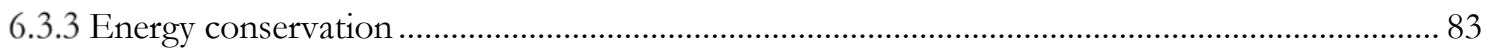

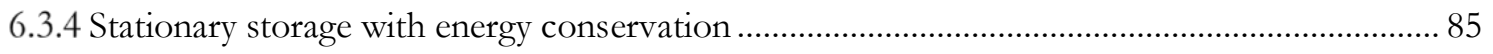

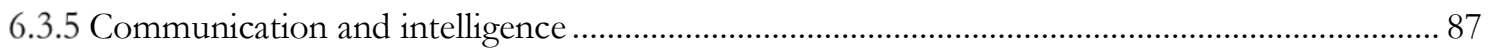

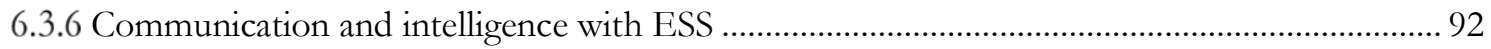

6.3.7 Communication and intelligence with energy conservation .................................................... 93

6.3.8 Communication and intelligence with ESS and energy conservation........................................ 95

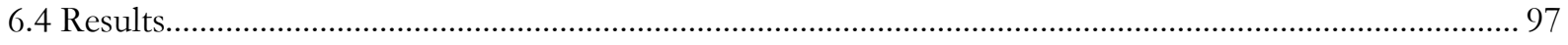

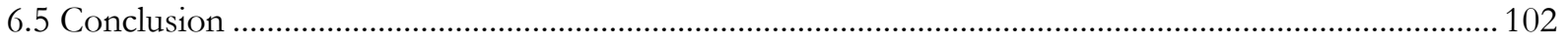

\section{CHAPTER 7}

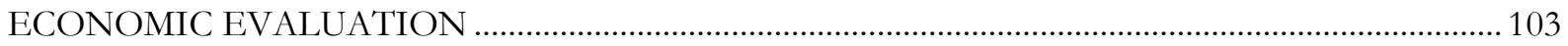

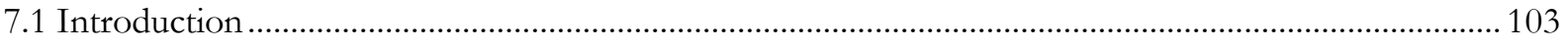

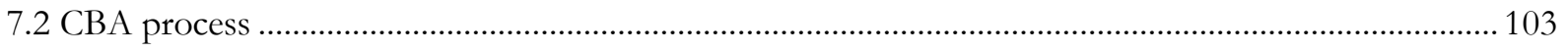

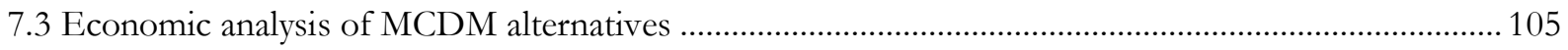

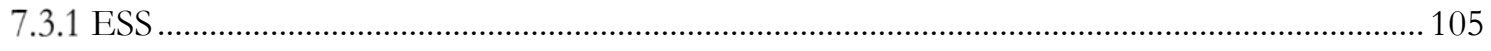

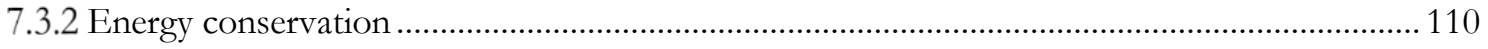


7.3.3 ESS with energy conservation

7.3.4 Communication and intelligence.

7.3.5 Communication and intelligence with ESS

7.3.6 Communication and intelligence with energy conservation

7.3.7 Communication and intelligence with ESS and energy conservation.

7.4 Results..

7.5 Conclusion

\section{CHAPTER 8}

CONCLUSION AND FUTURE WORK

8.1 Introduction

8.2 Conclusion

8.3 Future work

REFERENCES

\section{APPENDIX}

AHP questions for reducing GHG emissions with an electric distribution system

AHP questions for applying energy conservation to reduce GHG emissions with an electric distribution system 165

ANP questions for reducing GHG emissions with an electric distribution system 167 


\section{LIST OF TABLES}

Table 1-1: The Fundamental Scale for Pairwise Comparison [22] ……........................................................... 5

Table 1-2: Judgment Matrix for Alternatives with respect to Flood Control [25] …........................................ 7

Table 1-3: Judgment Matrix for Alternatives with respect to Recreation [25].................................................... 7

Table 1-4: Judgment Matrix for Alternatives with respect to Hydroelectric Power [25].................................... 7

Table 1-5: Judgment Matrix for Criteria with respect to Low Level [25] ........................................................ 7

Table 1-6: Judgment Matrix for Criteria with respect to Medium Level [25] ..................................................... 8

Table 1-7: Judgment Matrix for Criteria with respect to High Level [25]......................................................... 8

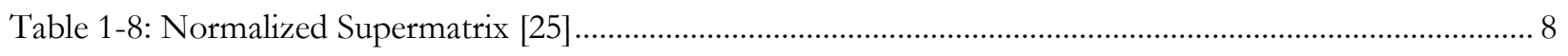

Table 1-9: Limit Matrix [25] ............................................................................................................... 9

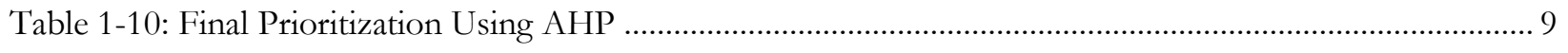

Table 4-1: Judgment Matrix and Global Priority for Criteria (before fixing inconsistency ratio) ...................... 31

Table 4-2: Judgment Matrix and Global Priority for Criteria (after fixing inconsistency ratio) .......................... 31

Table 4-3: Judgment Matrix for Alternatives with respect to CR1, i.e., Cost (before fixing inconsistency ratio)

Table 4-4: Judgment Matrix for Alternatives with respect to CR1, i.e., Cost (after fixing inconsistency ratio) 32 Table 4-5: Judgment Matrix for Alternatives with respect to CR2, i.e., Reliability (before fixing inconsistency

ratio)

Table 4-6: Judgment Matrix for Alternatives with respect to CR2, i.e., Reliability (after fixing inconsistency

ratio)

Table 4-7: Judgment Matrix for Alternatives with respect to CR3, i.e., Power Quality (before fixing inconsistency ratio)

Table 4-8: Judgment Matrix for Alternatives with respect to CR3, i.e., Power Quality (after fixing inconsistency ratio) 
Table 4-9: Judgment Matrix for Alternatives with respect to CR4, i.e., Environmental Collateral (before fixing inconsistency ratio)

Table 4-10: Judgment Matrix for Alternatives with respect to CR4, i.e., Environmental Collateral (after fixing inconsistency ratio)

Table 4-11: Judgment Matrix for Alternatives with respect to CR5, i.e., Socio-economic Equity (before fixing inconsistency ratio)

Table 4-12: Judgment Matrix for Alternatives with respect to CR5, i.e., Socio-economic Equity (after fixing inconsistency ratio)

Table 4-13: Judgment Matrix for Sub-alternatives with respect to CR1, i.e., Cost (before fixing inconsistency ratio)

Table 4-14: Judgment Matrix for Sub-alternatives with respect to CR1, i.e., Cost (after fixing inconsistency

ratio)

Table 4-15: Judgment Matrix for Sub-alternatives with respect to CR2, i.e., Reliability ...... .37

Table 4-16: Judgment Matrix for Sub-alternatives with respect to CR3, i.e., Power Quality..... 37

Table 4-17: Judgment Matrix for Sub-alternatives with respect to CR4, i.e., Environmental Collateral (before fixing inconsistency ratio).

Table 4-18: Judgment Matrix for Sub-alternatives with respect to CR4, i.e., Environmental Collateral (after fixing inconsistency ratio)

Table 4-19: Judgment Matrix for Sub-alternatives with respect to CR5, i.e., Socioeconomic Equity (before fixing inconsistency ratio)

Table 4-20: Judgment Matrix for Sub-alternatives with respect to CR5, i.e., Socioeconomic Equity (after fixing inconsistency ratio) 39

Table 4-21: Local Priority and Global Priority for Energy Consumption with respect to Each Criterion ....... 40

Table 4-22: Judgment Matrix for Alternatives under Energy Conservation with respect to CR1, i.e., Cost

(before fixing inconsistency ratio). 41 
Table 4-23: Judgment Matrix for Alternatives under Energy Conservation with respect to CR1, i.e., Cost

(after fixing inconsistency ratio)

Table 4-24: Judgment Matrix for Alternatives under Energy Conservation with respect to CR2, i.e., Reliability

Table 4-25: Judgment Matrix for Alternatives under Energy Conservation with respect to CR3, i.e., Power

Quality (before fixing inconsistency ratio)

Table 4-26: Judgment Matrix for Alternatives under Energy Conservation with respect to CR3, i.e., Power

Quality (after fixing inconsistency ratio)

Table 4-27: Judgment Matrix for Alternatives under Energy Conservation with respect to CR4, i.e.,

Environmental Collateral (before fixing inconsistency ratio)

Table 4-28: Judgment Matrix for Alternatives under Energy Conservation with respect to CR4, i.e.,

Environmental Collateral (after fixing inconsistency ratio)

Table 4-29: Judgment Matrix for Alternatives under Energy Conservation with respect to CR5, i.e., Socio-

economic Equity

Table 4-30: Energy Conservation Final Prioritization 44

Table 4-31: Judgment Matrix for Sub-alternatives with respect to CR1, i.e., Cost (before fixing inconsistency

ratio)

Table 4-32: Judgment Matrix for Sub-alternatives with respect to CR1, i.e., Cost (after fixing inconsistency ratio)

Table 4-33: Judgment Matrix for Sub-alternatives with respect to CR1, i.e., Reliability 45

Table 4-34: Judgment Matrix for Sub-alternatives with respect to CR3, i.e., Power Quality (before fixing inconsistency ratio)

Table 4-35: Judgment Matrix for Sub-alternatives with respect to CR3, i.e., Power Quality (after fixing inconsistency ratio) 46

Table 4-36: Judgment Matrix for Sub-alternatives with respect to CR4, i.e., Environmental Collateral 46 
Table 4-37: Judgment Matrix for Sub-alternatives with respect to CR5, i.e., Socio-economic Equity (before fixing inconsistency ratio)

Table 4-38: Judgment Matrix for Sub-alternatives with respect to CR5, i.e., Socio-economic Equity (after fixing inconsistency ratio)

Table 4-39: Local Priority and Global Priority for Communication and Intelligence with respect to Each

Criterion 48

Table 4-40: Judgment Matrix for Sub-alternatives with respect to CR1, i.e., Cost (before fixing inconsistency ratio)

Table 4-41: Judgment Matrix for Sub-alternatives with respect to CR1, i.e., Cost (after fixing inconsistency ratio)

Table 4-42: Judgment Matrix for Sub-alternatives with respect to CR2, i.e., Reliability (before fixing inconsistency ratio)

Table 4-43: Judgment Matrix for Sub-alternatives with respect to CR2, i.e., Reliability (after fixing inconsistency ratio)

Table 4-44: Judgment Matrix for Sub-alternatives with respect to CR3, i.e., Power Quality..... 51

Table 4-45: Judgment Matrix for Sub-alternatives with respect to CR4, i.e., Environmental Collateral (before fixing inconsistency ratio)

Table 4-46: Judgment Matrix for Sub-alternatives with respect to CR4, i.e., Environmental Collateral (after fixing inconsistency ratio)

Table 4-47: Judgment Matrix for Sub-alternatives with respect to CR5, i.e., Socio-economic Equity (before fixing inconsistency ratio)

Table 4-48: Judgment Matrix for Sub-alternatives with respect to CR5, i.e., Socio-economic Equity (after

fixing inconsistency ratio)

Table 4-49: Local Priority and Global Priority for Electrification of Heating and Transportation with respect to Each Criterion.

Table 4-50: Judgment Matrix for Sub-alternatives with respect to CR1, i.e., Cost... 54 
Table 4-51: Judgment Matrix for Sub-alternatives with respect to CR2, i.e., Reliability ...... 54

Table 4-52: Judgment Matrix for Sub-alternatives with respect to CR3, i.e., Power Quality............................. 54

Table 4-53: Judgment Matrix for Sub-alternatives with respect to CR4, i.e. Environmental Collateral ............ 54

Table 4-54: Judgment Matrix for Sub-alternatives with respect to CR5, i.e., Socio-economic Equity .............. 54

Table 4-55: Local Priority and Global Priority for DG with respect to Each Criterion ................................... 55

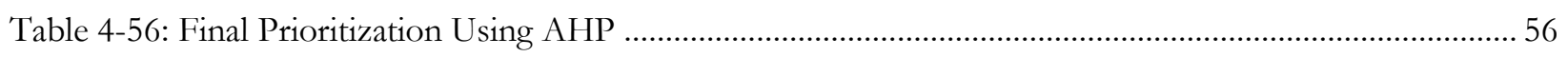

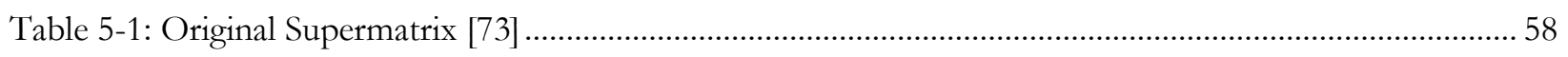

Table 5-2: Judgment Matrix for Criteria with respect to Energy Conservation (before fixing inconsistency) .. 60

Table 5-3: Judgment Matrix for Criteria with respect to Energy Conservation (after fixing inconsistency) ..... 60

Table 5-4: Judgment Matrix for Criteria with respect to Load Side Management (before fixing inconsistency)

Table 5-5: Judgment Matrix for Criteria with respect to Load Side Management (before fixing inconsistency)

Table 5-6: Judgment Matrix for Criteria with respect to Electric Stationary Storage (before fixing inconsistency)

Table 5-7: Judgment Matrix for Criteria with respect to Electric Stationary Storage (after fixing inconsistency)

Table 5-8: Judgment Matrix for Criteria with respect to Communication and Intelligence (before fixing inconsistency)

Table 5-9: Judgment Matrix for Criteria with respect to Communication and Intelligence (after fixing inconsistency)

Table 5-10: Judgment Matrix for Criteria with respect to Geo-exchange Heat Pump. 64

Table 5-11: Judgment Matrix for Criteria with respect to Electric Water Heater (before fixing inconsistency)

Table 5-12: Judgment Matrix for Criteria with respect to Electric Water Heater (after fixing inconsistency) .. 65

Table 5-13: Judgment Matrix for Criteria with respect to Electric Vehicles. .65 
Table 5-14: Judgment Matrix for Criteria with respect to Solar PV (before fixing inconsistency)...................... 66

Table 5-15: Judgment Matrix for Criteria with respect to Solar PV (after fixing inconsistency) ........................ 66

Table 5-16: Judgment Matrix for Criteria with respect to Combustion Generation (before fixing

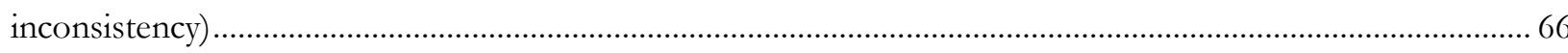

Table 5-17: Judgment Matrix for Criteria with respect to Combustion Generation (after fixing inconsistency)

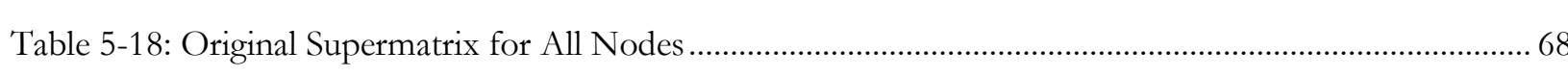

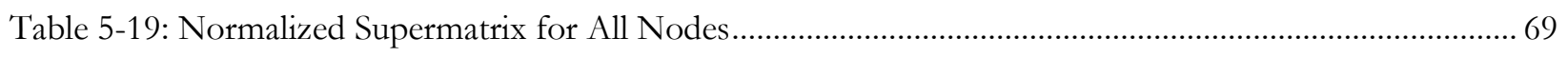

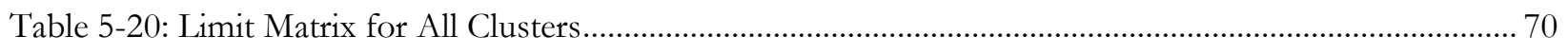

Table 5-21: Normalized Limit Matrix for All Clusters .................................................................................... 71

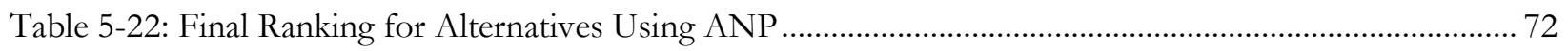

Table 5-23: Final Ranking for Alternatives Using AHP ................................................................................ 73

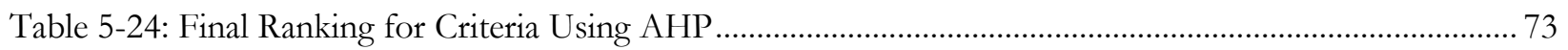

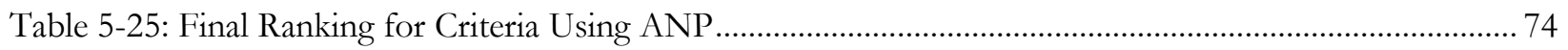

Table 6-1: Emissions, from the IEEE Test System, after ESS ...................................................................... 82

Table 6-2: Emissions, from the IEEE Test System after Energy Conservation................................................. 84

Table 6-3: Emissions, from the IEEE Test System, after using ESS with Energy Conservation ...................... 86

Table 6-4: Emissions, from the IEEE Test System, after using Residential DR ….......................................... 91

Table 6-5: Emissions, from the IEEE Test System, after using Residential DR with ESS ............................. 93

Table 6-6: Emissions, from the IEEE Test System, after using Residential DR with Energy Conservation ... 94

Table 6-7: Emissions, from the IEEE Test System, after combining all options .......................................... 96

Table 6-8: Emissions, from the IEEE Test System, after using ESS and Energy Conservation ...................... 99

Table 6-9: Emissions reduction, from the IEEE Test System, after integrating ESS and Energy Conservation

Table 6-10: Emissions, from the IEEE Test System, for all MCDM alternatives ............................................. 100 
Table 6-11: Emissions from the electricity residential sector, from the IEEE Test System, for all MCDM

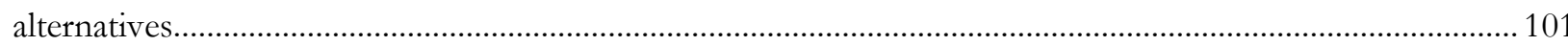

Table 7-1: ESS Estimated Prices............................................................................................................... 106

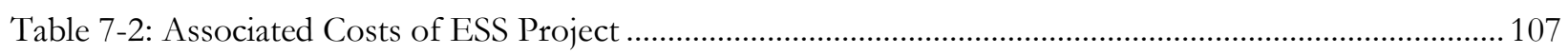

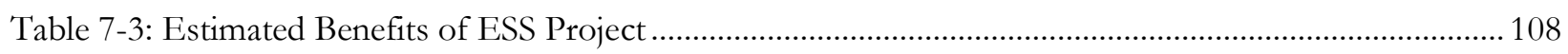

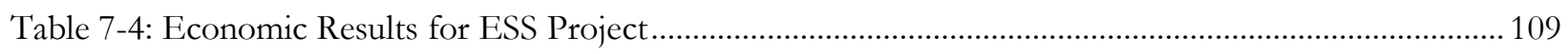

Table 7-5: Associated Costs of Energy Conservation Project ……............................................................... 111

Table 7-6: Estimated Benefits for Energy Conservation Project..................................................................... 111

Table 7-7: Economic Results for Energy Conservation Project....................................................................... 112

Table 7-8: Estimated Costs of combining ESS with Energy Conservation.................................................... 114

Table 7-9: Estimated Benefits of combining ESS with Energy Conservation Project ................................... 115

Table 7-10: Economic Results after using ESS and Energy Conservation Project ...................................... 116

Table 7-11: Residential Energy Rate before DR Program.............................................................................. 118

Table 7-12: The First Year Financial Impact ............................................................................................ 120

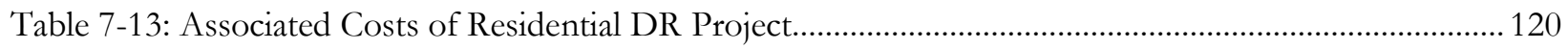

Table 7-14: Estimated Benefits of Applying Residential DR Project............................................................. 121

Table 7-15: Economic Results for Residential DR Project ............................................................................. 121

Table 7-16: The First Year Financial Impact for Residential DR with ESS Project......................................... 123

Table 7-17: Costs of deploying Residential DR with ESS Project.................................................................. 124

Table 7-18: Estimated Benefits of using Residential DR with ESS Project ................................................... 125

Table 7-19: Economic Results after Combining Residential DR and ESS Project.......................................... 126

Table 7-20: The First Year Financial Impact after incorporating Energy Conservation with Residential DR

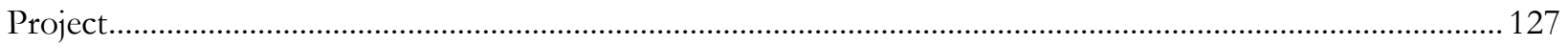

Table 7-21: Costs of applying Residential DR with Energy Conservation Project.......................................... 128

Table 7-22: Expected Benefit of merging Energy Conservation with Residential DR ................................. 129

Table 7-23: Economic Results for Residential DR with Energy Conservation Project .................................... 130 
Table 7-24: The First Year Financial Impact after combining All MCDM Alternatives.

Table 7-25: Costs of combining All MCDM Alternatives................................................................................ 133

Table 7-26: Benefits of combining All MCDM Alternatives ......................................................................... 134

Table 7-27: Economic Results for combining All MCDM Alternatives .......................................................... 135

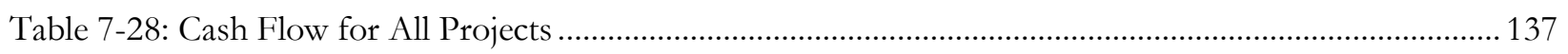

Table 7-29: Cumulative Cash Flow for All Projects............................................................................... 137

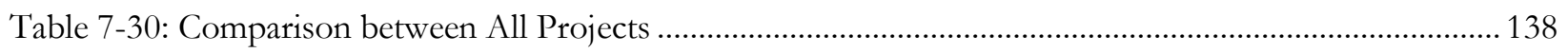




\section{LIST OF FIGURES}

Figure 1-1: A Problem structure reproduced from [25] …......................................................................... 6

Figure 2-1: The U.S. Electricity Generation from Coal in 2017 [35] .......................................................... 13

Figure 2-2: The U.S. Emission Reduction from Electric Sector in 2017 [41] .................................................. 14

Figure 2-3: $\mathrm{CO}_{2}$ Emissions from the Electric sector from the Alternative Cases [42] ................................... 16

Figure 2-4: Fort Collins Generation Resources [44] …............................................................................ 17

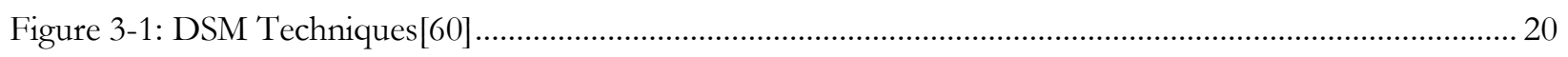

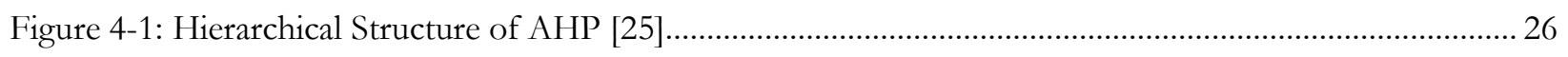

Figure 4-2: Hierarchy of Reducing GHG Emissions with an Electric Distribution System ............................ 28

Figure 5-1: Network Structure for ANP Problem ……................................................................................... 59

Figure 6-1: IEEE 13-node Test Feeder, recreated from [90] ...................................................................... 77

Figure 6-2: Load profile and generation mix, from the IEEE test system, for 2017 (base case) ...................... 79

Figure 6-3: Emissions from the electricity sector, from the IEEE test system, for 2017 (base case) ................ 80

Figure 6-4: Load profile and generation mix, from the IEEE test system, for 2017 after applying ESS .......... 81

Figure 6-5: Load profile and generation mix, from the IEEE test system, on 9/5/2019 after applying ESS .. 82

Figure 6-6: Emissions from the electricity sector, from the IEEE test system, for 2017 after applying ESS... 83

Figure 6-7: Load profile and generation mix, from the IEEE test system, for 2017 after applying energy

conservation

Figure 6-8: Emissions from the electricity sector, from the IEEE test system, for 2017 after applying energy

conservation

Figure 6-9: Load profile and generation mix, from the test system, for 2017 after combining ESS and energy

conservation 86

Figure 6-10: Emissions from the electricity sector, from the IEEE test system, for 2017 after combining ESS

and energy conservation 87

Figure 6-11: Non-Summer electricity prices corresponding to Fort Collins 88 
Figure 6-12: Summer electricity prices corresponding to Fort Collins

Figure 6-13: Residential load profile and generation mix, from the IEEE test system, for 2017 after using

residential DR 89

Figure 6-14: Residential load profile and generation mix, from the IEEE test system, on 1/9/2017 .90

Figure 6-15: Residential load profile and generation mix, from the IEEE test system, on 6/1/2017 90 Figure 6-16: Emissions from the electricity residential sector, from the IEEE test system, for 2017 after using residential DR . 91

Figure 6-17: Residential load profile and generation mix, from the IEEE test system, for 2017 after using residential DR with ESS

Figure 6-18: Emissions from the electricity residential sector, from the IEEE test system, for 2017 after using Residential DR with ESS .93

Figure 6-19: Residential load profile and generation mix, from the IEEE test system, for 2017 after using residential DR with energy conservation

Figure 6-20: Emissions from the electricity residential sector, from the IEEE test system, for 2017 after using residential DR with energy conservation .95

Figure 6-21: Residential load profile and generation mix, from the IEEE test system, for 2017 after combining all options. 96

Figure 6-22: Emissions from the electricity residential sector, from the IEEE test system, for 2017 after combining all options. 97 Figure 6-23: Load profile and generation mix, from the IEEE test system, for 2017 after considering ESS and energy conservation 98 Figure 6-24: Residential Load profile and generation mix, from the IEEE test system, for 2017 for all MCDM alternatives 98

Figure 6-25: Emissions from electricity sector, from the IEEE test system, for 2017 after ESS and energy conservation 
Figure 6-26: Emissions from the electricity residential sector, from the IEEE test system, for 2017 for all

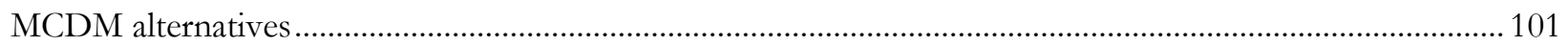

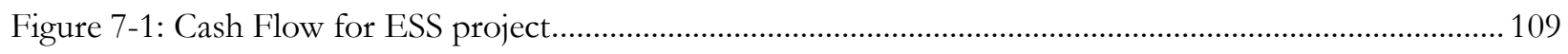

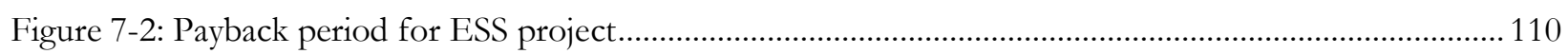

Figure 7-3: Cash Flow for energy conservation project........................................................................... 112

Figure 7-4: Payback period for energy conservation project.................................................................... 113

Figure 7-5: Cash Flow for the project of ESS with energy conservation......................................................... 116

Figure 7-6: Payback period for the project of ESS with energy conservation................................................. 117

Figure 7-7: Cash Flow for residential DR project ………........................................................................... 122

Figure 7-8: Payback period for residential DR project …............................................................................. 122

Figure 7-9: Cash flow for residential DR and ESS project................................................................. 126

Figure 7-10: Payback period for residential DR and ESS project............................................................... 127

Figure 7-11: Cash Flow for residential DR with energy conservation project ............................................... 131

Figure 7-12: Payback period from residential DR with energy conservation project ....................................... 131

Figure 7-13: Cash flow after combining all MCDM alternatives .................................................................... 135

Figure 7-14: Payback period after combining all MCDM alternatives ........................................................... 136

Figure 7-15: Projects ranking after combining environmental and economic impact .................................... 139

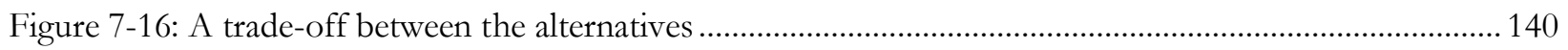




\section{NOMENCLATURE}

\begin{tabular}{|c|c|}
\hline $\mathrm{AB} 32$ & California Assembly Bill \\
\hline $\mathrm{AEO}$ & Annual Energy Outlook \\
\hline AHP & Analytic hierarchy process \\
\hline AMI & Advanced metering infrastructure \\
\hline ANP & Analytic network process \\
\hline BCR & Benefit to cost ratio \\
\hline CAA & Clean Air Act \\
\hline CAIDI & Customer Average Interruption Duration Index \\
\hline CAP & Climate Action Plan \\
\hline $\mathrm{CI}$ & Communication and intelligence \\
\hline $\mathrm{CBA}$ & Cost benefit analysis \\
\hline $\mathrm{CO}_{2}$ & Carbon dioxide \\
\hline $\mathrm{CPP}$ & Clean Power Plan \\
\hline DG & Distributed generation \\
\hline DER & Distributed energy resources \\
\hline DR & Demand response \\
\hline DSM & Demand side management \\
\hline $\mathrm{EE}$ & Energy efficiency \\
\hline $\mathrm{EC}$ & Energy consumption \\
\hline EGU & Electric utility generating unit \\
\hline EHT & Electrification of heating and transportation \\
\hline EPA & Environmental Protection Agency \\
\hline ESS & Energy storage system \\
\hline $\mathrm{EV}$ & Electric vehicles \\
\hline
\end{tabular}




$\begin{array}{ll}\text { GHG } & \text { Greenhouse gas } \\ \text { IEEE } & \text { Institute of Electrical and Electronics Engineers } \\ \text { IRR } & \text { Internal rate of return } \\ \text { IoT } & \text { Internet of things } \\ \text { MAIFI } & \text { Momentary Average Interruptions Frequency Index of durations under } 5 \text { minutes } \\ \text { MCDM } & \text { Multi Criteria Decision Making } \\ \text { NPV } & \text { Net present value } \\ \text { PRPA } & \text { Plate River Power Authority } \\ \text { RGGI } & \text { Regional Greenhouse Gas Initiative } \\ \text { SAIDI } & \text { System Average Interruption Duration Index } \\ \text { SAIFI } & \text { System Average Interruption Frequency Index } \\ \text { TOU } & \text { Time-of-use } \\ \text { U.S. } & \text { United States }\end{array}$




\section{CHAPTER 1}

\section{INTRODUCTION AND OVERVIEW}

\subsection{Motivation}

Growth in energy consumption leads to concerns of global GHG emissions. Most of the supplied energy is from carbon-emitting sources; the use of these sources increased by more than $25 \%$ in the last two decades. Further, an increase of $15 \%$ to $35 \%$ is expected by 2030 . One third of the global energy consumption comes from the manufacturing sector [1]. In 2016, human-caused $\mathrm{CO}_{2}$ emissions from the use of fossil fuels for energy usage was equivalent to $94 \%$ of the total of U.S. anthropogenic $\mathrm{CO}_{2}$ emissions and $76 \%$ of U.S. GHG. The remaining $6 \%$ of $\mathrm{CO}_{2}$ and $5 \%$ of total anthropogenic $\mathrm{GHG}$ come from other anthropogenic sources [2]. Further, coal is the dominant source of $\mathrm{CO}_{2}$ emissions from electricity generation, as of 2017, in the U.S. as it accounts for $69 \%$ of total energy-related $\mathrm{CO}_{2}$ emissions followed by natural gas, $29 \%$, and petroleum $1 \%$ [3]. Therefore, regulating electricity generation for emissions and establishing climate action plans to mitigate $\mathrm{CO}_{2}$ and GHG emissions can help achieve a meaningful impact. However, CPP repeal and the U.S. withdrawal from Paris Agreement diminish lowering GHG emissions. Further, DSM can directly and indirectly mitigate $\mathrm{CO}_{2}$ emissions. Some options like DR and energy conservation can reduce peak loads and in turn reduce emissions from dirty generating units. Indeed, DSM provides ancillary services that can directly mitigate emissions. The growth penetration in Renewable Energy (RE) leads to indirect impact toward emissions reduction [4].

\subsection{Objective}

The objective of the work is to quantify the impact of climate action plans in reducing GHG emission from electric power systems. It also demonstrates that DSM can help in achieving a meaningful reduction in emissions. This dissertation aims to pare down the numerous options available for DSM to those that will make the biggest difference for GHG reductions. In that regard, this work demonstrates the choice of DSM options using AHP and ANP algorithms to study the impact of climate action plans on reducing $\mathrm{CO}_{2}$ emissions, and 
in turn quantify the potential optimal alternatives that can achieve the goal. Another objective of this work is to incorporate the alternatives of ANP into a simulation to quantify GHG reduction. Further, this effort aims to evaluate the economics of the MCDM alternatives, along with the environmental analysis, find the optimal combination among DSM options.

\subsection{Scope}

The scope of the work is to discuss the impact of the CPP in reducing $\mathrm{CO}_{2}$ emissions and to illustrate solutions from the engineering field to minimize carbon footprint. This dissertation proposes a framework using MCDM algorithms to find the potential best solutions to mitigate GHG using DSM taking into consideration several aspects such as cost, reliability, power quality, environmental collateral, and socioeconomic equity.

AHP is one of the most common MCDM methods. AHP derives ratio scales from paired comparisons and uses it in making decisions that include ranking, organization, evaluation, and prediction. Hence, AHP is used to formulate the problem and demonstrate the final prioritization among the proposed options of DSM. ANP is another model of MCDM, and it is a generalization of AHP. Unlike AHP, ANP provides feedback and loops in addition to interdependency relationships. Therefore, ANP is used to help in making decisions with such complicated systems when hierarchal structures are not sufficient.

After obtaining the final ranking from MCDM, alternative solutions are simulated on the IEEE 13node test system to investigate the optimal solution that can provide best option among DSM alternatives. Therefore, several scenarios will be implemented, and CBA will be employed to compare multiple scenarios and to select the alternative that reduces costs and maximizes benefits. Hence, this paper considers the Climate Action Plan (CAP) of Fort Collins, Colorado, US as a choice of study. We use this particular distribution system because of its proximity to the author's home institution and the associated access to expertise; further, the municipal entity that operates this system has a climate action plan; the plan's target is to make the city carbon neutral by 2050 . 


\subsection{Literature survey}

\subsubsection{Climate change}

Clean Power Plan (CPP) is a prime example because it was the most comprehensive and largest climate protection plan in the U.S. until its proposed repeal in 2017. The plan provides several approaches and options to meet the targeted reduction of emissions from Electric Generating Units (EGUs) or power plants. Several scenarios have been proposed to incorporate with the plan, which would lead to achieving the goal with less impact on electricity generation. Further, several successful state and international climate plans encourage governments, communities, individuals, and businesses to take additional actions to reduce GHG. AB32 is a plan launched in 2006 to reach an 80\% emissions reduction below 1990 levels by 2050 [5]. Also, the RGGI is a cooperative program in the eastern U.S. to limit $\mathrm{CO}_{2}$ from the power sector. Internationally, the province of Ontario in Canada launched a plan to mitigate $\mathrm{CO}_{2}$ emissions from the electricity sector. The results show Ontario can achieve more than 50\% emissions reduction by removing coal-fired power plants [6]. Additionally, China is considering plans to control and mitigate air pollution from electricity generation [7]. Since the CPP has been proposed for repeal, there is a dire need for identifying alternatives to regulations on EGUs that can mitigate $\mathrm{CO}_{2}$ emissions from the electricity sector. In this regard, several options can be considered such as heat rate improvements, renewable energy installations, and electricity transmission and distribution improvements [8]. In fact, engineering solutions in the distribution system are one of the emerging strategies to reach $\mathrm{CO}_{2}$ mitigation goals.

\subsubsection{DSM}

DSM is a planning, implementation, and monitoring of the electric utility activities to influence the end user's use of electricity to meet the customer's needs with the utility' goal [9-12]. One of the objectives of DSM is providing cost-effective energy in addition to incorporating modern technologies and innovation in the distribution system [11]. DSM options provide economic and reliability benefits such as deferring investment in the electric power system, minimizing emergency cases, and reducing power outages in the system. Also, it can play a major role in reducing electricity costs and emissions caused by energy consumption by displacing the onus of emissions production to the distribution entities [13-15]. In fact, there are some factors that can 
accelerate the implementation of DSM, such as the growth in installation of renewable energy resources, the development in information and communication technologies, and pending retirements of aging assets in the electric power system. However, there are several challenges associated with the implementation of DSM including some distribution systems lack an existing smart infrastructure, the complexity of operation of new technologies, and security issues [16].

\subsubsection{AHP}

AHP is one of the available approaches to solve MCDM problems that was originally developed by Prof. Thomas L. Saaty [17]. AHP uses a framework for problem solving that organizes judgments into a hierarchy of criteria that influence decisions. The decision maker uses AHP to estimate relative magnitudes through paired comparisons and use that information for making decisions [18, 19]. In fact, AHP has been used for more than 40 years including studying U.S. presidential elections in 1976 and 1980 [20, 21]. Another use of AHP is to examine the impact of global climate change. Further, AHP is applied in a wide range of electric power system to study scheduling local loads in energy smart buildings and decision-making analysis in electric microgrids [21]. Implementing AHP requires following several steps until obtaining final ranking. First, structuring the problem in a hierarchal structure. Second, the decision maker uses a ratio scale to compare pairwise preferences. Table 1-1 shows AHP scale based on Saaty scale, recreated from [22] .

The next step is to construct a judgment matrix for criteria. After that, we develop a judgment matrix for alternatives with respect to each criterion. Step four is to check for inconsistency that must be $\leq 10 \%$. Then, overall ranking is used to select best choice $[18,19]$. 
Table 1-1: The Fundamental Scale for Pairwise Comparison [22]

\begin{tabular}{|c|c|c|}
\hline $\begin{array}{l}\text { Intensity of } \\
\text { importance }\end{array}$ & Definition & Explanation \\
\hline 1 & Equal importance & Two activities contribute equally to the objective \\
\hline 2 & Weak or slight & \\
\hline 3 & Moderate importance & $\begin{array}{l}\text { Experience and judgment slightly favor one activity over } \\
\text { another }\end{array}$ \\
\hline 4 & Moderate plus & \\
\hline 5 & Strong importance & $\begin{array}{l}\text { Experience and judgment strongly favor one activity over } \\
\text { another }\end{array}$ \\
\hline 6 & Strong plus & \\
\hline 7 & $\begin{array}{l}\text { Very strong or demonstrated } \\
\text { importance }\end{array}$ & $\begin{array}{l}\text { An activity is favor very strong over another; its dominance } \\
\text { demonstrated in practice }\end{array}$ \\
\hline 8 & Very, very strong & \\
\hline 9 & Extreme importance & $\begin{array}{l}\text { The evidence favoring one activity over another it the } \\
\text { highest possible order of affirmation }\end{array}$ \\
\hline $\begin{array}{l}\text { Reciprocals } \\
\text { of above }\end{array}$ & $\begin{array}{l}\text { If activity } i \text { has one of the } \\
\text { above nonzero numbers } \\
\text { assigned to it when compared } \\
\text { with activity } j \text {, then } j \text { has the } \\
\text { reciprocal value when } \\
\text { compared with } i\end{array}$ & A reasonable assumption \\
\hline
\end{tabular}




\subsubsection{ANP}

ANP is another tool to solve MCDM problems. It is a methodology that allows groups or individuals to deal with the interconnections between factors of complex problems in decision making processes. ANP allows to include relations of dependence and feedback among nodes of the system. The problem modeling is more complex, but it is more realistic [23]. ANP requires five major steps to obtain final prioritization. The first step is to construct the problem in a network model. Next is to perform a pairwise comparison for criteria and alternatives. The third step is to obtain a supermatrix that contains all nodes and then calculate a limit matrix. The last step is to select the optimal alternative based on final ranking [24].

Reference [25] demonstrates an example that explains the methodology of ANP and how it is different from AHP. The objective is to find the best solution in to manage a water reservoir. The decision is to choose one of the possible solutions of maintaining the water level in a dam at: low, medium, or high. The final decision depends on three-criteria, namely flood control, recreation, and the generation of hydroelectric power for the three options. The problem is constructed in a feedback system as shown in Figure 1.
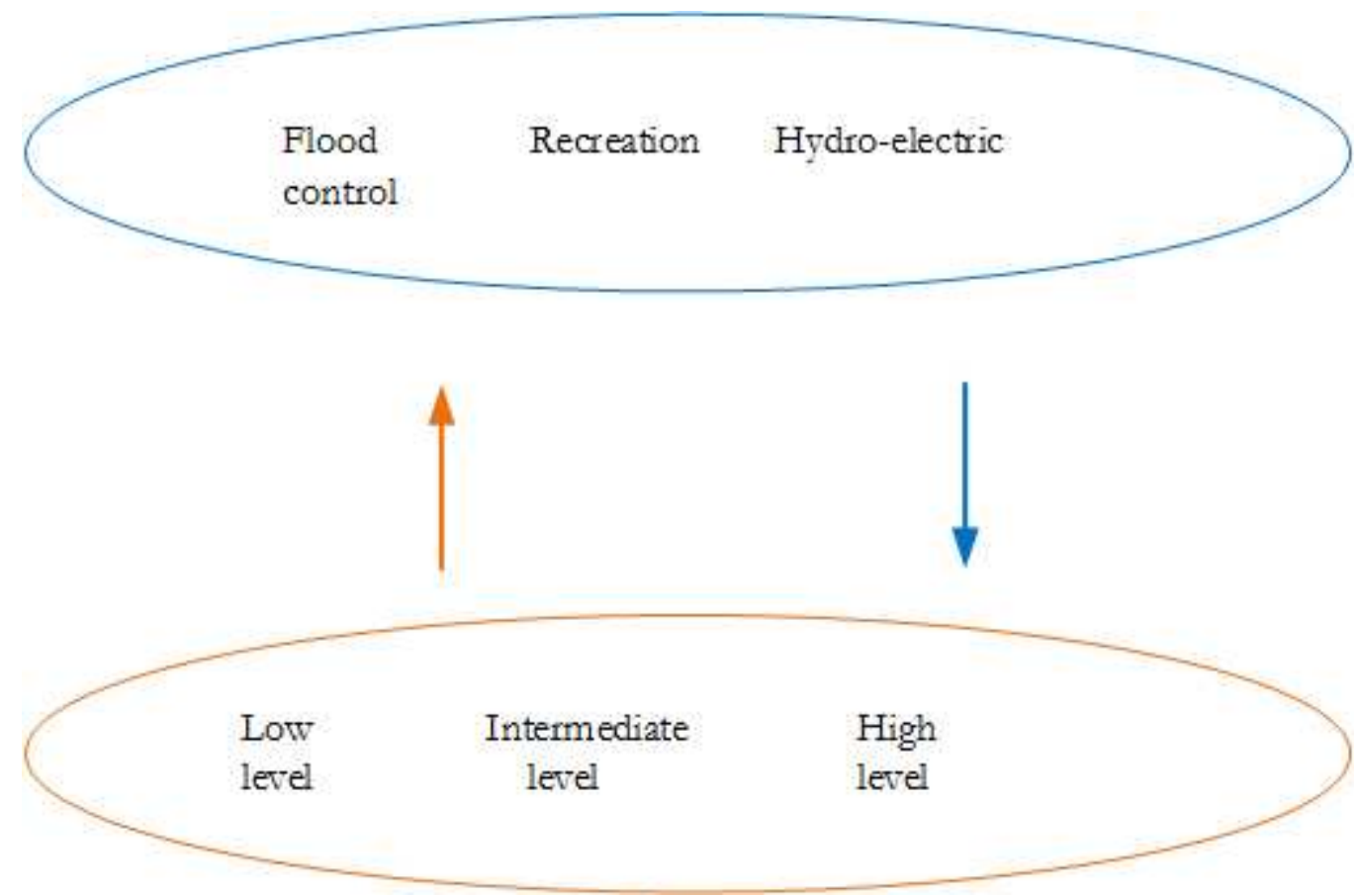

Figure 1-1: A Problem structure reproduced from [25] 
Then, A pairwise comparison is conducted for each alternative with respect to each criterion. Tables 1-2 to 1-4 present judgment matrices for each alternative with respect to each criterion.

Table 1-2: Judgment Matrix for Alternatives with respect to Flood Control [25]

\begin{tabular}{|c|c|c|c|c|}
\hline & Low & Medium & High & Priority \\
\hline Low & 1 & 5 & 7 & 0.722 \\
\hline Medium & $1 / 5$ & 1 & 4 & 0.205 \\
\hline High & $1 / 7$ & $1 / 4$ & 1 & 0.073 \\
\hline
\end{tabular}

Table 1-3: Judgment Matrix for Alternatives with respect to Recreation [25]

\begin{tabular}{|c|c|c|c|c|}
\hline & Low & Medium & High & Priority \\
\hline Low & 1 & $1 / 7$ & $1 / 5$ & 0.072 \\
\hline Medium & 7 & 1 & 3 & 0.649 \\
\hline High & 5 & $1 / 3$ & 1 & 0.279 \\
\hline
\end{tabular}

Table 1-4: Judgment Matrix for Alternatives with respect to Hydroelectric Power [25]

\begin{tabular}{|c|c|c|c|c|}
\hline & Low & Medium & High & Priority \\
\hline Low & 1 & $1 / 5$ & $1 / 9$ & 0.058 \\
\hline Medium & 5 & 1 & $1 / 5$ & 0.207 \\
\hline High & 9 & 5 & 1 & 0.735 \\
\hline
\end{tabular}

Now, we examine the influence of each criterion on the alternatives. Tables 1-5 to 1-7 illustrate pairwise comparisons for each criterion with respect to each alternative.

Table 1-5: Judgment Matrix for Criteria with respect to Low Level [25]

\begin{tabular}{|c|c|c|c|c|}
\hline & Low & Medium & High & Priority \\
\hline Flood control & 1 & 3 & 5 & 0.0637 \\
\hline Recreation & $1 / 3$ & 1 & 3 & 0.258 \\
\hline Hydroelectric power & $1 / 5$ & $1 / 3$ & 1 & 0.105 \\
\hline
\end{tabular}


Table 1-6: Judgment Matrix for Criteria with respect to Medium Level [25]

\begin{tabular}{|c|c|c|c|c|}
\hline & Low & Medium & High & Priority \\
\hline Flood control & 1 & $1 / 3$ & 1 & 0.2 \\
\hline Recreation & 3 & 1 & 3 & 0.6 \\
\hline Hydroelectric power & 1 & $1 / 3$ & 1 & 0.2 \\
\hline
\end{tabular}

Table 1-7: Judgment Matrix for Criteria with respect to High Level [25]

\begin{tabular}{|c|c|c|c|c|}
\hline & Low & Medium & High & Priority \\
\hline Flood control & 1 & $1 / 5$ & $1 / 9$ & 0.060 \\
\hline Recreation & 5 & 1 & $1 / 4$ & 0.231 \\
\hline Hydroelectric power & 9 & 4 & 1 & 0.709 \\
\hline
\end{tabular}

Inconsistency ratio $\quad 0.61 \%$

After finishing all comparisons, the normalized supermatrix is obtained as shown in Table 1-8.

Table 1-8: Normalized Supermatrix [25]

\begin{tabular}{|c|c|c|c|c|c|c|}
\hline & $\begin{array}{c}\text { Flood } \\
\text { control }\end{array}$ & Recreation & $\begin{array}{c}\text { Hydroelectric } \\
\text { power }\end{array}$ & Low & Medium & High \\
\hline Flood control & 0 & 0 & 0 & 0.637 & 0.2 & 0.060 \\
\hline Recreation & 0 & 0 & 0 & 0.258 & 0.6 & 0.231 \\
\hline $\begin{array}{c}\text { Hydroelectric } \\
\text { power }\end{array}$ & 0 & 0 & 0 & 0.105 & 0.2 & 0.709 \\
\hline Low & 0.722 & 0.072 & 0.058 & 0 & 0 & 0 \\
\hline Medium & 0.205 & 0.649 & 0.207 & 0 & 0 & 0 \\
\hline High & 0.073 & 0.279 & 0.735 & 0 & 0 & 0 \\
\hline
\end{tabular}


Then we obtain the final priorities for both, criteria and alternatives by raising the limiting power of the supermatrix where the matrix powers stabilize after 130 iterations as denoted in Table 1-9.

Table 1-9: Limit Matrix [25]

\begin{tabular}{|c|c|c|c|c|c|c|}
\hline & $\begin{array}{c}\text { Flood } \\
\text { control }\end{array}$ & Recreation & $\begin{array}{c}\text { Hydroelectric } \\
\text { power }\end{array}$ & Low & Medium & High \\
\hline Flood control & 0 & 0 & 0 & 0.241 & 0.241 & 0.241 \\
\hline Recreation & 0 & 0 & 0 & 0.374 & 0.374 & 0.374 \\
\hline $\begin{array}{c}\text { Hydroelectric } \\
\text { power }\end{array}$ & 0 & 0 & 0 & 0.385 & 0.385 & 0.385 \\
\hline Low & 0.223 & 0.223 & 0.223 & 0 & 0 & 0 \\
\hline Medium & 0.372 & 0.372 & 0.372 & 0 & 0 & 0 \\
\hline High & 0.405 & 0.405 & 0.405 & 0 & 0 & 0 \\
\hline
\end{tabular}

The results show that a high dam has the highest preference with priority 0.405 for the criterion of hydroelectric power generation with priority 0.385 . This indicates that ANP is able to solve any decision problem if interdependent relationships have significant impacts in the decision model. Table 1-10 shows the results of the same example solved by AHP.

Table 1-10: Final Prioritization Using AHP

\begin{tabular}{|c|c|c|c|c|}
\hline & Flood control & Recreation & $\begin{array}{c}\text { Hydroelectric } \\
\text { power }\end{array}$ & Priority \\
\hline Low & 0.087 & 0.031 & 0.018 & 0.136 \\
\hline Medium & 0.026 & 0.267 & 0.065 & 0.358 \\
\hline High & 0.009 & 0.117 & 0.218 & 0.345 \\
\hline
\end{tabular}

The findings show that the decision changes when the interdependent relationship is considered. Thus, interdependencies can affect final ranking. 


\subsubsection{IEEE 13-node test feeder}

IEEE 13-node is a test feeder was developed to perform analysis in the distribution system [26]. The test feeder will be used to simulate and test the performance of ANP alternatives to achieve the goal. Several studies have been conducted using the IEEE 13-node system. One example is published in [27] to examine allocating DG units on the IEEE 13-node system. The results show a reduction in power losses, increasing reliability, and maintaining voltage levels between 0.95 to 1.05 p.u.

OpenDSS is an open-source environment to perform power flow studies in electric distribution systems developed by the Electric Power Research Institute (EPRI) [28]. It has several capabilities such as general distribution planning and analysis, integration of Distributed Energy Resources (DER), and load and storage simulators. IEEE 13-node test feeder is run on OpenDSS to calculate voltages, currents, and system losses. The summary of power flow solution is as follows:

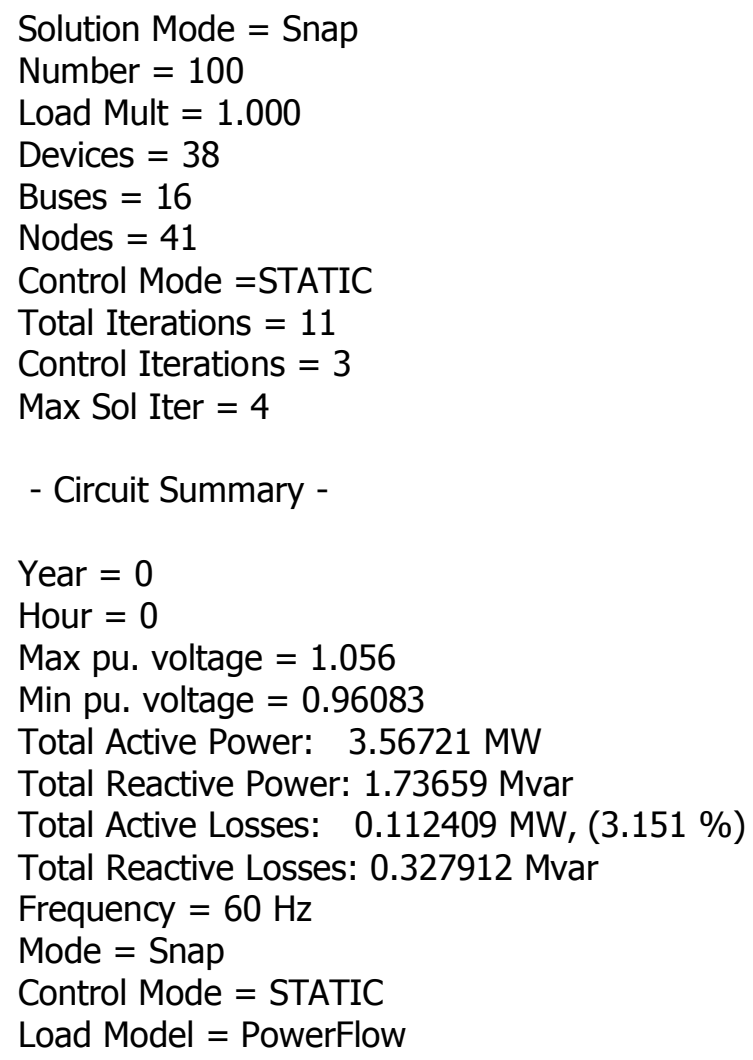




\subsubsection{CBA}

$\mathrm{CBA}$ is an economic framework to compare several options and select the one who provides maximum benefits. There are two major types of $\mathrm{CBA}$; ex ante $\mathrm{CBA}$ where the analysis is constructed while the project is under consideration or before its implementation and ex post $\mathrm{CBA}$ that is conducted at the end of the project [29]. CBA is used to study the economic viability of several applications such as smart grid, DR, energy storage, and RES [30-35].

\subsection{Software Tools}

MATLAB $^{\circledR}$ code was used for calculating local priorities and final priorities in chapters 4 and 5 . Also, OpenDSS software was used to simulate IEEE 13 node test system and then complied to MATLAB ${ }^{\circledR}$. All codes are presented in the appendix of this report.

\subsection{Organization of the Dissertation}

The remaining chapters of the report are organized as follows: a brief overview of the CPP and its approaches and scenarios and CAP of Fort Collins Colorado, U.S. are given in chapter 2. A background of DSM techniques and options is discussed in chapter 3 and chapter 4 explains the AHP, a MCDM methodology presents the problem framework and discusses the hierarchal structure through a case study on Fort Collins, Colorado, U.S. and its results. Chapter 5 explains the ANP, a MCDM methodology and presents the obtained results. Chapter 6 obtains modeling and simulation of the distribution system. Chapter 7 presents economic analysis using DSM alternatives. Chapter 8 concludes the work and presents the future path of the research. Part of chapter 1 and chapters 2-5 are verbatim reproduced from [36]. Also, part of chapter 1 and chapters 68 are verbatim reproduced from [37]. 


\section{CHAPTER 2}

\section{GOVERNMENT DIRECTED PLANS TO REDUCE GHG EMISSIONS ${ }^{1}$}

\subsection{Introduction}

This chapter discusses some climate action plans. It, first, gives an overview about the CPP and its benefits and challenges. Then, it explains several options of the CPP in reducing emissions and its repeal. Further, this chapter also discusses the CAP of Fort Collins and its timeline targets.

\subsection{Clean Power Plan}

Since there are no regulations to limit emissions of $\mathrm{CO}_{2}$ from electricity generation, power plants can emit unlimited amount of $\mathrm{CO}_{2}$. Consequently, about $40 \%$ of $\mathrm{CO}_{2}$ emissions are emitted from conventional power plants [38]. Therefore, rules are needed to regulate electricity generation and reduce air pollution exposure that endangers health and welfare. Hence, the Clean Air Act. (CAA) is a federal law that protect human health and environment by regulating air emissions from stationary, modified and reconstructed sources. This law authorize Environmental Protection Agency (EPA) to establish standards to solve air pollution problems [39]. The CPP is an action that has been launched under the CAA to reduce emissions from the electricity sector by about 32\% below 2005 levels by 2030 [40]. The goal of this legislation is to minimize air pollution and reduce the impact on climate change [41]. In the period between 1970 to 2015, total emissions of six common pollutants in the U.S., fell an average of $70 \%$ while gross domestic product grew 246\%. [42, 43]. Figure 2-1 shows the U.S. electricity generation from coal in 2017 without CPP compared to the annual energy outlook 2016 reference case (AEO2016) [44]. The AEO2016 reference case assumes compliance with the CPP where all states and regions will implement the plan.

${ }^{1}$ This chapter is verbatim reproduced from [36], and it is under review in the Utilities Policy Journal at the time of writing this dissertation 


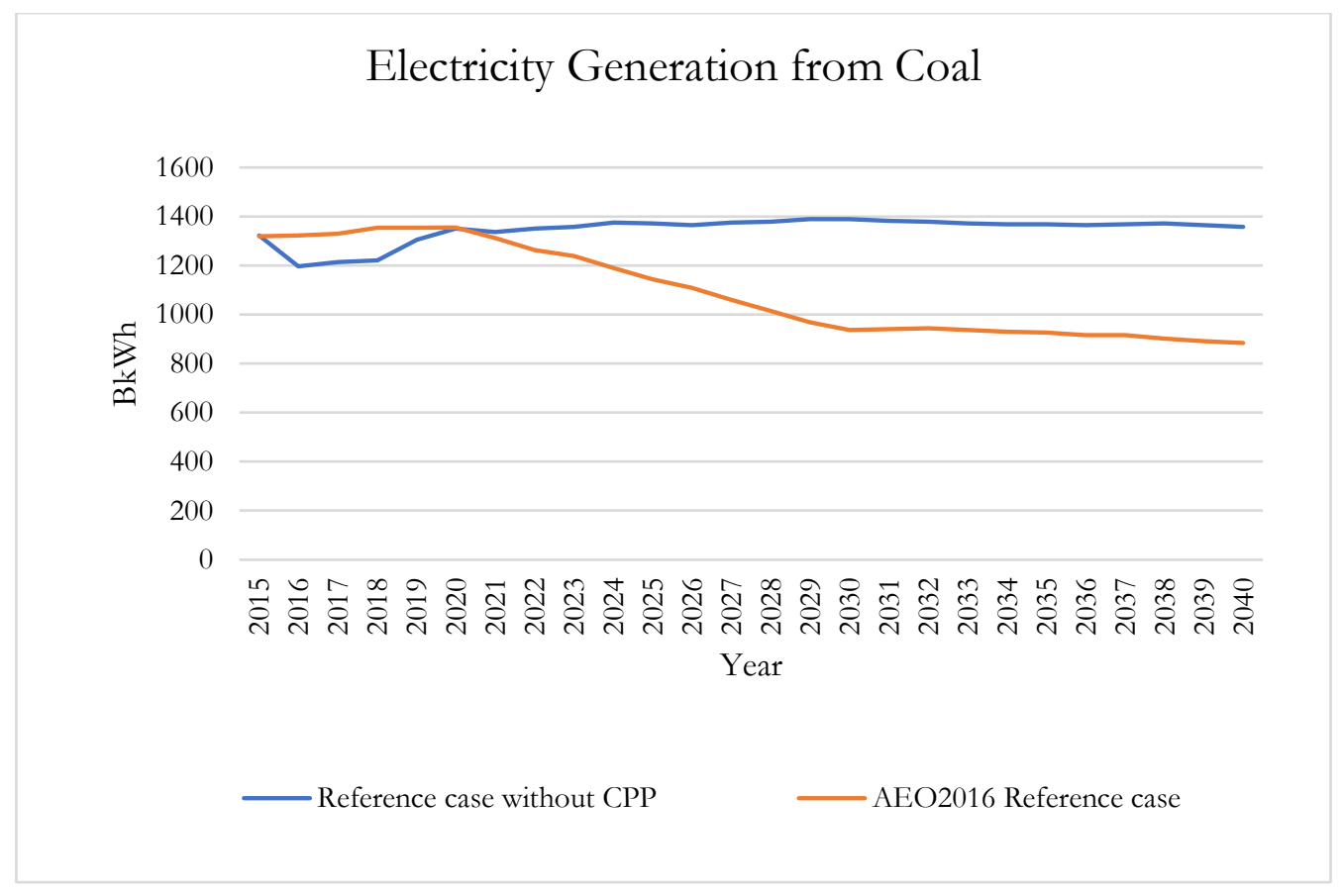

Figure 2-1: The U.S. Electricity Generation from Coal in 2017 [35]

In the CPP, section 111(b) directs EPA to develop a standard of performance for stationary sources of air pollution. Also, section 111(b) must establish an emission standard from modified and reconstructed sources where they must meet the standard. Section 111(d) mandates EPA to set emission standards for pollution emitted from existing sources. There is no specific form to perform section 111(b). Therefore, EPA requires states to design their standard of performance [45]. This might be identical to EPA's guideline or different but equivalent to EPA's guideline. The basic options include:

a. Performance standard that is limited or non-flexible

b. Flexible performance standard, with the option of banking, averaging, and trading, and

c. A state budget approach with banking and trading.

Reference [46] presents a study to examine the above options. The results show the first option is easy to administer, but it incorporates more cost per ton of $\mathrm{CO}_{2}$ reduced. Moreover, the advantage of the second option is avoiding placing a specific limit on emissions. Hence, conventional generators could increase the electricity output and emissions, if they satisfy the standard of performance. The study concludes that second 
and third options can be considered in existing sources as they provide cost-effective compliance solutions and investment. Further, the emission standard, set by EPA, must meet the emissions mitigation that is achieved through application demonstrated by EPA of "best system of emission reduction". The emission standard should take into consideration some factors such as the emission cost reduction, non-air quality health and environmental effect in addition to energy requirements [47].

As the new generating sources can be built with compliance with the standard of performance, there are options to minimize $\mathrm{CO}_{2}$ emissions from existing power generating units. It can be supply-side options to directly avoid $\mathrm{CO}_{2}$ emissions from the power plant by increasing energy efficiency. Or, it can indirectly reduce $\mathrm{CO}_{2}$ emissions from the power plant by increasing the penetration of less carbon-emitting sources and zerocarbon technologies such as renewable energy. Demand side can displace $\mathrm{CO}_{2}$ emissions from the power plant by decreasing electricity demand. This could happen by reducing the overall amount of electricity generated at $\mathrm{CO}_{2}$ emitting power plants or changing the dispatch of electric generators in response to lower electricity demand [41, 45, 48, 49]. Employing these options vary by state depending on the sources of electricity generation. Some factors that can play a role such are technologies, costs, and the emissions reduction. Therefore, states can combine several options to meet their goals.

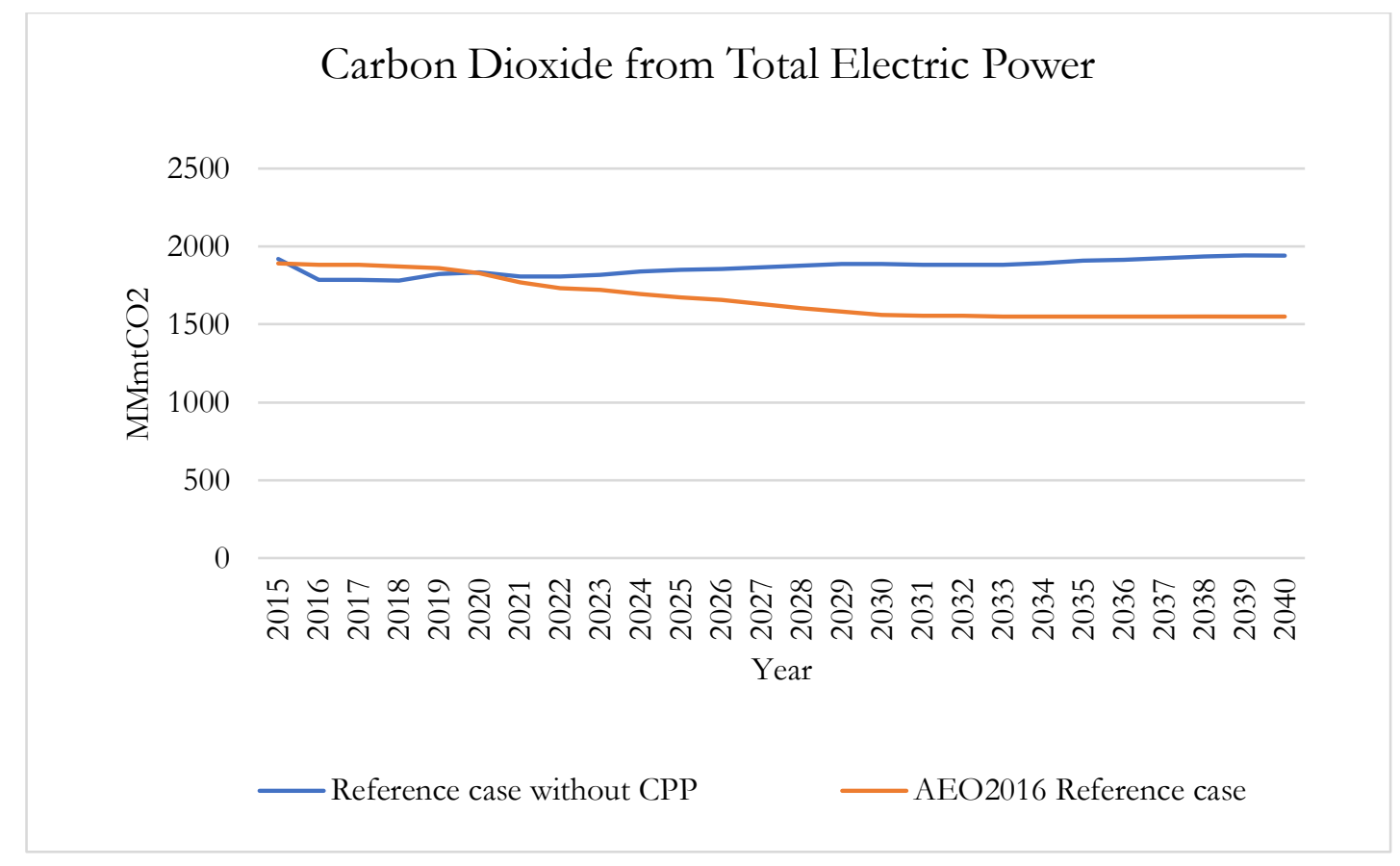

Figure 2-2: The U.S. Emission Reduction from Electric Sector in 2017 [41] 
Also, states can join in multi-state or regional entities to find the best cost options for reducing their carbon emissions. Figure 2-2 illustrates the U.S. emission reduction from the electric sector in 2017 without CPP compared to the AEO2016 reference case [50]. According to [8], the CPP regulations allow states to choose one of two approaches to measure $\mathrm{CO}_{2}$ emissions: mass-based or rate-based. A mass-based approach measures the annual limit of emissions the that can be produced from the affected power plants. A rate-based approach measures the annual emissions based on the emitted amount of $\mathrm{CO}_{2}$ divided by generation from affected sources (lbs $\mathrm{CO}_{2} / \mathrm{MWh}$ ) which means capacity from non-emitting sources such as renewable energy resources is included. Reference [51] performed a study on implementing alternative cases of the CPP. The outcomes of the study should illustrate how the results can change with different implementation of the CPP. The alternative CPP cases are explained below:

A. No CPP case: Assumes that the CPP is repealed and there is no regulation to reduce the emissions from existing generating units, but other programs remain active such as RGGI and AB32.

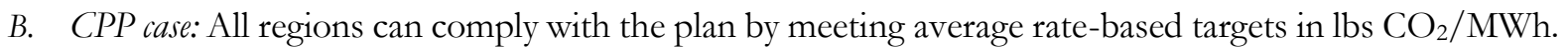

C. CPP interregional trading case: Any region that performs below the standard level earns credit. Therefore, the case considers that all states can choose to meet their targets following the mass-based approach, and the regions can trade their carbon allowances.

D. CPP extended case: Aims to achieve a reduction in $\mathrm{CO}_{2}$ beyond the target for $2030,32 \%$ reduction below 2005. The goal is to reduce the emissions by about $45 \%$ below 2005 levels in 2040 .

E. CPP hybrid case: Assumes regions with active plans can join with the CPP to meet the required reduction of $\mathrm{CO}_{2}$ emissions. 
F. CPP allocation to generators case: Considers that the allowances of emissions are allocated to electricity generating units rather than to load-serving entities.

The results show a 35\% reduction below 2005 level in the reference case by 2030 . Also, the same reduction can be achieved by implementing CPP rate case, but the mitigation reduces by $2 \%$ after 2030 due to the growth of generation. CPP extended case enforces more reduction as it continues the reduction to $45 \%$ by 2040 . Figure 2-3 demonstrates the reduction of $\mathrm{CO}_{2}$ emission in each case.

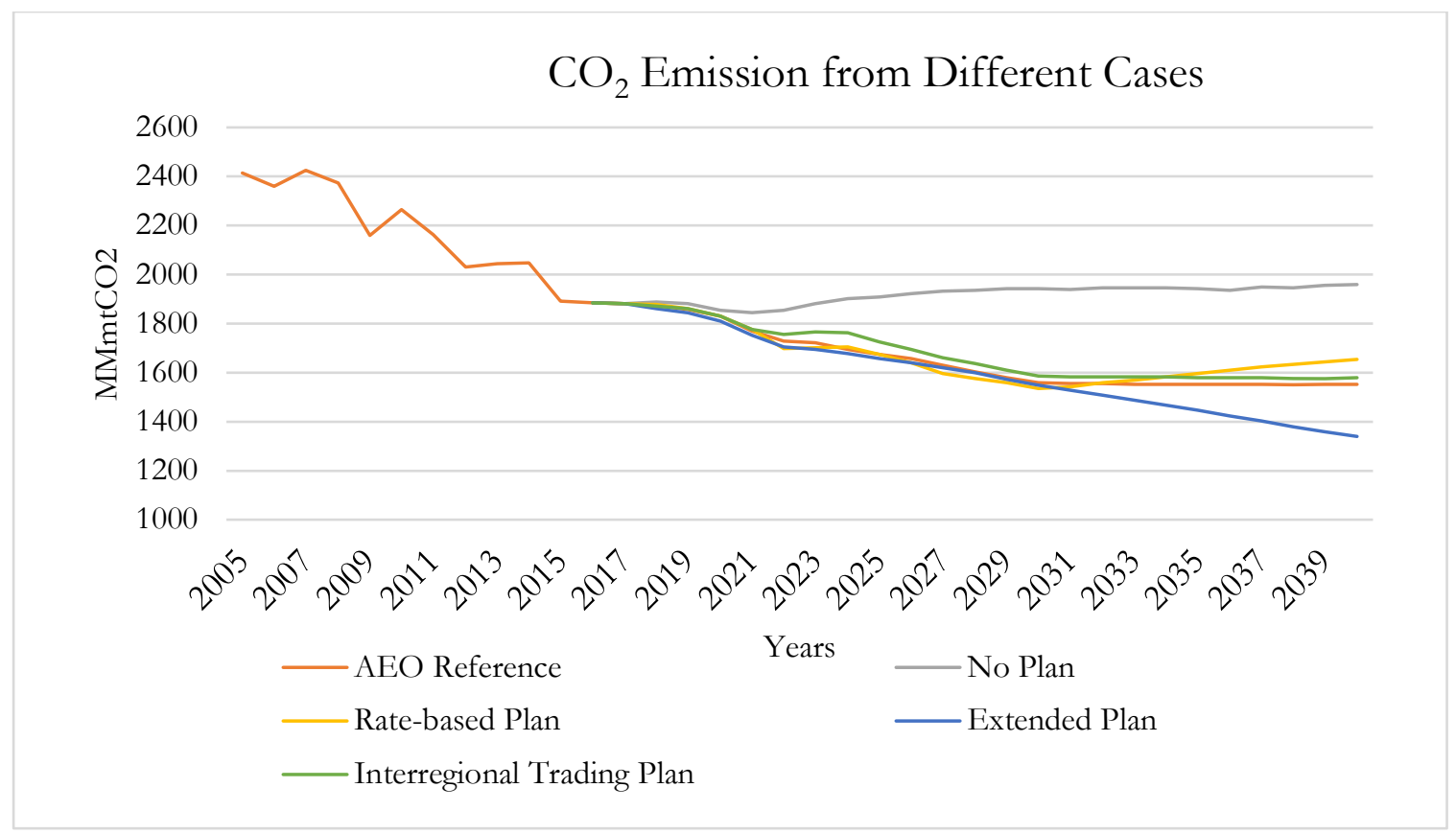

Figure 2-3: $\mathrm{CO}_{2}$ Emissions from the Electric sector from the Alternative Cases [42]

The CPP could have a positive environmental impact as well as health benefits. However, an executive order was signed on Tuesday October $10^{\text {th }}, 2017$ to repeal the CPP [52]. This likely means emitting more emissions from electricity generation. Therefore, a comprehensive engineering plan must be conducted to find alternative solutions that can overcome the impending pollution. Several options can be considered such as high penetration of renewable energy, increasing energy efficiency and investing in nuclear power generation. Further, DSM is a good opportunity from engineering practices to reduce $\mathrm{CO}_{2}$ emissions caused by electricity generation. DSM can also benefit the reliable and cost-effective operation of the distribution system. 


\subsection{Climate Action Plan}

The CAP is chosen a case study to investigate DSM options in reducing emissions. This plan is considered because the CAP target is to make Collins carbon natural by 2050 and some DSM options are not yet implemented and are not yet prioritized. Total GHG emissions in Fort Collins, Colorado, U.S. is expected to increase, above 2005 levels, by $16 \%$ in 2030 and 39\% in 2050 in the absence of actions to diminish the emissions. According to [53], about $95 \%$ of the emissions come from electricity generation, natural gas, and transportation activities. Indeed, $51 \%$ of the emissions inventory come from electricity generated by combusting fossil fuels. Electricity used in Fort Collins is generated by coal, natural gas, and renewable energy resources. Figure 2-4 shows the mix of electricity resources supplying Fort Collins's load.

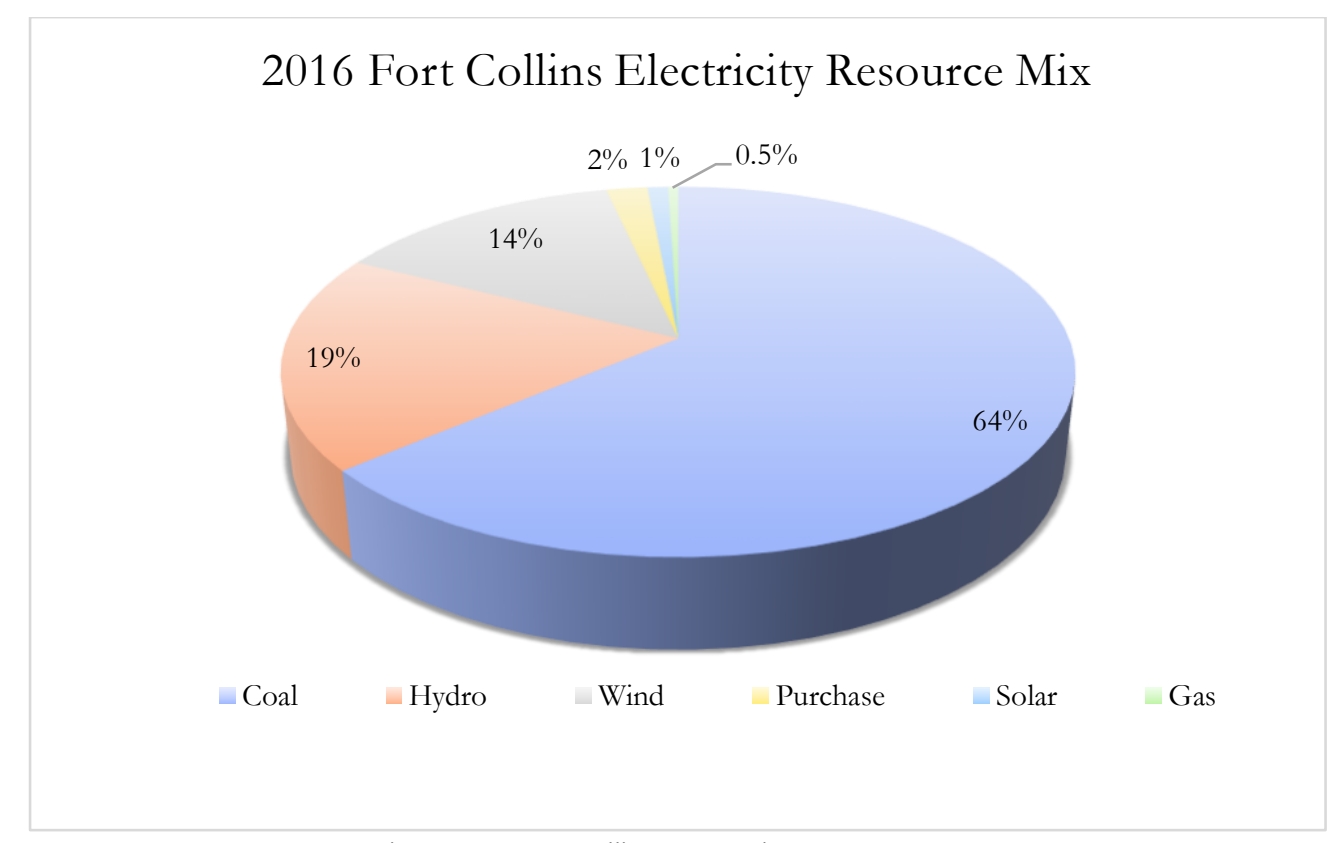

Figure 2-4: Fort Collins Generation Resources [44]

Fort Collins adopted a CAP to achieve GHG reduction goals. These goals are to reduce GHG 20\% below 2005 levels by $2020,80 \%$ by 2030 and $100 \%$ by 2050 [54]. While the population increased by $23 \%$ in 2016 , compared to 2005, $\mathrm{CO}_{2}$ emissions reduced by $12 \%$. Indeed, as of 2017, Fort Collins' carbon emissions were $17 \%$ lower than 2005 levels. This is reasonable as $80 \%$ of the population in Fort Collins believes that climate change requires more actions and investments in programs to address and mitigate climate change impact [55]. As Fort Collins is among the top 10 environmentally friendly cities in the U.S., 1 in 3 businesses have engaged 
in EE programs while saving annual business energy costs of over $\$ 9.5$ million [55].

Several renewable installations have led to this $\mathrm{CO}_{2}$ reduction; a $30 \mathrm{MW}$ utility-scale PV array increased clean energy installation by $2 \%$, equivalent to the energy consumption of 3500 household, while two recent wind farms added another _ \% to renewable generation. Investments in EE in 2016 achieved a savings equivalent of reducing electricity consumption of 3750 homes, which lead to a reduction in $\mathrm{CO}_{2}$ emissions [53]. However, though significant progress has been made through this combination of cleaner generation and DSM, we examined what could be done with only DSM given that Fort Collins municipal electric utility that own only distribution systems as associated assets. Thus, we investigate the optimal operation of DSM to achieve the city's goal. In that regard, we implement an AHP-based DSM model and ANP-based DSM model to examine the optimal options available from DSM.

This research is only dealing with the demand side, including DG on the distribution system, of the electric energy system. In doing so, not only must we consider electric demand reduction but also demand increases due to the electrification of other loads like transportation, heating for space, water, and processes. 


\section{CHAPTER 3}

\section{DEMAND SIDE MANAGEMENT²}

\subsection{Introduction}

This chapter presents alternatives from literature for DSM implementation. Several options are discussed to explain the effect of these alternatives on minimizing carbon footprints. Moreover, this section demonstrates the impact of DSM options on the operation of power grid.

\subsection{DSM}

The essential impact of controlling the demand occurred in 1970s when there was a need to shape the load profile [56]. In recent years, DSM has been introduced as a solution to manage the load in the distribution system. DSM means modifying end-use electrical energy consumption by some measures and operations to change power consumption to a desired level [7]. In fact, applying DSM to the distribution system provides meaningful benefits in areas such as economy, reliability, and the environmental. Specifically, DSM leads to cost reduction by reducing energy prices. Also, DSM defers the investments in generation, transmission, and distribution systems. Further, DSM helps in minimizing the impact of emergency/contingency cases in the electric power system and in reducing the reach of blackouts, and in turn, increasing the reliability [57]. Moreover, reducing energy consumption through DSM leads to a reduction in harmful emissions to the environment. A survey shows that a reduction in global warming-related emissions of GHGs is one of the top four reasons for implementing DSM programs [58]. Via DSM programs, energy usage can be reduced or shifted to benefit the utility and consumer.

Some examples of popular DSM techniques include peak clipping, which reduces the system peak loads during specific periods of time and valley filling, which allocates loads during the off-peak period in addition to the load shifting technique [59]. Common DSM techniques are shown in Figure 3-1, recreated from [60].

2 This chapter is verbatim reproduced from [36], and it is under review in the Utilities Policy Journal at the time of writing this dissertation 
Several examples of successful DSM programs illustrate significant improvements in electricity usage as well as economic and environmental impacts. In 2010, electric utility DSM programs in the U.S. reduced the peak load by $33.283 \mathrm{GW}$. This results in about 87,839 million kWh [61]. In 1999, about 459 utilities in the U.S. had implemented DSM programs. These programs saved about 50.6 billion kWh of energy generation. This represents $1.5 \%$ of the annual electricity sales of that year [62]. Globally, Vietnam has annual demand growth between $10 \%$ to $13 \%$. Therefore, the country applied a DSM program to face the spiking increase in electricity demands. According to [7], the DSM program, in Vietnam, is expected to achieve a reduction in peak demand of 2,928 GWh, which is equivalent to saving roughly 724 million tons of oil or 3.5 million tons of carbon emissions. In this section, we investigate the most common DSM programs to cost-effectively decrease the negative environmental impact of emissions by conventional power plants.
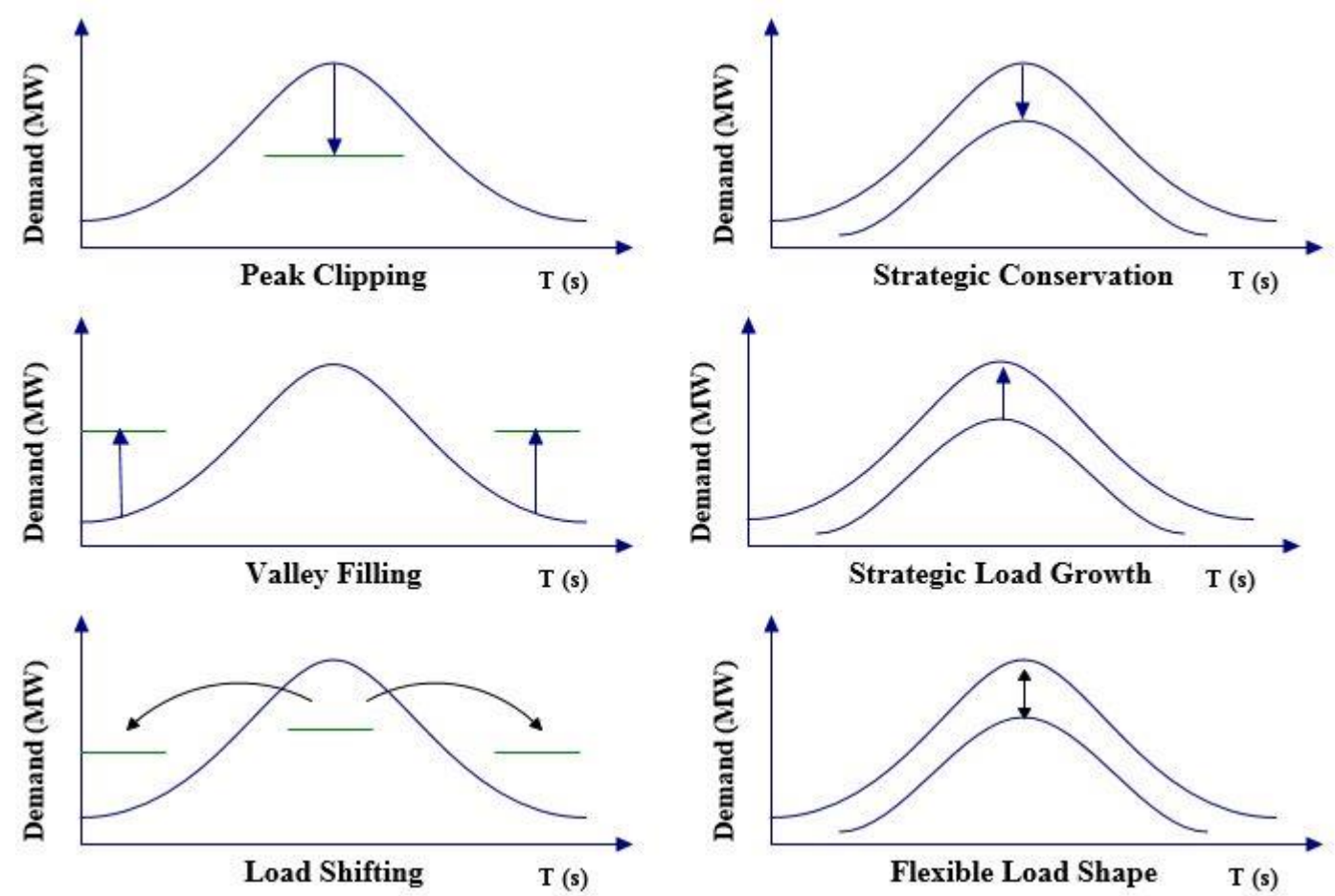

Figure 3-1: DSM Techniques[60]

\subsubsection{Demand Response (DR)}

DR refers to modifying the electricity usage by the end-user customers from their normal consumption patterns due to market price, system imbalance, or system stress. Specifically, DR programs are developed to 
increase electric system reliability by reducing peak hour loads [63]. DR can provide economic efficiency and environmental benefits. According to [64], DR can directly reduce $\mathrm{CO}_{2}$ emissions between $1 \%$ to $2 \%$ in the U.S., where a $1 \%$ reduction is equivalent to removing 6 coal-fired power plants during peak loads. DR programs can be categorized as either time-based or incentive-based programs. Time-based programs use price signals to reduce energy demand. Alternatively, incentive-based programs provide direct load control to lower demand for a fixed or predetermined incentive [65]. Below is a detailed explanation of DR programs [57, 66]:

\section{A. Time-Based Rates DR}

- Time-of-use rates (TOU) where the utility offers consumers a schedule of electricity rate that vary with the time of day, day of the week, or even the season of the year, but that is not varying with the real-time operating conditions of the electric power delivery system.

- Critical peak pricing uses time-based pricing on a limited number of days per year when the total load in the grid is expected to be the highest.

- Real-time pricing works as TOU except the rates change is real time depending on the operating conditions of the electric power deliver system.

\section{B. Incentive-Based DR}

- Direct load control where the utility directly controls some loads.

- Interruptible rates where customers get a special contract to curtail part of their load.

- Emergency DR programs where consumers can volunteer to respond to emergency signals.

- Demand bidding programs where customers can bid to curtail their load at attractive prices.

DR can potentially affect the utilization and efficiency of the coal power plants. Reference [67] shows that the demand that occur $1 \%$ of time in many systems in the U.S. and Australia could cost about $10 \%$ of the total electricity costs. Moreover, customers in the PJM Interconnection saved about $\$ 1.2$ billion from DR programs [68]. Beside its reliability and economic impacts, DR provides positive environment impacts. Reference [64] shows that reducing peak load and providing ancillary services can directly reduce $\mathrm{CO}_{2}$ emissions by more than 
1\%. Further, EPRI found that DR programs that focus on reducing peak load can achieve energy savings and emissions reductions. EPRI estimates that these programs can save up to 4 billion $\mathrm{kWh}$ of energy in 2030, in turn mitigating $\mathrm{CO}_{2}$ emissions by 2 million metric tons [69]. Aggregator-based DR can enhance economic and environmental sustainability. The results obtained from a proposed residential DR program show the demand is shifted from on-peak to off-peak periods and the total used energy before and after the DR program remains unchanged. This proposed strategy aims to increase capacity factor of peaking generators during off-peaking times. The study shows that although some generating units increased their $\mathrm{CO}_{2}$ emissions the total emissions are reduced by 32.77 million metric tons due to the changes in capacity factors of peaking and off-peaking generating units [70].

\subsubsection{Energy management}

Energy response is one of the most successful techniques in DSM and it can be implemented through either targeted education or incentive programs. Energy Efficiency (EE) means change in technologies, operations, and behavior to reduce energy consumption. In comparison to new generating units, investing in EE is preferred because it is cheaper, cleaner, safer, faster, more reliable, and more secure [71]. EE has positive economic and environmental impacts. According to [72], EE standards can provide a reduction in peak demand by about $240 \mathrm{GW}$ in 2035. Also, EE can cut $\mathrm{CO}_{2}$ emissions by 470 million metric tons in 2035, which is equivalent to the emissions from 118 coal power plants. Also, behavioral EE programs provide a saving between 1.8 to 2.2 quadrillion BTUs per year, which amounts to $16 \%$ to $20 \%$ of the U.S. residential energy use [73]. Such actions can be achieved by increasing the setpoint of air cooling temperature, decreasing the heating temperature setpoint, reducing shower time, changing the settings of dishwashers and washing machines, and turning off unused lights and electronics [74]. Energy management programs can be implemented in different ways such as [7]:

A. Providing incentives to customers to change energy consumption or end-use equipment. As an example, switching to more efficient light bulbs or refrigerators.

B. Joining EE performance contracts and other third-party initiatives. 
C. Educating customers on the available opportunities in efficiency programs.

D. Developing services in supply or end-use energy products.

Further, there are several tools to analyze the effect of EE. These tools are used to calculate energy usage by comparing peak load with baseline in addition to providing a weekly comparison of consumption time series. Also, these tools use benchmarks to compare performance to others and use process correlations of user settings with reference settings [11].

\subsubsection{Energy Storage System (ESS)}

Energy storage technologies, such as stationary batteries and electric vehicles, can play a major role in many aspects such as improving reliability, reducing energy cost, and minimizing $\mathrm{CO}_{2}$ emissions. The energy stored in the ESS is used to meet the demand without burning fossil fuels to generate electricity from conventional generators. Further, ESS are used with DG to balance the production and enhance the benefits of DG to the end-user and to the electric system. Therefore, ESS allows the end-use customers to use the electricity generated by their DG at different times than when it is produced $[71,75]$ for valley-filling or load-shifting.

\subsubsection{Distributed Generation (DG)}

DG refers to generating facilities that are interconnected to a distribution system and located next to the load. The integration of DG technologies into electrical networks has become an interesting solution in recent years due to the value they provide to grids. DG units provide several benefits of reliability, environmental, and economics such as power loss reduction and reduction in emissions from the electric power sector. DG is classified as renewable and non-renewable sourced. The primary renewable distributed generation technology is solar photovoltaic panels. Far less available are small wind turbines, small water turbines, and geothermal systems due to their uncommon site requirements. Non-renewable DG technologies combust fuel locally so that their waste heat can be used for heating space and water, and providing process heat; such units are said to be in a combined heat and power (CHP) configuration. These include natural gas fueled reciprocating engines, microturbines, and fuel cells. 
Recently, investment in DG has increased due to declining cost of components and technologies and the increased value to the electric system, costumers, and society. This decrease in cost is occurring at different rates for different technologies for different reasons [76, 77]. As an example, California has implemented policies for increasing DG and ESS in order to deploy 1.5 million zero-emission vehicles by 2025 [7]. 


\section{CHAPTER 4}

\section{ANALYTIC HIERARCHY PROCESS ALGORITHM TO PRIORITIZE DEMAND SIDE MANAGEMENT ALTERNATIVES 3}

\subsection{Introduction}

This section describes one of the most common MCDM algorithms, AHP. First, it presents a brief overview about AHP. Section 4.2 also demonstrates several steps to calculate final ranking among alternatives. Further, a problem framework is created corresponding to the goal of the CAP of Fort Collins, Colorado, U.S. The results show the final prioritization of the potential optimum alternatives.

\subsection{AHP}

AHP is one of the well-known MCDM methods. AHP derives ratio scales from paired comparisons and uses to make decisions that include ranking, organization, and evaluation. Thus, the input can be derived from actual measurements or from subjective opinion. AHP can also evaluate the reliability of the judgment matrix by checking inconsistency ratio. AHP follows several steps to obtain final prioritization. The first step is to define the decision-making problem. After that, we build the problem as a hierarchy structure, as shown in Figure 4-1, that contains the objective, criteria, and alternatives.

The next step is to build a matrix for a pairwise comparison that contains priority among criteria and alternatives. Next, we derive judgments from the pairwise comparisons using a reciprocal matrix:

$$
A=\left[\begin{array}{cccc}
1 & a_{12} & \cdots & a_{1 n} \\
a_{21} & 1 & \cdots & a_{2 n} \\
\vdots & \vdots & 1 & \vdots \\
a_{n 1} & a_{n 2} & \cdots & 1
\end{array}\right]
$$

where, $A$ is the judgment matrix, and $a_{i j}$ is the element of row $i$ column $j$ of the matrix, and gives the comparison of Criterion or Alternative $i$ compared to Criterion or Alternative $j$. Indices $i$, and $j=1,2 \ldots n$, where, $n$ is the number of elements and the lower triangular matrix is the reciprocal values of the

${ }^{3}$ Part of this chapter is verbatim reproduced from [36], and it is under review in the Utilities Policy Journal at the time of writing this dissertation 


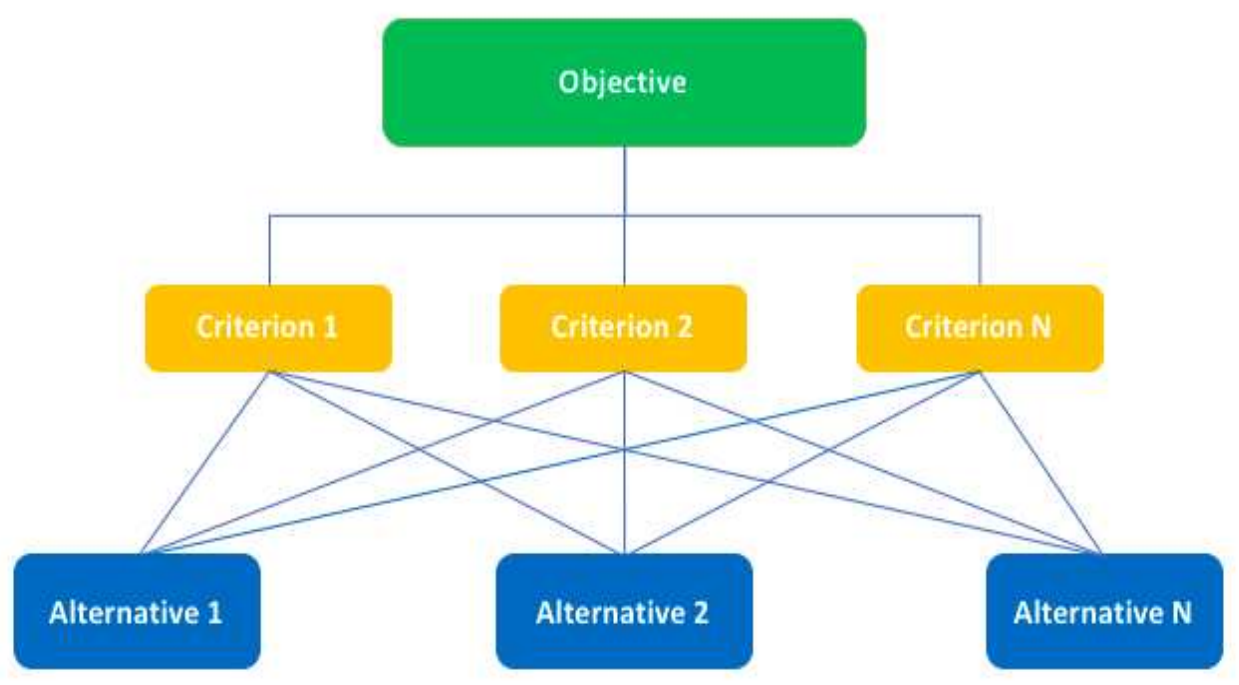

Figure 4-1: Hierarchical Structure of AHP [25]

upper diagonal. The next step is to calculate a weight vector, $x$, such that,

$$
A x=\lambda_{\max } x
$$

where, $\lambda_{\max }$ is the largest eigenvalue of $A$. The priority vector can be obtained by weighting the principal eigenvector of $A$. After that, it is important to check the consistency of the priorities. The degree of consistency can be obtained using the following formula:

$$
C I=\frac{\lambda_{\max }-n}{n-1}
$$

We use this index, $C I$, to compare it with the appropriate consistency index. The random consistency index is a fixed value of $R I$ generated by [78]. Afterward, the consistency ratio is calculated to determined consistency ratio using equation 4. Generally, the matrix is considered consistent if the largest inconsistency is $10 \%$ or less $[25,78-80]$.

$$
\text { Consistency Ratio }=\frac{C I}{R I}
$$

After that, the previous steps are performed for all levels in the hierarchy. Then, we develop an overall 
priority ranking to select the best alternative.

\subsection{Problem framework}

AHP requires a carefully crafted hierarchy with the main goal, criteria, and alternatives. Therefore, an AHP survey requires clear objective and definitions of the criteria and identification of solution alternatives. First, we must state the goals of the CAP, which primarily are to reduce GHG emissions on a schedule. The CAP framework includes a varying set of secondary goals that include community health, new business opportunities, reduced economic outflow to purchase energy, and energy independence; but, GHG reduction is its major goal. Therefore, the objective focuses on reducing GHG emissions with an electric distribution system, its assets, and associated operations only. Figure 4-2 containing the objective, criteria, and alternatives used to evaluate the alternatives.

\subsubsection{Criteria}

The hierarchy problem includes criteria to study and evaluate each alternative. These constraints include:

○ CR1: Cost includes the total direct cost to implement the alternative, i.e., fixed cost, operating and maintenance cost, and avoided cost. Also, cost excludes external costs, such as those associated with health effects.

O CR2: Reliability refers to the availability of power when the customer demands it. Reliability is quantified by popular indices such as System Average Interruption Frequency Index (SAIFI), System Average Interruption Duration Index (SAIDI), Consumer Average Interruption Frequency Index (CAIFI), Consumer Average Interruption Duration Index (CAIDI), and Momentary Average Interruption Frequency Index (MAIFI) [81].

- CR3: Power quality delivered by the alternative. This criterion includes acceptable levels of the following: harmonics, flicker, voltage deviations, and frequency variations.

O CR4: Environmental collateral is the damage caused by the alternative, e.g., toxic discharges and deforestation. Environmental collateral considers the footprint of the whole system, e.g., fuel extraction, in addition to fuel consumption 


\section{Criteria}

Alternatives
Level 1

\begin{tabular}{|c|}
\hline $\begin{array}{c}\text { Alternatives } \\
\text { Level } 2\end{array}$ \\
\hline
\end{tabular}
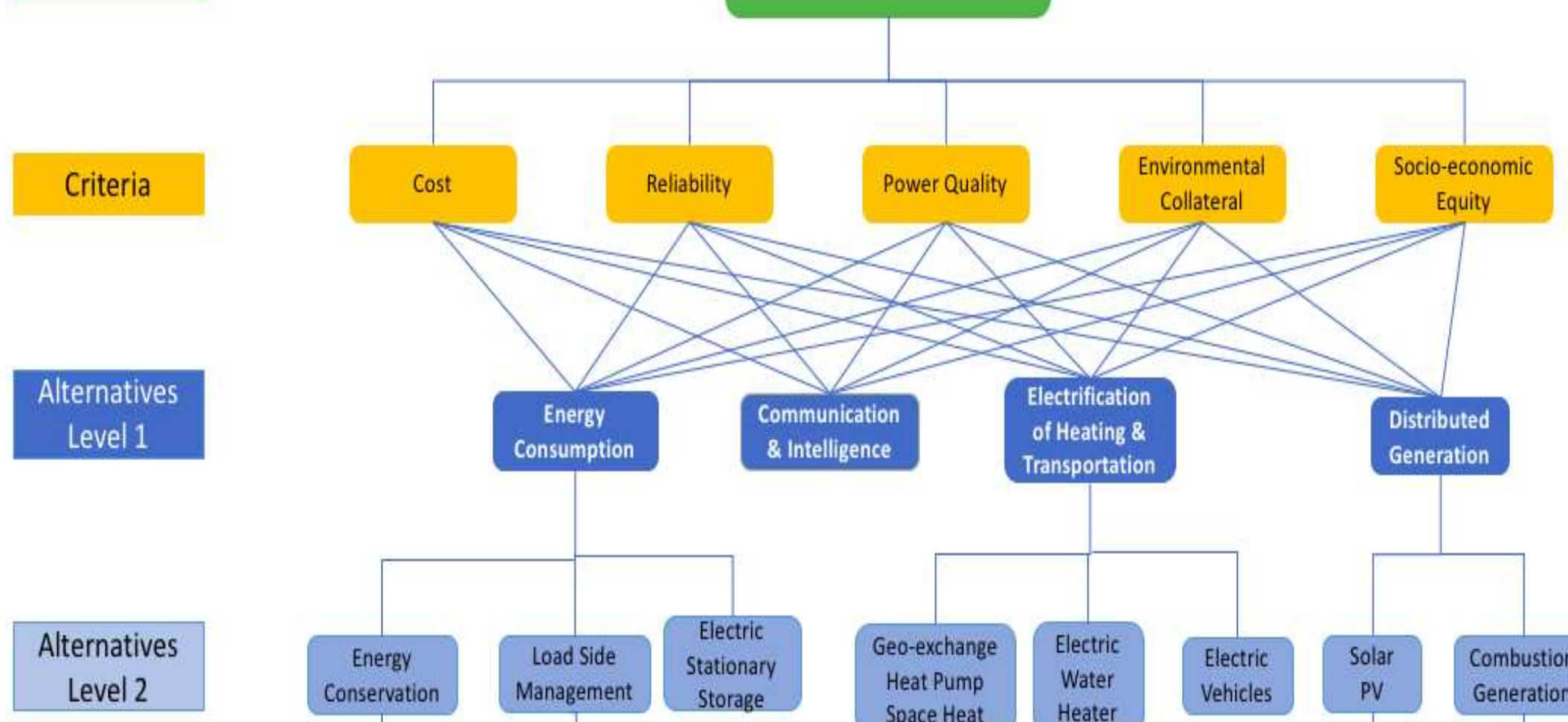

Alternatives
Level 3
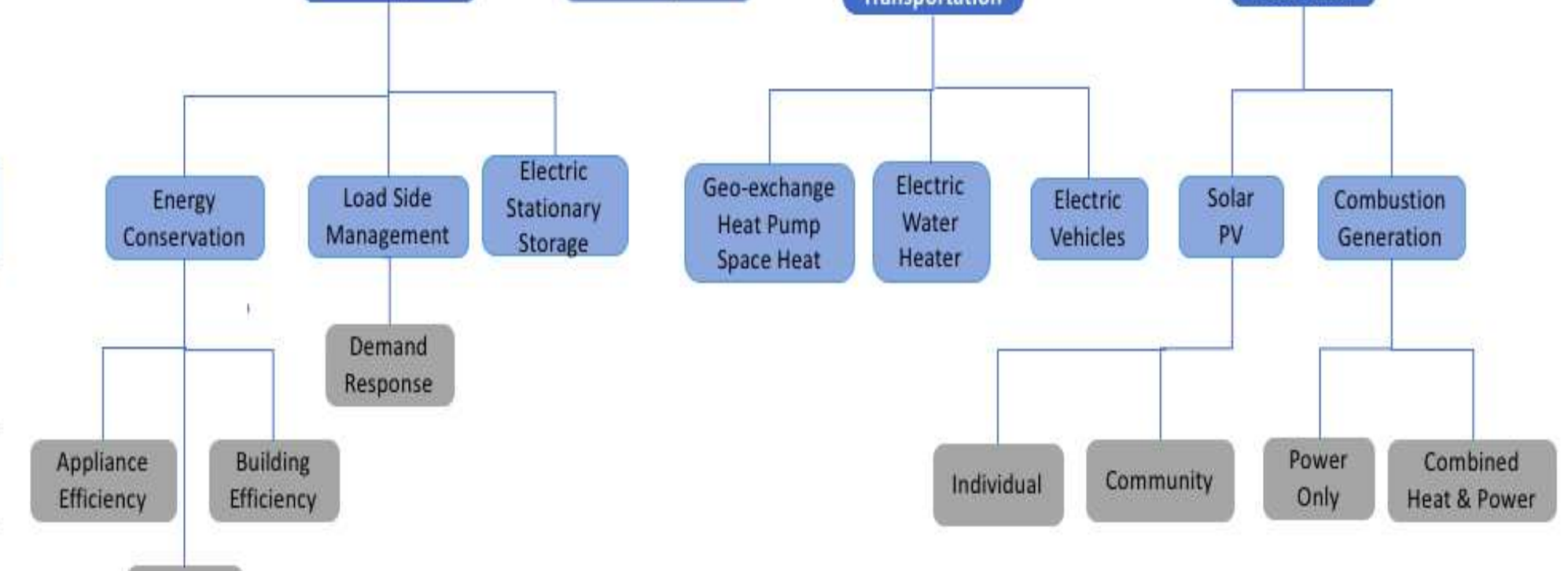

Behavior

Figure 4-2: Hierarchy of Reducing GHG Emissions with an Electric Distribution System 
- CR5: Socio-economic equity is the fairness in the access to and the benefit from the alternatives among social and economic groups.

\subsubsection{Alternatives}

The authors investigated options in the distribution system that can lead to achieving the goal. The options include a set of alternatives divided into three levels as shown in figure 7.

6.2.1 EC: energy consumption is the first alternative. It means reducing total amount of energy used by the community. This is a strategy alternative that encompasses energy conservation, load side management, and electric stationary storage. Energy conservation means reducing the useful work required. This can be implemented either by applying energy efficiency to reduce the energy input required to produce useful work or educational programs. Load side management is enabled to affect energy usage and in turn reduces GHG emission by generation's current GHG intensity. Electric stationary storage is an option to store and release electrical energy to balance load with the lowest GHG generation. Electric storage includes stationary battery that can be charged or discharged as needed to support grid operation.

6.2.2 CI: communication and intelligence is another option to achieve the goal. It is an automation to reduce energy or power and the time at which they are demanded. Communication and intelligence can include internet of things, smart meters and advanced metering infrastructure, real-time pricing, and smart appliance with controls automating energy conservation.

6.2.3 EHT: Electrification of heating and transportation is the third alternative. GHG can be reduced by transferring heating and transportation energy from combusting fossil fuels to renewable generation sources by electrification. This increase of the electric load on the distribution system must not be viewed as a failure of conservation but as a transfer from a dirty source a potentially cleaner source. A geo-exchange heat pump is the most efficient way to use electricity for space heating and cooling. It also is the most efficient way to use electricity to heat water for domestic use, not steam for industrial processes. Hot water can also be stored for up to a day, so a water heater, resistance or heat pump, is a very effective way to shift electric loads in time, which can be viewed as one-way electric storage. Charging electric vehicle can become an option which vehicle battery only whose charging can be scheduled to support grid operation. 
6.2.4 DG: Distributed generation can be defined as decentralized generation on the electrical distribution system. It is a means to collect intrinsically distributed energy like sunshine and ground heat and to distribute low-grade heat. The most available distributed generation usually is solar PV, which can use sunlight to generate either electricity or heat. Distributed generation can also combust a fuel in a heat engine to generate electricity and using the waste heat for space, water, or process heat. Combustion generation can be used with any of the fuels to which it is being compared.

After building the hierarchy, we created a survey-like set of questions aimed at identifying the priority of the alternatives for achieving the abovementioned main goal. We used a slider scale to evaluate each criterion and each option. We used slider scale to evaluate each criterion and each option. The alternatives are subjected to each criterion based on the following:

- The closer to the option, the better in achieving the goal with lower cost

- The closer to the option, the better in achieving the goal with high reliability

- The closer to the option, the better in achieving the goal with acceptable levels of power quality

- The closer to the option, the better in achieving the goal with lower environmental impact

- The closer to the option, the better in achieving the goal with equal socio-economic status

The alternatives were evaluated on the criteria by the former chair of the city energy advisory board evaluated the alternatives on the criteria based on his knowledge on the municipal electric utility and citizen values, but not in any official capacity pertaining to that position.

\subsection{Analysis and results}

Since we identify the norms and the alternatives, the authors followed a pairwise comparison process to perform a judgment matrix for the criteria and alternatives. A normalized judgment matrix is obtained by dividing each value by the others. 


\subsubsection{Criteria}

After normalizing the values, the results show the inconsistency ratio is $16.95 \%$, which is above the $10 \%$ significance threshold mentioned in Section 4.2. Table 4-1 shows the normalized matrix and priority for the criteria.

Table 4-1: Judgment Matrix and Global Priority for Criteria (before fixing inconsistency ratio)

\begin{tabular}{|c|c|c|c|c|c|c|}
\hline & CR1 & CR2 & CR3 & CR4 & CR5 & Priority \\
\hline CR1 & 1 & 0.167 & 0.2 & 3 & 2 & 0.123 \\
\hline CR2 & 6 & 1 & 3 & 3 & 3 & 0.415 \\
\hline CR3 & 5 & 0.333 & 1 & 4 & 5 & 0.302 \\
\hline CR4 & 0.333 & 0.333 & 0.25 & 1 & 1 & 0.080 \\
\hline CR5 & 0.5 & 0.333 & 0.2 & 1 & 1 & 0.080 \\
\hline
\end{tabular}

Inconsistency $\quad 16.95 \%$

Therefore, the authors fixed the inconsistency by modifying the eigenvector corresponding to $\lambda_{\max }$ [82]. As a result, the new consistency ratio is reduced to $2.94 \%$, as shown in Table 4-2. Also, we observe that "reliability" has the highest priority among the criteria, followed by "power quality".

Table 4-2: Judgment Matrix and Global Priority for Criteria (after fixing inconsistency ratio)

\begin{tabular}{|c|c|c|c|c|c|c|}
\hline & CR1 & CR2 & CR3 & CR4 & CR5 & Priority \\
\hline CR1 & 1 & 0.167 & 0.2 & 3 & 2 & 0.123 \\
\hline CR2 & $\mathbf{1 . 7 7 8}$ & 1 & 3 & 3 & 3 & 0.415 \\
\hline CR3 & 5 & 0.333 & 1 & 4 & 5 & 0.302 \\
\hline CR4 & 0.333 & 0.333 & 0.25 & 1 & 1 & 0.080 \\
\hline CR5 & 0.5 & 0.333 & 0.2 & 1 & 1 & 0.080 \\
\hline
\end{tabular}

Inconsistency

$2.94 \%$ 


\subsubsection{Alternatives}

The next step is to compare all the alternatives with respect to each criterion. Table 4-3 shows a comparison between alternatives with respect to the CR1, "cost".

Table 4-3: Judgment Matrix for Alternatives with respect to CR1, i.e., Cost (before fixing inconsistency ratio)

\begin{tabular}{|c|c|c|c|c|c|}
\hline & EC & CI & EHT & DG & Priority \\
\hline EC & 1.000 & 8.000 & 9.000 & 9.000 & 0.676 \\
\hline CI & 0.125 & 1.000 & 5.000 & 4.000 & 0.190 \\
\hline EHT & 0.111 & 0.200 & 1.000 & 3.000 & 0.086 \\
\hline DG & 0.111 & 0.250 & 0.333 & 1.000 & 0.047 \\
\hline
\end{tabular}

Inconsistency

$28.14 \%$

Table 4-4: Judgment Matrix for Alternatives with respect to CR1, i.e., Cost (after fixing inconsistency ratio)

\begin{tabular}{|c|c|c|c|c|c|}
\hline & EC & CI & EHT & DG & Priority \\
\hline EC & 1.000 & 8.000 & $\mathbf{1 . 1 4 9}$ & 9.000 & 0.676 \\
\hline CI & 0.125 & 1.000 & 5.000 & 4.000 & 0.190 \\
\hline EHT & 0.111 & 0.200 & 1.000 & 3.000 & 0.086 \\
\hline DG & 0.111 & 0.250 & 0.333 & 1.000 & 0.047 \\
\hline
\end{tabular}

Table 4-4 illustrates that the inconsistency ratio is reduced from $28.14 \%$ to 5.08\%. "Energy consumption" has the highest priority among the alternatives with respect to cost. The result is not surprising since energy consumption requires operating cost. 
Table 4-5: Judgment Matrix for Alternatives with respect to CR2, i.e., Reliability (before fixing inconsistency ratio)

\begin{tabular}{|c|c|c|c|c|c|}
\hline & EC & CI & EHT & DG & Priority \\
\hline EC & 1.000 & 6.000 & 8.000 & 9.000 & 0.639 \\
\hline CI & 0.167 & 1.000 & 8.000 & 4.000 & 0.233 \\
\hline EHT & 0.125 & 0.125 & 1.000 & 0.333 & 0.045 \\
\hline DG & 0.111 & 0.250 & 3.000 & 1.000 & 0.083 \\
\hline
\end{tabular}

When the alternatives are examined against reliability, "energy consumption" has the highest followed by "communication and intelligence" as presented in Table 4-6. The inconsistency ratio is also reduced using the technique described in [82] from $23.78 \%$, as illustrated in Table $4-5$, to $1.12 \%$.

Table 4-6: Judgment Matrix for Alternatives with respect to CR2, i.e., Reliability (after fixing inconsistency ratio)

\begin{tabular}{|c|c|c|c|c|c|}
\hline & EC & CI & EHT & DG & Priority \\
\hline EC & 1.000 & 6.000 & 8.000 & 1.171 & 0.638 \\
\hline CI & 0.167 & 1.000 & 8.000 & 4.000 & 0.233 \\
\hline EHT & 0.125 & 0.125 & 1.000 & 0.333 & 0.044 \\
\hline DG & 0.111 & 0.250 & 3.000 & 1.000 & 0.083 \\
\hline
\end{tabular}

Inconsistency $\quad 1.12 \%$

Table 4-7: Judgment Matrix for Alternatives with respect to CR3, i.e., Power Quality (before fixing inconsistency ratio)

\begin{tabular}{|c|c|c|c|c|c|}
\hline & EC & CI & EHT & DG & Priority \\
\hline EC & 1.000 & 0.167 & 2.000 & 5.000 & 0.192 \\
\hline CI & 6.000 & 1.000 & 6.000 & 6.000 & 0.617 \\
\hline EHT & 0.500 & 0.167 & 1.000 & 4.000 & 0.134 \\
\hline DG & 0.200 & 0.167 & 0.250 & 1.000 & 0.057 \\
\hline
\end{tabular}

Inconsistency $\quad 18.50 \%$ 
Table 4-7 illustrates the normalized weight for each alternative with respect to "power quality". From Table 4-8, with respect to "power quality", "communication and intelligence" has the highest priority (0.617) followed by "energy consumption" and "electrification of heating and transportation", respectively. This is reasonable since "communication and intelligence" includes smart appliances and advanced metering infrastructure. The inconsistency in this judgment matrix is corrected to $8.25 \%$ from $18.50 \%$.

Table 4-8: Judgment Matrix for Alternatives with respect to CR3, i.e., Power Quality (after fixing inconsistency ratio)

\begin{tabular}{|c|c|c|c|c|c|}
\hline & EC & CI & EHT & DG & Priority \\
\hline EC & 1.000 & 0.167 & 2.000 & 5.000 & 0.192 \\
\hline CI & 6.000 & 1.000 & 6.000 & $\mathbf{0 . 5 5 4}$ & 0.617 \\
\hline EHT & 0.500 & 0.167 & 1.000 & 4.000 & 0.134 \\
\hline DG & 0.200 & 0.167 & 0.250 & 1.000 & 0.057 \\
\hline
\end{tabular}

Inconsistency $\quad 8.25 \%$

Table 4-9: Judgment Matrix for Alternatives with respect to CR4, i.e., Environmental Collateral (before fixing inconsistency ratio)

\begin{tabular}{|c|c|c|c|c|c|}
\hline & EC & CI & EHT & DG & Priority \\
\hline EC & 1.000 & 2.000 & 2.000 & 5.000 & 0.389 \\
\hline CI & 0.500 & 1.000 & 0.167 & 4.000 & 0.152 \\
\hline EHT & 0.500 & 6.000 & 1.000 & 8.000 & 0.406 \\
\hline DG & 0.200 & 0.250 & 0.125 & 1.000 & 0.053 \\
\hline
\end{tabular}

Inconsistency $\quad 18.54 \%$

Table 4-10 shows reducing the inconsistency ratio from 18.54\%, from Table 4-9, to 6.18\%. Almost $80 \%$ of the importance for reducing "environmental collateral" is attributed to "electrification of heating and transportation" and to "energy consumption". Electrification of heating and transportation potentially replaces the use of fossil fuels in heating or transportation; the reduction in energy consumption reduces GHG 
emissions, if this electricity is generated by low carbon sources.

Table 4-10: Judgment Matrix for Alternatives with respect to CR4, i.e., Environmental Collateral (after fixing inconsistency ratio)

\begin{tabular}{|c|c|c|c|c|c|}
\hline & EC & CI & EHT & DG & $\begin{array}{c}\text { Priorit } \\
y\end{array}$ \\
\hline EC & 1.000 & 2.000 & 2.000 & 5.000 & 0.389 \\
\hline CI & 0.500 & 1.000 & 0.167 & 4.000 & 0.152 \\
\hline EHT & 0.500 & 6.000 & 1.000 & $\mathbf{1 . 0 4 4}$ & 0.406 \\
\hline DG & 0.200 & 0.250 & 0.125 & 1.000 & 0.053 \\
\hline
\end{tabular}

Inconsistency $\quad 6.18 \%$

Table 4-11: Judgment Matrix for Alternatives with respect to CR5, i.e., Socio-economic Equity (before fixing inconsistency ratio)

\begin{tabular}{|c|c|c|c|c|c|}
\hline & EC & CI & EHT & DG & Priority \\
\hline EC & 1.000 & 5.000 & 8.000 & 6.000 & 0.576 \\
\hline CI & 0.200 & 1.000 & 6.000 & 8.000 & 0.277 \\
\hline EHT & 0.125 & 0.167 & 1.000 & 4.000 & 0.097 \\
\hline DG & 0.167 & 0.125 & 0.250 & 1.000 & 0.050 \\
\hline \multicolumn{7}{|l|}{} \\
\end{tabular}

Socio-economic equity is difficult to quantify; therefore, it is hard to make a precise judgment. Hence, the inconsistency ratio for the alternatives with respect to socio-economic equity, from Table 4-11, was 34.61\%. The author successfully reduced the inconsistency ratio to 1.75\%. Table 4-12 shows the "energy consumption" alternative as the most effective with respect to socio-economic equity. 
Table 4-12: Judgment Matrix for Alternatives with respect to CR5, i.e., Socio-economic Equity (after fixing inconsistency ratio)

\begin{tabular}{|c|c|c|c|c|c|}
\hline & EC & CI & EHT & DG & Priority \\
\hline EC & 1.000 & 5.000 & 1.347 & 6.000 & 0.576 \\
\hline CI & 0.200 & 1.000 & 6.000 & 1.449 & 0.276 \\
\hline EHT & 0.125 & 0.167 & 1.000 & 4.000 & 0.097 \\
\hline DG & 0.167 & 0.125 & 0.250 & 1.000 & 0.050 \\
\hline
\end{tabular}

Inconsistency $\quad 1.75 \%$

\subsubsection{Sub-alternatives}

As explained earlier, the alternatives of the problem include sub-alternatives that propose solutions toward achieving the goal.

\section{A. Energy consumption}

As mentioned in Section 4.3, "energy consumption" contains three options: energy conservation, load side management, and electric stationary storage. Each sub-alternative is compared to each criterion to calculated local priority. Table 4-13 shows that the inconsistency ratio is $26.39 \%$, above the acceptable limit.

Table 4-13: Judgment Matrix for Sub-alternatives with respect to CR1, i.e., Cost (before fixing inconsistency ratio)

\begin{tabular}{|c|c|c|c|c|}
\hline & Energy conservation & Load side management & Stationary storage & Priority \\
\hline Energy conservation & 1.000 & 6.000 & 9.000 & 0.717 \\
\hline $\begin{array}{c}\text { Load side } \\
\text { management }\end{array}$ & 0.167 & 1.000 & 7.000 & 0.227 \\
\hline $\begin{array}{c}\text { Stationary storage } \\
\text { E }\end{array}$ & 0.111 & 0.143 & 1.000 & 0.055 \\
\hline
\end{tabular}

Inconsistency $\quad 36.39 \%$

We successfully reduced the inconsistency ratio to $1.18 \%$ by fixing the comparison between "energy conservation" and "stationary storage". Table 4-14 presents the judgment matrix after obtaining the new inconsistency ratio. 
Table 4-14: Judgment Matrix for Sub-alternatives with respect to CR1, i.e., Cost (after fixing inconsistency ratio)

\begin{tabular}{|c|c|c|c|c|}
\hline & Energy conservation & Load side management & Stationary storage & Priority \\
\hline Energy conservation & 1.000 & 6.000 & $\mathbf{0 . 6 9 0}$ & 0.717 \\
\hline Load side management & 0.167 & 1.000 & 7.000 & 0.227 \\
\hline Stationary storage & 0.111 & 0.143 & 1.000 & 0.055 \\
\hline
\end{tabular}

Inconsistency $\quad 36.39 \%$

Table 4-15 and Table 4-16 demonstrate that the inconsistency related to "energy consumption" is below the acceptable limit $10 \%$. It is $4.03 \%$ with respect to reliability and $3.84 \%$ when compared to power quality.

Table 4-15: Judgment Matrix for Sub-alternatives with respect to CR2, i.e., Reliability

\begin{tabular}{|c|c|c|c|c|}
\hline & Energy conservation & Load side management & Stationary storage & Priority \\
\hline Energy conservation & 1.000 & 0.250 & 0.143 & 0.080 \\
\hline Load side management & 4.000 & 1.000 & 0.333 & 0.265 \\
\hline Stationary storage & 7.000 & 3.000 & 1.000 & 0.656 \\
\hline
\end{tabular}

Inconsistency $\quad 4.03 \%$

Table 4-16: Judgment Matrix for Sub-alternatives with respect to CR3, i.e., Power Quality

\begin{tabular}{|c|c|c|c|c|}
\hline & Energy conservation & Load side management & Stationary storage & Priority \\
\hline Energy conservation & 1.000 & 0.111 & 0.200 & 0.070 \\
\hline Load side management & 9.000 & 1.000 & 1.000 & 0.510 \\
\hline Stationary storage & 5.000 & 1.000 & 1.000 & 0.420 \\
\hline
\end{tabular}

Inconsistency $\quad 3.84 \%$ 
As environmental collateral is an important factor to minimize GHG emissions, the comparison overestimates "energy conservation" and "load side management" against "stationary storage". The results are inconsistent by about $60.26 \%$ in that judgment as shown in Table 4-17.

Table 4-17: Judgment Matrix for Sub-alternatives with respect to CR4, i.e., Environmental Collateral (before fixing inconsistency ratio)

\begin{tabular}{|c|c|c|c|c|}
\hline & Energy conservation & Load side management & Stationary storage & Priority \\
\hline Energy conservation & 1.000 & 7.000 & 9.000 & 0.711 \\
\hline Load side management & 0.143 & 1.000 & 9.000 & 0.237 \\
\hline Stationary storage & 0.111 & 0.111 & 1.000 & 0.052 \\
\hline
\end{tabular}

Inconsistency $\quad 60.26 \%$

However, the inconsistency ratio successfully reduced to $0 \%$ by modifying the eigenvector corresponding to $\lambda_{\max }$ of “stationary storage". Table 4-18 illustrates judgment matrix after the new inconsistency. Table 4-18: Judgment Matrix for Sub-alternatives with respect to CR4, i.e., Environmental Collateral (after fixing inconsistency ratio)

\begin{tabular}{|c|c|c|c|c|}
\hline & Energy conservation & Load side management & Stationary storage & Priority \\
\hline Energy conservation & 1.000 & 7.000 & $\mathbf{0 . 6 4 6}$ & 0.711 \\
\hline Load side management & 0.143 & 1.000 & $\mathbf{1 . 9 3 7}$ & 0.237 \\
\hline Stationary storage & 0.111 & 0.111 & 1.000 & 0.051 \\
\hline
\end{tabular}

Inconsistency $\quad 0 \%$

Socio-economic equity is a difficult factor that measures the effectiveness of "energy consumption" in reducing GHG emissions. The results obtained in Table 4-19 show the we are 5.87\% above the limit. 
Table 4-19: Judgment Matrix for Sub-alternatives with respect to CR5, i.e., Socioeconomic Equity (before fixing inconsistency ratio)

\begin{tabular}{|c|c|c|c|c|}
\hline & Energy conservation & Load side management & Stationary storage & Priority \\
\hline Energy conservation & 1.000 & 5.000 & 7.000 & 0.709 \\
\hline Load side management & 0.200 & 1.000 & 4.000 & 0.214 \\
\hline Stationary storage & 0.143 & 0.250 & 1.000 & 0.077 \\
\hline
\end{tabular}

Inconsistency $\quad 15.87 \%$

The inconsistency ratio is reduced to $0.42 \%$ by affecting the judgment between "load side management" and stationary storage". Table 4-20 explains the change in the judgment matrix that results a reduction in the inconsistency.

Table 4-20: Judgment Matrix for Sub-alternatives with respect to CR5, i.e., Socioeconomic Equity (after fixing inconsistency ratio)

\begin{tabular}{|c|c|c|c|c|}
\hline & Energy conservation & Load side management & Stationary storage & Priority \\
\hline Energy conservation & 1.000 & 5.000 & 7.000 & 0.709 \\
\hline Load side management & 0.200 & 1.000 & 1.421 & 0.214 \\
\hline Stationary storage & 0.143 & 0.250 & 1.000 & 0.076 \\
\hline
\end{tabular}

Inconsistency $\quad 0.42 \%$

The global priority of a sub-alternative is calculated by multiplying its local priority by the respective alternative. Table 4-21 demonstrates that "energy conservation" is the highest preferred option with respect to cost. Also, load side management is the suitable option for both reliability and power quality. For environmental collateral and socio-economic equity, we observe that energy conservation is the highest-ranked sub-alternative. 
Table 4-21: Local Priority and Global Priority for Energy Consumption with respect to Each Criterion

\begin{tabular}{|c|c|c|c|}
\hline Criterion & & Local priority & Global priority \\
\hline \multirow{3}{*}{ CR1 } & Energy conservation & 0.717 & 0.060 \\
\hline & Load side management & 0.227 & 0.019 \\
\hline & Stationary storage & 0.055 & 0.005 \\
\hline \multirow{3}{*}{ CR2 } & Energy conservation & 0.080 & 0.021 \\
\hline & Load side management & 0.265 & 0.070 \\
\hline & Stationary storage & 0.655 & 0.173 \\
\hline \multirow{3}{*}{ CR3 } & Energy conservation & 0.070 & 0.004 \\
\hline & Load side management & 0.510 & 0.030 \\
\hline & Stationary storage & 0.420 & 0.024 \\
\hline \multirow{3}{*}{ CR4 } & Energy conservation & 0.711 & 0.022 \\
\hline & Load side management & 0.237 & 0.007 \\
\hline & Stationary storage & 0.051 & 0.002 \\
\hline \multirow{3}{*}{ CR5 } & Energy conservation & 0.709 & 0.033 \\
\hline & Load side management & 0.214 & 0.010 \\
\hline & Stationary storage & 0.076 & 0.004 \\
\hline
\end{tabular}

Further, "energy conservation" is the first most important option toward achieving the goal. It consists of three options; efficient appliances, efficient buildings, and behavior. Therefore, we constructed a pairwise comparison between the considered solutions under "energy conservation". Table 4-22 shows that the inconsistency ratio for those options violates the $10 \%$ limit. 
Table 4-22: Judgment Matrix for Alternatives under Energy Conservation with respect to CR1, i.e., Cost (before fixing inconsistency ratio)

\begin{tabular}{|c|c|c|c|c|}
\hline & Efficient appliances & Efficient buildings & Behavior & Priority \\
\hline Efficient appliances & 1.000 & 4.000 & 0.167 & 0.191 \\
\hline Efficient buildings & 0.250 & 1.000 & 0.125 & 0.069 \\
\hline Behavior & 6.000 & 8.000 & 1.000 & 0.739 \\
\hline
\end{tabular}

Inconsistency $\quad 17.90 \%$

The inconsistency is successfully reduced to $4.55 \%$ as shown in Table $4-23$.

Table 4-23: Judgment Matrix for Alternatives under Energy Conservation with respect to CR1, i.e., Cost (after fixing inconsistency ratio)

\begin{tabular}{|c|c|c|c|c|}
\hline & Efficient appliances & Efficient buildings & Behavior & Priority \\
\hline Efficient appliances & 1.000 & $\mathbf{1 . 4 4 5}$ & 0.167 & 0.191 \\
\hline Efficient buildings & 0.250 & 1.000 & 0.125 & 0.069 \\
\hline Behavior & 6.000 & 8.000 & 1.000 & 0.739 \\
\hline
\end{tabular}

Inconsistency $\quad 4.55 \%$

The weighted matrix for the previously mentioned options is constructed and illustrated in Table 4-24.

Table 4-24: Judgment Matrix for Alternatives under Energy Conservation with respect to CR2, i.e., Reliability

\begin{tabular}{|c|c|c|c|c|}
\hline & Efficient appliances & Efficient buildings & Behavior & Priority \\
\hline Efficient appliances & 1.000 & 1.000 & 0.200 & 0.131 \\
\hline Efficient buildings & 1.000 & 1.000 & 0.125 & 0.112 \\
\hline Behavior & 5.000 & 8.000 & 1.000 & 0.756 \\
\hline
\end{tabular}

Inconsistency $\quad 2.93 \%$ 
Table 4-25 presents that the judgment matrix for power quality contains inconsistence comparison as the inconsistency was $17.98 \%$.

Table 4-25: Judgment Matrix for Alternatives under Energy Conservation with respect to CR3, i.e., Power Quality (before fixing inconsistency ratio)

\begin{tabular}{|c|c|c|c|c|}
\hline & Efficient appliances & Efficient buildings & Behavior & Priority \\
\hline Efficient appliances & 1.000 & 6.000 & 4.000 & 0.658 \\
\hline Efficient buildings & 0.167 & 1.000 & 0.200 & 0.079 \\
\hline Behavior & 0.250 & 5.000 & 1.000 & 0.261 \\
\hline
\end{tabular}

Inconsistency $\quad 17.98 \%$

The inconsistency ratio is corrected after modifying eigenvector corresponding to "behavior" against “efficient appliances" as demonstrated in Table 4-26.

Table 4-26: Judgment Matrix for Alternatives under Energy Conservation with respect to CR3, i.e., Power Quality (after fixing inconsistency ratio)

\begin{tabular}{|c|c|c|c|c|}
\hline & Efficient appliances & Efficient buildings & Behavior & Priority \\
\hline Efficient appliances & 1.000 & 6.000 & 4.000 & 0.658 \\
\hline Efficient buildings & 0.167 & 1.000 & 0.200 & 0.079 \\
\hline Behavior & 0.250 & 1.513 & 1.000 & 0.261 \\
\hline
\end{tabular}

Inconsistency $\quad 2.88 \%$

The normalized comparison with respect to environmental collateral in Table 4-27 shows an increase by about $10 \%$ above the permissible limit for inconsistency. Therefore, Table $4-28$ explains that the best reduction in the inconsistency was $10 \%$. 
Table 4-27: Judgment Matrix for Alternatives under Energy Conservation with respect to CR4, i.e., Environmental Collateral (before fixing inconsistency ratio)

\begin{tabular}{|c|c|c|c|c|}
\hline & Efficient appliances & Efficient buildings & Behavior & Priority \\
\hline Efficient appliances & 1.000 & 0.333 & 0.125 & 0.073 \\
\hline Efficient buildings & 3.000 & 1.000 & 0.125 & 0.152 \\
\hline Behavior & 8.000 & 8.000 & 1.000 & 0.774 \\
\hline
\end{tabular}

Inconsistency $\quad 20 \%$

Table 4-28: Judgment Matrix for Alternatives under Energy Conservation with respect to CR4, i.e., Environmental Collateral (after fixing inconsistency ratio)

\begin{tabular}{|c|c|c|c|c|}
\hline & Efficient appliances & Efficient buildings & Behavior & Priority \\
\hline Efficient appliances & 1.000 & 0.333 & 0.125 & 0.073 \\
\hline Efficient buildings & 3.000 & 1.000 & $\mathbf{0 . 6 3 7}$ & 0.152 \\
\hline Behavior & $\mathbf{0 . 7 5 5}$ & 8.000 & 1.000 & 0.774 \\
\hline
\end{tabular}

Inconsistency $\quad 10 \%$

The last matrix has been generated to compare the three-option of "energy conservation" with respect to CR5. i.e, Socio-economic equity. Table 4-29 shows the weighted matrix for this comparison.

Table 4-29: Judgment Matrix for Alternatives under Energy Conservation with respect to CR5, i.e., Socio-economic Equity

\begin{tabular}{|c|c|c|c|c|}
\hline & Efficient appliances & Efficient buildings & Behavior & Priority \\
\hline Efficient appliances & 1.000 & 1.544 & 0.250 & 0.267 \\
\hline Efficient buildings & 0.167 & 1.000 & 0.143 & 0.069 \\
\hline Behavior & 4.000 & 7.000 & 1.000 & 0.664 \\
\hline
\end{tabular}

Inconsistency $\quad 3.03 \%$

Table 4-30 demonstrates the weight for each alternative under "energy conservation". The result shows that educational programs are the best way to reduce energy use followed by efficient appliances and efficient buildings. 
Table 4-30: Energy Conservation Final Prioritization

\begin{tabular}{|c|c|c|}
\hline & Priority & Ranking \\
\hline Behavior & 0.100 & 1 \\
\hline Efficient appliances & 0.027 & 2 \\
\hline Efficient buildings & 0.012 & 3 \\
\hline
\end{tabular}

\section{B. Communication and intelligence}

The judgment matrix is constructed for the communication and intelligence alternative. As mentioned in Section 4.3, this alternative includes Internet of Things (Iot), smart meters and Advanced Metering Infrastructure (AMI), real-time pricing, and smart appliances. The framework compares all sub-alternatives to evaluate the best option under "communication and intelligence". Table 4-31 illustrates the first comparison under "communication and intelligence" with a $21.85 \%$ inconsistency.

Table 4-31: Judgment Matrix for Sub-alternatives with respect to CR1, i.e., Cost (before fixing inconsistency ratio)

\begin{tabular}{|c|c|c|c|c|c|}
\hline & Iot & $\begin{array}{c}\text { Smart meters \& } \\
\text { AMI }\end{array}$ & Real-time pricing & $\begin{array}{c}\text { Smart } \\
\text { appliances }\end{array}$ & Priority \\
\hline Iot & 1.000 & 0.200 & 1.000 & 0.333 & 0.118 \\
\hline Smart meters \& AMI & 5.000 & 1.000 & 1.000 & 0.200 & 0.228 \\
\hline Real-time pricing & 1.000 & 1.000 & 1.000 & 0.333 & 0.146 \\
\hline Smart appliances & 3.000 & 5.000 & 3.000 & 1.000 & 0.508 \\
\hline
\end{tabular}

This violation has been solved after fixing cost estimation between smart appliances and smart meters and AMI as shown in Table 4-32. 
Table 4-32: Judgment Matrix for Sub-alternatives with respect to CR1, i.e., Cost (after fixing inconsistency ratio)

\begin{tabular}{|c|c|c|c|c|c|}
\hline & Iot & $\begin{array}{c}\text { Smart meters \& } \\
\text { AMI }\end{array}$ & $\begin{array}{c}\text { Real-time } \\
\text { pricing }\end{array}$ & $\begin{array}{c}\text { Smart } \\
\text { appliances }\end{array}$ & Priority \\
\hline Iot & 1.000 & 0.200 & 1.000 & 0.333 & 0.118 \\
\hline Smart meters \& AMI & 5.000 & 1.000 & 1.000 & 0.200 & 0.228 \\
\hline Real-time pricing & 1.000 & 1.000 & 1.000 & 0.333 & 0.146 \\
\hline Smart appliances & 3.000 & 2.249 & 3.000 & 1.000 & 0.508 \\
\hline
\end{tabular}

Inconsistency $\quad 0.54 \%$

With respect to CR2, Reliability, the decision maker was consistence during the pairwise comparison process as illustrated in Table 4-33.

Table 4-33: Judgment Matrix for Sub-alternatives with respect to CR1, i.e., Reliability

\begin{tabular}{|c|c|c|c|c|c|}
\hline & Iot & $\begin{array}{c}\text { Smart meters \& } \\
\text { AMI }\end{array}$ & $\begin{array}{c}\text { Real-time } \\
\text { pricing }\end{array}$ & $\begin{array}{c}\text { Smart } \\
\text { appliances }\end{array}$ & Priority \\
\hline Iot & 1.000 & 0.500 & 0.250 & 2.000 & 0.147 \\
\hline Smart meters \& AMI & 2.000 & 1.000 & 2.000 & 5.000 & 0.421 \\
\hline Real-time pricing & 4.000 & 0.500 & 1.000 & 5.000 & 0.359 \\
\hline Smart appliances & 0.500 & 0.200 & 0.200 & 1.000 & 0.073 \\
\hline
\end{tabular}

A $22.52 \%$ increase in the inconsistency limit was observed when the potions under "communication and intelligence" were compared with respect to CR3, Power quality. Table 4-34 denotes to the inconsistency.

Table 4-34: Judgment Matrix for Sub-alternatives with respect to CR3, i.e., Power Quality (before fixing inconsistency ratio)

\begin{tabular}{|c|c|c|c|c|c|}
\hline & Iot & $\begin{array}{c}\text { Smart meters \& } \\
\text { AMI }\end{array}$ & Real-time pricing & $\begin{array}{c}\text { Smart } \\
\text { appliances }\end{array}$ & Priority \\
\hline Iot & 1.000 & 0.167 & 0.200 & 3.000 & 0.099 \\
\hline Smart meters \& AMI & 6.000 & 1.000 & 6.000 & 6.000 & 0.581 \\
\hline Real-time pricing & 5.000 & 0.167 & 1.000 & 7.000 & 0.266 \\
\hline Smart appliances & 0.333 & 0.167 & 0.143 & 1.000 & 0.054 \\
\hline
\end{tabular}


The inconsistency was solved by fixing the comparison between smart meters and AMI and real-time pricing. The new inconsistency was reduced by $29.21 \%$ as shown in Table $4-35$.

Table 4-35: Judgment Matrix for Sub-alternatives with respect to CR3, i.e., Power Quality (after fixing inconsistency ratio)

\begin{tabular}{|c|c|c|c|c|c|}
\hline & Iot & $\begin{array}{c}\text { Smart meters \& } \\
\text { AMI }\end{array}$ & Real-time pricing & $\begin{array}{c}\text { Smart } \\
\text { appliances }\end{array}$ & Priority \\
\hline Iot & 1.000 & 0.167 & 0.200 & 6.000 & 0.099 \\
\hline Smart meters \& AMI & 6.000 & 1.000 & 2.747 & 7.000 & 0.266 \\
\hline Real-time pricing & 5.000 & 0.167 & 1.000 & 1.000 & 0.054 \\
\hline Smart appliances & 0.333 & 0.167 & 0.143 & & 0.58 \\
\hline
\end{tabular}

Inconsistency $\quad 3.31 \%$

The decision maker was consistent when those local alternatives are compared. Table 4-36 tells that the inconsistency was $2.99 \%$ below the maximum limit.

Table 4-36: Judgment Matrix for Sub-alternatives with respect to CR4, i.e., Environmental Collateral

\begin{tabular}{|c|c|c|c|c|c|}
\hline & Iot & $\begin{array}{c}\text { Smart meters \& } \\
\text { AMI }\end{array}$ & Real-time pricing & $\begin{array}{c}\text { Smart } \\
\text { appliances }\end{array}$ & Priority \\
\hline Iot & 1.000 & 2.000 & 0.333 & 0.500 & 0.150 \\
\hline Smart meters \& AMI & 0.500 & 1.000 & 0.250 & 0.200 & 0.083 \\
\hline Real-time pricing & 3.000 & 4.000 & 1.000 & 3.000 & 0.488 \\
\hline Smart appliances & 2.000 & 5.000 & 0.333 & 1.000 & 0.277 \\
\hline
\end{tabular}

Inconsistency $\quad 7.01 \%$

CR5, Socio-economic equity, leads the decision maker to be inconsistence by more than $25 \%$. The relationship between smart meters and AMI and real-time pricing caused this violation in the inconsistency as explained in Table 4-37. 
Table 4-37: Judgment Matrix for Sub-alternatives with respect to CR5, i.e., Socio-economic Equity (before fixing inconsistency ratio)

\begin{tabular}{|c|c|c|c|c|c|}
\hline & Iot & $\begin{array}{c}\text { Smart meters \& } \\
\text { AMI }\end{array}$ & Real-time pricing & $\begin{array}{c}\text { Smart } \\
\text { appliances }\end{array}$ & Priority \\
\hline Iot & 1.000 & 0.167 & 0.200 & 1.000 & 0.096 \\
\hline Smart meters \& AMI & 6.000 & 1.000 & 4.000 & 3.000 & 0.501 \\
\hline Real-time pricing & 5.000 & 0.250 & 1.000 & 0.200 & 0.166 \\
\hline Smart appliances & 1.000 & 0.333 & 5.000 & 1.000 & 0.237 \\
\hline
\end{tabular}

Inconsistency $\quad 35.43 \%$

Therefore, the inconsistency ratio was reduced to $7.35 \%$ by modifying the largest eigenvector, in Table 4-38.

Table 4-38: Judgment Matrix for Sub-alternatives with respect to CR5, i.e., Socio-economic Equity (after fixing inconsistency ratio)

\begin{tabular}{|c|c|c|c|c|c|}
\hline & Iot & $\begin{array}{c}\text { Smart meters \& } \\
\text { AMI }\end{array}$ & Real-time pricing & $\begin{array}{c}\text { Smart } \\
\text { appliances }\end{array}$ & Priority \\
\hline Iot & 1.000 & 0.167 & 0.200 & 1.000 & 0.096 \\
\hline Smart meters \& AMI & 6.000 & 1.000 & 1.325 & 3.000 & 0.501 \\
\hline Real-time pricing & 5.000 & 0.250 & 1.000 & 0.200 & 0.166 \\
\hline Smart appliances & 1.000 & 0.333 & 5.000 & 1.000 & 0.237 \\
\hline
\end{tabular}

Inconsistency $\quad 7.35 \%$

Final prioritization for a sub-alternative is calculated by multiplying its local priority by the respective alternative. Table 4-39 demonstrates that "smart appliances" is the highest preferred option with respect to cost. Also, smart meters \& AMI is the suitable option for both reliability, power quality, and socio-economic equity. For environmental collateral, we observe that real-time pricing is the highest-ranked sub-alternative. 
Table 4-39: Local Priority and Global Priority for Communication and Intelligence with respect to Each Criterion

\begin{tabular}{|c|c|c|c|}
\hline Criterion & & Local priority & Global priority \\
\hline \multirow{4}{*}{ CR1 } & Iot & 0.118 & 0.003 \\
\hline & Smart meters \& AMI & 0.228 & 0.005 \\
\hline & Real-time pricing & 0.146 & 0.003 \\
\hline & Smart appliances & 0.507 & 0.012 \\
\hline \multirow{4}{*}{ CR2 } & Iot & 0.146 & 0.014 \\
\hline & Smart meters \& AMI & 0.421 & 0.041 \\
\hline & Real-time pricing & 0.359 & 0.035 \\
\hline & Smart appliances & 0.073 & 0.007 \\
\hline \multirow{4}{*}{ CR3 } & Iot & 0.099 & 0.018 \\
\hline & Smart meters \& AMI & 0.581 & 0.108 \\
\hline & Real-time pricing & 0.266 & 0.050 \\
\hline & Smart appliances & 0.054 & 0.010 \\
\hline \multirow{4}{*}{ CR4 } & Iot & 0.150 & 0.002 \\
\hline & Smart meters \& AMI & 0.083 & 0.001 \\
\hline & Real-time pricing & 0.488 & 0.006 \\
\hline & Smart appliances & 0.277 & 0.003 \\
\hline \multirow{4}{*}{ CR5 } & Iot & 0.096 & 0.002 \\
\hline & Smart meters \& AMI & 0.501 & 0.011 \\
\hline & Real-time pricing & 0.166 & 0.004 \\
\hline & Smart appliances & 0.237 & 0.005 \\
\hline
\end{tabular}




\section{Electrification of heating and transportation}

The judgment matrix is constructed for the electrification of heating and transportation alternative. This alternative contains three alternatives: geo-exchange heat pump, electric water heater, and electric vehicles as grid to vehicle capability. Each sub-alternative is compared to each criterion in order to determine local priority. When we constructed a judgment matrix for the options under "electrification of heating and transportation" against "cost", the inconsistency ratio was $123.17 \%$. Table $4-40$ illustrates the judgment matrix before fixing the inconsistency ratio.

Table 4-40: Judgment Matrix for Sub-alternatives with respect to CR1, i.e., Cost (before fixing inconsistency ratio)

\begin{tabular}{|c|c|c|c|c|}
\hline & $\begin{array}{c}\text { Geo-exchange heat } \\
\text { pump }\end{array}$ & Electric water heater & Electric vehicles & Priority \\
\hline $\begin{array}{c}\text { Geo-exchange heat } \\
\text { pump }\end{array}$ & 1.000 & 1.000 & 0.111 & 0.182 \\
\hline Electric water heater & 1.000 & 1.000 & 3.000 & 0.416 \\
\hline Electric vehicles & 9.000 & 0.333 & 1.000 & 0.401 \\
\hline
\end{tabular}

Inconsistency $\quad 123.17 \%$

We tried to reduce the inconsistency, but the best potential minimization for the inconsistency was $13.59 \%$, as demonstrated in Table 4-41, which is higher than $10 \%$.

Table 4-41: Judgment Matrix for Sub-alternatives with respect to CR1, i.e., Cost (after fixing inconsistency ratio)

\begin{tabular}{|c|c|c|c|c|}
\hline & $\begin{array}{c}\text { Geo-exchange heat } \\
\text { pump }\end{array}$ & Electric water heater & Electric vehicles & Priority \\
\hline $\begin{array}{c}\text { Geo-exchange heat } \\
\text { pump }\end{array}$ & 1.000 & 0.143 & 0.333 & 0.082 \\
\hline Electric water heater & 7.000 & 1.000 & 6.000 & 0.739 \\
\hline Electric vehicles & 3.000 & 0.167 & 1.000 & 0.179 \\
\hline
\end{tabular}

Inconsistency $\quad 13.59 \%$ 
The judgment matrix in Table 4-42 shows the decision maker were not precisely comparing the threeoption of "electrification of heating and transportation". However, the inconsistency was reduced after revisiting the compared objects as demonstrated in Table 4-43.

Table 4-42: Judgment Matrix for Sub-alternatives with respect to CR2, i.e., Reliability (before fixing inconsistency ratio)

\begin{tabular}{|c|c|c|c|c|}
\hline & $\begin{array}{c}\text { Geo-exchange heat } \\
\text { pump }\end{array}$ & Electric water heater & Electric vehicles & Priority \\
\hline $\begin{array}{c}\text { Geo-exchange heat } \\
\text { pump }\end{array}$ & 1.000 & 0.167 & 0.500 & 0.098 \\
\hline Electric water heater & 6.000 & 1.000 & 8.000 & 0.761 \\
\hline Electric vehicles & 2.000 & 0.125 & 1.000 & 0.141 \\
\hline
\end{tabular}

Inconsistency $\quad 15.51 \%$

Table 4-43: Judgment Matrix for Sub-alternatives with respect to CR2, i.e., Reliability (after fixing inconsistency ratio)

\begin{tabular}{|c|c|c|c|c|}
\hline & $\begin{array}{c}\text { Geo-exchange heat } \\
\text { pump }\end{array}$ & Electric water heater & Electric vehicles & Priority \\
\hline $\begin{array}{c}\text { Geo-exchange heat } \\
\text { pump }\end{array}$ & 1.000 & 0.167 & 0.500 & 0.098 \\
\hline Electric water heater & 6.000 & 1.000 & 8.000 & 0.761 \\
\hline Electric vehicles & $\mathbf{1 . 3 9 0}$ & 0.125 & 1.000 & 0.141 \\
\hline
\end{tabular}

Inconsistency $\quad 10.96 \%$

Power quality is an important criterion when we construct a pairwise comparison for the electrification of heating and transportation alternative. In Table 4-44, inconsistency is below 10\%. 
Table 4-44: Judgment Matrix for Sub-alternatives with respect to CR3, i.e., Power Quality

\begin{tabular}{|c|c|c|c|c|}
\hline & $\begin{array}{c}\text { Geo-exchange heat } \\
\text { pump }\end{array}$ & Electric water heater & Electric vehicles & Priority \\
\hline $\begin{array}{c}\text { Geo-exchange heat } \\
\text { pump }\end{array}$ & 1.000 & 0.333 & 2.000 & 0.252 \\
\hline Electric water heater & 3.000 & 1.000 & 3.000 & 0.589 \\
\hline Electric vehicles & 0.500 & 0.333 & 1.000 & 0.159 \\
\hline
\end{tabular}

Inconsistency $\quad 5.33 \%$

As "environmental collateral” is an essential factor to quantify GHG reduction. Therefore, a $11.76 \%$ inconsistency ratio, in Table 4-45, was not acceptable during comparing the options of "electrification of heating and transportation.

Table 4-45: Judgment Matrix for Sub-alternatives with respect to CR4, i.e., Environmental Collateral (before fixing inconsistency ratio)

\begin{tabular}{|c|c|c|c|c|}
\hline & $\begin{array}{c}\text { Geo-exchange heat } \\
\text { pump }\end{array}$ & Electric water heater & Electric vehicles & Priority \\
\hline $\begin{array}{c}\text { Geo-exchange heat } \\
\text { pump }\end{array}$ & 1.000 & 0.143 & 3.000 & 0.155 \\
\hline Electric water heater & 7.000 & 1.000 & 9.000 & 0.777 \\
\hline Electric vehicles & 0.333 & 0.111 & 1.000 & 0.069 \\
\hline
\end{tabular}

Inconsistency $\quad 11.76 \%$

Hence, we fixed the relationship between geo-exchange heat pump and electric vehicles to reduce the inconsistency to $2.69 \%$ as illustrated in Table 4-46. 
Table 4-46: Judgment Matrix for Sub-alternatives with respect to CR4, i.e., Environmental Collateral (after fixing inconsistency ratio)

\begin{tabular}{|c|c|c|c|c|}
\hline & $\begin{array}{c}\text { Geo-exchange heat } \\
\text { pump }\end{array}$ & Electric water heater & Electric vehicles & Priority \\
\hline $\begin{array}{c}\text { Geo-exchange heat } \\
\text { pump }\end{array}$ & 1.000 & 0.143 & $\mathbf{1 . 3 1 6}$ & 0.155 \\
\hline Electric water heater & 7.000 & 1.000 & 9.000 & 0.777 \\
\hline Electric vehicles & 0.333 & 0.111 & 1.000 & 0.069 \\
\hline
\end{tabular}

\section{Inconsistency $\quad 2.69 \%$}

Moreover, the pairwise comparison in Table 4-47 shows a spike increase in the inconsistency ratio with reference to "socio-economic equity". However, a reduction by more than $30 \%$ was successfully achieved as demonstrated in Table 4-48.

Table 4-47: Judgment Matrix for Sub-alternatives with respect to CR5, i.e., Socio-economic Equity (before fixing inconsistency ratio)

\begin{tabular}{|c|c|c|c|c|}
\hline & $\begin{array}{c}\text { Geo-exchange heat } \\
\text { pump }\end{array}$ & Electric water heater & Electric vehicles & Priority \\
\hline $\begin{array}{c}\text { Geo-exchange heat } \\
\text { pump }\end{array}$ & 1.000 & 0.200 & 0.250 & 0.094 \\
\hline Electric water heater & 5.000 & 1.000 & 6.000 & 0.686 \\
\hline Electric vehicles & 4.000 & 0.167 & 1.000 & 0.220 \\
\hline
\end{tabular}

Inconsistency $\quad 35.52 \%$

Table 4-48: Judgment Matrix for Sub-alternatives with respect to CR5, i.e., Socio-economic Equity (after fixing inconsistency ratio)

\begin{tabular}{|c|c|c|c|c|}
\hline & $\begin{array}{c}\text { Geo-exchange heat } \\
\text { pump }\end{array}$ & Electric water heater & Electric vehicles & Priority \\
\hline $\begin{array}{c}\text { Geo-exchange heat } \\
\text { pump }\end{array}$ & 1.000 & 0.200 & 0.250 & 0.094 \\
\hline Electric water heater & $\mathbf{0 . 6 8 5}$ & 1.000 & 6.000 & 0.686 \\
\hline Electric vehicles & 4.000 & 0.167 & 1.000 & 0.220 \\
\hline
\end{tabular}

Inconsistency $\quad 5.07 \%$ 
The results obtained in Table 4-49 show that electric water heater is superior to the other subalternatives. The electric vehicles option is the second-ranked solution with respect to the criteria, except for power quality.

Table 4-49: Local Priority and Global Priority for Electrification of Heating and Transportation with respect to Each Criterion

\begin{tabular}{|c|c|c|c|}
\hline & & Local priority & Global priority \\
\hline \multirow{3}{*}{ CR1 } & Geo-exchange heat pump & 0.082 & 0.001 \\
\hline & Electric water heater & 0.739 & 0.008 \\
\hline & Electric vehicles & 0.179 & 0.002 \\
\hline \multirow{3}{*}{ CR2 } & Geo-exchange heat pump & 0.098 & 0.002 \\
\hline & Electric water heater & 0.761 & 0.014 \\
\hline & Electric vehicles & 0.141 & 0.003 \\
\hline \multirow{3}{*}{ CR3 } & Geo-exchange heat pump & 0.252 & 0.010 \\
\hline & Electric water heater & 0.589 & 0.024 \\
\hline & Electric vehicles & 0.159 & 0.006 \\
\hline \multirow{3}{*}{ CR4 } & Geo-exchange heat pump & 0.155 & 0.005 \\
\hline & Electric water heater & 0.777 & 0.025 \\
\hline & Electric vehicles & 0.068 & 0.002 \\
\hline \multirow{3}{*}{ CR5 } & Geo-exchange heat pump & 0.094 & 0.001 \\
\hline & Electric water heater & 0.686 & 0.005 \\
\hline & Electric vehicles & 0.220 & 0.002 \\
\hline
\end{tabular}




\section{DG}

The last alternative is "DG". This alternative consists of two solutions apropos distribution systems, i.e., solar PV and combustion generation. Solar PV can be either individual installations at an end user or an aggregated installation such as a community share facility. The authors consider combustion generation as two categories only: power and CHP installations. As mentioned in Section 4.2, inconsistency ratio is applied when is are more than two alternatives. Thus, the inconsistency ratio is not calculated for the options of "DG". The results in Tables from 4-50 to 4-54 show the judgment matrixes for the DG alternatives with respect to each criterion.

Table 4-50: Judgment Matrix for Sub-alternatives with respect to CR1, i.e., Cost

\begin{tabular}{|c|c|c|c|}
\hline & Solar PV & Combustion generation & Priority \\
\hline Solar PV & 1 & 6.00 & 0.857 \\
\hline Combustion generation & 0.167 & 1 & 0.143 \\
\hline
\end{tabular}

Table 4-51: Judgment Matrix for Sub-alternatives with respect to CR2, i.e., Reliability

\begin{tabular}{|c|c|c|c|}
\hline & Solar PV & Combustion generation & Priority \\
\hline Solar PV & 1 & 0.14 & 0.125 \\
\hline Combustion generation & 7 & 1 & 0.875 \\
\hline
\end{tabular}

Table 4-52: Judgment Matrix for Sub-alternatives with respect to CR3, i.e., Power Quality

\begin{tabular}{|c|c|c|c|}
\hline & Solar PV & Combustion generation & Priority \\
\hline Solar PV & 1.000 & 3.000 & 0.750 \\
\hline Combustion generation & 0.333 & 1.000 & 0.250 \\
\hline
\end{tabular}

Table 4-53: Judgment Matrix for Sub-alternatives with respect to CR4, i.e. Environmental Collateral

\begin{tabular}{|c|c|c|c|}
\hline & Solar PV & Combustion generation & Priority \\
\hline Solar PV & 1.000 & 9.000 & 0.900 \\
\hline Combustion generation & 0.111 & 1.000 & 0.100 \\
\hline
\end{tabular}

Table 4-54: Judgment Matrix for Sub-alternatives with respect to CR5, i.e., Socio-economic Equity

\begin{tabular}{|c|c|c|c|}
\hline & Solar PV & Combustion generation & Priority \\
\hline Solar PV & 1.000 & 5.000 & 0.833 \\
\hline Combustion generation & 0.200 & 1.000 & 0.167 \\
\hline
\end{tabular}


The results are not surprising since solar PV is more important in terms of cost while combustion generation is preferable when it comes to reliability. Table 4-55 presents the local priorities and global priorities for the previous mentioned options with respect to each criterion.

Table 4-55: Local Priority and Global Priority for DG with respect to Each Criterion

\begin{tabular}{|c|c|c|c|}
\hline Criterion & & Local priority & Global priority \\
\hline \multirow{2}{*}{ CR1 } & Solar PV & 0.857 & 0.005 \\
\hline & Combustion generation & 0.143 & 0.001 \\
\hline \multirow{2}{*}{ CR2 } & Solar PV & 0.125 & 0.004 \\
\hline & Combustion generation & 0.875 & 0.030 \\
\hline \multirow{2}{*}{ CR3 } & Solar PV & 0.750 & 0.013 \\
\hline & Combustion generation & 0.250 & 0.004 \\
\hline \multirow{2}{*}{ CR4 } & Solar PV & 0.900 & 0.004 \\
\hline & Combustion generation & 0.100 & 0.000 \\
\hline \multirow{2}{*}{ CR5 } & Solar PV & 0.833 & 0.003 \\
\hline & Combustion generation & 0.167 & 0.001 \\
\hline
\end{tabular}

\subsubsection{Final prioritization}

As mentioned in section 4.2, the last step in AHP is to calculate the overall rank of the alternatives to arrive at the final prioritization. Global priorities are calculated for each alternative and each sub-alternative to obtain the total weight of the respective solution. The option with the highest priority is the most optimal alternative for achieving the goal. Table 4-56 shows final prioritization for each alternative and the overall ranking, and the difference between the options. The reason for calculating the differences between the alternatives is to trim down the options for further evaluation.

From Table 4-56, "communication and intelligence" is the most important alternative in reducing GHG in the distribution system. The second alternative is "electric stationary storage" followed by "energy 
conservation", and "load side management". Electric stationary storage has the second highest importance because it enables greater utilization of variable renewable generating sources, both those on the distribution system and those from the bulk generation provider, and for its contribution to reliability.

Table 4-56: Final Prioritization Using AHP

\begin{tabular}{|c|c|c|c|}
\hline & Global priority & Overall ranking & Difference \\
\hline Communication and intelligence & 0.341 & 1 & 0.133 \\
\hline Electric stationary storage & 0.207 & 2 & 0.068 \\
\hline Energy conservation & 0.140 & 3 & 0.060 \\
\hline Load side management & 0.136 & 4 & 0.040 \\
\hline Electric water heater & 0.076 & 5 & 0.007 \\
\hline Combustion generation & 0.036 & 7 & 0.011 \\
\hline Solar PV & 0.029 & 8 & 0.004 \\
\hline Geo-exchange heat pump & 0.019 & 9 & \\
\hline
\end{tabular}

\subsection{Conclusion}

The paper presents a framework of AHP to analyze and investigate the potential DSM solution to reduce GHG emissions from an electric distribution system. The results suggest that "communication and intelligence" technologies are the most important to achieve the goal. As mentioned in Chapter 1, AHP aims to find the most important alternative in achieving the goal. AHP evaluates the decision elements in a hierarchical way with ignoring the impact of alternatives on the weight of criteria. Therefore, final ranking might be affected, overestimating or underestimating criteria or alternatives, with such a complex problem. In that regard, ANP in another model in MCDM that allows interdependencies, outerdependencies and feedbacks connections among decision elements in the network structure to effectively rank alternatives. 


\section{CHAPTER 5}

\section{ANALYTIC NETWORK PROCESS ALGORITHM TO PRIORITIZE DEMAND SIDE MANAGEMENT ALTERNATIVES ${ }^{4}$}

\subsection{Introduction}

This chapter presents a general overview regarding ANP. It defines ANP and describes general steps to calculate final prioritization by means of ANP. After that, ANP DSM-based problem is constructed to obtain important available option in reducing carbon footprint. Analysis and observations are discussed at the end of this chapter.

\subsection{ANP}

ANP is an MCDM method that is a generalization of the AHP. In detail, ANP is used to help make decisions in complex problems where a hierarchical model is not sufficient for prioritizing the alternative [24]. Key features of ANP are feedback connections and loops and providing interdependence relationships. The ANP structure is organized as nodes in a network, where the nodes might be criteria, sub-criteria, alternatives, or sub-alternatives. Hence, the ranking of alternatives might not depend on the weight of the criteria, but the alternatives can influence final prioritization [83, 84].

Solving a problem based on ANP requires a network modularization of the problem and weighting of the elements. Modeling any ANP problem as a network starts by identifying the elements of the network, criteria, and alternatives. Next step is to group the elements into clusters and analyzing the specific influence within the network. After that, ANP can obtain final ranking by the following six steps [83-85];

A. Calculating the priorities among criteria and alternatives

B. Calculating the priorities among the nodes

C. Building the original supermatrix that includes all nodes, criteria, sub-criteria, alternatives, or sub-alternatives

${ }^{4}$ Part of this chapter is verbatim reproduced from [36], and it is under review in the Utilities Policy Journal at the time of writing this dissertation 
D. Normalizing the unweighted supermatrix after finalizing all comparisons

E. Calculating the limit supermatrix by raising the normalized supermatrix to powers until it converges

F. Obtaining final prioritization of the alternatives

\begin{tabular}{|c|c|c|c|c|c|c|c|}
\hline & & Table 5 & : Origir & & & & \\
\hline & \multirow[b]{2}{*}{ Goal } & \multicolumn{3}{|c|}{ Criteria } & \multicolumn{3}{|c|}{ Alternatives } \\
\hline & & CR1 & CR2 & CR3 & Alternative 1 & Alternative 2 & Alternative 3 \\
\hline \multicolumn{8}{|l|}{ Goal } \\
\hline \multicolumn{8}{|l|}{ CR1 } \\
\hline \multicolumn{8}{|l|}{ CR2 } \\
\hline \multicolumn{8}{|l|}{ CR3 } \\
\hline \multicolumn{8}{|l|}{ Alternative 1} \\
\hline \multicolumn{8}{|l|}{ Alternative 2} \\
\hline Alternative 3 & & & & & & & \\
\hline
\end{tabular}

ANP is more flexible than AHP, making the model closer to reality and promising more precise results. However, ANP requires more calculations and time due to its complexity $[24,86]$.

\subsection{Problem framework}

As mentioned in the previous section, ANP provides feedback and interdependence relationships. Network connection helps in prioritizing criteria with considering alternatives. This means a judgment matrix is constructed for criteria with respect to each alternative. Final ranking of criteria could be changed by asking how important they are if the alternatives being considered, the decision maker learn from feedback. Figure 51 illustrates network structure for our example where interdependence relationship is considered. In this figure, "energy conservation", "load side management", and "electric stationary storage" are options under "energy consumption". Further, "geo-exchange heat pump", "electric water heater", and "electric vehicles" are under "electrification of heating and transportation" while "DG" contains "PVs" and "combustion generation". 


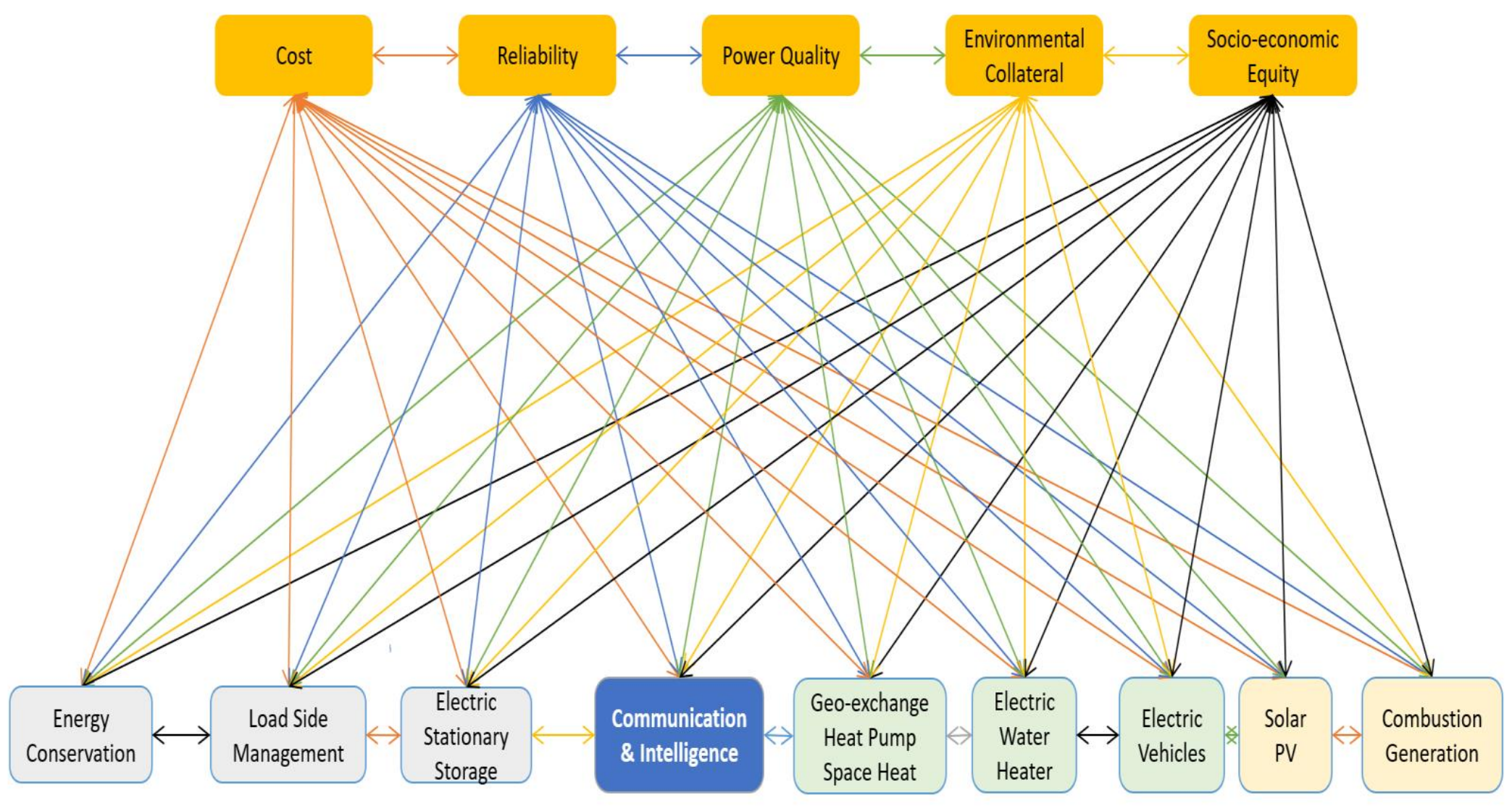

Figure 5-1: Network Structure for ANP Problem 


\subsection{Analysis and results}

As has been done in the previous chapter, all alternatives are compared with respect to each criterion. However, ANP aims to study the importance of each criterion with respect to each alternative. This could strengthen or weaknesses the importance of that criterion based on its relationship with that alternative. In that regard, pairwise comparisons are conducted for criteria with reference to each alternative. The impact of alternatives on criteria is evaluated by the same expert who completed the AHP survey. Table 5-2 shows a judgment matrix for criteria with respect to "energy conservation" before fixing the inconsistency.

Table 5-2: Judgment Matrix for Criteria with respect to Energy Conservation (before fixing inconsistency)

\begin{tabular}{|c|c|c|c|c|c|c|}
\hline & CR1 & CR2 & CR3 & CR4 & CR5 & Priority \\
\hline CR1 & 1.000 & 0.250 & 0.500 & 3.000 & 6.000 & 0.178 \\
\hline CR2 & 4.000 & 1.000 & 3.000 & 7.000 & 3.000 & 0.430 \\
\hline CR3 & 2.000 & 0.333 & 1.000 & 6.000 & 5.000 & 0.247 \\
\hline CR4 & 0.333 & 0.143 & 0.167 & 1.000 & 0.200 & 0.041 \\
\hline CR5 & 0.167 & 0.333 & 0.200 & 5.000 & 1.000 & 0.104 \\
\hline
\end{tabular}

Inconsistency

$19.05 \%$

Therefore, we follow the same steps to fix the inconsistency as shown in Table 5-3. We observe that CR2, reliability, is the most suitable criterion in present of "energy conservation".

Table 5-3: Judgment Matrix for Criteria with respect to Energy Conservation (after fixing inconsistency)

\begin{tabular}{|c|c|c|c|c|c|c|}
\hline & CR1 & CR2 & CR3 & CR4 & CR5 & Priority \\
\hline CR1 & 1.000 & 0.250 & 0.500 & 3.000 & $\mathbf{3 . 5 0 6}$ & 0.178 \\
\hline CR2 & 4.000 & 1.000 & 3.000 & 7.000 & 3.000 & 0.430 \\
\hline CR3 & 2.000 & 0.333 & 1.000 & 6.000 & 2.105 & 0.247 \\
\hline CR4 & 0.333 & 0.143 & 0.167 & 1.000 & 0.200 & 0.041 \\
\hline CR5 & 0.167 & 0.333 & 0.200 & 5.000 & 1.000 & 0.104 \\
\hline
\end{tabular}

Inconsistency $\quad 7.26 \%$ 
Inconsistent comparisons caused about $10 \%$ violation when criteria compared to "load side management" as illustrated in Table 5-4.

Table 5-4: Judgment Matrix for Criteria with respect to Load Side Management (before fixing inconsistency)

\begin{tabular}{|c|c|c|c|c|c|c|}
\hline & CR1 & CR2 & CR3 & CR4 & CR5 & Priority \\
\hline CR1 & 1.000 & 0.250 & 0.250 & 5.000 & 5.000 & 0.169 \\
\hline CR2 & 4.000 & 1.000 & 4.000 & 7.000 & 6.000 & 0.476 \\
\hline CR3 & 4.000 & 0.250 & 1.000 & 5.000 & 3.000 & 0.232 \\
\hline CR4 & 0.200 & 0.143 & 0.200 & 1.000 & 0.250 & 0.039 \\
\hline CR5 & 0.200 & 0.167 & 0.333 & 4.000 & 1.000 & 0.084 \\
\hline
\end{tabular}

However, more than a 15\% reduction were successfully achieved by modifying maximum eigenvector vectors. The findings show that priority of reliability will increase by considering "load side management" as explained in Table 5-5.

Table 5-5: Judgment Matrix for Criteria with respect to Load Side Management (before fixing inconsistency)

\begin{tabular}{|c|c|c|c|c|c|c|}
\hline & CR1 & CR2 & CR3 & CR4 & CR5 & Priority \\
\hline CR1 & 1.000 & 0.250 & 0.250 & 5.000 & 2.485 & 0.169 \\
\hline CR2 & 4.000 & 1.000 & $\mathbf{1 . 9 5 0}$ & 7.000 & 6.000 & 0.476 \\
\hline CR3 & 4.000 & 0.250 & 1.000 & 5.000 & 3.000 & 0.232 \\
\hline CR4 & 0.200 & 0.143 & 0.200 & 1.000 & 0.250 & 0.039 \\
\hline CR5 & 0.200 & 0.167 & 0.333 & 4.000 & 1.000 & 0.084 \\
\hline
\end{tabular}

Further, the decision maker was not accurate in comparing CR1, Cost, against CR5, Socio-economic equity, with respect to "electric stationary storage". This results a higher limit in the inconsistency ratio by more 
than $5 \%$ as denoted in Table $5-6$. Thus, the inconsistency was reduced from $15.52 \%$ to $8.43 \%$ and CR1, Cost, is superior among other criteria.

Table 5-6: Judgment Matrix for Criteria with respect to Electric Stationary Storage (before fixing inconsistency)

\begin{tabular}{|c|c|c|c|c|c|c|}
\hline & CR1 & CR2 & CR3 & CR4 & CR5 & Priority \\
\hline CR1 & 1.000 & 6.000 & 6.000 & 5.000 & 3.000 & 0.471 \\
\hline CR2 & 0.167 & 1.000 & 1.000 & 0.333 & 0.250 & 0.061 \\
\hline CR3 & 0.167 & 1.000 & 1.000 & 3.000 & 0.167 & 0.094 \\
\hline CR4 & 0.200 & 3.000 & 0.333 & 1.000 & 0.200 & 0.089 \\
\hline CR5 & 0.333 & 4.000 & 6.000 & 5.000 & 1.000 & 0.286 \\
\hline
\end{tabular}

Table 5-7: Judgment Matrix for Criteria with respect to Electric Stationary Storage (after fixing inconsistency)

\begin{tabular}{|c|c|c|c|c|c|c|}
\hline & CR1 & CR2 & CR3 & CR4 & CR5 & Priority \\
\hline CR1 & 1.000 & 6.000 & 6.000 & 5.000 & 1.822 & 0.471 \\
\hline CR2 & 0.167 & 1.000 & 1.000 & 0.333 & 0.250 & 0.061 \\
\hline CR3 & 0.167 & 1.000 & 1.000 & 3.000 & 0.167 & 0.094 \\
\hline CR4 & 0.200 & 3.000 & 0.333 & 1.000 & 0.200 & 0.089 \\
\hline CR5 & 0.333 & 4.000 & 6.000 & 5.000 & 1.000 & 0.286 \\
\hline
\end{tabular}

"communication and intelligence" option contains four options as mentioned in section 4.3. One of the most challenges is how to quantify those options in reducing GHG. Hence, this leads to inaccurate estimation for criteria with respect to that alternative and in turn cause a spike increase in the inconsistency as shown in Table 5-8. Therefore, four comparisons are fixed in order to maintain the inconsistency below 10\%. 
Table 5-8: Judgment Matrix for Criteria with respect to Communication and Intelligence (before fixing inconsistency)

\begin{tabular}{|c|c|c|c|c|c|c|}
\hline & CR1 & CR2 & CR3 & CR4 & CR5 & Priority \\
\hline CR1 & 1.000 & 7.000 & 4.000 & 9.000 & 0.333 & 0.334 \\
\hline CR2 & 0.143 & 1.000 & 3.000 & 9.000 & 1.000 & 0.203 \\
\hline CR3 & 0.250 & 0.333 & 1.000 & 8.000 & 0.200 & 0.098 \\
\hline CR4 & 0.111 & 0.111 & 0.125 & 1.000 & 0.200 & 0.030 \\
\hline CR5 & 3.000 & 1.000 & 5.000 & 5.000 & 1.000 & 0.335 \\
\hline
\end{tabular}

Inconsistency $\quad 33.32 \%$

Table 5-9: Judgment Matrix for Criteria with respect to Communication and Intelligence (after fixing inconsistency)

\begin{tabular}{|c|c|c|c|c|c|c|}
\hline & CR1 & CR2 & CR3 & CR4 & CR5 & Priority \\
\hline CR1 & 1.000 & $\mathbf{4 . 2 5 4}$ & 4.000 & 9.000 & 0.333 & 0.334 \\
\hline CR2 & 0.143 & 1.000 & 3.000 & $\mathbf{1 . 3 3 0}$ & 1.000 & 0.203 \\
\hline CR3 & 0.250 & 0.333 & 1.000 & $\mathbf{2 . 4 4 9}$ & 0.200 & 0.098 \\
\hline CR4 & 0.111 & 0.111 & 0.125 & 1.000 & 0.200 & 0.030 \\
\hline CR5 & 3.000 & 1.000 & $\mathbf{1 . 4 6 3}$ & 5.000 & 1.000 & 0.335 \\
\hline
\end{tabular}

Inconsistency $\quad 5.95 \%$

A consistent judgment matrix occurred when the criteria is compared to "geo-exchange heat pump". Table 5-10 illustrates the judgment matrix. A $0.24 \%$ increase in the inconsistency is acceptable since it has no effect on the inconsistency ratio. Moreover, "electric water heater" shows a surprise increase the inconsistency. The decision maker overestimated CR1, Cost, and CR3, Power quality against CR2, Reliability and CR4, Environmental collateral, respectively. However, the inconsistency ratio was effectively reduced to 10.21 as explained in Table 5-12. 
Table 5-10: Judgment Matrix for Criteria with respect to Geo-exchange Heat Pump

\begin{tabular}{|c|c|c|c|c|c|c|}
\hline & CR1 & CR2 & CR3 & CR4 & CR5 & Priority \\
\hline CR1 & 1.000 & 3.000 & 9.000 & 8.000 & 3.000 & 0.484 \\
\hline CR2 & 0.333 & 1.000 & 1.000 & 6.000 & 0.250 & 0.135 \\
\hline CR3 & 0.111 & 1.000 & 1.000 & 1.000 & 0.250 & 0.066 \\
\hline CR4 & 0.125 & 0.167 & 1.000 & 1.000 & 0.167 & 0.046 \\
\hline CR5 & 0.333 & 4.000 & 4.000 & 6.000 & 1.000 & 0.270 \\
\hline
\end{tabular}

Inconsistency $\quad 10.24 \%$

Table 5-11: Judgment Matrix for Criteria with respect to Electric Water Heater (before fixing inconsistency)

\begin{tabular}{|c|c|c|c|c|c|c|}
\hline & CR1 & CR2 & CR3 & CR4 & CR5 & Priority \\
\hline CR1 & 1.000 & 9.000 & 4.000 & 6.000 & 0.333 & 0.342 \\
\hline CR2 & 0.111 & 1.000 & 1.000 & 5.000 & 0.333 & 0.115 \\
\hline CR3 & 0.250 & 1.000 & 1.000 & 7.000 & 0.333 & 0.139 \\
\hline CR4 & 0.167 & 0.200 & 0.143 & 1.000 & 0.333 & 0.051 \\
\hline CR5 & 3.000 & 3.000 & 3.000 & 3.000 & 1.000 & 0.353 \\
\hline
\end{tabular}

Unlike "electric water heater", a judgment matrix for "electric vehicles" shows a consistent ratio as Table 5-13 illustrates. CR5, Socio-economic equity is the optimal criterion followed by CR1, Cost with a higher margin. 
Table 5-12: Judgment Matrix for Criteria with respect to Electric Water Heater (after fixing inconsistency)

\begin{tabular}{|c|c|c|c|c|c|c|}
\hline & CR1 & CR2 & CR3 & CR4 & CR5 & Priority \\
\hline CR1 & 1.000 & $\mathbf{3 . 0 2 6}$ & 4.000 & 6.000 & 0.333 & 0.342 \\
\hline CR2 & 0.111 & 1.000 & 1.000 & 5.000 & 0.333 & 0.115 \\
\hline CR3 & 0.250 & 1.000 & 1.000 & 2.568 & 0.333 & 0.139 \\
\hline CR4 & 0.167 & 0.200 & 0.143 & 1.000 & 0.333 & 0.051 \\
\hline CR5 & 3.000 & 3.000 & 3.000 & 3.000 & 1.000 & 0.353 \\
\hline
\end{tabular}

Inconsistency $\quad 10.21 \%$

Table 5-13: Judgment Matrix for Criteria with respect to Electric Vehicles

\begin{tabular}{|c|c|c|c|c|c|c|}
\hline & CR1 & CR2 & CR3 & CR4 & CR5 & Priority \\
\hline CR1 & 1.000 & 4.000 & 9.000 & 7.000 & 2.000 & 0.487 \\
\hline CR2 & 0.250 & 1.000 & 1.000 & 2.000 & 0.333 & 0.104 \\
\hline CR3 & 0.111 & 1.000 & 1.000 & 0.250 & 0.250 & 0.059 \\
\hline CR4 & 0.143 & 0.500 & 4.000 & 1.000 & 0.333 & 0.099 \\
\hline CR5 & 0.500 & 3.000 & 4.000 & 3.000 & 1.000 & 0.252 \\
\hline
\end{tabular}

When the criteria are compared with respect to "solar PV", the inconsistency increased to $42.60 \%$. This requires following steps to minimize this violation or revisiting some comparisons to reduce the inconsistency. So, Table 5-15 demonstrates that the inconsistency ratio was reduced to \% after modifying the largest eigenvectors. 
Table 5-14: Judgment Matrix for Criteria with respect to Solar PV (before fixing inconsistency)

\begin{tabular}{|c|c|c|c|c|c|c|}
\hline & CR1 & CR2 & CR3 & CR4 & CR5 & Priority \\
\hline CR1 & 1.000 & 6.000 & 9.000 & 0.250 & 4.000 & 0.332 \\
\hline CR2 & 0.167 & 1.000 & 0.333 & 0.250 & 0.200 & 0.035 \\
\hline CR3 & 0.111 & 3.000 & 1.000 & 0.200 & 0.143 & 0.057 \\
\hline CR4 & 4.000 & 4.000 & 5.000 & 1.000 & 0.250 & 0.276 \\
\hline CR5 & 0.250 & 5.000 & 7.000 & 4.000 & 1.000 & 0.300 \\
\hline
\end{tabular}

Inconsistency $\quad 42.60 \%$

Table 5-15: Judgment Matrix for Criteria with respect to Solar PV (after fixing inconsistency)

\begin{tabular}{|c|c|c|c|c|c|c|}
\hline & CR1 & CR2 & CR3 & CR4 & CR5 & Priority \\
\hline CR1 & 1.000 & $\mathbf{0 . 6 3 3}$ & $\mathbf{1 . 5 4 5}$ & 0.250 & $\mathbf{3 . 6 1 4}$ & 0.332 \\
\hline CR2 & 0.167 & 1.000 & 0.333 & 0.250 & 0.200 & 0.035 \\
\hline CR3 & 0.111 & 3.000 & 1.000 & 0.200 & 0.143 & 0.057 \\
\hline CR4 & 4.000 & $\mathbf{0 . 5 0 7}$ & $\mathbf{1 . 0 3 3}$ & 1.000 & 0.250 & 0.276 \\
\hline CR5 & 0.250 & $\mathbf{0 . 5 8 3}$ & $\mathbf{1 . 3 3 0}$ & $\mathbf{3 . 6 8 0}$ & 1.000 & 0.300 \\
\hline
\end{tabular}

Inconsistency $\quad 8.03 \%$

Table 5-16: Judgment Matrix for Criteria with respect to Combustion Generation (before fixing inconsistency)

\begin{tabular}{|c|c|c|c|c|c|c|}
\hline & CR1 & CR2 & CR3 & CR4 & CR5 & Priority \\
\hline CR1 & 1.000 & 0.333 & 3.000 & 0.143 & 2.000 & 0.118 \\
\hline CR2 & 3.000 & 1.000 & 6.000 & 0.200 & 4.000 & 0.255 \\
\hline CR3 & 0.333 & 0.167 & 1.000 & 0.167 & 0.333 & 0.042 \\
\hline CR4 & 7.000 & 5.000 & 6.000 & 1.000 & 1.000 & 0.433 \\
\hline CR5 & 0.500 & 0.250 & 3.000 & 1.000 & 1.000 & 0.151 \\
\hline
\end{tabular}

Inconsistency $\quad 26.53 \%$ 
Last comparison is to compare the criteria with respect to "combustion generation". Final ranking shows CR4, Environmental collateral is the most important criterion as denoted in Table 5-17.

Table 5-17: Judgment Matrix for Criteria with respect to Combustion Generation (after fixing inconsistency)

\begin{tabular}{|c|c|c|c|c|c|c|}
\hline & CR1 & CR2 & CR3 & CR4 & CR5 & Priority \\
\hline CR1 & 1.000 & 0.333 & 3.000 & 0.143 & 2.000 & 0.118 \\
\hline CR2 & 3.000 & 1.000 & 6.000 & 0.200 & $\mathbf{2 . 3 6 9}$ & 0.255 \\
\hline CR3 & 0.333 & 0.167 & 1.000 & 0.167 & 0.333 & 0.042 \\
\hline CR4 & $\mathbf{1 . 9 0 8}$ & 5.000 & 6.000 & 1.000 & 1.000 & 0.433 \\
\hline CR5 & 0.500 & 0.250 & 3.000 & 1.000 & 1.000 & 0.151 \\
\hline
\end{tabular}

As discussed in section 5.2, we build the original supermatrix after completing all comparisons. Table 5-18 shows a supermatrix that contains all nodes. After that, the weighted supermatrix is calculated after normalizing the matrix in Table 5-18 as demonstrated in Table 5-19. The next step is to calculate the limit matrix. The limit matrix is obtained by raising the weighted super matrix to powers until it converges. Table 520 and Table 5-21 show the limit matrix and the normalized matrix, respectively. 
Table 5-18: Original Supermatrix for All Nodes

\begin{tabular}{|c|c|c|c|c|c|c|c|c|c|c|c|c|c|c|}
\hline & CR1 & CR2 & CR3 & CR4 & CR5 & $\begin{array}{c}\text { Energy } \\
\text { conservation }\end{array}$ & $\begin{array}{l}\text { Load side } \\
\text { management }\end{array}$ & $\begin{array}{l}\text { Stationary } \\
\text { storage }\end{array}$ & $\begin{array}{l}\text { Communication } \\
\text { \& intelligence }\end{array}$ & $\begin{array}{l}\text { Geo-exchange } \\
\text { heat pump }\end{array}$ & $\begin{array}{l}\text { Electric } \\
\text { water } \\
\text { heater }\end{array}$ & $\begin{array}{l}\text { Electric } \\
\text { vehicles }\end{array}$ & Solar PV & $\begin{array}{l}\text { Combustion } \\
\text { generation }\end{array}$ \\
\hline CR1 & 1 & 0 & 0 & 0 & 0 & 0.178 & 0.169 & 0.471 & 0.334 & 0.484 & 0.342 & 0.487 & 0.332 & 0.118 \\
\hline CR2 & 0 & 1 & 0 & 0 & 0 & 0.430 & 0.476 & 0.061 & 0.203 & 0.135 & 0.115 & 0.104 & 0.035 & 0.255 \\
\hline CR3 & 0 & 0 & 1 & 0 & 0 & 0.247 & 0.232 & 0.094 & 0.098 & 0.066 & 0.139 & 0.059 & 0.057 & 0.042 \\
\hline CR4 & 0 & 0 & 0 & 1 & 0 & 0.041 & 0.039 & 0.089 & 0.030 & 0.046 & 0.051 & 0.099 & 0.276 & 0.433 \\
\hline CR5 & 0 & 0 & 0 & 0 & 1 & 0.104 & 0.084 & 0.286 & 0.335 & 0.270 & 0.353 & 0.252 & 0.300 & 0.151 \\
\hline $\begin{array}{c}\text { Energy } \\
\text { conservation }\end{array}$ & 0.060 & 0.021 & 0.004 & 0.022 & 0.033 & 1 & 0 & 0 & 0 & 0 & 0 & 0 & 0 & 0 \\
\hline $\begin{array}{c}\text { Load side } \\
\text { management }\end{array}$ & 0.019 & 0.070 & 0.030 & 0.007 & 0.010 & 0 & 1 & 0 & 0 & 0 & 0 & 0 & 0 & 0 \\
\hline $\begin{array}{l}\text { Stationary } \\
\text { storage }\end{array}$ & 0.005 & 0.173 & 0.024 & 0.002 & 0.004 & 0 & 0 & 1 & 0 & 0 & 0 & 0 & 0 & 0 \\
\hline $\begin{array}{l}\text { Communication } \\
\text { \& intelligence }\end{array}$ & 0.023 & 0.097 & 0.186 & 0.012 & 0.022 & 0 & 0 & 0 & 1 & 0 & 0 & 0 & 0 & 0 \\
\hline $\begin{array}{l}\text { Geo-exchange } \\
\text { heat pump }\end{array}$ & 0.002 & 0.002 & 0.010 & 0.005 & 0.001 & 0 & 0 & 0 & 0 & 1 & 0 & 0 & 0 & 0 \\
\hline $\begin{array}{c}\text { Electric water } \\
\text { heater }\end{array}$ & 0.004 & 0.014 & 0.024 & 0.025 & 0.005 & 0 & 0 & 0 & 0 & 0 & 1 & 0 & 0 & 0 \\
\hline Electric vehicles & 0.004 & 0.003 & 0.006 & 0.002 & 0.002 & 0 & 0 & 0 & 0 & 0 & 0 & 1 & 0 & 0 \\
\hline Solar PV & 0.005 & 0.004 & 0.013 & 0.004 & 0.003 & 0 & 0 & 0 & 0 & 0 & 0 & 0 & 1 & 0 \\
\hline $\begin{array}{l}\text { Combustion } \\
\text { generation }\end{array}$ & 0.001 & 0.030 & 0.004 & 0.000 & 0.001 & 0 & 0 & 0 & 0 & 0 & 0 & 0 & 0 & 1 \\
\hline
\end{tabular}


Table 5-19: Normalized Supermatrix for All Nodes

\begin{tabular}{|c|c|c|c|c|c|c|c|c|c|c|c|c|c|c|}
\hline & CR1 & CR2 & CR3 & CR4 & CR5 & $\begin{array}{c}\text { Energy } \\
\text { conservation }\end{array}$ & $\begin{array}{l}\text { Load side } \\
\text { management }\end{array}$ & $\begin{array}{l}\text { Stationary } \\
\text { storage }\end{array}$ & $\begin{array}{l}\text { Communication } \\
\& \text { intelligence }\end{array}$ & $\begin{array}{l}\text { Geo-exchange } \\
\text { heat pump }\end{array}$ & $\begin{array}{l}\text { Electric } \\
\text { water } \\
\text { heater }\end{array}$ & $\begin{array}{l}\text { Electric } \\
\text { vehicles }\end{array}$ & Solar PV & $\begin{array}{l}\text { Combustion } \\
\text { generation }\end{array}$ \\
\hline CR1 & 0.891 & 0 & 0 & 0 & 0 & 0.089 & 0.085 & 0.235 & 0.167 & 0.242 & 0.171 & 0.243 & 0.166 & 0.059 \\
\hline CR2 & 0 & 0.707 & 0 & 0 & 0 & 0.215 & 0.238 & 0.030 & 0.102 & 0.067 & 0.058 & 0.052 & 0.018 & 0.128 \\
\hline CR3 & 0 & 0 & 0.768 & 0 & 0 & 0.124 & 0.116 & 0.047 & 0.049 & 0.033 & 0.070 & 0.029 & 0.029 & 0.021 \\
\hline$\overline{\text { CR4 }}$ & 0 & 0 & 0 & 0.926 & 0 & 0.021 & 0.020 & 0.044 & 0.015 & 0.023 & 0.026 & 0.049 & 0.138 & 0.217 \\
\hline CR5 & 0 & 0 & 0 & 0 & 0.926 & 0.052 & 0.042 & 0.143 & 0.168 & 0.135 & 0.177 & 0.126 & 0.150 & 0.076 \\
\hline $\begin{array}{c}\text { Energy } \\
\text { conservation }\end{array}$ & 0.053 & 0.015 & 0.003 & 0.020 & 0.030 & 0.5 & 0 & 0 & 0 & 0 & 0 & 0 & 0 & 0 \\
\hline $\begin{array}{c}\text { Load side } \\
\text { management }\end{array}$ & 0.017 & 0.050 & 0.023 & 0.007 & 0.009 & 0 & 0.5 & 0 & 0 & 0 & 0 & 0 & 0 & 0 \\
\hline $\begin{array}{l}\text { Stationary } \\
\text { storage }\end{array}$ & 0.004 & 0.123 & 0.019 & 0.001 & 0.003 & 0 & 0 & 0.5 & 0 & 0 & 0 & 0 & 0 & 0 \\
\hline $\begin{array}{l}\text { Communication } \\
\text { \& intelligence }\end{array}$ & 0.021 & 0.068 & 0.143 & 0.011 & 0.020 & 0 & 0 & 0 & 0.5 & 0 & 0 & 0 & 0 & 0 \\
\hline $\begin{array}{l}\text { Geo-exchange } \\
\text { heat pump }\end{array}$ & 0.002 & 0.001 & 0.008 & 0.005 & 0.001 & 0 & 0 & 0 & 0 & 0.5 & 0 & 0 & 0 & 0 \\
\hline $\begin{array}{c}\text { Electric water } \\
\text { heater }\end{array}$ & 0.004 & 0.010 & 0.018 & 0.023 & 0.005 & 0 & 0 & 0 & 0 & 0 & 0.5 & 0 & 0 & 0 \\
\hline Electric vehicles & 0.004 & 0.002 & 0.005 & 0.002 & 0.002 & 0 & 0 & 0 & 0 & 0 & 0 & 0.5 & 0 & 0 \\
\hline Solar PV & 0.004 & 0.003 & 0.010 & 0.004 & 0.003 & 0 & 0 & 0 & 0 & 0 & 0 & 0 & 0.5 & 0.0 \\
\hline $\begin{array}{l}\text { Combustion } \\
\text { generation }\end{array}$ & 0.001 & 0.021 & 0.003 & 0.000 & 0.001 & 0 & 0 & 0 & 0 & 0 & 0 & 0 & 0 & 0.5 \\
\hline
\end{tabular}


Table 5-20: Limit Matrix for All Clusters

\begin{tabular}{|c|c|c|c|c|c|c|c|c|c|c|c|c|c|c|}
\hline & CR1 & CR2 & CR3 & CR4 & CR5 & $\begin{array}{c}\text { Energy } \\
\text { conservation }\end{array}$ & $\begin{array}{l}\text { Load side } \\
\text { management }\end{array}$ & $\begin{array}{l}\text { Stationary } \\
\text { storage }\end{array}$ & $\begin{array}{l}\text { Communication } \\
\text { \& intelligence }\end{array}$ & $\begin{array}{l}\text { Geo- } \\
\text { exchange } \\
\text { heat pump }\end{array}$ & $\begin{array}{c}\text { Electric water } \\
\text { heater }\end{array}$ & $\begin{array}{l}\text { Electric } \\
\text { vehicles }\end{array}$ & Solar PV & $\begin{array}{l}\text { Combustion } \\
\text { generation }\end{array}$ \\
\hline CR1 & 0.26 & 0.26 & 0.26 & 0.26 & 0.26 & 0.262 & 0.262 & 0.262 & 0.262 & 0.262 & 0.262 & 0.262 & 0.262 & 0.262 \\
\hline CR2 & $\begin{array}{l}0.09 \\
\end{array}$ & 0.09 & 0.09 & 0.09 & 0.09 & 0.09 & 0.09 & 0.09 & 0.09 & 0.09 & 0.09 & 0.09 & 0.0899 & 0.0899 \\
\hline CR3 & 0.07 & 0.07 & 0.07 & 0.07 & 0.07 & 0.0656 & 0.0656 & 0.0656 & 0.0656 & 0.0656 & 0.0656 & 0.0656 & 0.0656 & 0.0656 \\
\hline CR4 & 0.09 & 0.09 & 0.09 & 0.09 & 0.09 & 0.0861 & 0.0861 & 0.0861 & 0.0861 & 0.0861 & 0.0861 & 0.0861 & 0.0861 & 0.0861 \\
\hline CR5 & 0.30 & 0.30 & 0.30 & 0.30 & 0.30 & 0.2989 & 0.2989 & 0.2989 & 0.2989 & 0.2989 & 0.2989 & 0.2989 & 0.2989 & 0.2989 \\
\hline Energy conservation & $\begin{array}{c}0.052 \\
5\end{array}$ & $\begin{array}{c}0.052 \\
5\end{array}$ & $\begin{array}{c}0.052 \\
5\end{array}$ & $\begin{array}{c}0.052 \\
5\end{array}$ & 0.0525 & 0.0525 & 0.0525 & 0.0525 & 0.0525 & 0.0525 & 0.0525 & 0.0525 & 0.0525 & 0.0525 \\
\hline $\begin{array}{c}\text { Load side } \\
\text { management }\end{array}$ & $\begin{array}{c}0.027 \\
4\end{array}$ & $\begin{array}{c}0.027 \\
4\end{array}$ & $\begin{array}{c}0.027 \\
4\end{array}$ & $\begin{array}{c}0.027 \\
4\end{array}$ & 0.0274 & 0.0274 & 0.0274 & 0.0274 & 0.0274 & 0.0274 & 0.0274 & 0.0274 & 0.0274 & 0.0274 \\
\hline Stationary storage & $\begin{array}{c}0.028 \\
8\end{array}$ & $\begin{array}{c}0.028 \\
8\end{array}$ & $\begin{array}{c}0.028 \\
8\end{array}$ & $\begin{array}{c}0.028 \\
8\end{array}$ & 0.0288 & 0.0288 & 0.0288 & 0.0288 & 0.0288 & 0.0288 & 0.0288 & 0.0288 & 0.0288 & 0.0288 \\
\hline $\begin{array}{c}\text { Communication \& } \\
\text { intelligence }\end{array}$ & $\begin{array}{c}0.056 \\
2\end{array}$ & $\begin{array}{c}0.056 \\
2\end{array}$ & $\begin{array}{c}0.056 \\
2\end{array}$ & $\begin{array}{c}0.056 \\
2\end{array}$ & 0.0562 & 0.0562 & 0.0562 & 0.0562 & 0.0562 & 0.0562 & 0.0562 & 0.0562 & 0.0562 & 0.0562 \\
\hline $\begin{array}{c}\text { Geo-exchange heat } \\
\text { pump }\end{array}$ & $\begin{array}{c}0.003 \\
4\end{array}$ & $\begin{array}{c}0.003 \\
4\end{array}$ & $\begin{array}{c}0.003 \\
4\end{array}$ & $\begin{array}{c}0.003 \\
4\end{array}$ & 0.0034 & 0.0034 & 0.0034 & 0.0034 & 0.0034 & 0.0034 & 0.0034 & 0.0034 & 0.0034 & 0.0034 \\
\hline Electric water heater & $\begin{array}{c}0.013 \\
2\end{array}$ & $\begin{array}{c}0.013 \\
2\end{array}$ & $\begin{array}{c}0.013 \\
2\end{array}$ & $\begin{array}{c}0.013 \\
2\end{array}$ & 0.0132 & 0.0132 & 0.0132 & 0.0132 & 0.0132 & 0.0132 & 0.0132 & 0.0132 & 0.0132 & 0.0132 \\
\hline Electric vehicles & $\begin{array}{c}0.004 \\
3\end{array}$ & $\begin{array}{c}0.004 \\
3\end{array}$ & $\begin{array}{c}0.004 \\
3\end{array}$ & $\begin{array}{c}0.004 \\
3\end{array}$ & 0.0043 & 0.0043 & 0.0043 & 0.0043 & 0.0043 & 0.0043 & 0.0043 & 0.0043 & 0.0043 & 0.0043 \\
\hline Solar PV & $\begin{array}{c}0.006 \\
6\end{array}$ & $\begin{array}{c}0.006 \\
6\end{array}$ & $\begin{array}{c}0.006 \\
6\end{array}$ & $\begin{array}{c}0.006 \\
6\end{array}$ & 0.0066 & 0.0066 & 0.0066 & 0.0066 & 0.0066 & 0.0066 & 0.0066 & 0.0066 & 0.0066 & 0.0066 \\
\hline $\begin{array}{l}\text { Combustion } \\
\text { generation }\end{array}$ & $\begin{array}{c}0.005 \\
1\end{array}$ & $\begin{array}{c}0.005 \\
1\end{array}$ & $\begin{array}{c}0.005 \\
1\end{array}$ & $\begin{array}{c}0.005 \\
1\end{array}$ & 0.0051 & 0.0051 & 0.0051 & 0.0051 & 0.0051 & 0.0051 & 0.0051 & 0.0051 & 0.0051 & 0.0051 \\
\hline
\end{tabular}


Table 5-21: Normalized Limit Matrix for All Clusters

\begin{tabular}{|c|c|c|c|c|c|c|c|c|c|c|c|c|c|c|}
\hline & CR1 & $\mathrm{CR} 2$ & CR3 & CR4 & CR5 & $\begin{array}{c}\text { Energy } \\
\text { conservation }\end{array}$ & $\begin{array}{c}\text { Load side } \\
\text { management }\end{array}$ & $\begin{array}{c}\text { Stationary } \\
\text { storage }\end{array}$ & $\begin{array}{l}\text { Communication } \\
\& \text { intelligence }\end{array}$ & $\begin{array}{l}\text { Geo- } \\
\text { exchange } \\
\text { heat pump }\end{array}$ & $\begin{array}{c}\text { Electric water } \\
\text { heater }\end{array}$ & $\begin{array}{l}\text { Electric } \\
\text { vehicles }\end{array}$ & Solar PV & $\begin{array}{l}\text { Combustion } \\
\text { generation }\end{array}$ \\
\hline CR1 & 0.326 & 0.326 & 0.326 & 0.326 & 0.326 & 0.326 & 0.326 & 0.326 & 0.326 & 0.326 & 0.326 & 0.326 & 0.326 & 0.326 \\
\hline CR2 & 0.112 & 0.112 & 0.112 & 0.112 & 0.112 & 0.112 & 0.112 & 0.112 & 0.112 & 0.112 & 0.112 & 0.112 & 0.112 & 0.112 \\
\hline CR3 & 0.082 & 0.082 & 0.082 & 0.082 & 0.082 & 0.082 & 0.082 & 0.082 & 0.082 & 0.082 & 0.082 & 0.082 & 0.082 & 0.082 \\
\hline CR4 & 0.107 & 0.107 & 0.107 & 0.107 & 0.107 & 0.107 & 0.107 & 0.107 & 0.107 & 0.107 & 0.107 & 0.107 & 0.107 & 0.107 \\
\hline CR5 & 0.372 & 0.372 & 0.372 & 0.372 & 0.372 & 0.372 & 0.372 & 0.372 & 0.372 & 0.372 & 0.372 & 0.372 & 0.372 & 0.372 \\
\hline Energy conservation & 0.266 & 0.266 & 0.266 & 0.266 & 0.266 & 0.266 & 0.266 & 0.266 & 0.266 & 0.266 & 0.266 & 0.266 & 0.266 & 0.266 \\
\hline $\begin{array}{c}\text { Load side } \\
\text { management }\end{array}$ & 0.139 & 0.139 & 0.139 & 0.139 & 0.139 & 0.139 & 0.139 & 0.139 & 0.139 & 0.139 & 0.139 & 0.139 & 0.139 & 0.139 \\
\hline Stationary storage & 0.146 & 0.146 & 0.146 & 0.146 & 0.146 & 0.146 & 0.146 & 0.146 & 0.146 & 0.146 & 0.146 & 0.146 & 0.146 & 0.146 \\
\hline $\begin{array}{c}\text { Communication \& } \\
\text { intelligence }\end{array}$ & 0.285 & 0.285 & 0.285 & 0.285 & 0.285 & 0.285 & 0.285 & 0.285 & 0.285 & 0.285 & 0.285 & 0.285 & 0.285 & 0.285 \\
\hline $\begin{array}{c}\text { Geo-exchange heat } \\
\text { pump }\end{array}$ & 0.017 & 0.017 & 0.017 & 0.017 & 0.017 & 0.017 & 0.017 & 0.017 & 0.017 & 0.017 & 0.017 & 0.017 & 0.017 & 0.017 \\
\hline Electric water heater & 0.067 & 0.067 & 0.067 & 0.067 & 0.067 & 0.067 & 0.067 & 0.067 & 0.067 & 0.067 & 0.067 & 0.067 & 0.067 & 0.067 \\
\hline Electric vehicles & 0.022 & 0.022 & 0.022 & 0.022 & 0.022 & 0.022 & 0.022 & 0.022 & 0.022 & 0.022 & 0.022 & 0.022 & 0.022 & 0.022 \\
\hline Solar PV & 0.033 & 0.033 & 0.033 & 0.033 & 0.033 & 0.033 & 0.033 & 0.033 & 0.033 & 0.033 & 0.033 & 0.033 & 0.033 & 0.033 \\
\hline $\begin{array}{l}\text { Combustion } \\
\text { generation }\end{array}$ & 0.026 & 0.026 & 0.026 & 0.026 & 0.026 & 0.026 & 0.026 & 0.026 & 0.026 & 0.026 & 0.026 & 0.026 & 0.026 & 0.026 \\
\hline
\end{tabular}


The last step is to prioritize alternatives. The findings show the final ranking changes when interdependent relationships are considered. Table 5-22 shows the final ranking after implementing ANP on the problem. The results show "communication and intelligence" is the most preferred alternative followed by "energy conservation". We observe from Tables 5-22 and 5-23 that "electric stationary storage" is the third suitable option while it was the second alternative in AHP. Also, "solar PV" and "combustion generation" are flipped while "load side management" and "electric water heater" maintain the same rank.

Table 5-22: Final Ranking for Alternatives Using ANP

\begin{tabular}{|c|c|c|}
\hline & Priority & Ranking \\
\hline Communication \& intelligence & 0.284 & 1 \\
\hline Energy conservation & 0.266 & 2 \\
\hline Electric stationary storage & 0.146 & 3 \\
\hline Load side management & 0.139 & 4 \\
\hline Electric water heater & 0.067 & 5 \\
\hline Solar PV & 0.033 & 6 \\
\hline Combustion generation & 0.026 & 7 \\
\hline Electric vehicles & 0.022 & 8 \\
\hline
\end{tabular}


Table 5-23: Final Ranking for Alternatives Using AHP

\begin{tabular}{|c|c|c|}
\hline & Priority & Ranking \\
\hline Communication \& intelligence & 0.341 & 1 \\
\hline Stationary storage & 0.207 & 2 \\
\hline Energy conservation & 0.140 & 3 \\
\hline Load side management & 0.136 & 4 \\
\hline Electric water heater & 0.076 & 5 \\
\hline Combustion generation & 0.036 & 6 \\
\hline Solar PV & 0.029 & 7 \\
\hline Geo-exchange heat pump & 0.019 & 8 \\
\hline Electric vehicles & 0.015 & 9 \\
\hline
\end{tabular}

From the previous tables, we realize the final ranking of priorities has changed when alternatives linked to criteria. In AHP, the decision maker traverses the problem top-down by making comparisons, without considering the impact of the actual alternatives. This over-estimates the importance of reliability and power quality. The following table illustrates final ranking for criteria using AHP. Table 5-24 illustrates final prioritization using AHP.

Table 5-24: Final Ranking for Criteria Using AHP

\begin{tabular}{|c|c|}
\hline & Priority \\
\hline CR1 & 0.123 \\
\hline CR2 & 0.415 \\
\hline CR3 & 0.302 \\
\hline CR4 & 0.080 \\
\hline CR5 & 0.080 \\
\hline
\end{tabular}


In our case study, the expert learned through feedback comparisons in ANP that the originally assigned priority for reliability and power quality are not as high as expected, when the question was phrased abstractly. Table 5-25 illustrates final ranking for criteria using ANP

Table 5-25: Final Ranking for Criteria Using ANP

\begin{tabular}{|c|c|}
\hline & Priority \\
\hline CR1 & 0.327 \\
\hline CR2 & 0.112 \\
\hline CR3 & 0.082 \\
\hline CR4 & 0.108 \\
\hline CR5 & 0.372 \\
\hline
\end{tabular}

\subsection{Conclusion and discussion}

This chapter descripted the methodology of ANP and its steps. It illustrated some differences between ANP and AHP. ANP can provide measures that are more accurate since it contains interdependence relationships. The results show "communication and intelligence" is the most suitable alternative to reduce GHG emissions followed by "energy conservation" and "stationary storage", respectively. However, implementing DSM in the electrical system requires incorporating new innovations and technologies. It requires telecommunication, automation, and network control. Therefore, there are several challenges facing the implementation of DSM. One of the challenges is that DSM increases the complexity in operation compared to the traditional electric system. However, providing flexibility in DSM plays an important role in dealing with complexity and uncertainty in the system. Further, cyber security is one of the issues in such a smart distribution system. Changing price signal will change load scheduling in the distribution system. Also, incorporating smart technologies makes the system vulnerable to injecting misinformation into the system and in turn changing the load decision or the generation capacity. Therefore, security is a big challenge in a networked DSM system [15, 87]. 
According to [15], although DSM provides efficient use of generation capacity, it might present more complexity to the market structure. In some electric systems, implementing DSM is a challenge because of the lack of information and communication technologies infrastructure. Enhancement of DSM needs deployment of sensors, advanced measurement, control technologies, communication systems and intelligence equipment. In recent years, new technologies, initiatives, and changing consumer behavior have shown a significant reduction in energy consumption. Further, load forecasting and smart management of electric vehicle charging will increase the utilization factor of loads. In addition, improving energy storage capabilities can play a major role in an efficient operation of DSM. However, more research is needed to examine, incorporate and understand new technologies and future implementation of DSM [16]. In that regard, environmental modeling of Fort Collins distribution system using IEEE 13-node test system will be implemented to quantify the effectiveness of the potential alternatives in reducing carbon footprint. 


\section{CHAPTER 6}

\section{MODELING AND SIMULATION OF THE DISTRIBUTION SYSTEM ${ }^{5}$}

\subsection{Introduction}

This chapter presents methods from literature for calculating GHG emissions from a distribution system using the IEEE 13-node test feeder. It explains basic characteristics of the IEEE 13-node system and original power flow results. This chapter also analyzes 2017 hourly load data, from [88], corresponding to Fort Collins, Colorado area. The analysis includes simulating the base case load profile and then considering the MCDM options as a solution for emissions reduction. Such analysis includes performing radial power flow studies on the IEEE 13-node test feeder in normal steady-state operation. Power flow analysis focuses on various aspects such as active power, reactive power, and distribution system losses for each hour. Then, the obtained results are converted into environmental metrics to calculate GHG contribution from such particular load [89].

\subsection{IEEE 13-node test feeder}

According to [26], IEEE 13-node system is a small circuit model that was designed to test some features in the distribution system and benchmark algorithms in solving unbalanced three phase radial systems. This distribution system is supplied at one end as illustrated in Figure 6-1 [90]. The system is characterized by being short and highly loaded and interconnected with:
○ 10 overhead and underground lines
$\circ$ one generation unit
$\circ$ one voltage regulator unit
○ one $\Delta \mathrm{Y} 115 / 4.16 \mathrm{kV}$ transformer
○ one YY 4.16/0.480 kV (in-line transformer)
$\circ$ two shunt capacitor banks, and

\footnotetext{
${ }^{5}$ Part of this chapter is verbatim reproduced from [37], and it is submitted to the Journal of Energy Transitions at the time of writing this dissertation
} 
○ unbalanced spot and distributed loads

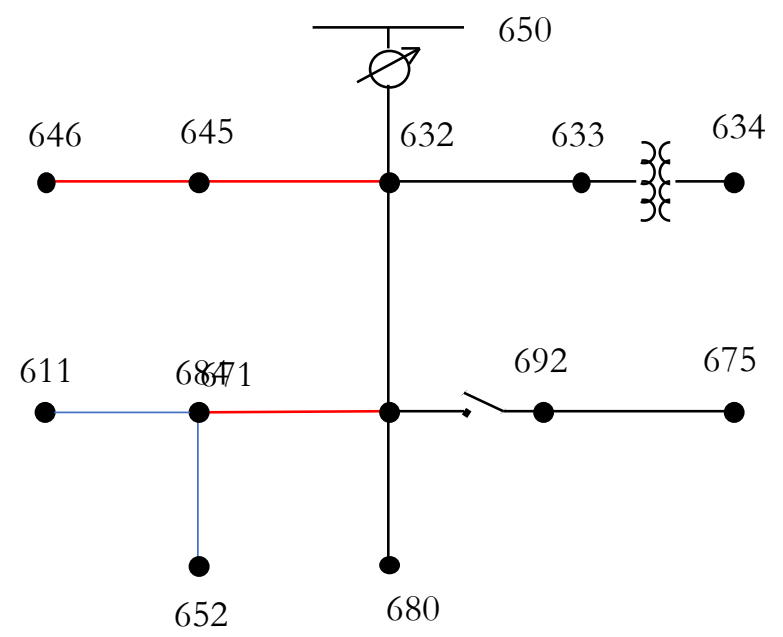

Figure 6-1: IEEE 13-node Test Feeder, recreated from [90]

This test feeder includes data for lines, transformers, capacitors, spot loads, and distributed loads, included in Appendix. Next section explains the findings after simulating the base case on the Fort Collins, C. distribution system as well as some strategies to test the ability of the MCDM solutions in achieving the goal.

\subsection{Simulation analysis}

As known, load profiles change per daily, seasonally, and annually. Therefore, this simulation considers the yearly load profile from which we can obtain the output of the generators to meet the demand and in turn get an estimated amount of GHG emissions.

To determine the environmental impact, the load profile corresponding to Fort Collins is translated and mapped on the IEEE 13-node system through OpenDSS simulation tool. The IEEE 13 node test feeder is designed to evaluate and benchmark algorithms, and this test system provides simple ways to make modifications on the test feeders to include DERs. Thus, it is used to adapt the load of Fort Collins distribution grid on the small circuit test system. The load curve in 2017 has a peak of $660 \mathrm{MW}$. This demand curve is scaled down to match the peak of the test system, 3.577 MW. To establish a strategy for GHG reduction, this section simulates the load profile and generation mix for the base case. After that, the analysis considers different 
scenarios from the MCDM options to reduce the GHG emissions compared to the base case. The analysis also combines several scenarios from MCDM alternatives to examine the expected impact in reducing the emissions and investigate the effectiveness of each alternative in achieving the goal. In that regard, the work studies the most preferred alternatives from the MCDM ranking list, communication and intelligence, stationary storage, and energy conservation.

\subsubsection{Base case}

In order to obtain the load profile and generation mix for the year of 2017, using OpenDSS with the COM interface, the actual load curve in mapped on the test system. A meter was embedded at bus 650 (main bus) to obtain hourly power flow data of the system for the entire year. Figure 6-2 illustrates demand curve and generation mix for the base case on the IEEE 13-node test feeder using Fort Collins load data. This figure indicates that the peak demand occurs on July $19^{\text {th }}$ at $3 \mathrm{pm}$. After performing analysis on the supply and demand curves, environmental assessment calculates the emissions generated from conventional generating units for meeting the demand. In fact, there are four dirty generating units in the system. Each unit has its associated emissions as follow:
- Rawhide coal: $\approx 0.929 \mathrm{Kg} / \mathrm{kWh}$
○ Craig coal (unit 1): $\approx 1.02 \mathrm{Kg} / \mathrm{kWh}$
○ Craig coal (unit 2): $\approx 1.02 \mathrm{Kg} / \mathrm{kWh}$
○ Rawhide CTs: $\approx 0.635 \mathrm{Kg} / \mathrm{kWh}$ 


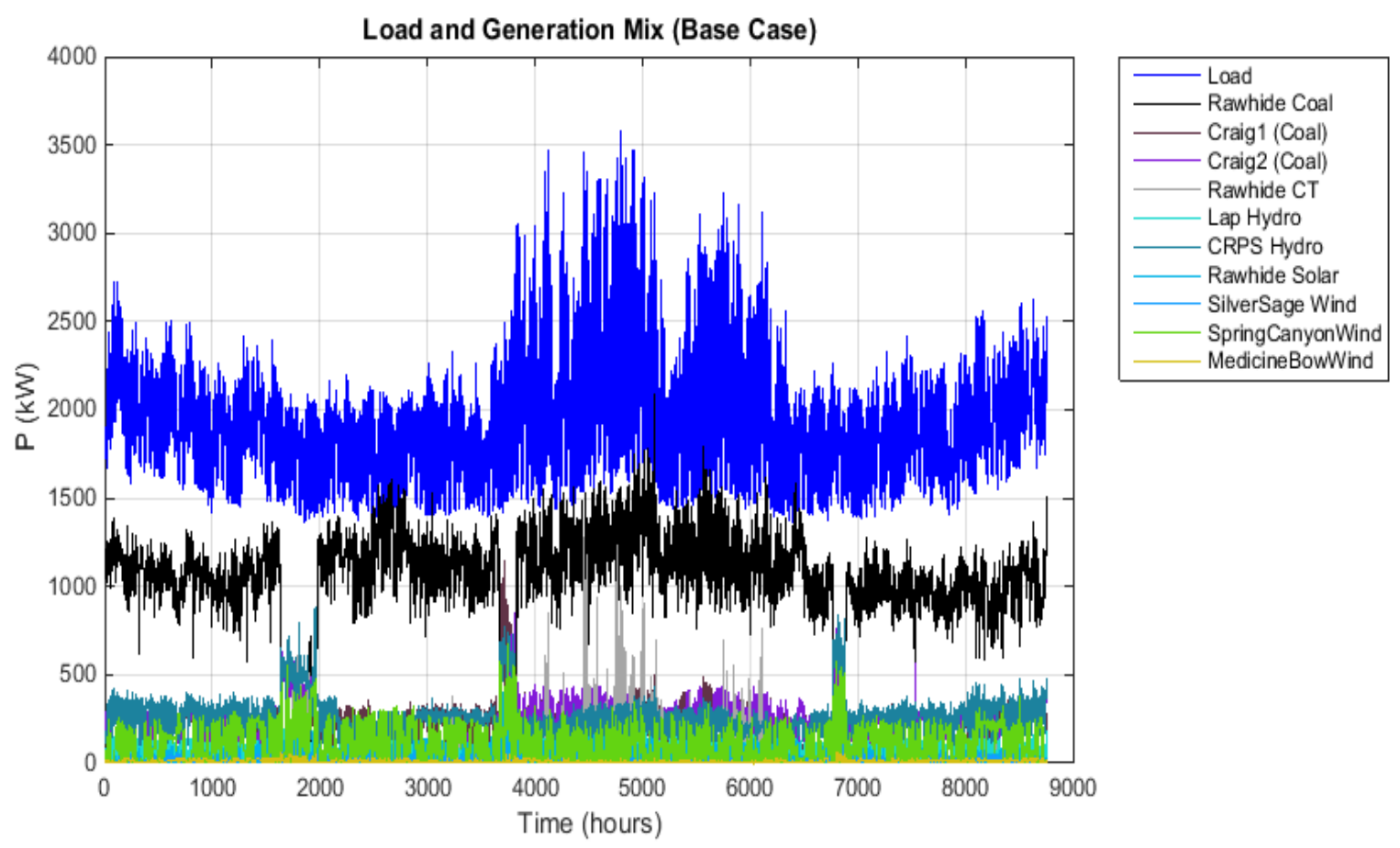

Figure 6-2: Load profile and generation mix, from the IEEE test system, for 2017 (base case)

The results pertaining to the base case show that the amount of emissions from the electricity sector is equivalent to 13,692 tons of $\mathrm{CO}_{2}$ per year, as shown in Figure 6-3. Table 6-1 illustrates the generated emissions per source. A GHG equivalence calculator demonstrates that this amount of emissions equals the emissions produced by burning more than 7,484 tons of coal per year and the captured emissions from about 16,115 acres of the U.S. forests in one year [91]. As the city's energy environmental indicator shows a 16\% emissions reduction in 2017 from 2005 level, the simulation illustrates that the reduction in emissions from 2005 level is $16.26 \%$ for the same year [92]. 


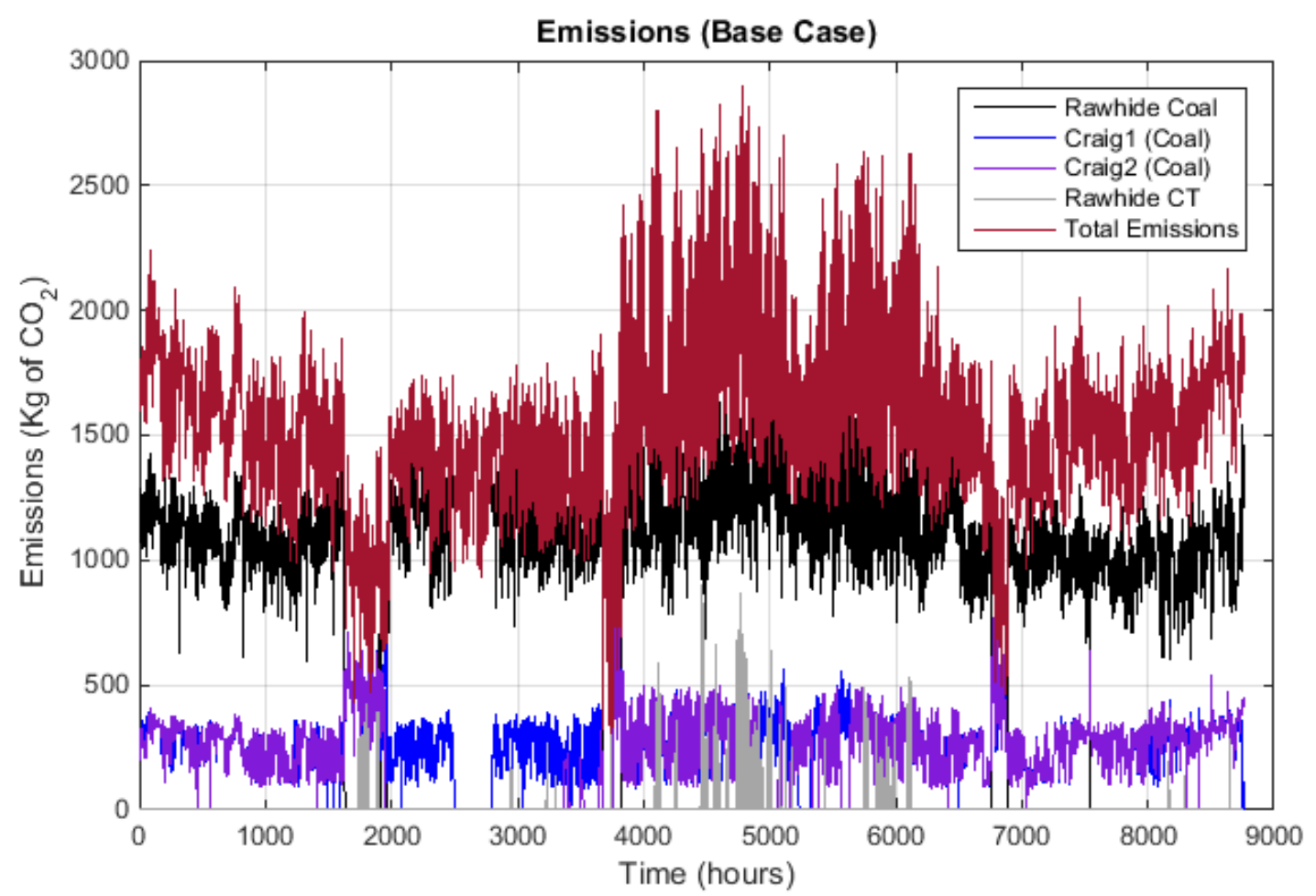

Figure 6-3: Emissions from the electricity sector, from the IEEE test system, for 2017 (base case)

\subsubsection{Stationary storage}

Storage is one of the top-prioritized MCDM technologies. According to [93], ESS can be used during peak hours to shave the load using the energy stored in ESS during off-peak periods and in turn minimize the need for high emission generators during the high demand times. Platte River Power Authority (PRPA) proposes using a Lithium-ion battery since it is the second most used technology (after lead acid) in the stationary storage market. PRPA wants to use Lithium-ion battery because it can operate over more and deeper cycles than a lead acid battery, resulting in a lower cost per cycle. PRPA proposes batteries for a capacity of 50 MW for four-peak load hours, $200 \mathrm{MWh}$. This simulation scales down the storage parameters to fit the test system. Therefore, the ESS provides about $271 \mathrm{~kW}$ for the duration of four hours $(1084 \mathrm{kWh})$ to shave the peak load. Looking at the 2017 load curve, , it is noteworthy that the peak hourly load usually exceeds the average load by $20 \%$. Thus, the simulation is designed to enable ESS to shave $10 \%$ of the peak load when the load at the specified hour exceeds the average load by $20 \%$. A storage system can provide aggressive reduction in peaking load, up to $15 \%$, during the coincident peak, the highest user demand that occurs one hour a month 
when the system demand is at its highest [94]. The storage system remains inactive when the load is lower than $120 \%$ of the average load. The system charges the deployed energy during off-peak hours when the load is at its lowest.

$$
\text { if }\left[\begin{array}{c}
L(t)>\text { avg. load } * 1.2 \text { then } L(t)_{N e w}=L(t) * 0.9 \\
L(t)>\text { avg. load } * 1.2 \text { at coincident peak then } L(t)_{N e w}=L(t) * 0.85 \\
L(t) \leq \text { avg. load } * 1.2 \text { then } L(t)_{N e w}=L(t)
\end{array}\right.
$$

Figure 6-4 shows the load and generation mix, from the test system, for 2017. To explain the previous figure in more detail, Figure 6-5 represents a simulation pertaining to the load profile on September $5^{\text {th }}, 2019$. The results show that the storage system is enabled for two hours to shave the peak demand. The amount of energy provided by storage system displaced the demand from Rawhide coal power plant. As scheduled, the batteries start charging when the demand at its lowest. More than $50 \%$ of storage charging come from hydro power plants.

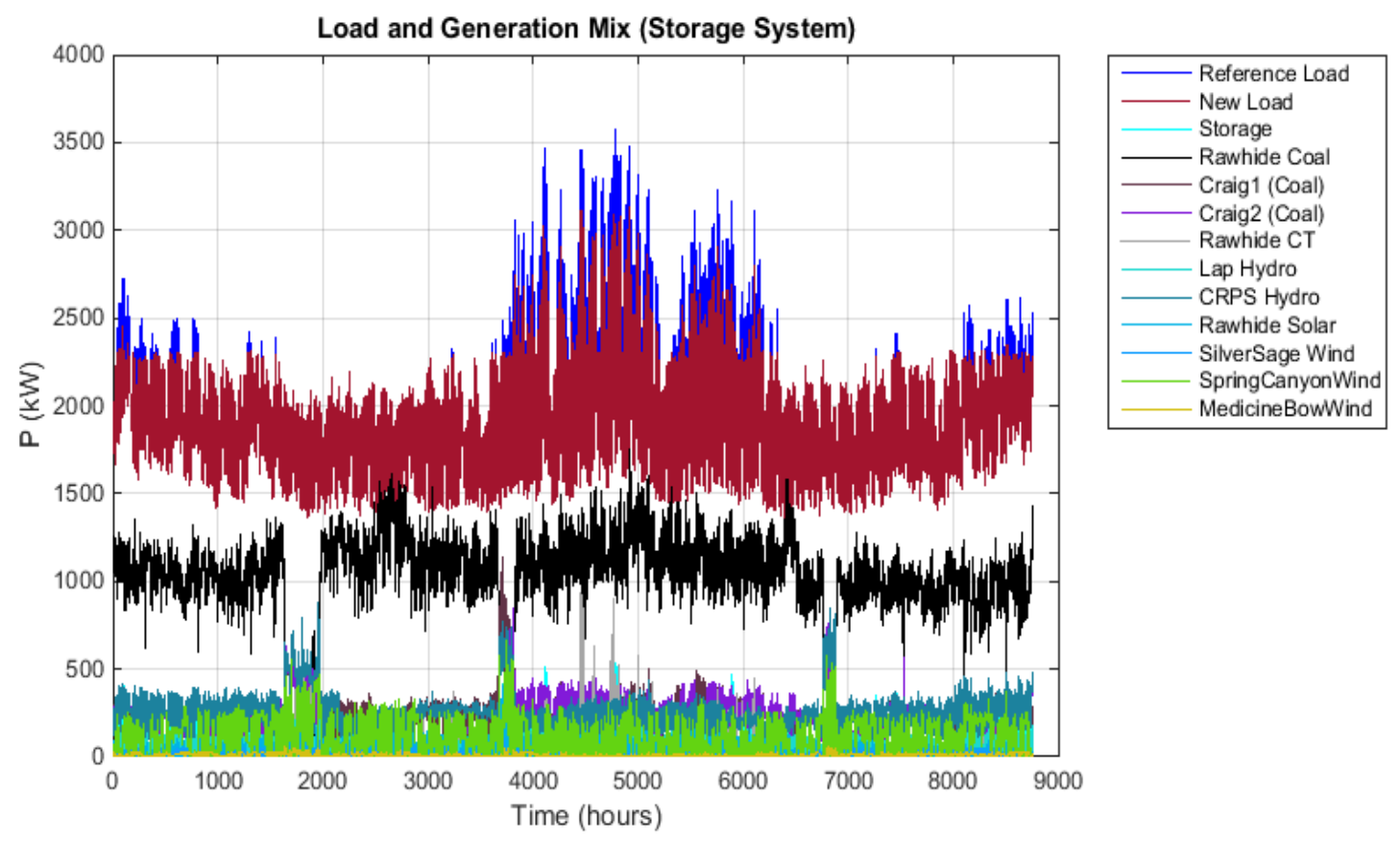

Figure 6-4: Load profile and generation mix, from the IEEE test system, for 2017 after applying ESS 


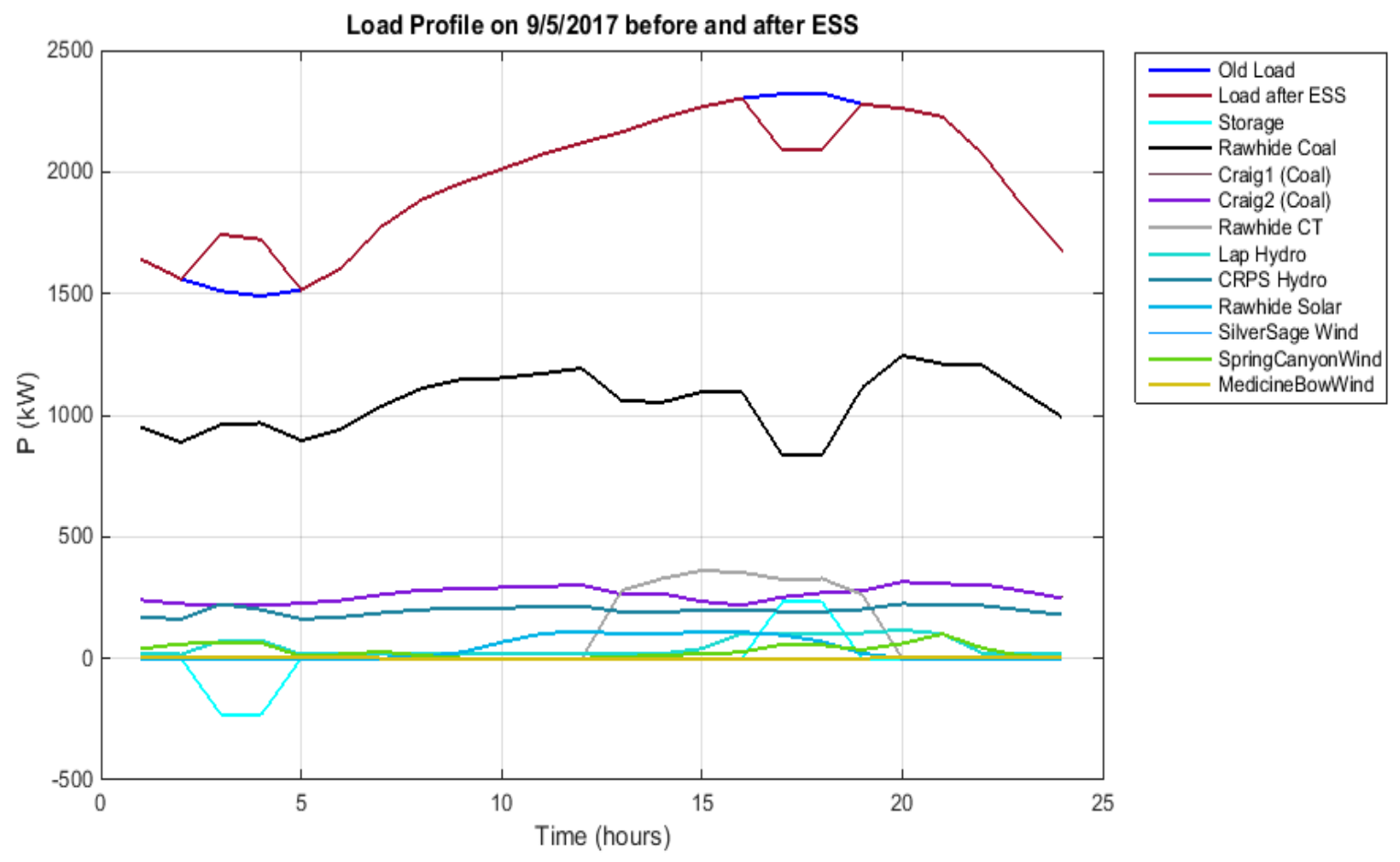

Figure 6-5: Load profile and generation mix, from the IEEE test system, on 9/5/2019 after applying ESS

The results show ESS with this technique mitigates the total emissions from 2005 level by $18.13 \%$, equivalent to 13,385 tons of $\mathrm{CO}_{2}$ per year. Figure 6-6 explains the emissions reduction per source after integrating ESS. This mitigation comes from diminishing the emissions from Rawhide coal power plant. Table 6-1 indicates the emissions reduction per source after ESS.

Table 6-1: Emissions, from the IEEE Test System, after ESS

\begin{tabular}{|l|c|c|c|}
\hline & Base Case (tons of $\mathrm{CO}_{2}$ ) & After ESS (tons of $\left.\mathrm{CO}_{2}\right)$ & $\begin{array}{c}\text { Emissions } \\
\text { Reduction }(\%)\end{array}$ \\
\hline Rawhide coal & 9,284 & 9,046 & 2.57 \\
\hline Craig coal (unit 1) & 2,361 & 2,361 & 0 \\
\hline Craig coal (unit 2) & 1,916 & 1,916 & 0 \\
\hline Rawhide CTs & 130 & 130 & 0 \\
\hline
\end{tabular}




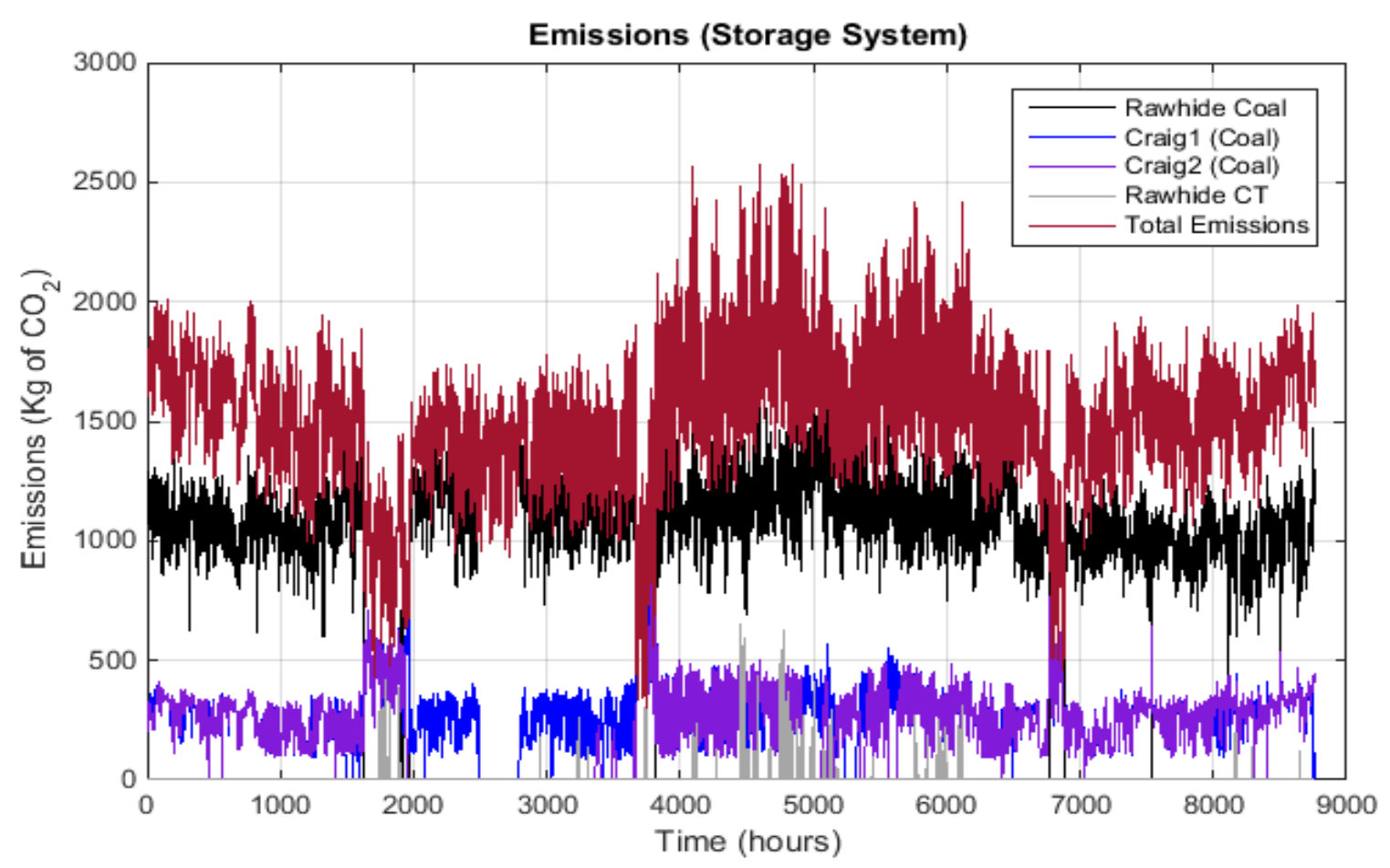

Figure 6-6: Emissions from the electricity sector, from the IEEE test system, for 2017 after applying ESS

\subsubsection{Energy conservation}

This alternative means reducing the energy input to meet the demand. As mentioned in section 4.3.1, energy conservation can be implemented either by applying energy efficiency to reduce the energy input required to produce useful work or educational programs to reduce the work requested of the system. In that regard, this scenario uses the ideal case for the simulation analyses based on a $5 \%$ curtailment in the entire load. Therefore, a one-year simulation is implemented after reducing the demand by $5 \%$. The red curve in Figure 6 7 points out such a reduction in the total demand curve for 2017. 


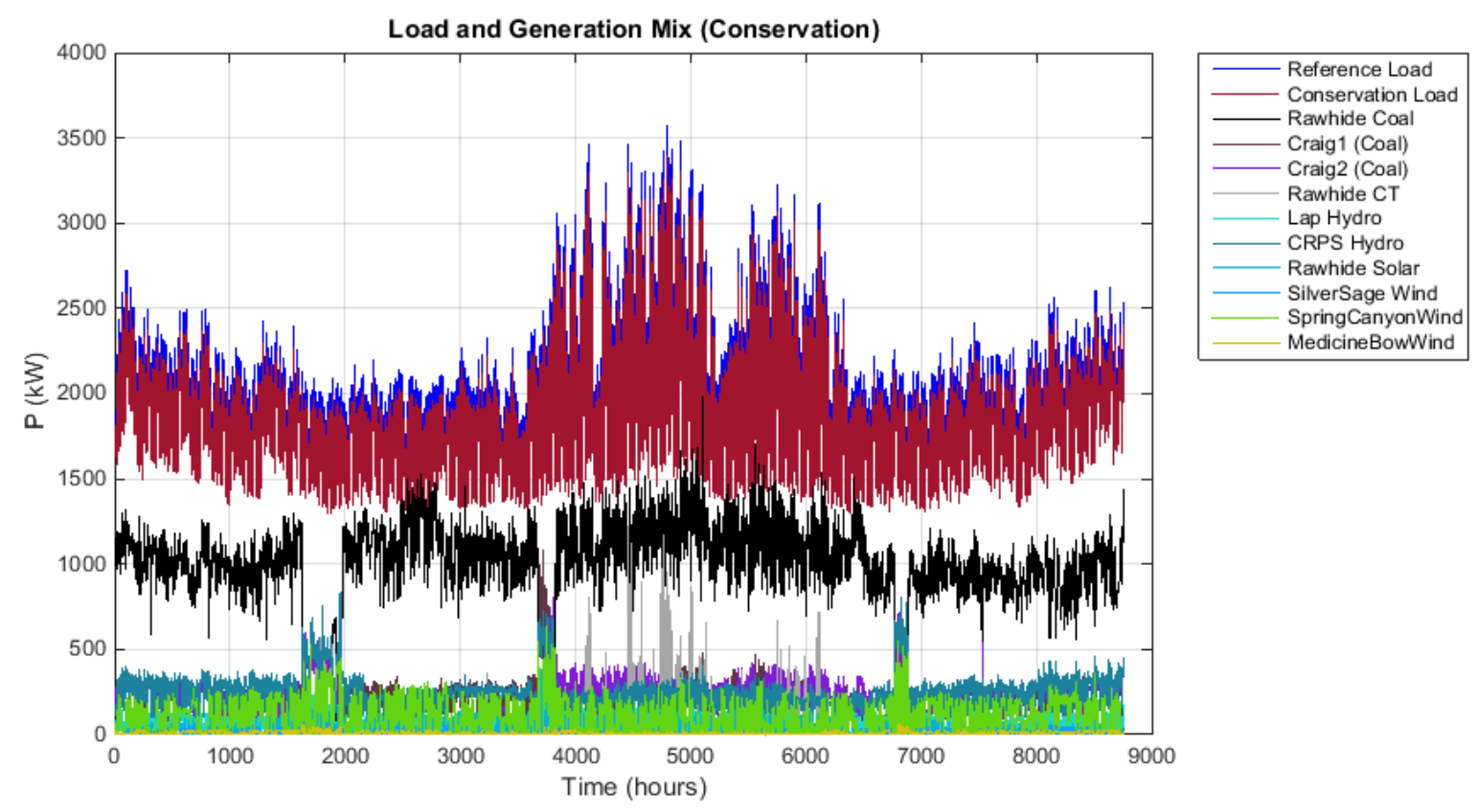

Figure 6-7: Load profile and generation mix, from the IEEE test system, for 2017 after applying energy conservation

This energy saving successfully minimized the total emissions by more than $20 \%$, compared to the 2005 level. The emissions generated from the test system after curtailing the energy demand is equal to 13,016 tons of $\mathrm{CO}_{2}$ per year, compared to 16,350 tons of $\mathrm{CO}_{2}$ in 2005. Figure 6-8 demonstrates this notable mitigation in emissions. The major reduction comes from Rawhide coal power plant where the emissions from this unit is reduced by about $458 \mathrm{CO}_{2}$ tons as shown in Table 6-2:

Table 6-2: Emissions, from the IEEE Test System after Energy Conservation

\begin{tabular}{|l|c|c|c|}
\hline & Base Case (tons of $\mathrm{CO}_{2}$ ) & $\begin{array}{c}\text { After Energy } \\
\text { Conservation (tons of } \\
\left.\mathrm{CO}_{2}\right)\end{array}$ & $\begin{array}{c}\text { Emissions Reduction } \\
(\%)\end{array}$ \\
\hline Rawhide coal & 9,284 & 8,826 & 4.93 \\
\hline Craig coal (unit 1) & 2,361 & 2,244 & 4.93 \\
\hline Craig coal (unit 2) & 1916 & 1,821 & 4.93 \\
\hline Rawhide CTs & 130 & 123 & 4.95 \\
\hline
\end{tabular}




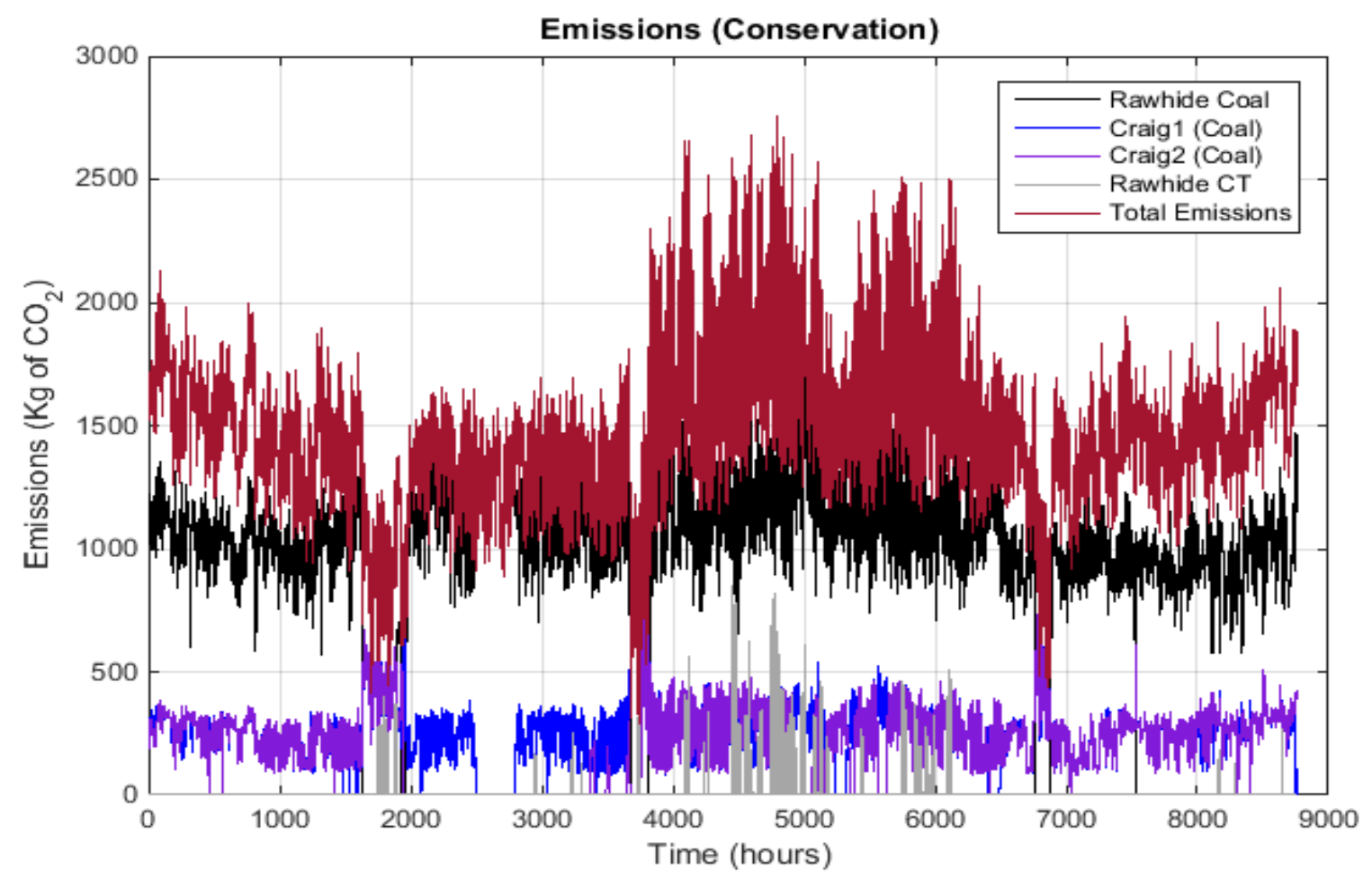

Figure 6-8: Emissions from the electricity sector, from the IEEE test system, for 2017 after applying energy conservation

\subsubsection{Stationary storage with energy conservation}

This scenario studies the load behavior and emissions amount after combining two options: ESS and energy conservation. The aim of considering such scenario is to investigate the availability of achieving more emissions reduction. This scenario follows the same simulation strategies for ESS and conservation programs that are explained in subsections 6.3.2 and 6.3.3. Figure 6-9 illustrates that such a combination affected the total energy demand. 


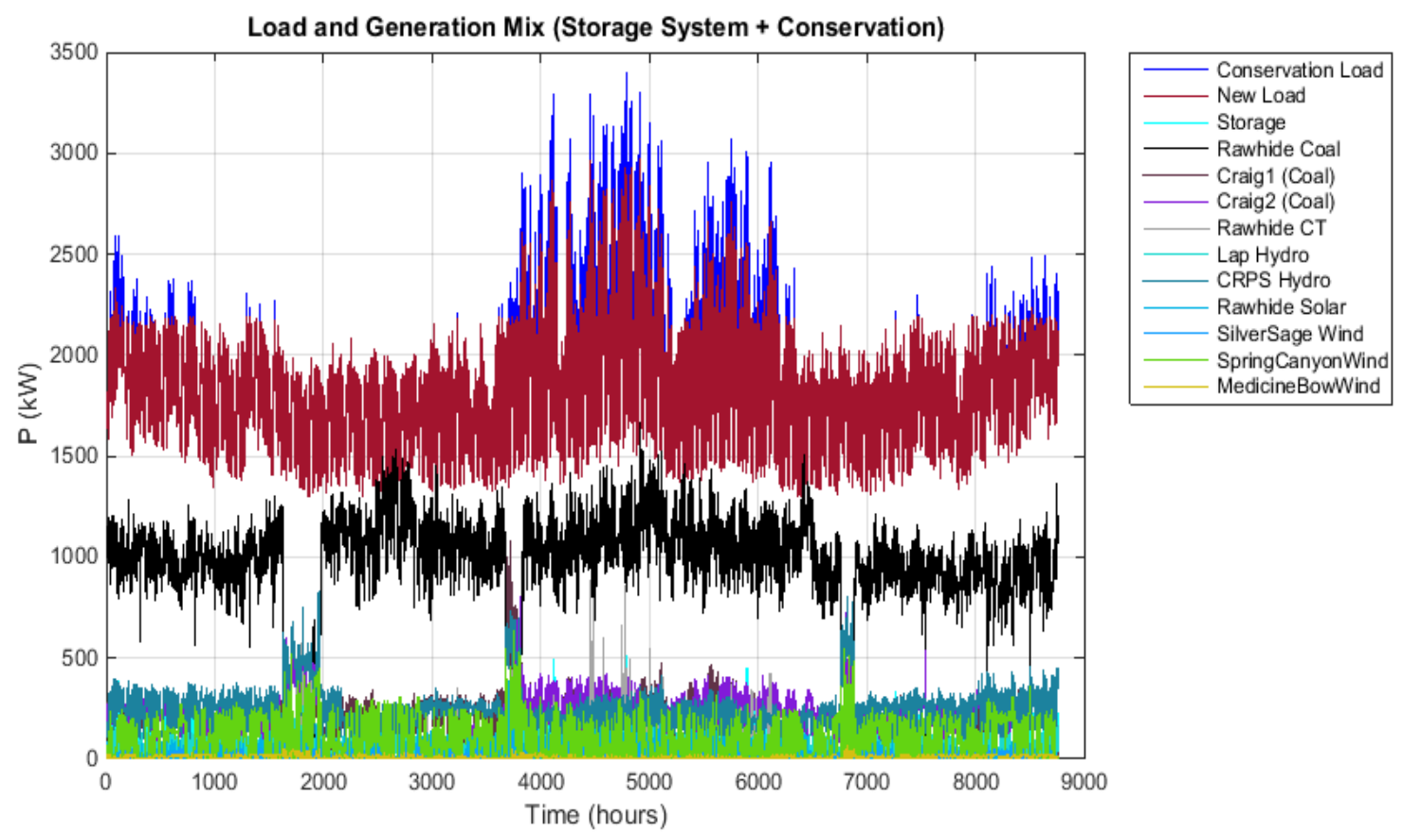

Figure 6-9: Load profile and generation mix, from the test system, for 2017 after combining ESS and energy conservation

This scenario can achieve reduction in emissions more than the city's goal. While the city has a goal of reaching a $20 \%$ emissions reduction by 2020 , this scenario is able to reduce the carbon footprints by about $22 \%$. As stated, the base case generates 16,350 ton of emissions while this option can minimize it to 12,725 $\mathrm{CO}_{2}$ ton. Figure 6-10 presents the generated emissions from each emitting source, and Table 6-3 represents the values of emissions. From this table, we observe that ESS displaced energy needed from Rawhide coal.

Table 6-3: Emissions, from the IEEE Test System, after using ESS with Energy Conservation

\begin{tabular}{|l|c|c|c|}
\hline & Base Case (tons of $\mathrm{CO}_{2}$ ) & $\begin{array}{c}\text { After ESS with Energy } \\
\text { Conservation (tons of } \\
\mathrm{CO}_{2} \text { ) }\end{array}$ & $\begin{array}{c}\text { Emissions Reduction } \\
(\%)\end{array}$ \\
\hline Rawhide coal & 9,284 & 8,600 & 7.37 \\
\hline Craig coal (unit 1) & 2,361 & 2,244 & 4.93 \\
\hline Craig coal (unit 2) & 1916 & 1,821 & 4.94 \\
\hline Rawhide CTs & 130 & 123 & 4.95 \\
\hline
\end{tabular}




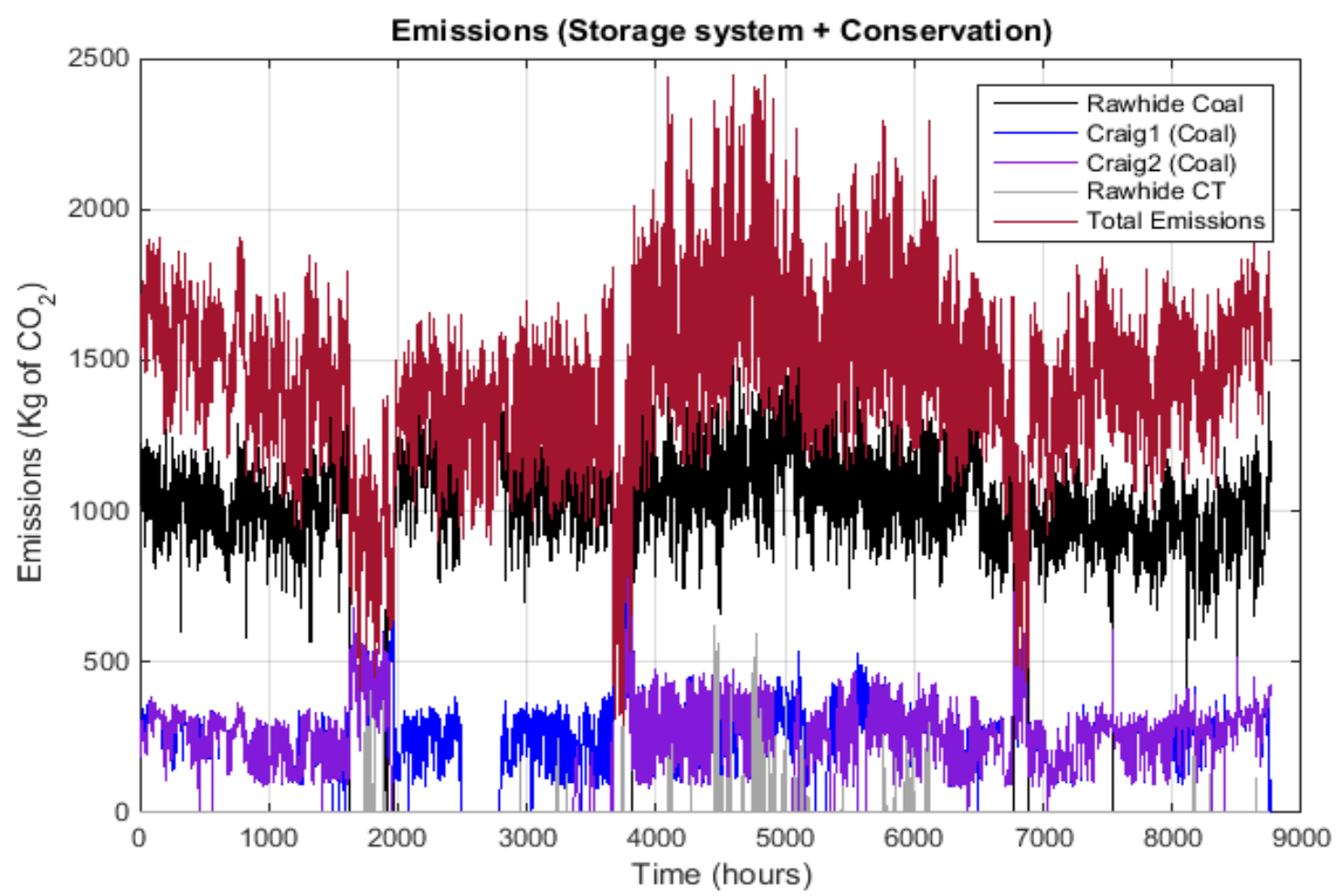

Figure 6-10: Emissions from the electricity sector, from the IEEE test system, for 2017 after combining ESS and energy conservation

\subsubsection{Communication and intelligence}

The aim of using communication and intelligence is to improve the matching of load to the availability of variable clean generating sources and to reduce peak demand. We treat this option as a residential DR since this option includes internet of things, smart meters and advanced metering infrastructure, real-time pricing, and smart appliance with controls automating energy conservation. Therefore, the simulation uses only the residential load curve to apply the DR program. According to [95], Fort Collins utility has a new Time-of-Day pricing mechanism for summer and non-summer seasons. Figure 6-11 and Figure 6-12 show electricity daily prices, regenerated from [96]. In DR, the demand changes as the prices change. The formula for price elasticity of demand is:

$$
\varepsilon=\frac{\% \Delta Q_{D}}{\% \Delta P}
$$


where $\Delta Q_{D}$ is the change is demand and $\Delta P$ is the change is prices [97]. In [98], there are two values for price elasticity of demand; long-term and short-term. Since this work conducts a one-year simulation, we consider the price elasticity for the short-term demand, -0.02 .

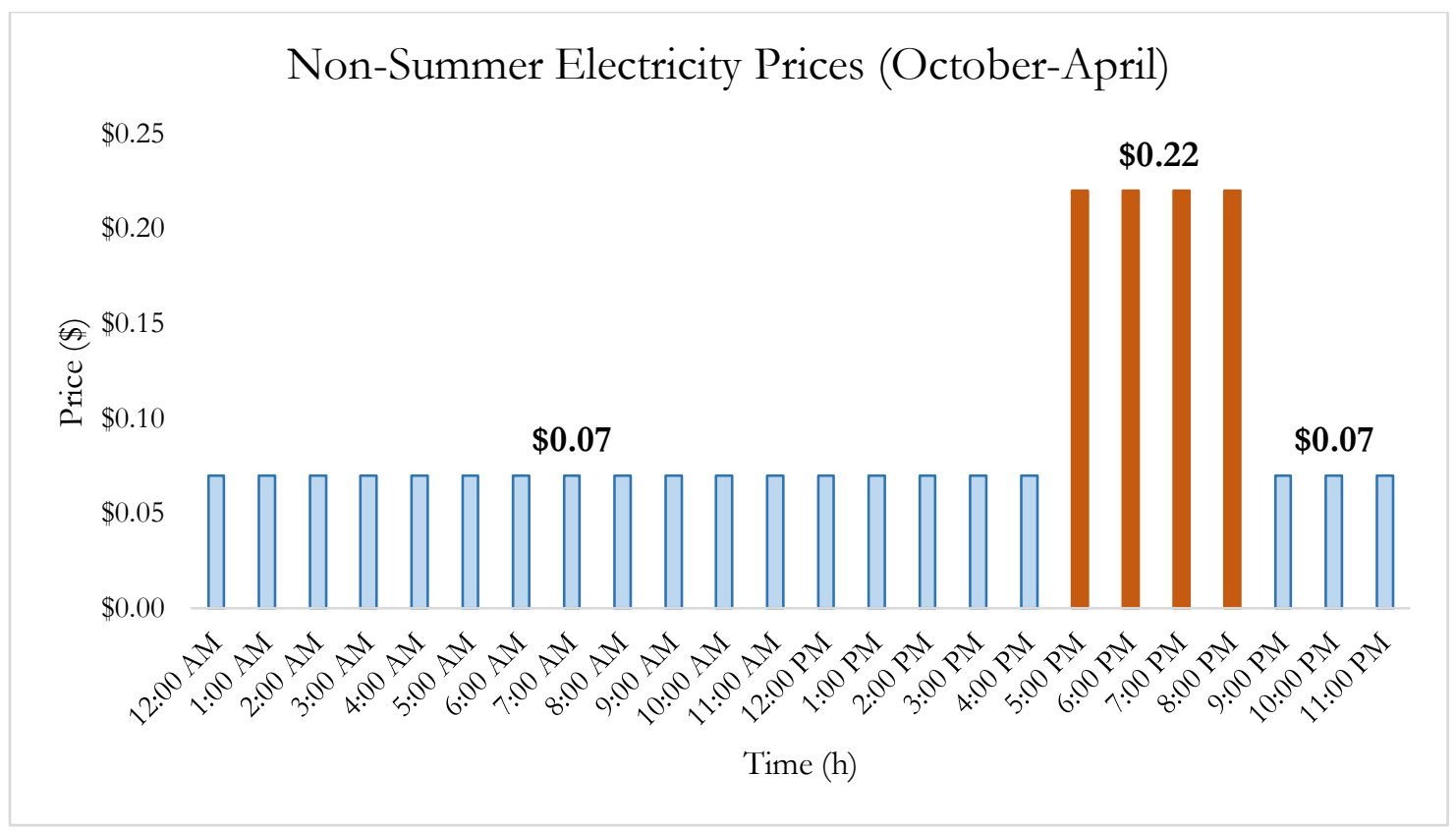

Figure 6-11: Non-Summer electricity prices corresponding to Fort Collins

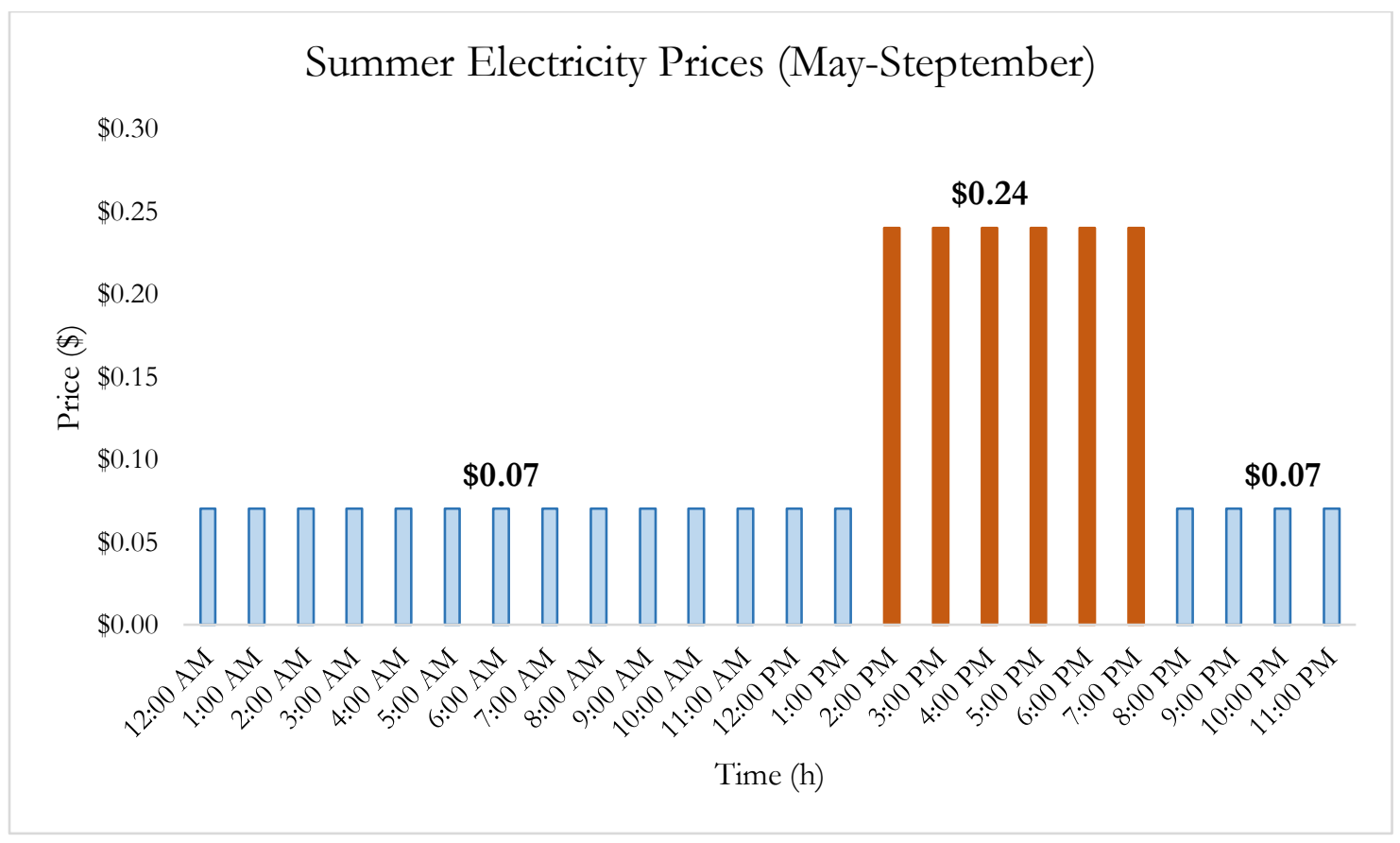

Figure 6-12: Summer electricity prices corresponding to Fort Collins 
After performing the analysis, the Time-of-Day rates helped in reducing the load during peak hours. Figure 6-13 illustrates the residential load profile after applying DR in the residential sector. To explain the change in the demand during the summer season and the non-summer season, Figure 6-14 and Figure 6-15 demonstrates the load behavior with DR, respectively.

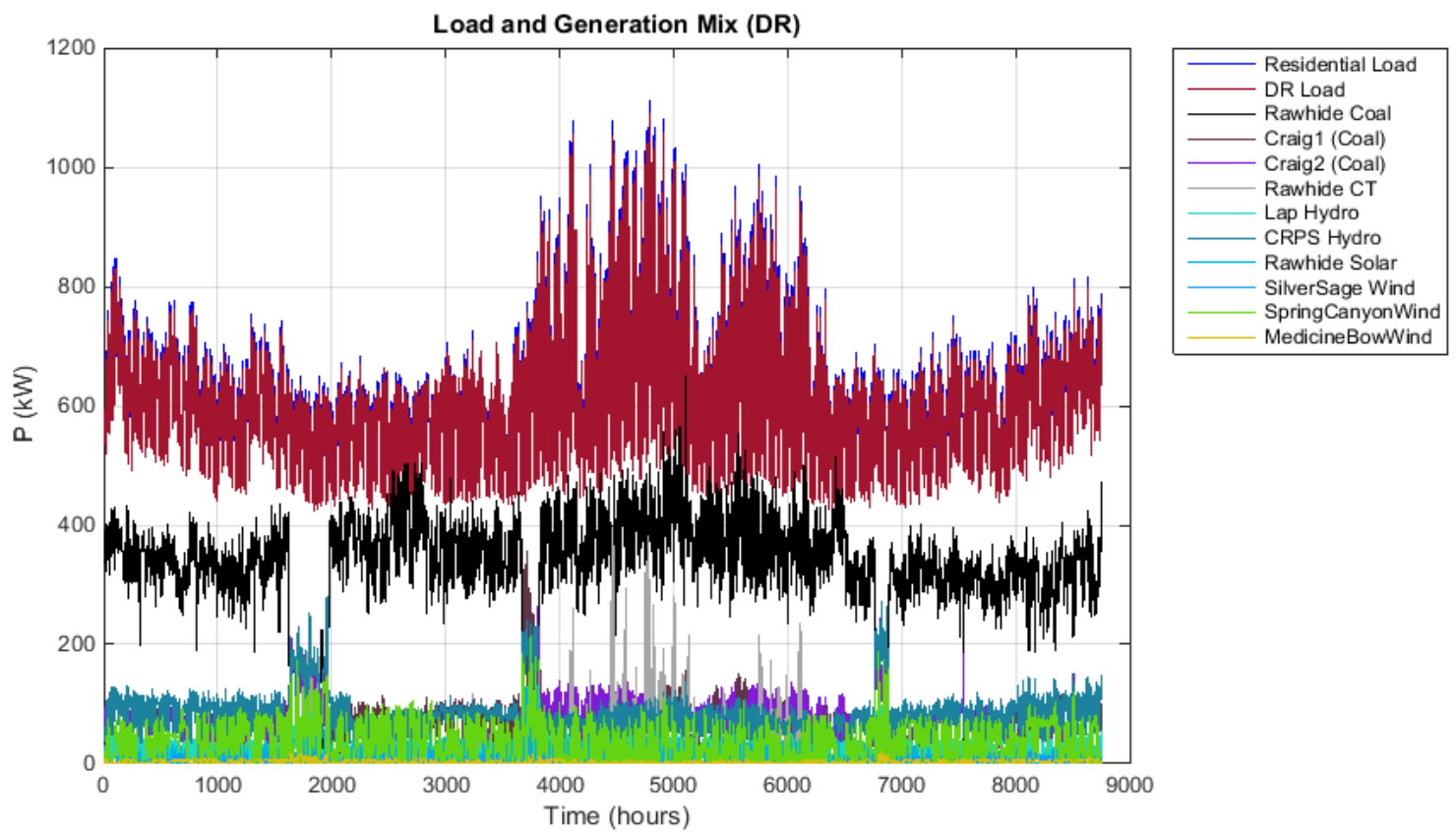

Figure 6-13: Residential load profile and generation mix, from the IEEE test system, for 2017 after using residential DR 


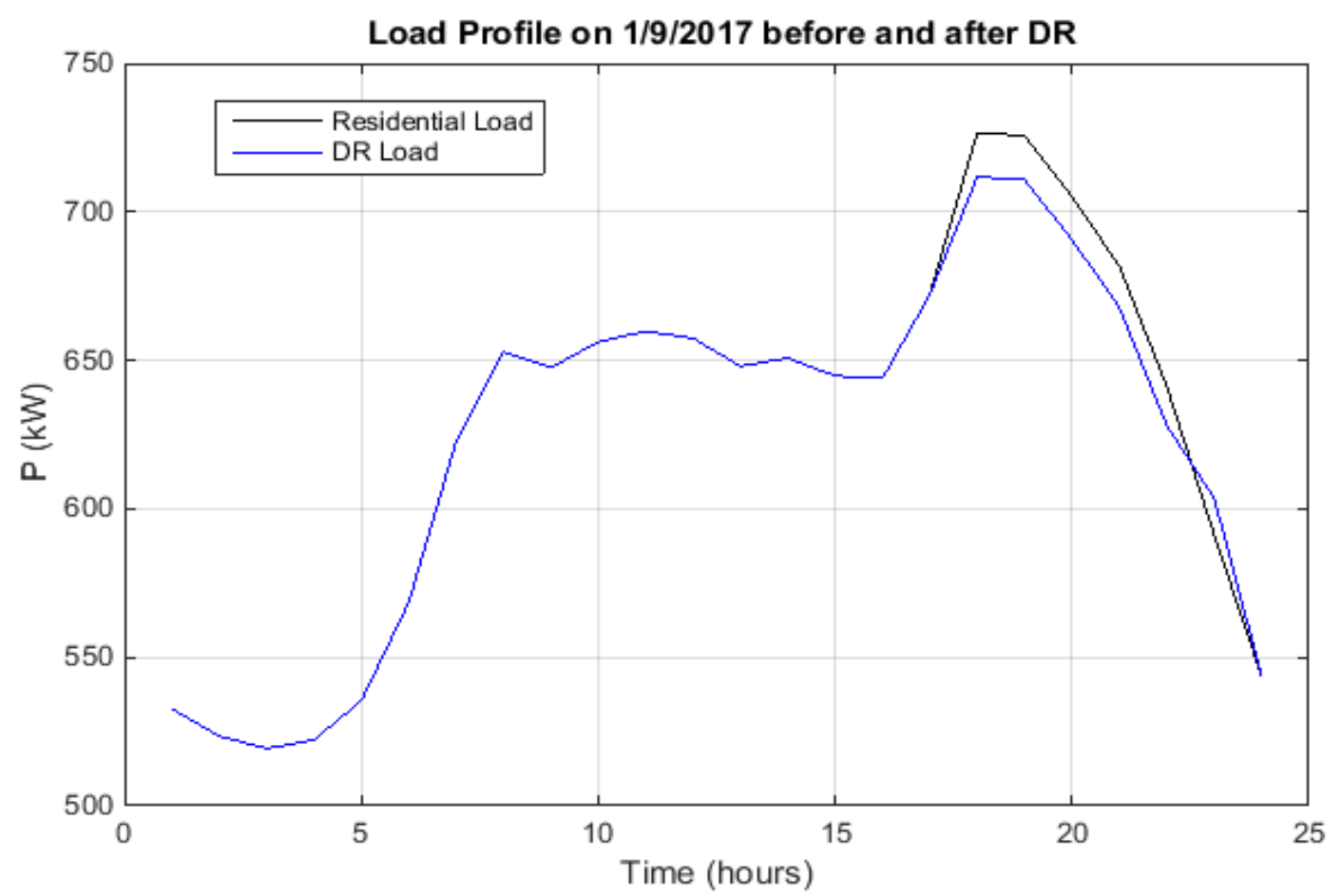

Figure 6-14: Residential load profile and generation mix, from the IEEE test system, on 1/9/2017

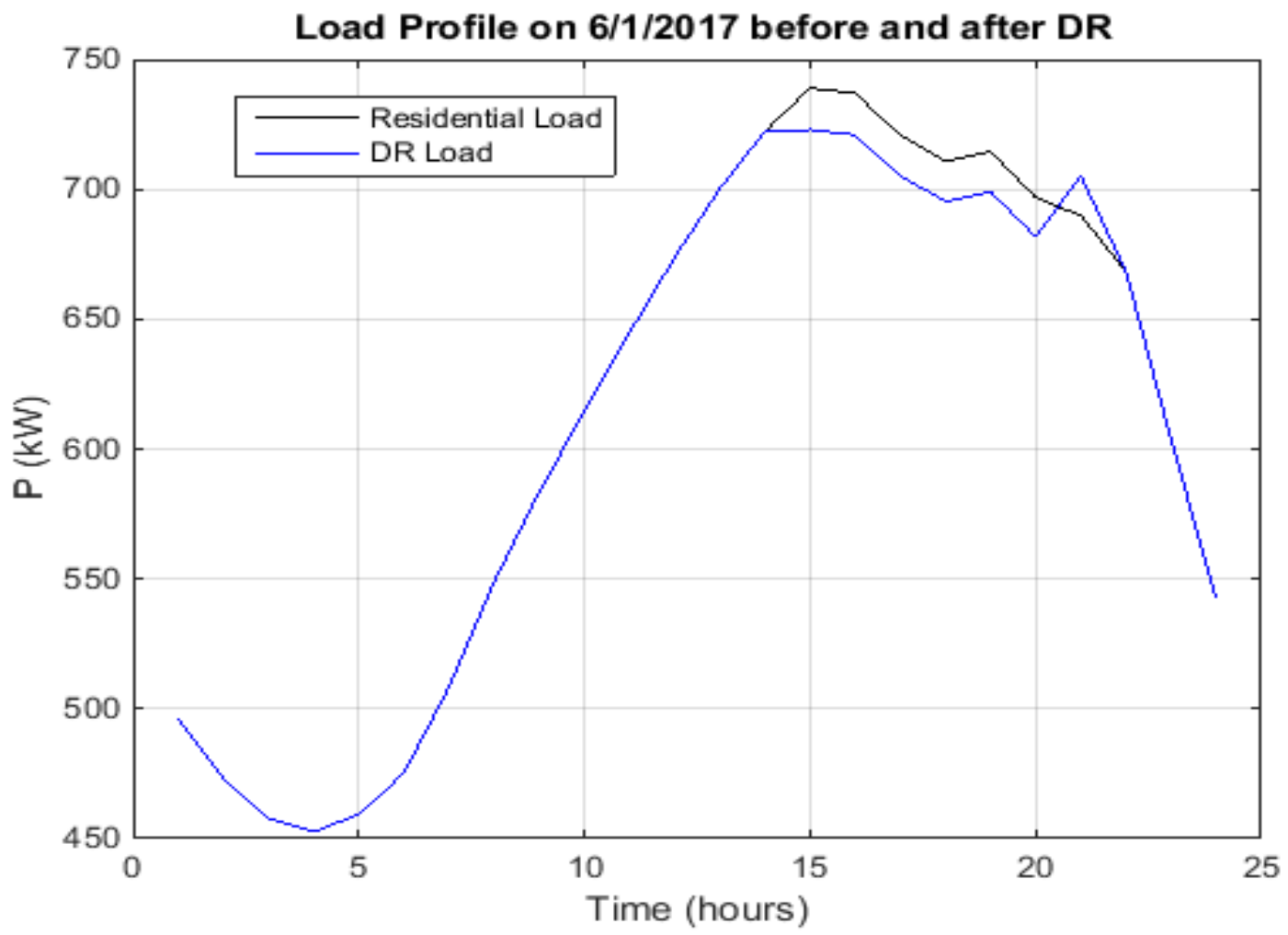

Figure 6-15: Residential load profile and generation mix, from the IEEE test system, on 6/1/2017 
While the goal of deploying DR is shaving the peak load, the total emissions from the residential sector is reduced by about $14 \%$ from residential emissions in 2005 level. The pollution for residential sector was 5,068 $\mathrm{CO}_{2}$ tons in 2005 and then DR dropped the emissions to 4,363 $\mathrm{CO}_{2}$ tons. Table 6-4 shows the reduction in emissions, from the base case, after DR, and Figure 6-16 explains the emissions curve for each source.

Table 6-4: Emissions, from the IEEE Test System, after using Residential DR

\begin{tabular}{|l|c|c|c|}
\hline & $\begin{array}{c}\text { Residential } \mathrm{Base} \text { Case } \\
\text { (tons of } \mathrm{CO}_{2} \text { ) }\end{array}$ & $\begin{array}{c}\text { After Residential DR } \\
\left.\text { (tons of } \mathrm{CO}_{2}\right)\end{array}$ & $\begin{array}{c}\text { Emissions Reduction } \\
(\%)\end{array}$ \\
\hline Rawhide coal & 2,972 & 2,960 & 0.41 \\
\hline Craig coal (unit 1) & 755 & 750 & 0.71 \\
\hline Craig coal (unit 2) & 613 & 610 & 0.45 \\
\hline Rawhide CTs & 41 & 40 & 1.28 \\
\hline
\end{tabular}

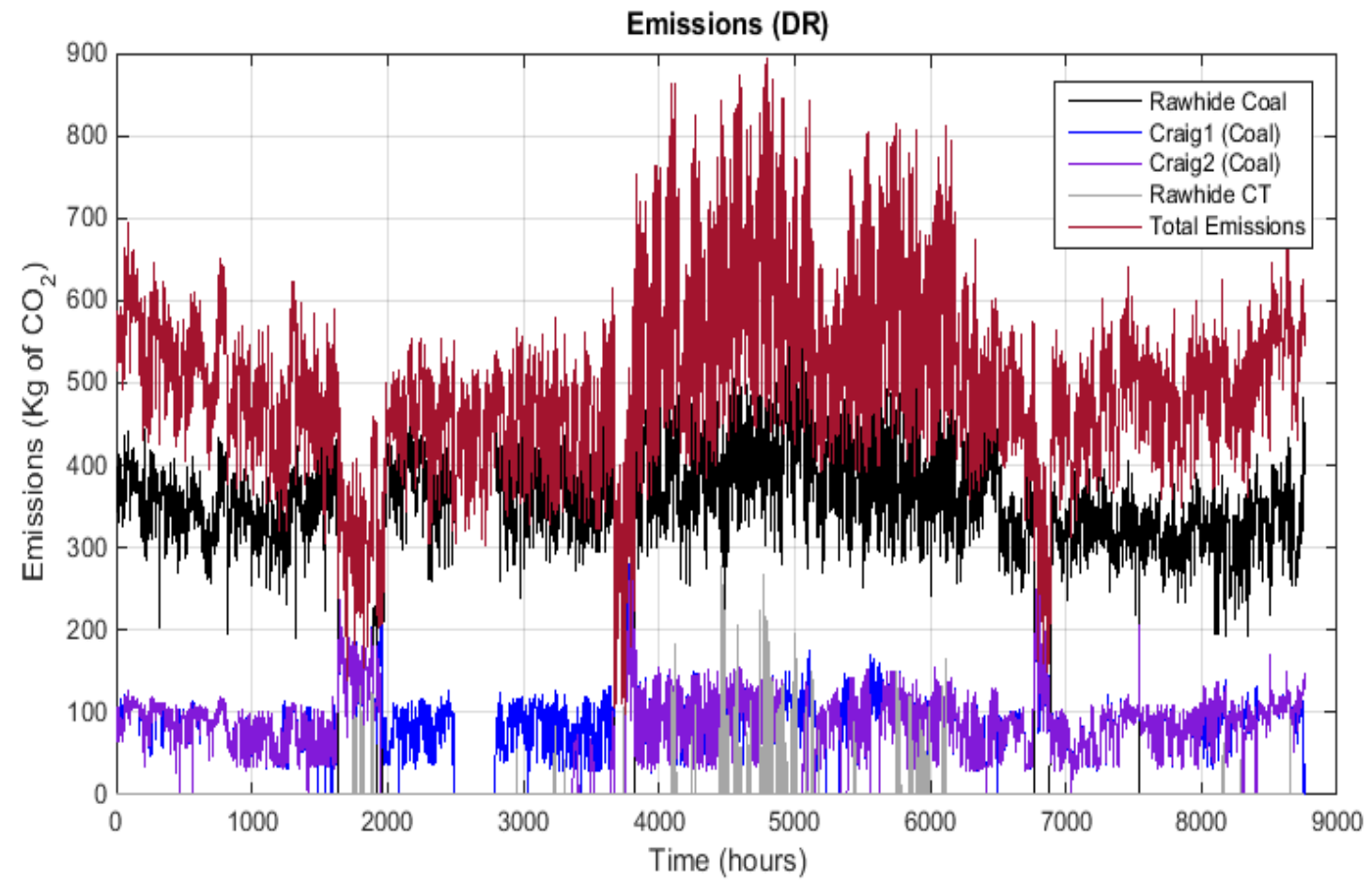

Figure 6-16: Emissions from the electricity residential sector, from the IEEE test system, for 2017 after using residential DR 


\subsubsection{Communication and intelligence with ESS}

This subsection investigates the combination between residential DR and ESS in diminishing the pollution from the residential electric sector. In such simulation, we apply the same above-described approaches for residential DR and ESS. Since both these options aim to shave the peaking load, Figure 6-17 demonstrates the reduction in the peak load. Integrating ESS helped in saving emissions from the residential sector by about $2.48 \%$. As a result, this scenario helped in minimizing the total emissions to almost $15.68 \%$ compared to 2005 level. The total emissions obtained from the IEEE 13 -node system dropped to $4,2734 \mathrm{CO}_{2}$ tons for this scenario. Table 6-5 explains the associated emissions reduction per source while Figure 6-18 illustrates the generated emissions after applying this scenario.

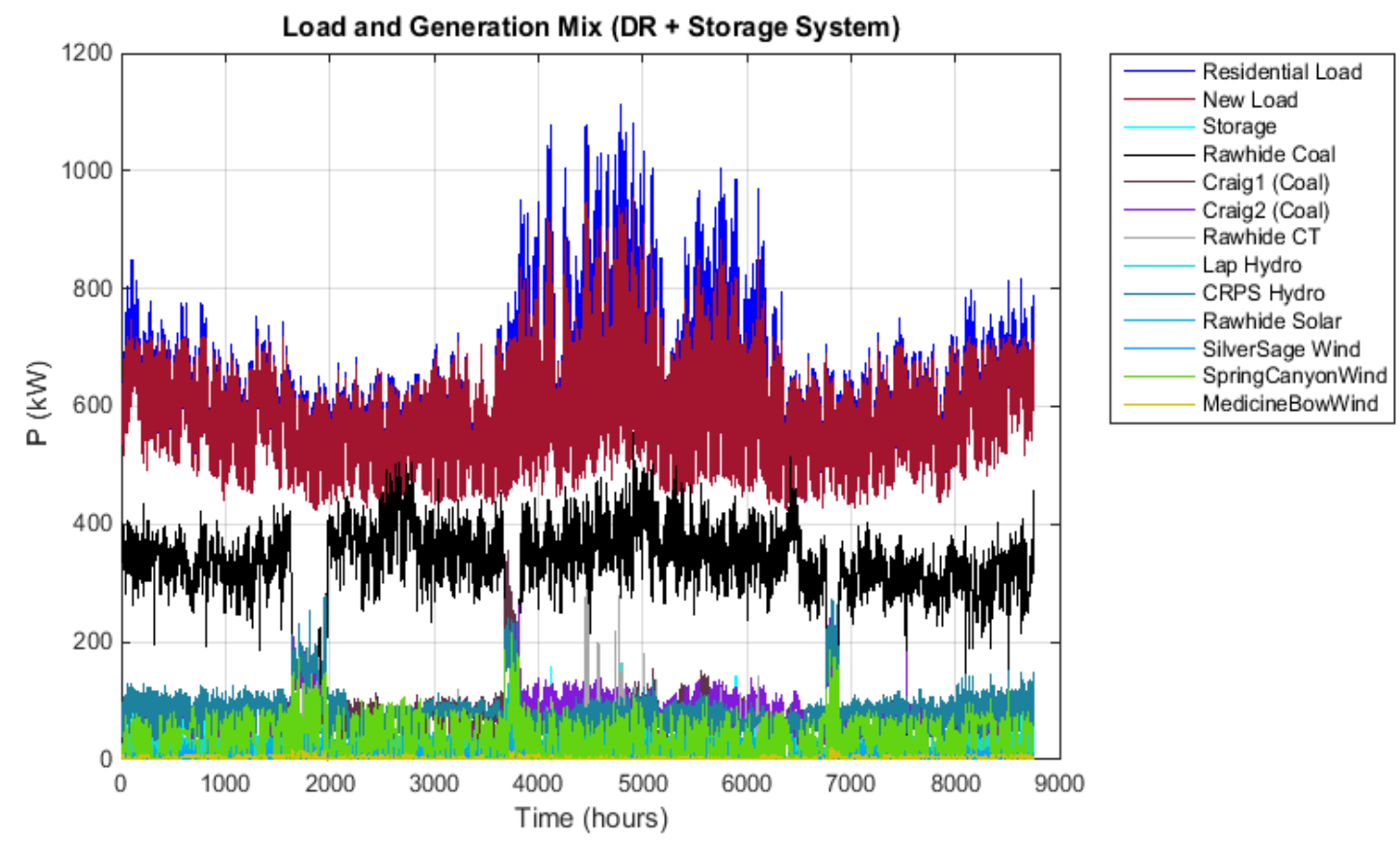

Figure 6-17: Residential load profile and generation mix, from the IEEE test system, for 2017 after using residential DR with ESS 
Table 6-5: Emissions, from the IEEE Test System, after using Residential DR with ESS

\begin{tabular}{|l|c|c|c|}
\hline & $\begin{array}{c}\text { Residential Base Case } \\
\text { (tons of } \mathrm{CO}_{2} \text { ) }\end{array}$ & $\begin{array}{c}\text { After Residential DR } \\
\text { with ESS (tons of } \mathrm{CO}_{2} \text { ) }\end{array}$ & $\begin{array}{c}\text { Emissions Reduction } \\
(\%)\end{array}$ \\
\hline Rawhide coal & 2,972 & 2,891 & 2.72 \\
\hline Craig coal (unit 1) & 755 & 752 & 0.46 \\
\hline Craig coal (unit 2) & 613 & 610 & 0.45 \\
\hline Rawhide CTs & 41 & 20 & 51.62 \\
\hline
\end{tabular}

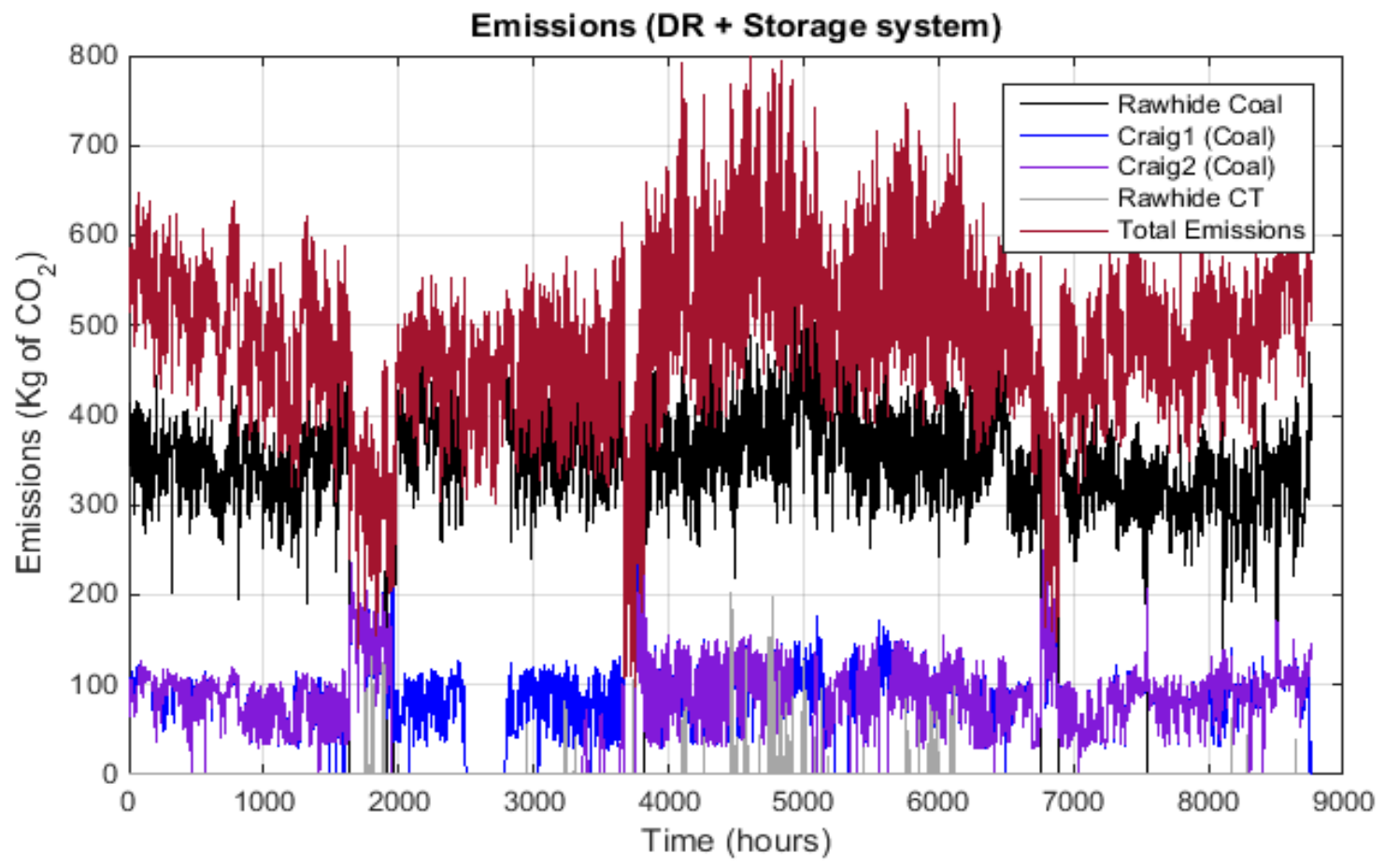

Figure 6-18: Emissions from the electricity residential sector, from the IEEE test system, for 2017 after using Residential DR with ESS

\subsubsection{Communication and intelligence with energy conservation}

In order to examine all the potential options that could reduce the carbon footprints from the electric sector, this scenario takes into account merging residential DR with energy conservation programs. In fact, energy conservation can play a major role toward attaining the goal when it is integrated with residential DR. In Figure 6-19, we realize a reduction in the demand curve due to the aggressive curtailment in energy use. Figure 6-20 depicts the emissions from the electric residential sector for 2017. It shows that this combination 
resulted in more than $18 \%$ emission reduction, dropping from 5,069 $\mathrm{CO}_{2}$ tons in 2005 to $4,151 \mathrm{CO}_{2}$ tons. Table 6-6 highlights where this reduction comes from.

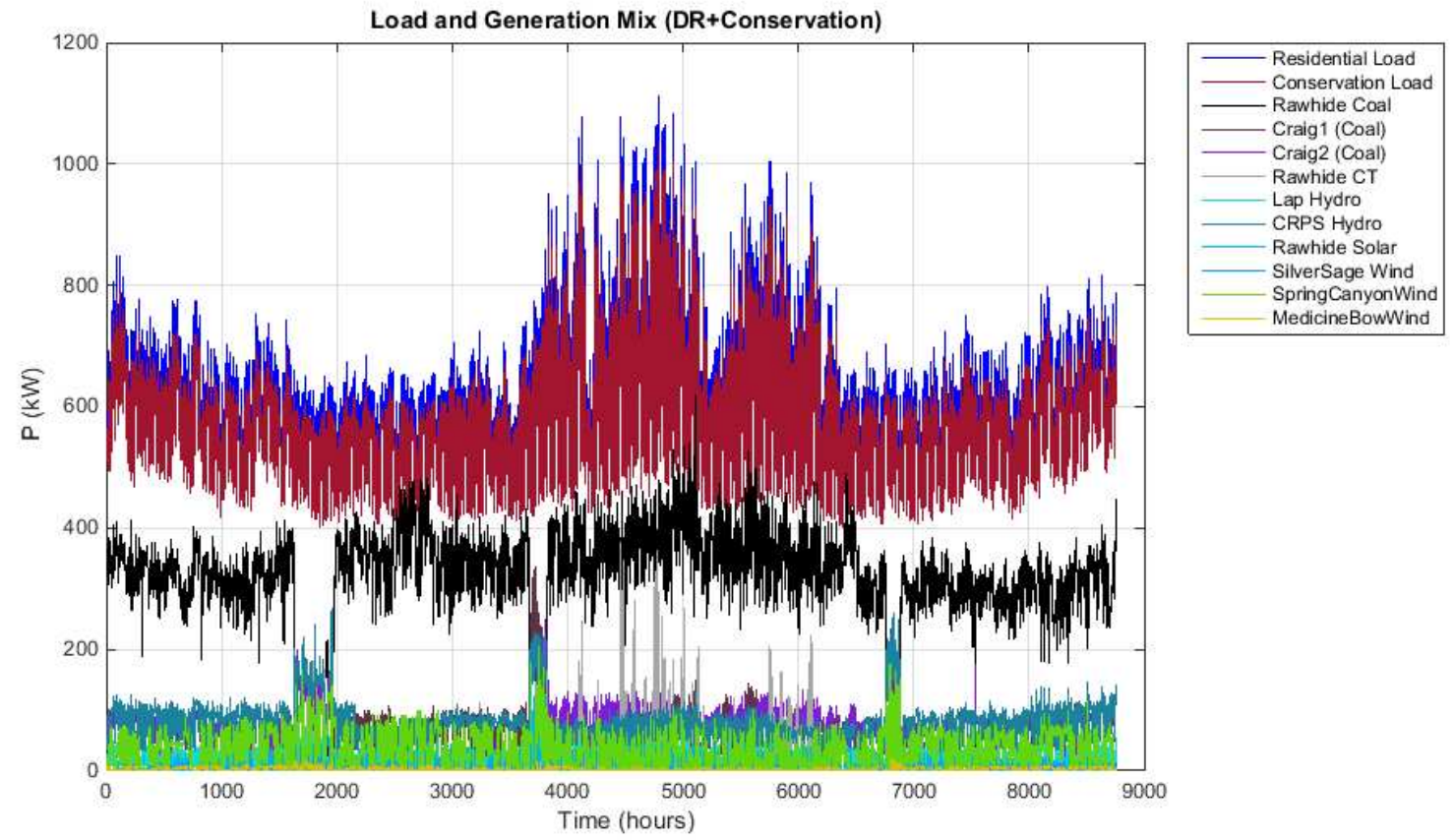

Figure 6-19: Residential load profile and generation mix, from the IEEE test system, for 2017 after using residential DR with energy conservation

Table 6-6: Emissions, from the IEEE Test System, after using Residential DR with Energy Conservation

\begin{tabular}{|l|c|c|c|}
\hline & $\begin{array}{c}\text { Residential Base Case } \\
\left.\text { (tons of } \mathrm{CO}_{2}\right)\end{array}$ & $\begin{array}{c}\text { After Residential DR } \\
\text { with Energy } \\
\text { Conservation (tons of } \\
\mathrm{CO}_{2}\end{array}$ & $\begin{array}{c}\text { Emissions Reduction } \\
(\%)\end{array}$ \\
\hline Rawhide coal & 2,972 & 2,818 & 5.18 \\
\hline Craig coal (unit 1) & 755 & 716 & 5.22 \\
\hline Craig coal (unit 2) & 613 & 581 & 6.09 \\
\hline Rawhide CTs & 41 & 38 & 5.22 \\
\hline
\end{tabular}




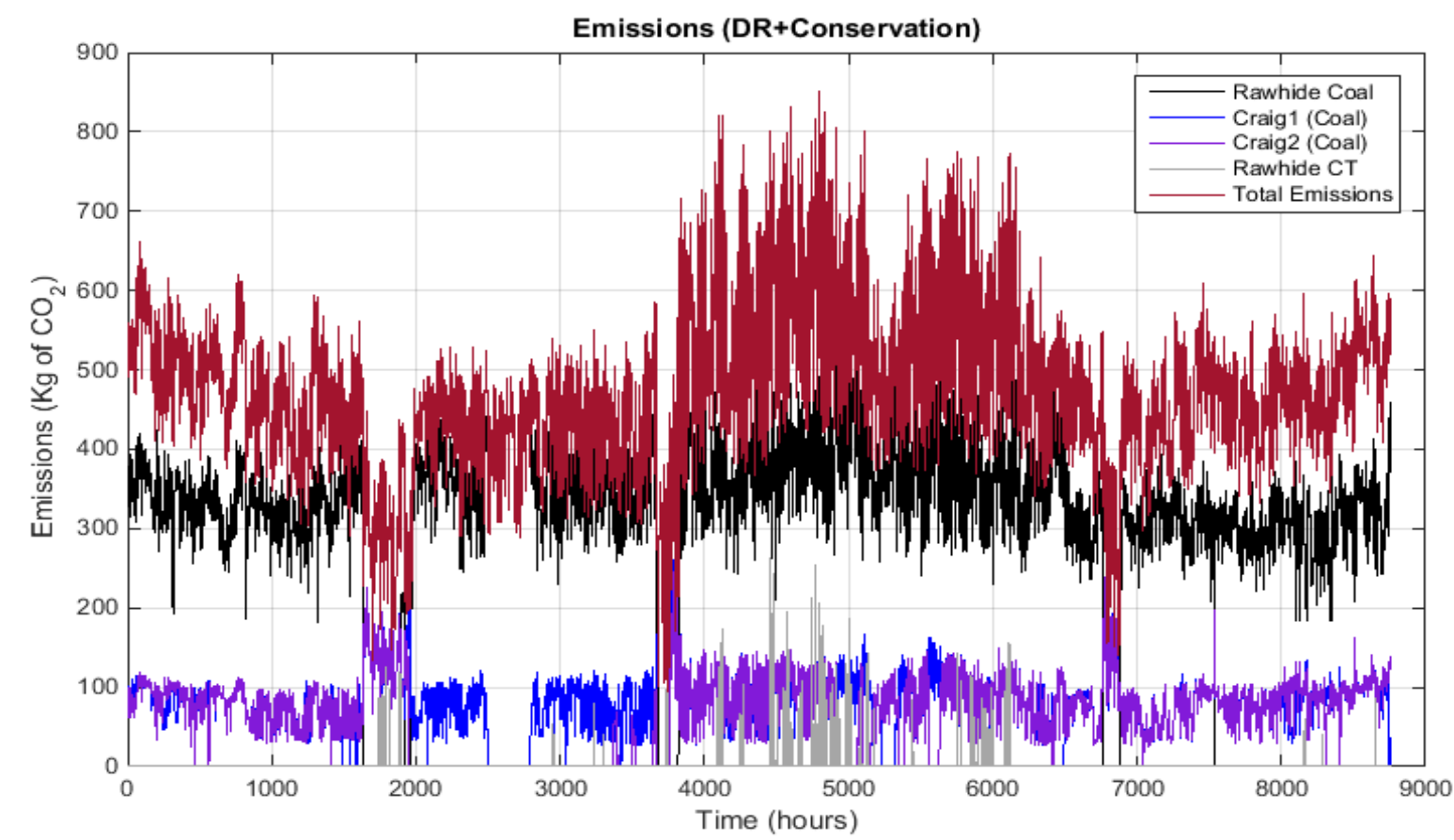

Figure 6-20: Emissions from the electricity residential sector, from the IEEE test system, for 2017 after using residential DR with energy conservation

\subsubsection{Communication and intelligence with ESS and energy conservation}

The last scenario is to examine all the three options together, i.e., we combine residential DR, ESS, and energy conservation in one scenario and then analyze their contribution to emissions reduction. Each scenario is applied with its designed methodology that is explained in the above-subsections. This scenario provides more options and flexibility during the year and in turn achieves more reduction in associated pollution. The obtained results show significant energy saving after integrating such options. It is notable from Figure 6-21 that this scenario minimized the total energy used in 2017 from the residential sector from 5.36 GWh for the base case to $4.97 \mathrm{GWh}$. Therefore, this scenario successfully reduces emissions, from the 2005 level, by about 19.72\%. Table 6-7 presents the emissions from each source, and Figure 6-22 represents the emissions for the entire year. 


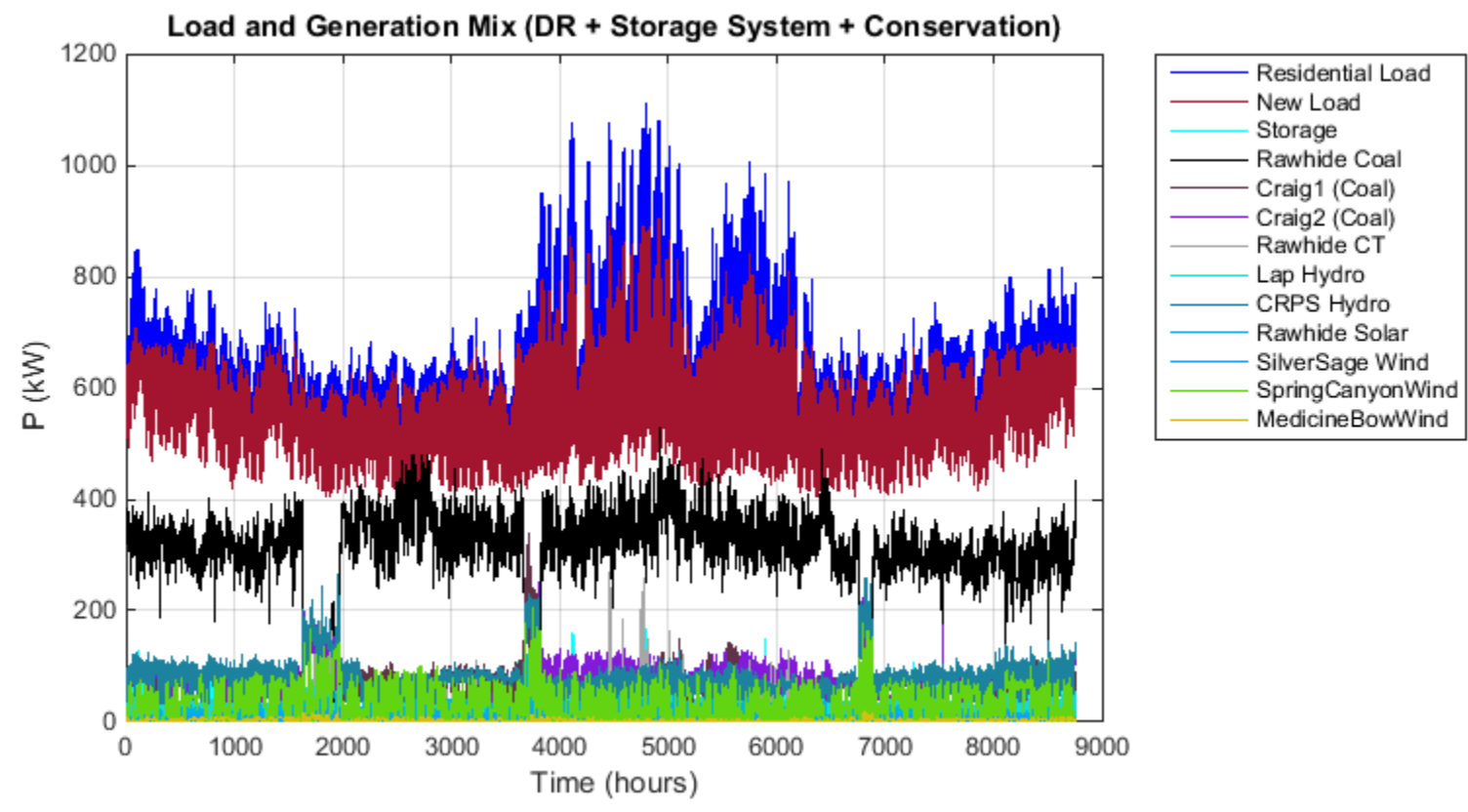

Figure 6-21: Residential load profile and generation mix, from the IEEE test system, for 2017 after combining all options

Table 6-7: Emissions, from the IEEE Test System, after combining all options

\begin{tabular}{|l|c|c|c|}
\hline & $\begin{array}{c}\text { Residential Base Case } \\
\text { (tons of } \mathrm{CO}_{2} \text { ) }\end{array}$ & $\begin{array}{c}\text { After combining All } \\
\left.\text { options (tons of } \mathrm{CO}_{2}\right)\end{array}$ & $\begin{array}{c}\text { Emissions Reduction } \\
(\%)\end{array}$ \\
\hline Rawhide coal & 2,972 & 2,753 & 7.38 \\
\hline Craig coal (unit 1) & 755 & 716 & 5.24 \\
\hline Craig coal (unit 2) & 613 & 581 & 5.22 \\
\hline Rawhide CTs & 41 & 19 & 53.91 \\
\hline
\end{tabular}




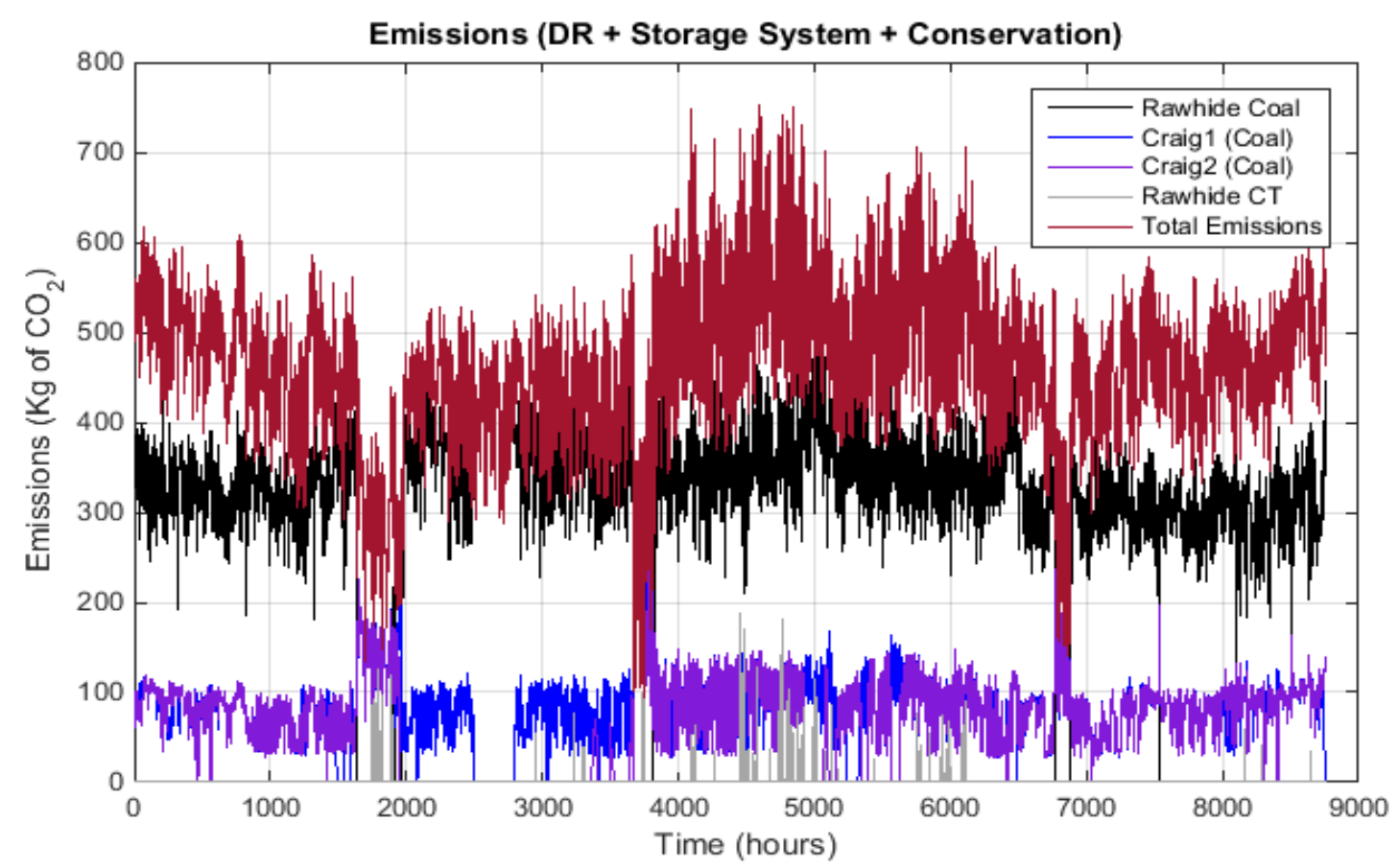

Figure 6-22: Emissions from the electricity residential sector, from the IEEE test system, for 2017 after combining all options

6.4 Results

This section discusses the demand curve and total emissions reduction for each scenario. The figures in this section make a comparison between all the scenarios and then quantify the progress of each scenario in achieving the goal. In that regard, Figure 6-23 shows the demand curve from the IEEE test system for 2017 after examining the first-three scenarios; ESS, energy conservation, and the scenario that combines ESS with energy conservation. Figure 6-24 illustrates the residential demand curve from the test system after considering communication and intelligence alternative and then merging it with other scenarios. 


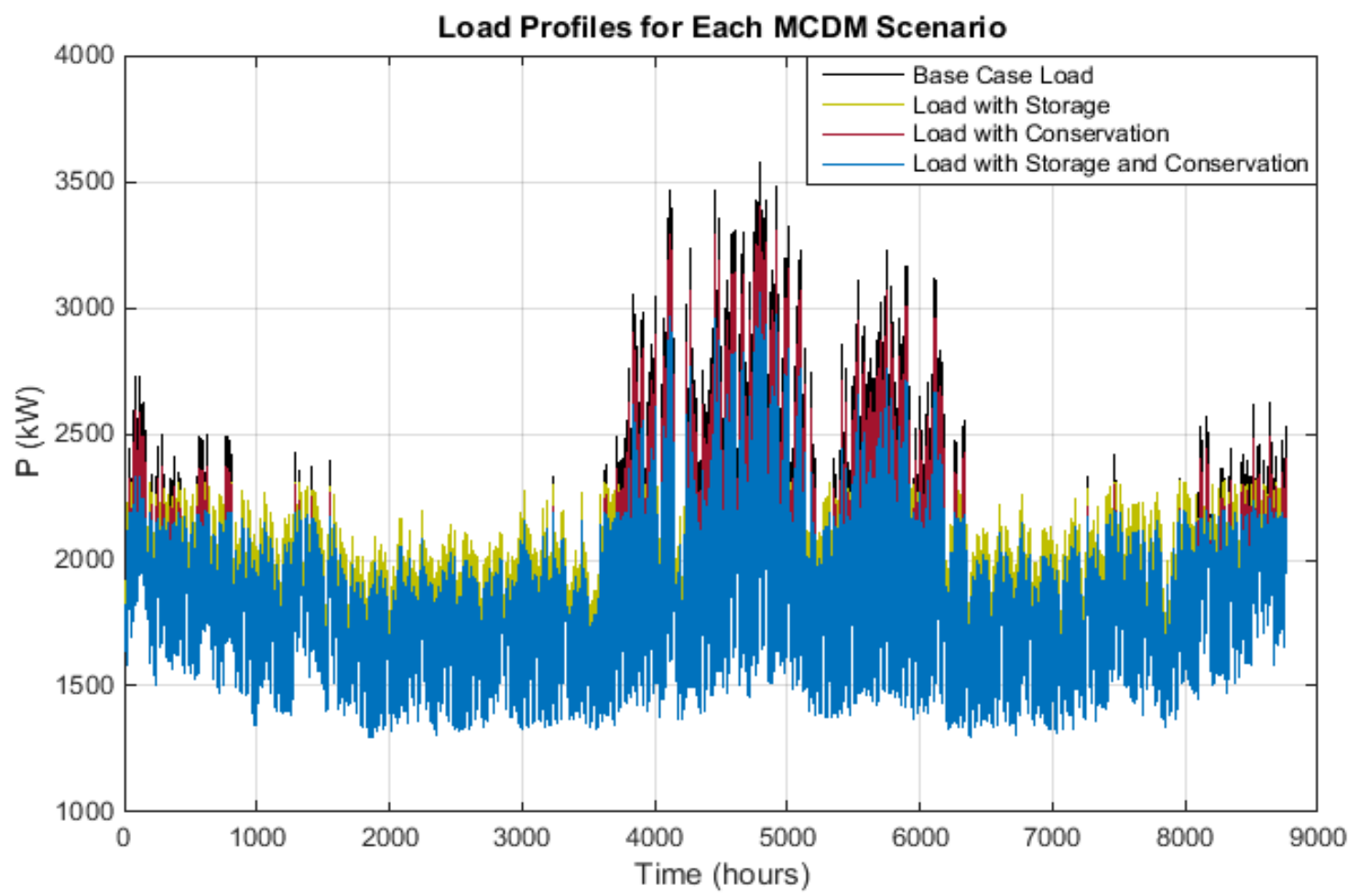

Figure 6-23: Load profile and generation mix, from the IEEE test system, for 2017 after considering ESS and energy conservation

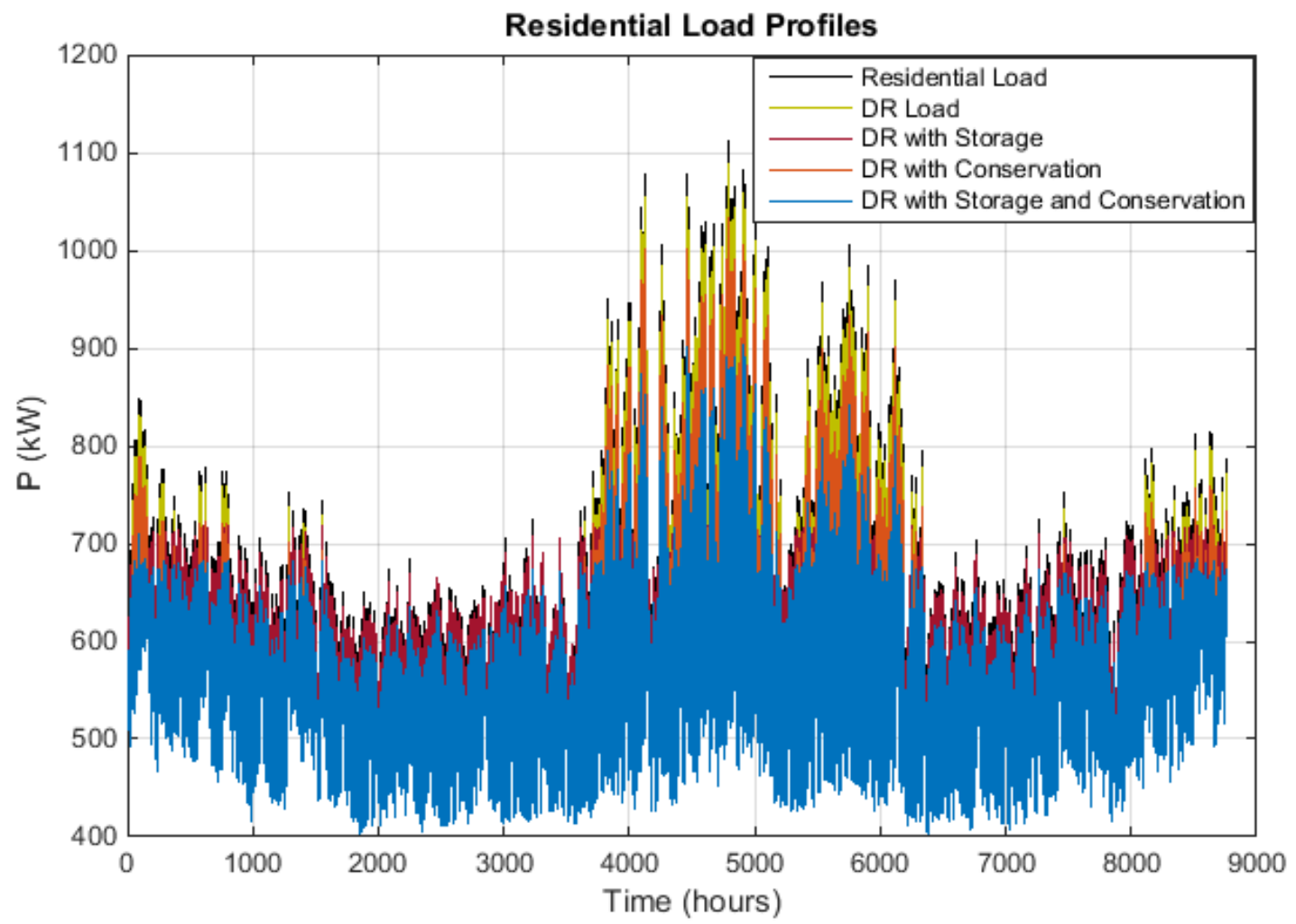

Figure 6-24: Residential Load profile and generation mix, from the IEEE test system, for 2017 for all MCDM alternatives 
The results also show the environmental footprints is different for each scenario. Table 6-8 demonstrates the emissions from the emitted sources after integrating ESS and energy conservation while the behavior of each source is explained in Figure 6-25.

Table 6-8: Emissions, from the IEEE Test System, after using ESS and Energy Conservation

\begin{tabular}{|l|c|c|c|c|}
\hline & $\begin{array}{c}\text { Base Case (tons of } \\
\mathrm{CO}_{2} \text { ) }\end{array}$ & $\begin{array}{c}\text { After ESS (tons of } \\
\left.\mathrm{CO}_{2}\right)\end{array}$ & $\begin{array}{c}\text { After Energy } \\
\text { Conservation } \\
\text { (tons of } \mathrm{CO}_{2} \text { ) }\end{array}$ & $\begin{array}{c}\text { After ESS and } \\
\text { Energy } \\
\text { Conservation } \\
\text { (tons of } \mathrm{CO}_{2}\end{array}$ \\
\hline Rawhide coal & 9,284 & 9,046 & 8,826 & 8,600 \\
\hline Craig coal (unit 1) & 2,361 & 2,361 & 2,244 & 2,244 \\
\hline Craig coal (unit 2) & 1,916 & 1,916 & 1,821 & 1,821 \\
\hline Rawhide CTs & 130 & 130 & 123 & 123 \\
\hline
\end{tabular}

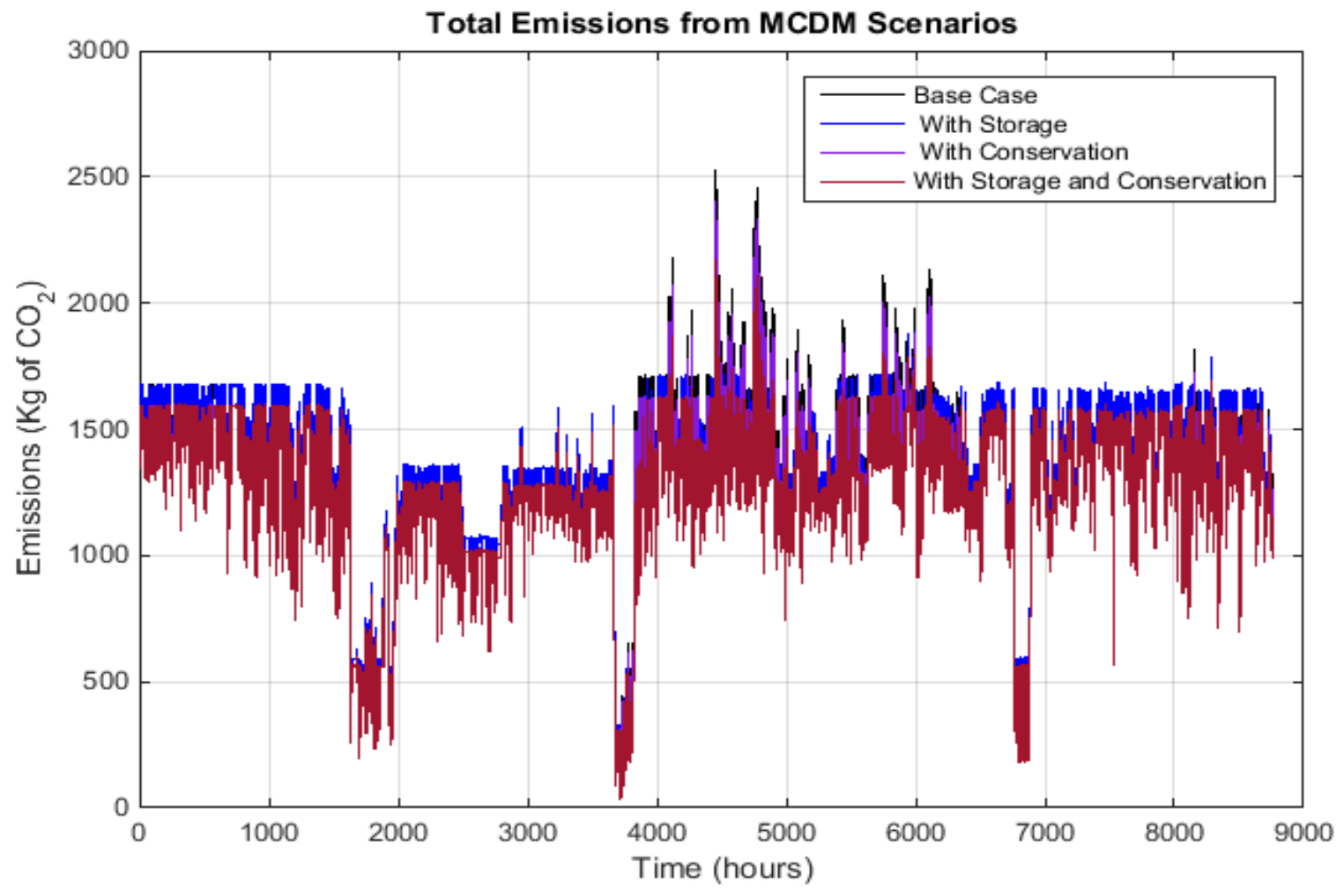

Figure 6-25: Emissions from electricity sector, from the IEEE test system, for 2017 after ESS and energy conservation 
Table 6-9 shows the percentage of emissions reduction from each scenario. The values indicate that the MCDM options can help in a meaningful reduction in total emissions. It is obvious that merging ESS with energy conservation provides more improvement in environmental footprints.

Table 6-9: Emissions reduction, from the IEEE Test System, after integrating ESS and Energy Conservation

\begin{tabular}{|l|c|c|}
\hline \multicolumn{1}{|c|}{ Scenario } & Emissions (tons of $\mathrm{CO}_{2}$ ) & Reduction from 2005 Level (\%) \\
\hline 2005 level & 16,350 & -- \\
\hline Base case & 13,692 & $16.26 \%$ \\
\hline ESS & 13,385 & $18.13 \%$ \\
\hline Energy conservation & 13,016 & $20.39 \%$ \\
\hline ESS and energy conservation & 12,725 & $22.17 \%$ \\
\hline
\end{tabular}

By including residential DR as a representing technique for communication and intelligence, the residential sector can save up to $20 \%$ of 2005 electric residential sector emissions. Table 6-10 explains the emissions per source from electric residential sector. Further, Figure 6-26 illustrates the hourly emissions in 2017 per source.

Table 6-10: Emissions, from the IEEE Test System, for all MCDM alternatives

\begin{tabular}{|l|c|c|c|c|c|}
\hline Scenario & $\begin{array}{c}\text { Residential } \\
\text { Base Case } \\
\text { (tons of } \\
\left.\mathrm{CO}_{2}\right)\end{array}$ & $\begin{array}{c}\text { After } \\
\text { Residential } \\
\text { DR (tons of } \\
\mathrm{CO}_{2}\end{array}$ & $\begin{array}{c}\text { After Residential } \\
\text { DR with ESS (tons } \\
\left.\text { of } \mathrm{CO}_{2}\right)\end{array}$ & $\begin{array}{c}\text { After Residential } \\
\text { DR with Energy } \\
\text { Conservation } \\
\left.\text { (tons of } \mathrm{CO}_{2}\right)\end{array}$ & $\begin{array}{c}\text { After combining } \\
\text { All options (tons } \\
\left.\text { of } \mathrm{CO}_{2}\right)\end{array}$ \\
\hline $\begin{array}{l}\text { Rawhide } \\
\text { coal }\end{array}$ & 2,972 & 2,960 & 2,891 & 2,818 & 2,753 \\
\hline $\begin{array}{l}\text { Craig } \\
\text { coal (unit } \\
\text { 1) }\end{array}$ & 755 & 750 & 752 & 716 & 716 \\
\hline $\begin{array}{l}\text { Craig } \\
\text { coal (unit } \\
2)\end{array}$ & 613 & 610 & 610 & 581 & 581 \\
\hline $\begin{array}{l}\text { Rawhide } \\
\text { CTs }\end{array}$ & 41 & 40 & 20 & 38 & 19 \\
\hline
\end{tabular}


Total Emissions from Residential Sector

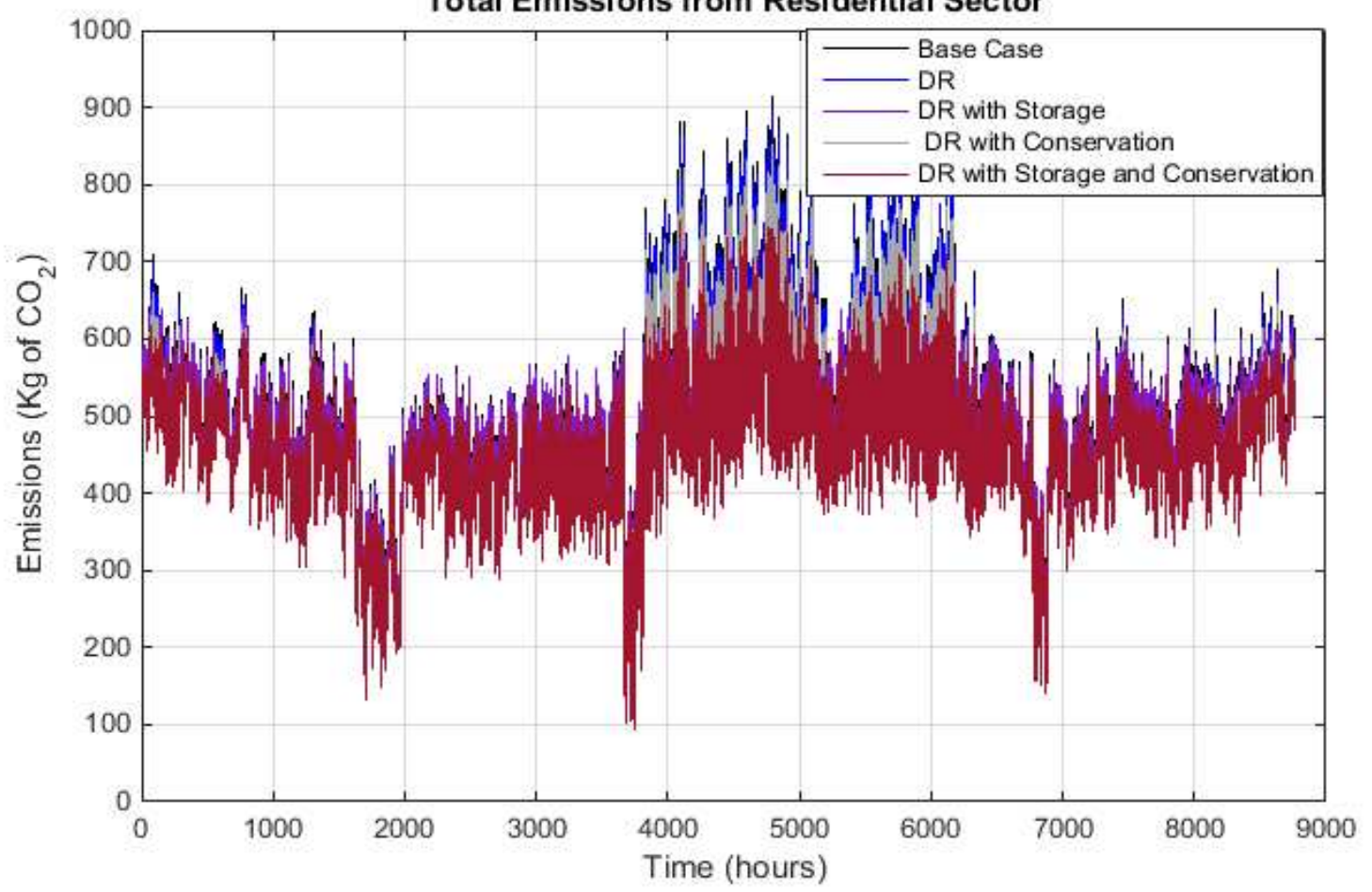

Figure 6-26: Emissions from the electricity residential sector, from the IEEE test system, for 2017 for all MCDM alternatives

The results indicate that applying all the MCDM options together in the electricity residential sector can provide the highest reduction in emissions as shown in Table 6-11.

Table 6-11: Emissions from the electricity residential sector, from the IEEE Test System, for all MCDM alternatives

\begin{tabular}{|l|c|c|}
\hline \multicolumn{1}{|c|}{ Scenario } & Emissions (tons of $\mathrm{CO}_{2}$ ) & Reduction from 2005 Level (\%) \\
\hline 2005 level & 5,068 & -- \\
\hline Base case & 4,382 & $13.54 \%$ \\
\hline Residential DR & 4,363 & $13.91 \%$ \\
\hline Residential DR and ESS & 4,274 & $15.68 \%$ \\
\hline Residential DR and energy conservation & 4,154 & $18.04 \%$ \\
\hline $\begin{array}{l}\text { Residential DR with ESS and energy } \\
\text { conservation }\end{array}$ & 4,069 & $19.72 \%$ \\
\hline
\end{tabular}




\subsection{Conclusion}

This chapter presented a simulation study on the IEEE 13-node system through OpenDSS. The analysis includes examining the behavior of the demand curve for the first-three MCDM alternatives; communication and intelligence, ESS, and energy conservation. It also quantifies the impact of the proposed alternatives in reducing environmental footprints. The results show combining ESS and conservation programs can achieve a meaningful impact on the entire system. Moreover, employing communicating and intelligence in the residential sector helps in achieving the city's target for emissions reduction. The analysis on the residential sector shows merging all the MCDM options can help Fort Collins in meeting their 2020 goal. However, this analysis is implemented based on environmental evaluation only and other factors can affect this ranking. Thus, it is important to investigate those alternatives from another perspective. In that regard, the next chapter will perform economic evaluation for all alternatives. Hence, Chapter 7 will conduct a CBA to study economic, technical, and environmental cost and benefits associated with each alternative. 


\section{CHAPTER 7}

\section{ECONOMIC EVALUATION ${ }^{6}$}

\subsection{Introduction}

This chapter presents an economic analysis, using $\mathrm{CBA}$, on the MCDM alternatives. $\mathrm{CBA}$ is an analytical tool used to help decision-makers justify different options by making judgments and evaluating the available options in turn. $\mathrm{CBA}$ is an economic tool that assists in determining the worth of a project or resource. Hence, it identifies and evaluates the benefits and costs associated with investing in such decisions. This chapter employs a CBA to calculate the expected costs and the estimated benefits in given alternatives to determine options that maximize benefits and reduce costs [99].

\subsection{CBA process}

The aim of using CBA is to make an assessment for each scenario and to quantify the net benefit to the system. This analysis evaluates the costs and benefits associated with each solution proposed to reduce emissions. The analysis quantifies environmental, technical, and economic costs and benefits. This evaluation should explain all costs associated with each alternative such as fixed costs, operating and maintenance costs, and customer dropout and removal costs. Benefits can be a reduction in the costs of generation, transmission, and distribution. Additionally, there can be customer benefits such as reducing the cost of electricity bill or utility benefits such as lowering cost of services or improving operation and efficiency. Social benefits such as reducing environmental degradation, conserving resources, or protecting the global environment are also considered. A key issue is the monetization of environmental and social impacts. A social cost of carbon emissions and a carbon price resulted from climate policies are two proposed approaches to establish monetary values for emissions $[100,101]$.

${ }^{6}$ Part of this chapter is verbatim reproduced from [37], and it is submitted to the Journal of Energy Transitions at the time of writing this dissertation 
CBA follows several steps to select the potential optimal alternative. The first step is to specify the set of alternative options. The next step is to define the boundaries of the analysis to explain which benefits and costs are included. Step three is to select indicators before measuring all costs and benefits of the selected measurements. Then, we monetize all costs and benefits before applying a discount rate to calculate the Net Present Value (NPV). The last step is to calculate NPV, Internal Rate of Return (IRR), the payback period, and Benefit to Cost Ratio (BCR) to select the most economically beneficial alternative for reducing emissions in this particular distribution system. The NPV computes all expected cash flows associated with the project and subtracts it from the capital cost $[65,102,103]$. Thus, the NPV of any project is

$$
\mathrm{NPV}=\sum_{t=1}^{T} \frac{C F_{t}}{(1+r)^{t}}-C F_{0}
$$

where $\mathrm{T}$ is the period of the project, $r$ is the discount rate, $C F_{0}$ is investment cost, $C F_{t}$ is the net cash flow at time $t$. The project is accepted if NPV $>0$ while the decision maker rejects the project when NPV $<$ 0. IRR is another metric that measures the profitability of the project. So, the IRR is the discount rate that makes the NPV equals zero.

$$
\mathrm{IRR}=\mathrm{NPV}=\sum_{t=1}^{T} \frac{C F_{t}}{(1+r)^{t}}-C F_{0}=0
$$

The payback period is the time required to recover the capital investment in a project. The cash flow is summed until it equals the initial investment in the project. Benefit to cost ratio, BCR, is another useful measure that summarizes the relationship between the related costs and benefits of the project. The benefits exceed the costs when $\mathrm{BCR}>1$ and the project should be accepted. When $\mathrm{BCR}=1$, the project indicates that the costs and benefits are equal, and the project can be accepted with little viability. If BCR $<1$, it means the costs are higher than the benefits, and the project should be rejected $[65,102,103]$. 


$$
\mathrm{BCR}=\frac{\text { Present value of benefits }}{\text { Present value of costs }}
$$

The next section deploys CBA to estimate all costs and benefits which determine the best approach to achieving the goal.

\subsection{Economic analysis of MCDM alternatives}

This section investigates the benefits and costs of integrating DSM alternatives programs to the distribution system. Such analysis quantifies all the associated costs, and measures the estimated benefits for each scenario. Since each scenario has its own costs parameters, the costs vary based on the specified alternative. Further, the benefits obtained from every scenario take into account the revenue from the avoided operating and maintenance costs or bill reduction. It also monetizes the impact of every scenario on power quality, reliability, environmental collateral, and socioeconomic equity. Final results will show a rank the weighted value for each scenario to choose the one that gives the highest benefit over cost. It also allows the participant to trade off the proposed scenarios to choose the option with the best environmental impact for economic output and vice versa.

\subsubsection{ESS}

As explained in Section 6.3, ESS is dispatched during peak hours to shave the demand and avoid running resources like coal. While ESS has a capacity of $50 \mathrm{MW}, 200 \mathrm{MWh}$, and serving for 4-hour peak load, this capacity is adjusted to match the IEEE 13-node system capacity. The new size of ESS is scaled down to $270.98 \mathrm{~kW}$ for 4-hour peak shaving (i.e. $1083.93 \mathrm{kWh}$ ). In that regard, PRPA proposes the estimated cost range of ESS for peak shaving. According to [93], the battery cost ranges between $\$ 340$ and $\$ 450$ per kWh. Power Conversion System (PCS) costs $\$ 150$ to $\$ 350$ per kW while power control system starts from $\$ 80$ to $\$ 120 / \mathrm{kW}$. Balance of plant could cost $\$ 90$ up to $\$ 120$ per $\mathrm{kW}$, and procurement construction costs $\$ 150$ to $\$ 180 / \mathrm{kWh}$. Further, this study adjusts the cost of recycling to the size of the ESS used in the test system [104]. Since this is an economic evaluation for a new technology in the system, we take into account the worst-case scenario. 
Hence, the analysis considers the highest price for each parameter. The prices for installing ESS are explained in Table 7-1, taken from [105].

Table 7-1: ESS Estimated Prices

\begin{tabular}{|c|c|}
\hline Item & Price \\
\hline Battery $(\$ / \mathrm{kWh})$ & 450 \\
\hline Power conversion system $(\$ / \mathrm{kW})$ & 350 \\
\hline Power control system $(\$ / \mathrm{kW})$ & 120 \\
\hline Balance of plant $(\$ / \mathrm{kW})$ & 120 \\
\hline Procurement construction $(\$ / \mathrm{kWh})$ & 180 \\
\hline Fixed O\&M cost $(\$ / \mathrm{kW}$ year $)$ & 14 \\
\hline Variable cost $(\$ / \mathrm{kWh})$ & 0.0703 \\
\hline
\end{tabular}

A research study in [105] estimates the discount rate for a storage system project is $5.09 \%$ while PRPA expects a 10 years lifetime for the ESS project. Further, EIA estimates the average load growth is $0.2 \%$ which is the load growth assumed in this calculation [106]. As PRPA proposes ESS to relief the stress on the system, all the costs and outcomes are studies based on the utility perspective. After performing a CBA, Table 7-2 illustrates all associated costs for installing ESS. 
Table 7-2: Associated Costs of ESS Project

\begin{tabular}{|c|c|c|c|c|c|c|c|c|c|}
\hline & Battery (\$) & $\operatorname{PCS}(\$)$ & $\begin{array}{c}\text { Power } \\
\text { Control } \\
\text { System } \\
(\$)\end{array}$ & $\begin{array}{c}\text { Balance of } \\
\text { Plant }(\$)\end{array}$ & $\begin{array}{c}\text { Procurement } \\
\text { Construction } \\
(\$)\end{array}$ & $\begin{array}{c}\text { Recycling } \\
(\$)\end{array}$ & $\begin{array}{c}\text { Fixed } \\
\text { O\&M } \\
\text { Cost }(\$)\end{array}$ & $\begin{array}{l}\text { Variable } \\
\text { Cost }(\$)\end{array}$ & $\begin{array}{c}\text { Total Cost } \\
(\$)\end{array}$ \\
\hline Investment & 487,773 & 94,845 & 32,518 & 130,073 & 48,777 & & & & 793,986 \\
\hline $1 \mathrm{Y}$ & & & & & & & 3,794 & 23,640 & 27,433 \\
\hline $2 \mathrm{Y}$ & & & & & & & 3,801 & 23,687 & 27,488 \\
\hline $3 \mathrm{Y}$ & & & & & & & 3,809 & 23,734 & 27,543 \\
\hline $4 \mathrm{Y}$ & & & & & & & 3,817 & 23,782 & 27,598 \\
\hline $5 \mathrm{Y}$ & & & & & & & 3,824 & 23,829 & 27,654 \\
\hline $6 Y$ & & & & & & & 3,832 & 23,877 & 27,709 \\
\hline $7 \mathrm{Y}$ & & & & & & & 3,840 & 23,925 & 27,764 \\
\hline $8 Y$ & & & & & & & 3,847 & 23,973 & 27,820 \\
\hline $9 \mathrm{Y}$ & & & & & & & 3,855 & 24,021 & 27,876 \\
\hline $10 \mathrm{Y}$ & & & & & & 125,000 & 3,863 & 24,069 & 152,931 \\
\hline Total & 487,773 & 94,845 & 32,518 & 130,073 & 48,777 & 125,000 & 38,281 & 238,536 & $1,195,803$ \\
\hline
\end{tabular}


The benefits of installing ESS can be measured as a fuel saving cost, network support, or environmental benefits. The work in [105] concludes that integrating a storage system in the grid would improve DG integration by increasing electricity utilization. EIA determines a levelized avoided cost for resources like coal and natural gas. This calculation uses a $\$ 0.082$ and $\$ 0.080$ per kWh for coal and natural gas, respectively, to estimate the cost of fuel saving [107]. According to [108], there is a social cost of using fossil fueled generating units in which the environmental cost is $\$ 11$ per $\mathrm{Kg}$ of $\mathrm{CO}_{2}$ and the cost will increase to reach $\$ 26$ per $\mathrm{Kg}$ of $\mathrm{CO}_{2}$ by 2050 . Thus, the avoided emissions, as a result of enabling ESS, is multiplied by $\$ 11$ to quantify the environmental benefits. According to [105], the benefit of utilizing DG is $\$ 52.28 / \mathrm{MWh}$, avoided from conventional resources. Maintaining acceptable limits of power quality and reliability could save up to $\$ 62.71$ per kW. The estimated benefits of integrating ESS in the distribution system is shown in Table 7-3.

Table 7-3: Estimated Benefits of ESS Project

\begin{tabular}{|c|c|c|c|c|c|}
\hline & Fuel Saving & Environmental benefit & DG Integration & Network & Total Benefit \\
& $(\$)$ & $(\$)$ & $(\$)$ & Support $\$)$ & $(\$)$ \\
\hline $1 \mathrm{Y}$ & 26,860 & 3,373 & 175,801 & 16,993 & 223,028 \\
\hline $2 \mathrm{Y}$ & 26,914 & 3,379 & 176,153 & 16,993 & 223,440 \\
\hline $3 \mathrm{Y}$ & 26,968 & 3,386 & 176,505 & 16,993 & 223,853 \\
\hline $4 \mathrm{Y}$ & 27,022 & 3,393 & 176,858 & 16,993 & 224,267 \\
\hline $5 \mathrm{Y}$ & 27,076 & 3,400 & 177,212 & 16,993 & 224,681 \\
\hline $6 \mathrm{Y}$ & 27,130 & 3,406 & 177,566 & 16,993 & 225,097 \\
\hline $7 \mathrm{Y}$ & 27,185 & 3,413 & 177,922 & 16,993 & 225,513 \\
\hline $8 \mathrm{Y}$ & 27,239 & 3,420 & 178,277 & 16,993 & 225,930 \\
\hline $9 \mathrm{Y}$ & 27,293 & 3,427 & 178,634 & 16,993 & 226,348 \\
\hline $10 \mathrm{Y}$ & 27,348 & 3,434 & 178,991 & 16,993 & 226,767 \\
\hline Total & 271,037 & 34,031 & $1,773,920$ & 169,935 & $2,248,923$ \\
\hline
\end{tabular}


Table 7-4 summarizes the findings from the economic evaluation. The project is beneficial since BCR is greater than 1, and the project will pay its capital cost after about 4 years.

Table 7-4: Economic Results for ESS Project
\begin{tabular}{|c|c|}
\hline NPV (\$) & 644,975 \\
\hline IRR & $20.40 \%$ \\
\hline Payback (years) & 4.05 \\
\hline BCR & 1.392 \\
\hline
\end{tabular}

Figure 7-1 shows cash flow and cumulative cash flow for ESS. In Figure 7-2, the project starts getting positive cash flow after the fourth year.

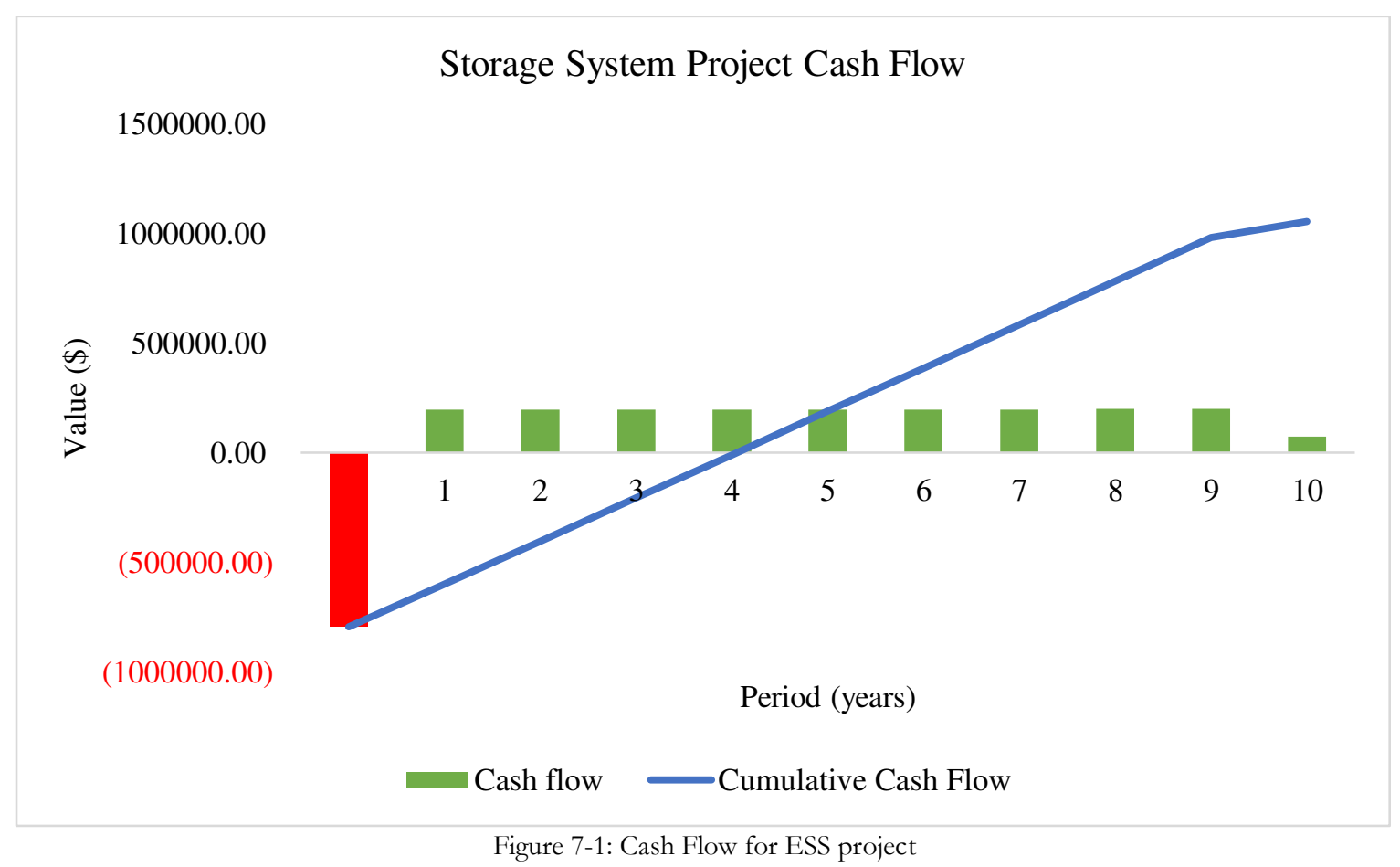

Figure 7-1: Cash Flow for ESS project 


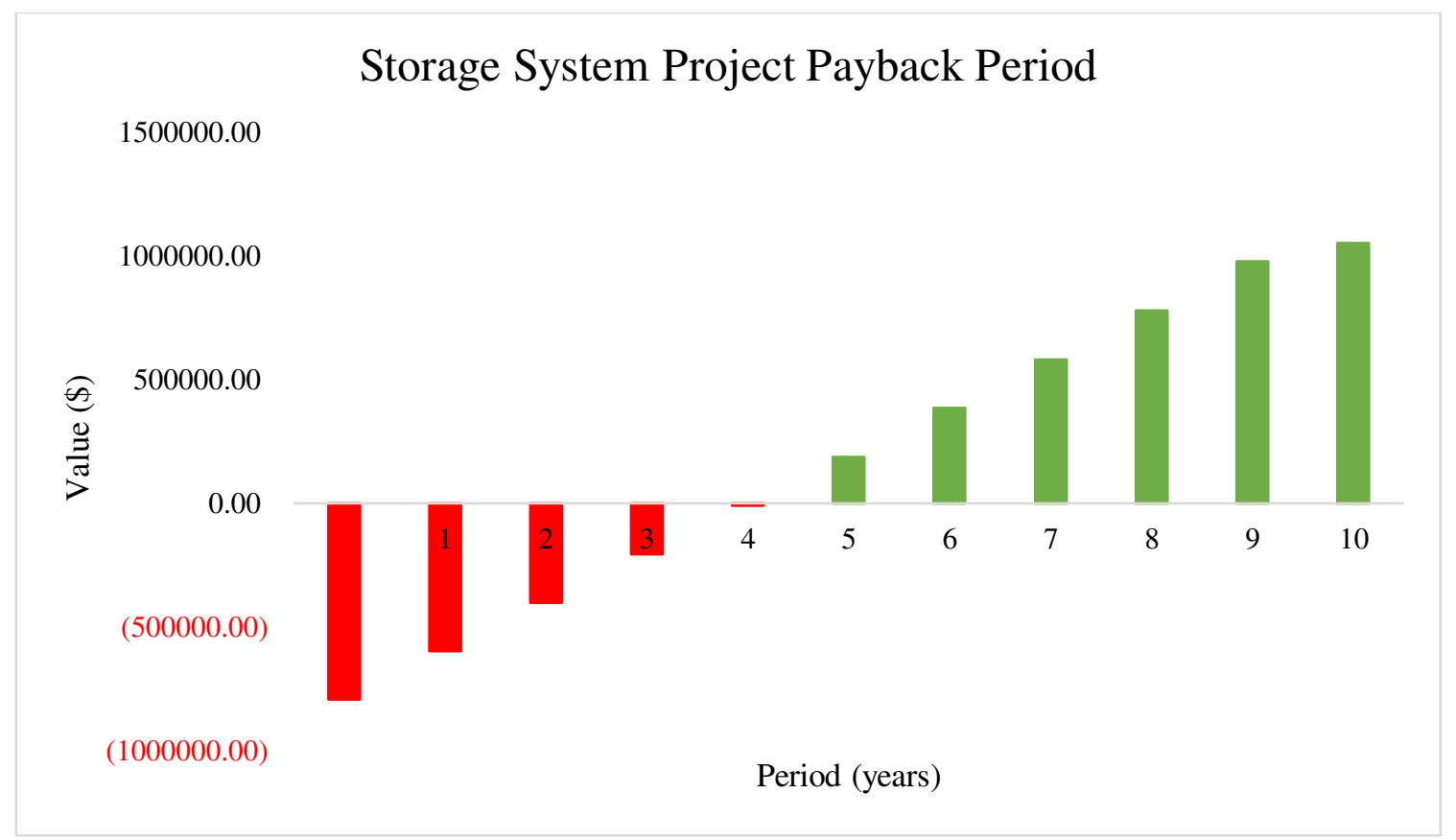

Figure 7-2: Payback period for ESS project

\subsubsection{Energy conservation}

The DOE explains the cost of implementing a conservation program in Fort Collins in [109]. This includes installing about 85,328 smart meters, 2,347 programmable communicating thermostats, and 1,710 direct load control devices. The investment cost of this energy conservation project is adjusted to the test system. Further, there is an operating cost to deploy such a project which is $\$ 0.035$ per $\mathrm{kWh}$ saved [110]. Implementing energy conservation programs can cause inconvenience for the participants. Therefore, this analysis defines socioeconomic cost as a societal cost. EPA estimates socioeconomic cost as $\$ 0.214$ per $\mathrm{kWh}$ [111]. Moreover, Fort Collins has a rebate program to replace the low efficient equipment with higher efficiency appliances [112]. Table 7-5 illustrates the utility costs of deploying energy conservation project. 
Table 7-5: Associated Costs of Energy Conservation Project

\begin{tabular}{|c|c|c|c|c|c|}
\hline & $\begin{array}{c}\text { Capital Cost } \\
(\$)\end{array}$ & Program Cost (\$) & $\begin{array}{c}\text { Socioeconomic } \\
\text { Cost }(\$)\end{array}$ & Rebate $(\$)$ & Total Cost $(\$)$ \\
\hline Investment & 216,188 & & & 217,532 \\
\hline $1 Y$ & & 30,165 & 184,437 & 214,602 \\
\hline $2 Y$ & & 30,225 & 184,806 & 215,031 \\
\hline $3 Y$ & & 30,286 & 185,175 & 215,461 \\
\hline $4 Y$ & 30,346 & 185,546 & 215,892 \\
\hline $5 Y$ & & 30,407 & 185,917 & 216,324 \\
\hline $6 Y$ & & 30,468 & 186,289 & & 216,756 \\
\hline $7 Y$ & & 30,529 & 186,661 & & 217,190 \\
\hline $8 Y$ & & 30,590 & 187,034 & & 217,624 \\
\hline $9 Y$ & & 30,651 & 187,408 & & 218,059 \\
\hline $10 Y$ & & 30,712 & 187,783 & 1,344 & 218,496 \\
\hline Total & 216,188 & 304,378 & $1,861,056$ & 1,344 & $2,382,966$ \\
\hline
\end{tabular}

The benefits obtained from reducing the energy demand and mitigating environmental footprints are calculated as explained in subsection 7.3.1. The report from [109] shows the utility avoided and deferred costs after implementing the conservation project while the socioeconomic benefit is obtained, from [111] after excluding avoided carbon cost. Table 7-6 presents the benefits yielding the utility uses the conservation program.

Table 7-6: Estimated Benefits for Energy Conservation Project

\begin{tabular}{|l|c|c|c|c|c|c|c|}
\hline & $\begin{array}{c}\text { Fuel } \\
\text { Saving } \\
(\$)\end{array}$ & $\begin{array}{c}\text { Reduced } \\
\text { O\&M } \\
\text { Cost }(\$)\end{array}$ & $\begin{array}{c}\text { Environmental } \\
\text { Benefit }(\$)\end{array}$ & $\begin{array}{c}\text { Deferred } \\
\text { Investment } \\
(\$)\end{array}$ & $\begin{array}{c}\text { Network } \\
\text { Support } \\
(\$)\end{array}$ & $\begin{array}{c}\text { Socioeconomic } \\
\text { Benefit }(\$)\end{array}$ & $\begin{array}{c}\text { Total } \\
\text { Benefit } \\
(\$)\end{array}$ \\
\hline $1 \mathrm{Y}$ & 96,709 & 4,811 & 7,431 & 1,626 & 2,168 & 142,206 & 254,951 \\
\hline $2 \mathrm{Y}$ & 96,902 & 4,821 & 7,446 & 1,629 & 2,172 & 142,490 & 255,461 \\
\hline $3 \mathrm{Y}$ & 97,096 & 4,830 & 7,461 & 1,632 & 2,177 & 142,775 & 255,972 \\
\hline $4 \mathrm{Y}$ & 97,290 & 4,840 & 7,476 & 1,636 & 2,181 & 143,061 & 256,484 \\
\hline $5 \mathrm{Y}$ & 97,485 & 4,850 & 7,491 & 1,639 & 2,185 & 143,347 & 256,997 \\
\hline $6 \mathrm{Y}$ & 97,680 & 4,859 & 7,506 & 1,642 & 2,190 & 143,634 & 257,511 \\
\hline $7 \mathrm{Y}$ & 97,875 & 4,869 & 7,521 & 1,646 & 2,194 & 143,921 & 258,026 \\
\hline $8 \mathrm{Y}$ & 98,071 & 4,879 & 7,536 & 1,649 & 2,198 & 144,209 & 258,542 \\
\hline $9 \mathrm{Y}$ & 98,267 & 4,889 & 7,551 & 1,652 & 2,203 & 144,497 & 259,059 \\
\hline $10 \mathrm{Y}$ & 98,463 & 4,898 & 7,566 & 1,655 & 2,207 & 144,786 & 259,577 \\
\hline Total & 975,837 & 48,546 & 74,987 & 16,406 & 21,875 & $1,434,926$ & $2,572,578$ \\
\hline
\end{tabular}


Table 7-7 demonstrates the final calculation for the energy conservation project. Although the project is acceptable, the project takes a longer time than ESS to recover its expenses.

Table 7-7: Economic Results for Energy Conservation Project

\begin{tabular}{|c|c|}
\hline NPV (\$) & 95,229 \\
\hline IRR & $13.34 \%$ \\
\hline Payback (years) & 5.37 \\
\hline BCR & 1.051 \\
\hline
\end{tabular}

The economic behavior of this project is shown in Figure 7-3, and Figure 7-4 clarifies that the project requires half its lifetime to recover its expenses.

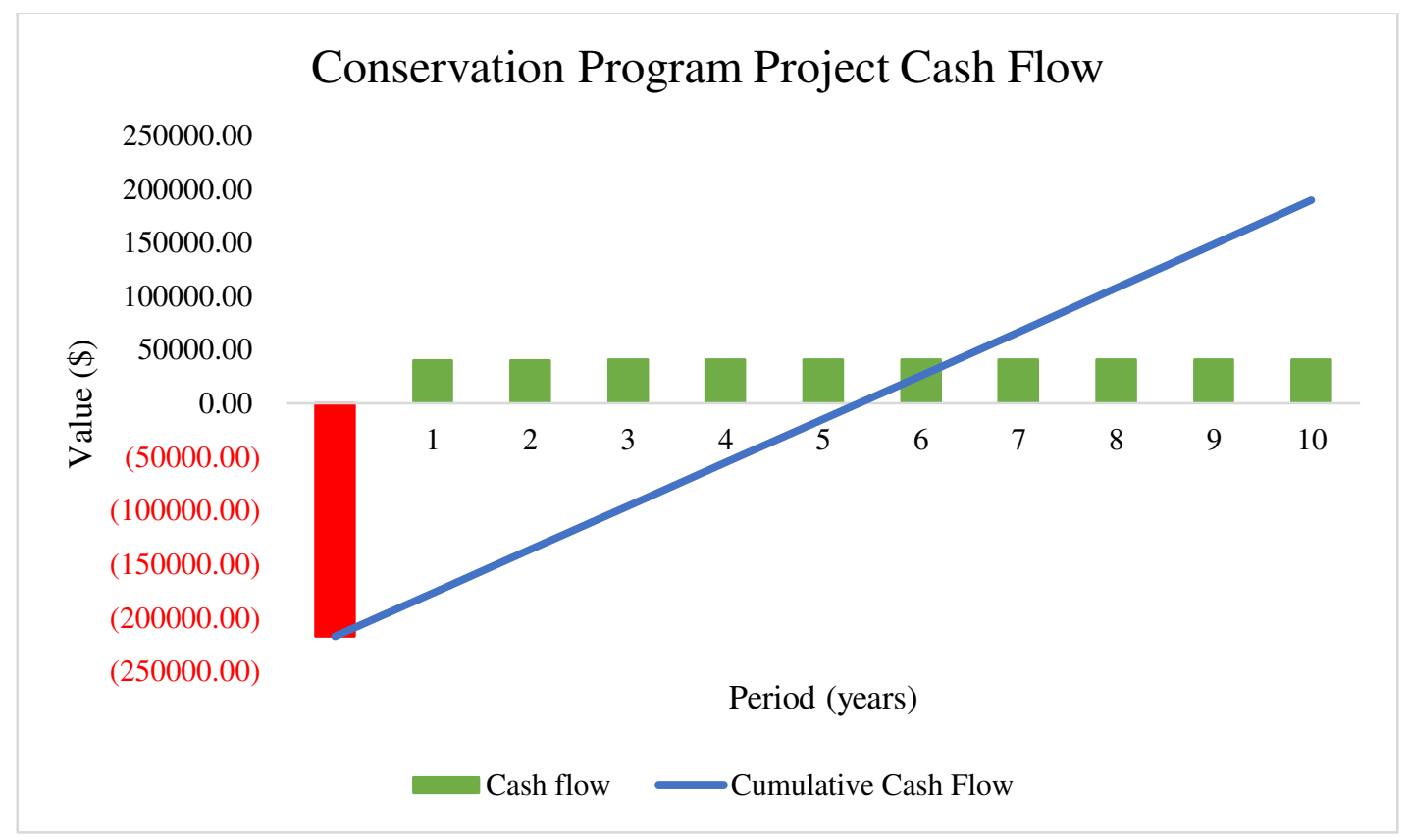

Figure 7-3: Cash Flow for energy conservation project 


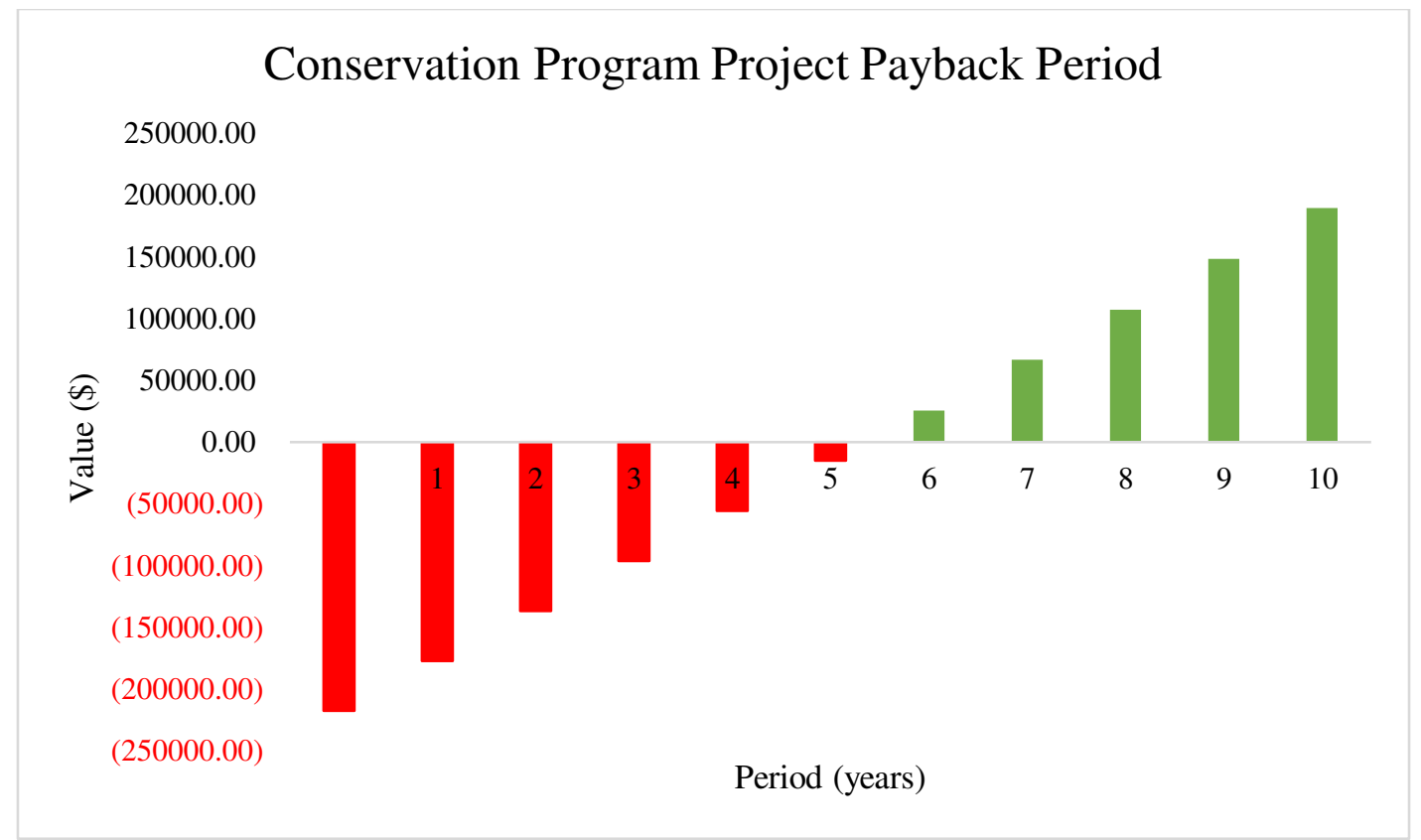

Figure 7-4: Payback period for energy conservation project

\subsubsection{ESS with energy conservation}

The economic analysis of this scenario includes all the expected costs from ESS and energy conservation. Table 7-8 states all the expenses needed to deploy this project. We notice that the final cost after 10 years is higher than expected. This is reasonable since this scenario has a capital cost and higher operating costs. After calculating the outcomes of this scenario, it saves energy more than expected since ESS and efficient appliances are displacing the energy needed from other resources. Table 7-9 shows all the expected benefits from this scenario. 
Table 7-8: Estimated Costs of combining ESS with Energy Conservation

\begin{tabular}{|c|c|c|c|c|c|c|c|c|c|c|c|c|c|}
\hline & $\begin{array}{l}\text { Battery } \\
\text { (\$) }\end{array}$ & PCS (\$) & $\begin{array}{c}\text { Power } \\
\text { Control } \\
\text { System } \\
(\$) \\
\end{array}$ & $\begin{array}{c}\text { Balance } \\
\text { of plant } \\
(\$)\end{array}$ & $\begin{array}{c}\text { Procurement } \\
\text { Construction } \\
\quad \text { (\$) }\end{array}$ & $\begin{array}{c}\text { Conservation } \\
\text { Capital cost } \\
\text { (\$) }\end{array}$ & $\begin{array}{l}\text { Socioeconomic } \\
\text { Cost }\end{array}$ & $\begin{array}{c}\text { Fixed } \\
\text { O\&M } \\
\text { Cost } \\
(\$) \\
\end{array}$ & $\begin{array}{l}\text { Variable } \\
\text { Cost (\$) }\end{array}$ & $\begin{array}{l}\text { Conservation } \\
\text { Program } \\
\text { Cost } \$ \text { (\$) }\end{array}$ & $\begin{array}{l}\text { Recycling } \\
\text { (\$) }\end{array}$ & $\begin{array}{c}\text { Rebate } \\
(\$)\end{array}$ & $\begin{array}{c}\text { Total Cost } \\
\text { (\$) }\end{array}$ \\
\hline Investment & 439,898 & 85,453 & 29,298 & 117,306 & 43,947 & 216,188 & & & & & & & 932,089 \\
\hline $1 \mathrm{Y}$ & & & & & & & 184,437 & 3,598 & 22,458 & 30,165 & & & 240,657 \\
\hline $2 \mathrm{Y}$ & & & & & & & 184,806 & 3,605 & 22,503 & 30,225 & & & 241,139 \\
\hline $3 Y$ & & & & & & & 185,175 & 3,612 & 22,548 & 30,286 & & & 241,621 \\
\hline $4 \mathrm{Y}$ & & & & & & & 185,546 & 3,620 & 22,593 & 30,346 & & & 242,104 \\
\hline $5 \mathrm{Y}$ & & & & & & & 185,917 & 3,627 & 22,638 & 30,407 & & & 242,588 \\
\hline $6 \mathrm{Y}$ & & & & & & & 186,289 & 3,634 & 22,683 & 30,468 & & & 243,074 \\
\hline $7 Y$ & & & & & & & 186,661 & 3,641 & 22,729 & 30,529 & & & 243,560 \\
\hline $8 Y$ & & & & & & & 187,034 & 3,649 & 22,774 & 30,590 & & & 244,047 \\
\hline $9 \mathrm{Y}$ & & & & & & & 187,409 & 3,656 & 22,820 & 30,651 & & & 244,535 \\
\hline $10 \mathrm{Y}$ & & & & & & & 187,783 & 3,663 & 22,865 & 30,712 & 125,000 & 1,344 & 371,368 \\
\hline Total & 439,898 & 85,453 & 29,298 & 117,306 & 43,947 & 216,188 & $1,861,056$ & 36,306 & 226,609 & 304,378 & 125,000 & 1,344 & $3,486,782$ \\
\hline
\end{tabular}


Table 7-9: Estimated Benefits of combining ESS with Energy Conservation Project

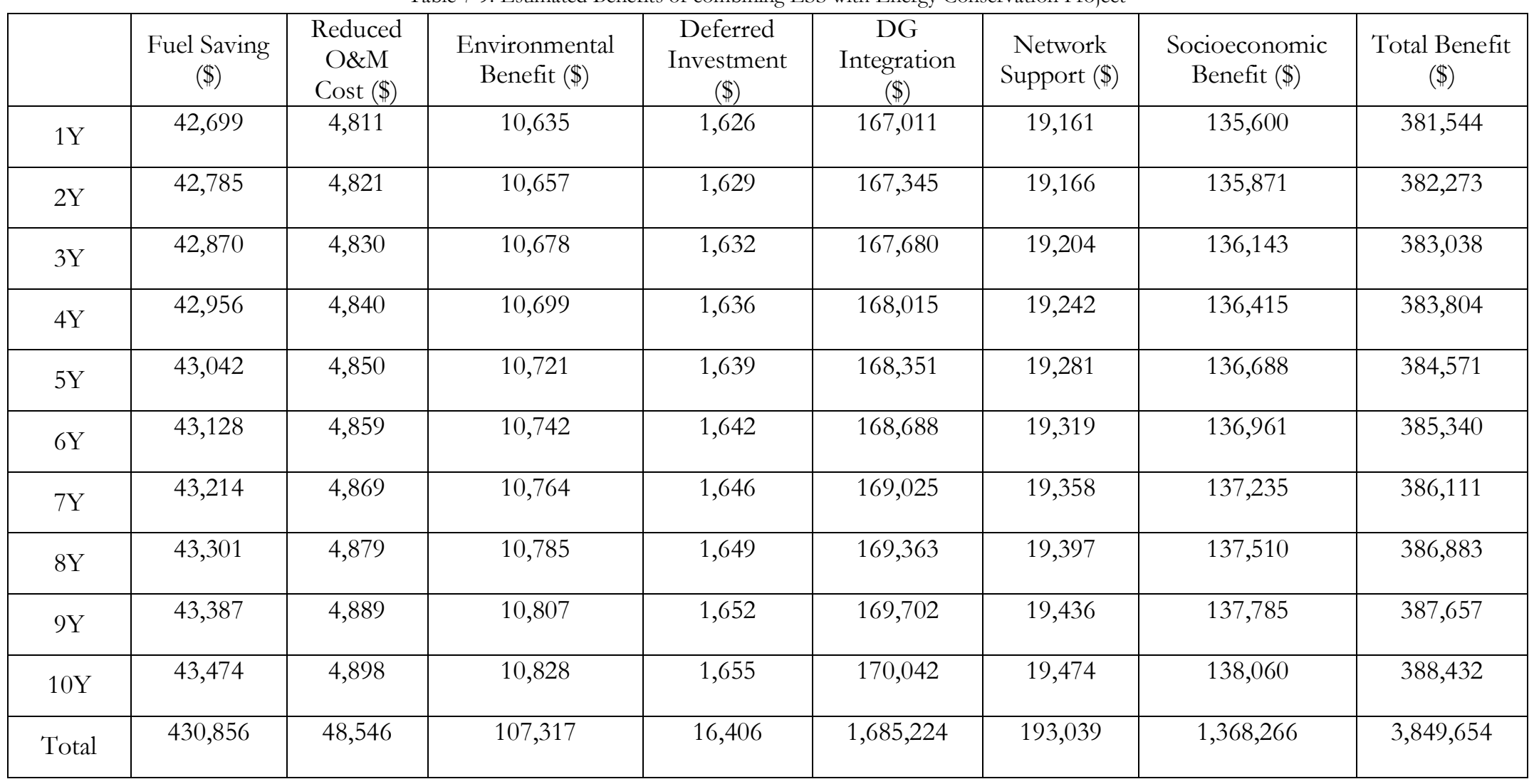


The results are not surprising since this scenario incorporates more cost. The project requires more than 6 years and 6 months to pay its investment cost. However, it is still economically acceptable. Table 7-10 gives an economic summary about merging ESS and conservation programs. Figure 7-5 and 7-6 represents the project's cash flow and the payback period, respectively.

Table 7-10: Economic Results after using ESS and Energy Conservation Project

\begin{tabular}{|c|c|}
\hline NPV $(\$)$ & 82,837 \\
\hline IRR & $7.02 \%$ \\
\hline Payback (years) & 6.58 \\
\hline BCR & 1.027 \\
\hline
\end{tabular}

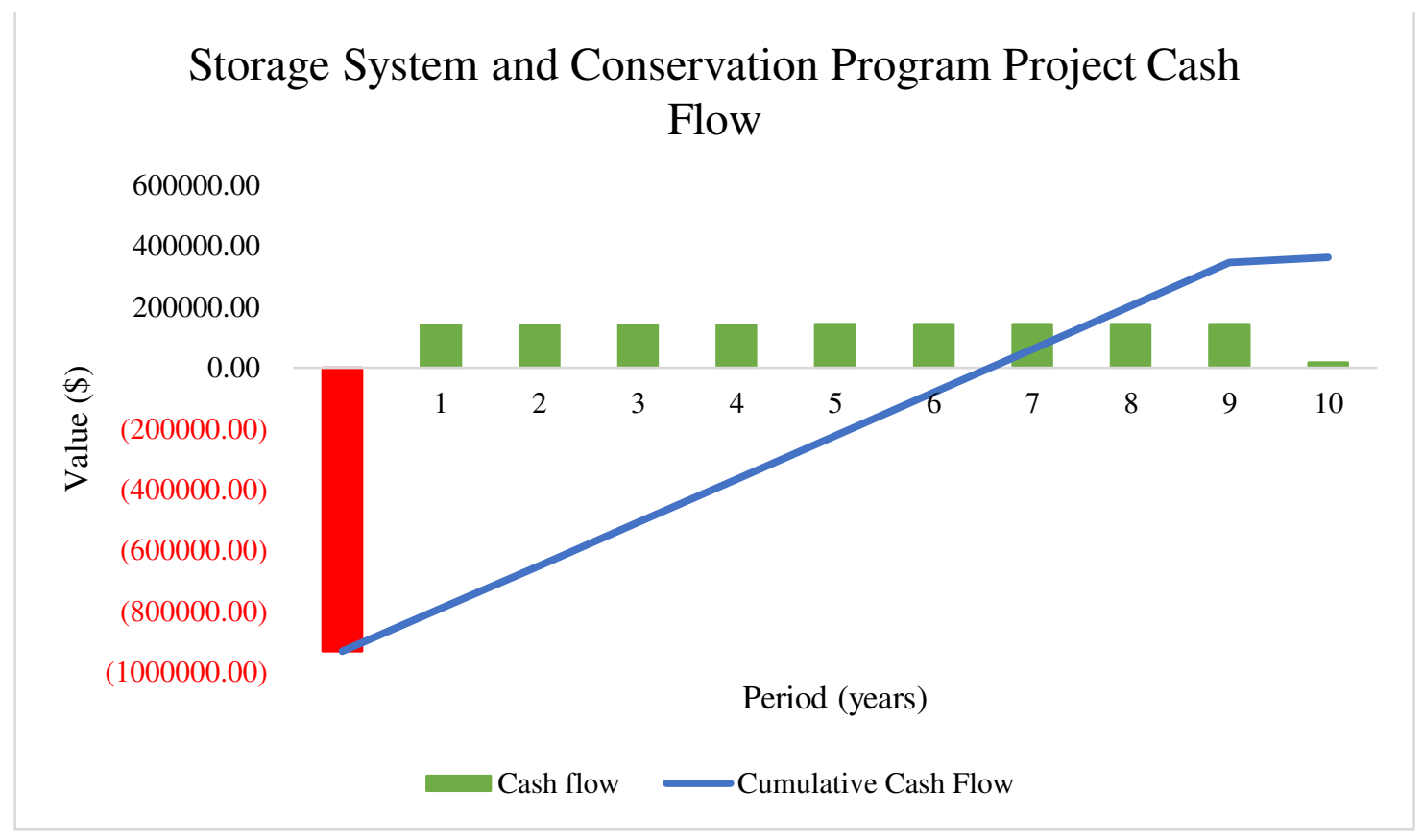

Figure 7-5: Cash Flow for the project of ESS with energy conservation 


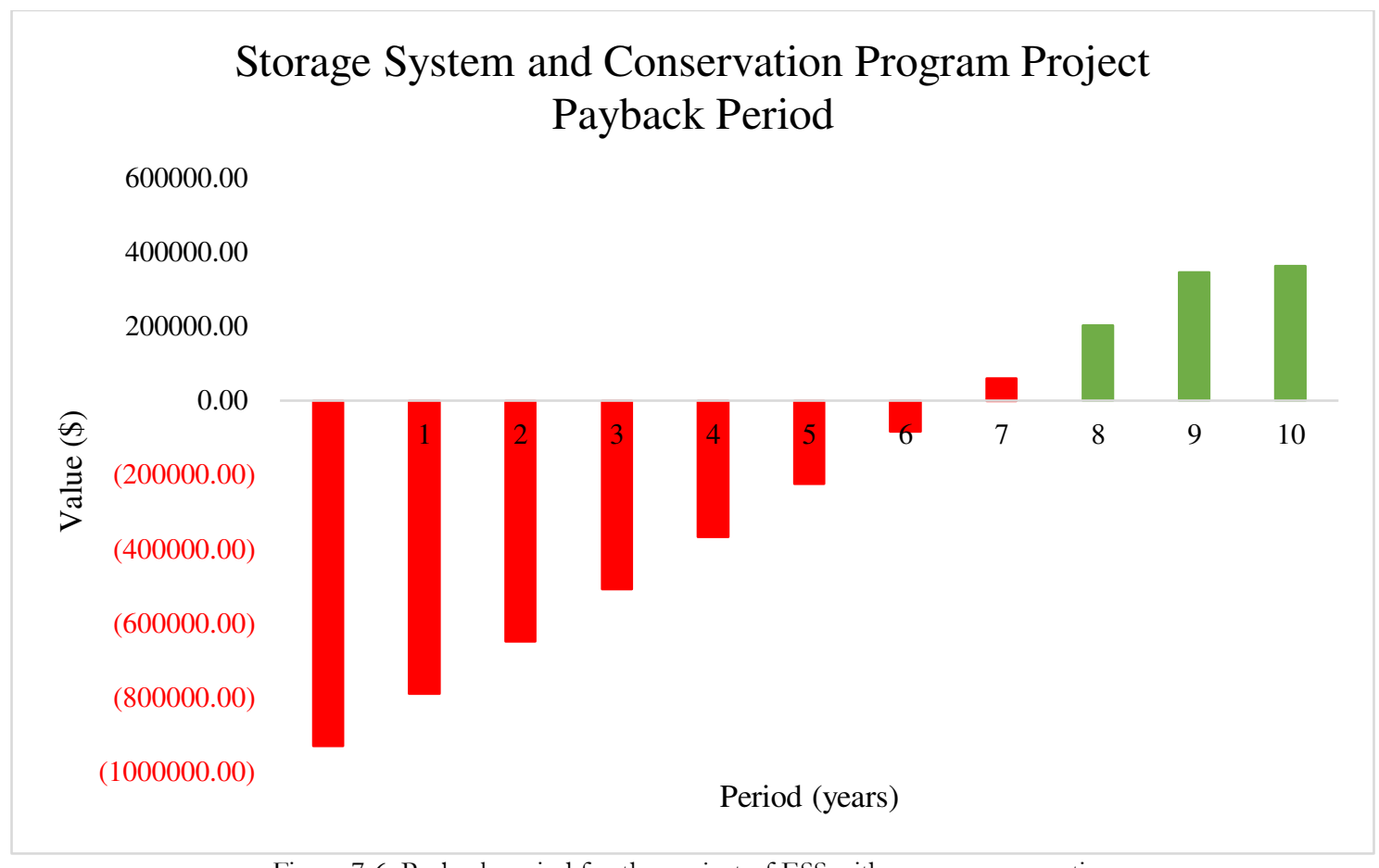

Figure 7-6: Payback period for the project of ESS with energy conservation 


\subsubsection{Communication and intelligence}

As explained in Chapter 6, the residential DR program represents communication and intelligence since this alternative leads to change the end-use demand curve. The economic evaluation of this option is implemented according the DR model in [65], which studies the system from the utility point of view. Since this alternative is deployed in the residential sector, the capital cost is excluded and scaled down from [109]. The energy cost, energy sales, and peak demand cost for the base case are calculated as follows [65]:

$$
\text { Energy cost }=Q^{*} \pi_{r}
$$

where $\mathrm{Q}$ is the energy consumption and $\pi_{r}$ is the retail price. PRPA determines the energy charges as $\$ 0.04282 / \mathrm{kWh}$ for summer season and $\$ 0.04109 / \mathrm{kWh}$ for winter season [113]. The energy sales before DR can be calculated from:

$$
\text { Energy sales }=D^{*} \pi_{w h}
$$

Where $D$ is the demand curve and $\pi_{w h}$ is the wholesale price. The utility charges the customers for energy usage based on the old electric rates for residential energy use, before DR. Table 7-11 shows the usage charge per $\mathrm{kWh}$, regenerated from [114].

Table 7-11: Residential Energy Rate before DR Program

\begin{tabular}{|l|c|c|}
\hline \multicolumn{1}{|c|}{ Usage Charge } & Summer Season & Non-Summer Season \\
\hline First $500 \mathrm{kWh}$ & $\$ 0.09582$ & $\$ 0.09031$ \\
\hline Next $500 \mathrm{kWh}$ & $\$ 0.11448$ & $\$ 0.09487$ \\
\hline All additional kWh & $\$ 0.15158$ & $\$ 0.10494$ \\
\hline
\end{tabular}

Monthly peak demand is the user's demand during the hour that coincides with the system's monthly peak. An $\$ 11.56$ charge is applied per $\mathrm{kW}$ as a demand charge for summer season and this charge decreases to $\$ 8.81 / \mathrm{kW}$ for non-summer times [113]. The utility applies a 60 -minute charge on coincident demand using: 


$$
\mathrm{PCD}=\sum_{m=1}^{12} \pi_{D C} * P_{m}
$$

where PCD is the peak demand charge, $P_{m}$ is the coincident peak demand, and $\pi_{D C}$ is the demand charge. The energy cost, energy sales, and peak demand cost for the DR are calculated for the modified energy consumption, Q':

$$
\text { Energy cost }=Q^{*} \pi_{r}
$$

The electricity sold after DR depends on the new demand curve, D', and the pricing mechanism, explained in Figure 6-10 and Figure 6-11:

$$
\text { Energy sales }=\mathrm{D}^{*} * \pi_{w h}
$$

While the peak demand charge, PCD', changes according to the new coincident peak demand, $\mathrm{P}_{\mathrm{m}}{ }^{\prime}$, the monthly peak demand rates remains the same during coincident demand:

$$
\mathrm{PCD}=\sum_{m=1}^{12} \pi_{D C} * P_{m}{ }^{\prime}
$$

The cost of incorporating such a technique requires evaluating the capital cost and the variable costs. According to [115], the variable cost of applying DR is adjusted, $\$ 28$ per $\mathrm{kW}$, to match the size of the test system. The operating and maintenance costs can be communications labor cost or controls labor cost [115]. The following equation shows all the associated costs of $\mathrm{DR}$ where $\mathrm{DR}_{\mathrm{inv}}$ is the investment cost of $\mathrm{DR}$ and $\mathrm{C}_{\mathrm{O} \& \mathrm{M}}$ is the annual operating and maintenance cost.

$$
\text { Total cost }=\mathrm{DR}_{\text {inv }}+\mathrm{C}_{\mathrm{O} \& \mathrm{M}}
$$

This alternative incurs a yearly financial benefit by obtaining the difference between the energy sales and the peak demand charges. Table 7-12 illustrates the first-year financial impact. 
Total benefits $=\sum_{t=1}^{8760}\left(P C D^{\prime}-P C D\right)+\left(\mathrm{D}^{\prime} * \pi_{w h}-\mathrm{D} * \pi_{w h}\right)$

Table 7-12: The First Year Financial Impact

\begin{tabular}{|c|c|c|c|c|}
\hline & Energy Sales (\$) & Energy Cost (\$) & Demand Charge (\$) & DR Cost (\$) \\
\hline Base case & 492,378 & 224,074 & 105,930 & \\
\hline DR & 595,012 & 221,440 & 103,694 & 67,018 \\
\hline
\end{tabular}

After performing a CBA, the economic analysis in Table 7-13 shows the cost of residential DR for 10 years.

Table 7-13: Associated Costs of Residential DR Project

\begin{tabular}{|c|c|c|c|}
\hline & Fixed Cost $(\$)$ & Variable Cost $(\$)$ & Total Cost $(\$)$ \\
\hline Investment & 67,018 & & 67,018 \\
\hline $1 \mathrm{Y}$ & & 100,156 & 100,156 \\
\hline $2 \mathrm{Y}$ & & 100,356 & 100,356 \\
\hline $3 \mathrm{Y}$ & & 100,557 & 100,557 \\
\hline $4 \mathrm{Y}$ & & 100,758 & 100,758 \\
\hline $5 \mathrm{Y}$ & & 100,960 & 100,960 \\
\hline $6 \mathrm{Y}$ & & 101,162 & 101,162 \\
\hline $7 \mathrm{Y}$ & & 101,364 & 101,364 \\
\hline $8 \mathrm{Y}$ & & 101,567 & 101,567 \\
\hline $9 \mathrm{Y}$ & & 101,770 & 101,770 \\
\hline $10 \mathrm{Y}$ & & 101,973 & 101,973 \\
\hline Total & 67,018 & $1,010,622$ & $1,077,640$ \\
\hline
\end{tabular}

The analysis shows several benefits from the program. As smart meters and thermostat devices are the enablers of residential DR, the analysis adjusted the expected benefits such as reduced cost and investment deferral from [109]. Table 7-14 summarizes the expected benefits after using residential DR. 
Table 7-14: Estimated Benefits of Applying Residential DR Project

\begin{tabular}{|c|c|c|c|c|c|c|c|}
\hline & $\begin{array}{c}\text { Sold } \\
\text { Electricity } \\
(\$)\end{array}$ & $\begin{array}{c}\text { Fuel } \\
\text { Saving } \\
(\$)\end{array}$ & $\begin{array}{c}\text { Reduced } \\
\text { O\&M } \\
\text { Cost }(\$)\end{array}$ & $\begin{array}{c}\text { Environmental } \\
\text { Benefit }(\$)\end{array}$ & $\begin{array}{c}\text { Deferred } \\
\text { Investment } \\
(\$)\end{array}$ & $\begin{array}{c}\text { Network } \\
\text { Support } \\
(\$)\end{array}$ & $\begin{array}{c}\text { Total } \\
\text { Benefit } \\
(\$)\end{array}$ \\
\hline $1 \mathrm{Y}$ & 104,226 & 6,516 & 1,491 & 209 & 504 & 672 & 113,618 \\
\hline $2 \mathrm{Y}$ & 106,662 & 6,529 & 1,494 & 209 & 505 & 673 & 116,073 \\
\hline $3 \mathrm{Y}$ & 106,875 & 6,542 & 1,497 & 210 & 506 & 675 & 116,305 \\
\hline $4 \mathrm{Y}$ & 107,089 & 6,555 & 1,500 & 210 & 507 & 676 & 116,538 \\
\hline $5 \mathrm{Y}$ & 107,303 & 6,568 & 1,503 & 211 & 508 & 677 & 116,771 \\
\hline $6 \mathrm{Y}$ & 107,518 & 6,581 & 1,506 & 211 & 509 & 679 & 117,005 \\
\hline $7 \mathrm{Y}$ & 107,733 & 6,594 & 1,509 & 212 & 510 & 680 & 117,239 \\
\hline $8 \mathrm{Y}$ & 107,948 & 6,608 & 1,512 & 212 & 511 & 682 & 117,473 \\
\hline $9 \mathrm{Y}$ & 108,164 & 6,621 & 1,515 & 212 & 512 & 683 & 117,708 \\
\hline $10 \mathrm{Y}$ & 108,381 & 6,634 & 1,519 & 213 & 513 & 684 & 117,944 \\
\hline Total & $1,071,900$ & 65,749 & 15,049 & 2,109 & 5,086 & 6,781 & $1,166,674$ \\
\hline
\end{tabular}

The economic evaluation shows the project in economically beneficial in order to reduce the environmental impact. Table 7-15 explains the economic outcomes of this alternative.

Table 7-15: Economic Results for Residential DR Project

\begin{tabular}{|c|c|}
\hline NPV (\$) & 52,450 \\
\hline IRR & $18.83 \%$ \\
\hline Payback (years) & 4.40 \\
\hline BCR & 1.062 \\
\hline
\end{tabular}

Figure 7-7 and Figure 7-8 demonstrate that the project pays the investment after the fourth year. Although the project requires annual expenses to implement the program, it takes less time to recover the capital cost with less benefit. 


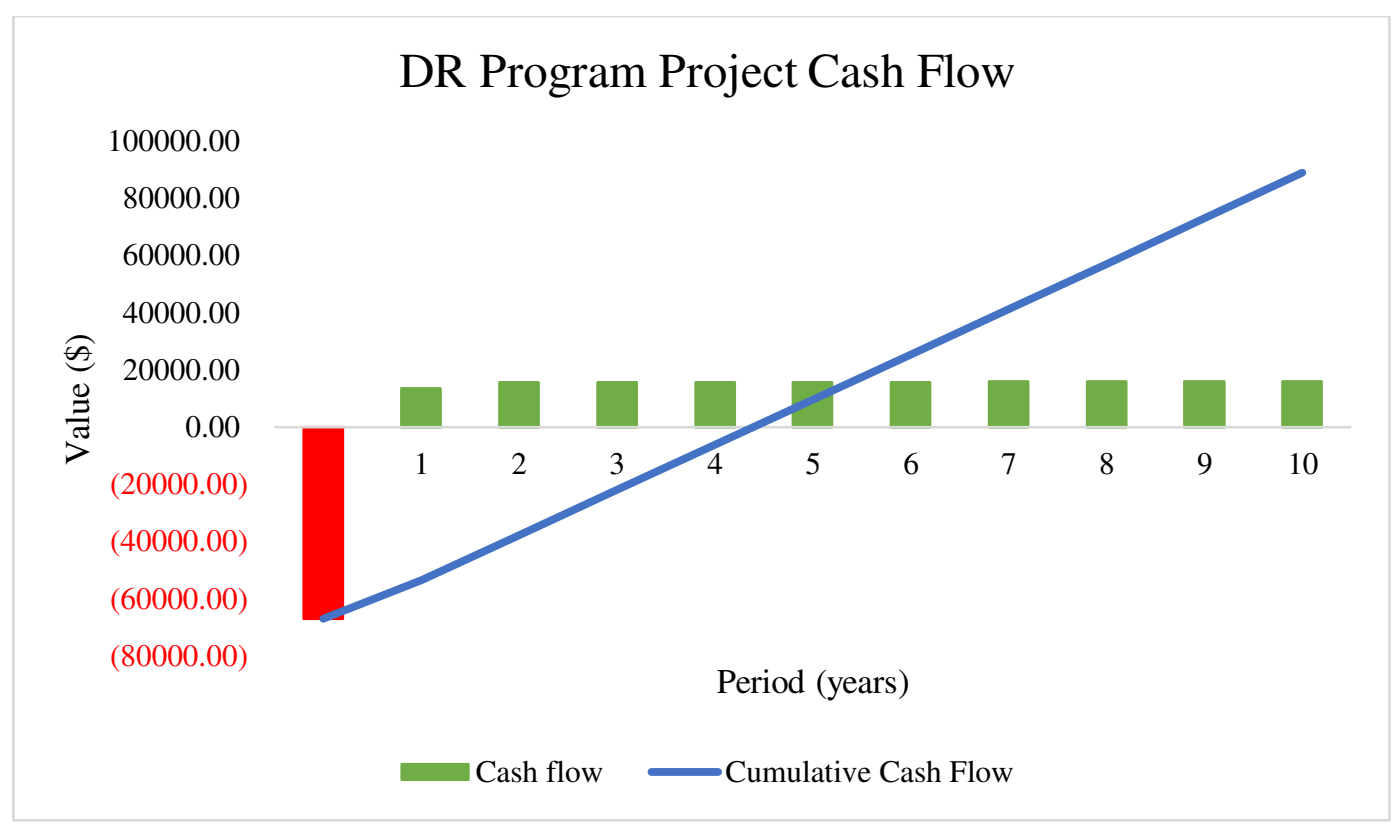

Figure 7-7: Cash Flow for residential DR project

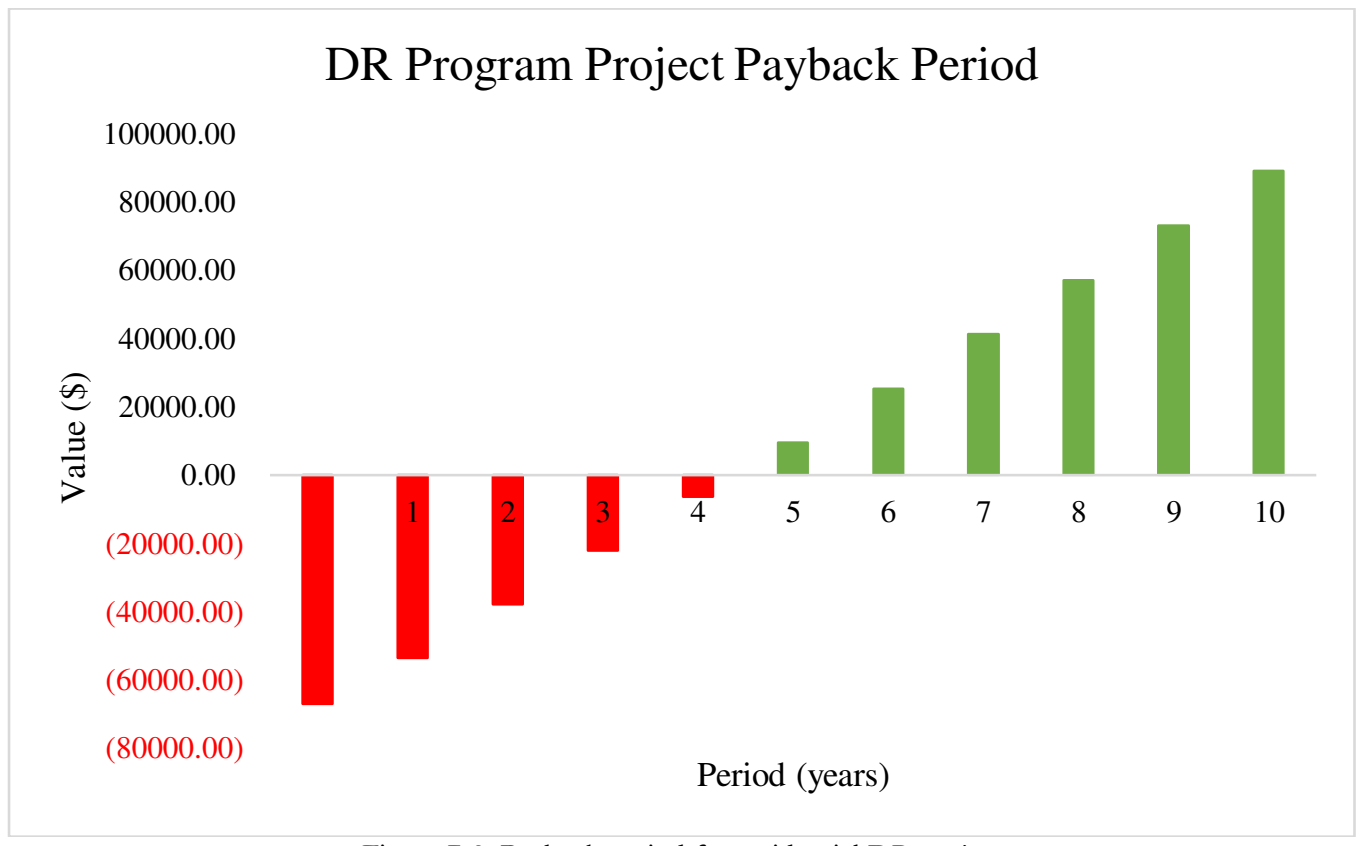

Figure 7-8: Payback period for residential DR project

\subsubsection{Communication and intelligence with ESS}

This subsection investigates the economic approach of combining residential DR and ESS.

All the utility costs and benefits follow the methodologies explained in subsections 7.3.1 and 7.3.4. Since ESS is integrated in the residential electricity sector, the investment cost in Table 7-2 is extracted for 
the residential sector only, and the DR framework model is the same. Table 7-16 shows the financial year impact of merging residential DR and ESS.

Table 7-16: The First Year Financial Impact for Residential DR with ESS Project

\begin{tabular}{|l|c|c|c|c|}
\hline & Energy Sales $(\$)$ & Energy Cost $(\$)$ & Demand Charge $(\$)$ & DR Cost $(\$)$ \\
\hline Base case & 492,378 & 224,074 & 105,930 & \\
\hline $\begin{array}{l}\text { DR with } \\
\text { ESS }\end{array}$ & 578,846 & 217,432 & 95,899 & 67,018 \\
\hline
\end{tabular}

All the costs relevant to the residential DR or ESS are discussed and adapted to the size of the test system as stated in Table 7-17. In Table 7-18, all the expected benefits from this type of combination are investigated. It shows how DR and ESS work together to achieve such benefits. The results are not surprising since the main goal of these alternatives is shaving the peak during high demand for electricity. Even this scenario takes a longer time than the residential DR project to pay the capital cost, Table 7-19 shows this option is more beneficial than the previous alternative. 
Table 7-17: Costs of deploying Residential DR with ESS Project

\begin{tabular}{|c|c|c|c|c|c|c|c|c|c|c|}
\hline & $\begin{array}{c}\text { DR } \\
\text { Capital } \\
\text { Cost }(\$)\end{array}$ & Battery $(\$)$ & $\operatorname{PCS}(\$)$ & $\begin{array}{c}\text { Power } \\
\text { Control } \\
\text { System } \\
\text { Cost }(\$)\end{array}$ & $\begin{array}{c}\text { Balance } \\
\text { of Plant } \\
(\$)\end{array}$ & $\operatorname{EPC}(\$)$ & $\begin{array}{c}\text { Recycling } \\
(\$)\end{array}$ & $\begin{array}{c}\text { Fixed } \\
\text { O\&M Cost } \\
(\$)\end{array}$ & $\begin{array}{l}\text { Variable } \\
\text { Cost }(\$)\end{array}$ & $\begin{array}{c}\text { Total Cost } \\
(\$)\end{array}$ \\
\hline Investment & 67,018 & 151,210 & 29,402 & 10,081 & 40,323 & 15,121 & & & & 313,154 \\
\hline $1 \mathrm{Y}$ & & & & & & & & 101,332 & 6,929 & 108,261 \\
\hline $2 \mathrm{Y}$ & & & & & & & & 101,535 & 6,943 & 108,478 \\
\hline $3 \mathrm{Y}$ & & & & & & & & 101,738 & 6,957 & 108,695 \\
\hline $4 Y$ & & & & & & & & 101,941 & 6,971 & 108,912 \\
\hline $5 \mathrm{Y}$ & & & & & & & & 102,145 & 6,985 & 109,130 \\
\hline $6 Y$ & & & & & & & & 102,349 & 6,999 & 109,348 \\
\hline $7 \mathrm{Y}$ & & & & & & & & 102,554 & 7,013 & 109,567 \\
\hline $8 Y$ & & & & & & & & 102,759 & 7,027 & 109,786 \\
\hline $9 \mathrm{Y}$ & & & & & & & & 102,965 & 7,041 & 110,005 \\
\hline $10 \mathrm{Y}$ & & & & & & & 38,750 & 103,171 & 7,055 & 148,975 \\
\hline Total & 67,018 & 151,210 & 29,402 & 10,081 & 40,323 & 15,121 & 38,750 & $1,022,489$ & 69,918 & $1,444,310$ \\
\hline
\end{tabular}


Table 7-18: Estimated Benefits of using Residential DR with ESS Project

\begin{tabular}{|c|c|c|c|c|c|c|c|c|}
\hline & $\begin{array}{c}\text { Sold } \\
\text { Electricity } \\
(\$)\end{array}$ & $\begin{array}{l}\text { Fuel Saving } \\
\qquad(\$)\end{array}$ & $\begin{array}{c}\text { Reduced } \\
\text { O\&M } \\
\text { Cost }(\$) \\
\end{array}$ & $\begin{array}{c}\text { Environmental } \\
\text { Benefit }(\$)\end{array}$ & $\begin{array}{c}\text { Deferred } \\
\text { Investment } \\
(\$)\end{array}$ & $\begin{array}{c}\mathrm{DG} \\
\text { Integration } \\
(\$) \\
\end{array}$ & $\begin{array}{c}\text { Network } \\
\text { Support } \\
(\$)\end{array}$ & $\begin{array}{c}\text { Total Benefit } \\
(\$)\end{array}$ \\
\hline $1 Y$ & 87,870 & 22,682 & 1,491 & 1,195 & 504 & 51,530 & 5,940 & 171,213 \\
\hline $2 \mathrm{Y}$ & 89,894 & 22,728 & 1,494 & 1,197 & 505 & 51,633 & 5,952 & 173,403 \\
\hline $3 Y$ & 90,074 & 22,773 & 1,497 & 1,199 & 506 & 51,736 & 5,963 & 173,750 \\
\hline $4 \mathrm{Y}$ & 90,254 & 22,819 & 1,500 & 1,202 & 507 & 51,840 & 5,975 & 174,097 \\
\hline $5 Y$ & 90,434 & 22,864 & 1,503 & 1,204 & 508 & 51,944 & 5,987 & 174,445 \\
\hline $6 Y$ & 90,615 & 22,910 & 1,506 & 1,207 & 509 & 52,048 & 5,999 & 174,794 \\
\hline $7 Y$ & 90,797 & 22,956 & 1,509 & 1,209 & 510 & 52,152 & 6,011 & 175,144 \\
\hline $8 Y$ & 90,978 & 23,002 & 1,512 & 1,211 & 511 & 52,256 & 6,023 & 175,494 \\
\hline $9 Y$ & 91,160 & 23,048 & 1,515 & 1,214 & 512 & 52,360 & 6,035 & 175,845 \\
\hline $10 \mathrm{Y}$ & 91,342 & 23,094 & 1,519 & 1,216 & 513 & 52,465 & 6,047 & 176,197 \\
\hline Total & 903,419 & 228,876 & 15,049 & 12,054 & 5,086 & 519,964 & 59,934 & $1,744,383$ \\
\hline
\end{tabular}


Table 7-19: Economic Results after Combining Residential DR and ESS Project

\begin{tabular}{|c|c|}
\hline NPV $(\$)$ & 163,759 \\
\hline IRR & $15.27 \%$ \\
\hline Payback (years) & 4.84 \\
\hline BCR & 1.139 \\
\hline
\end{tabular}

To track the financial behavior for each year, Figures 7-9 and 7-10 shows cash flow, cumulative cash flow, and the payback period.

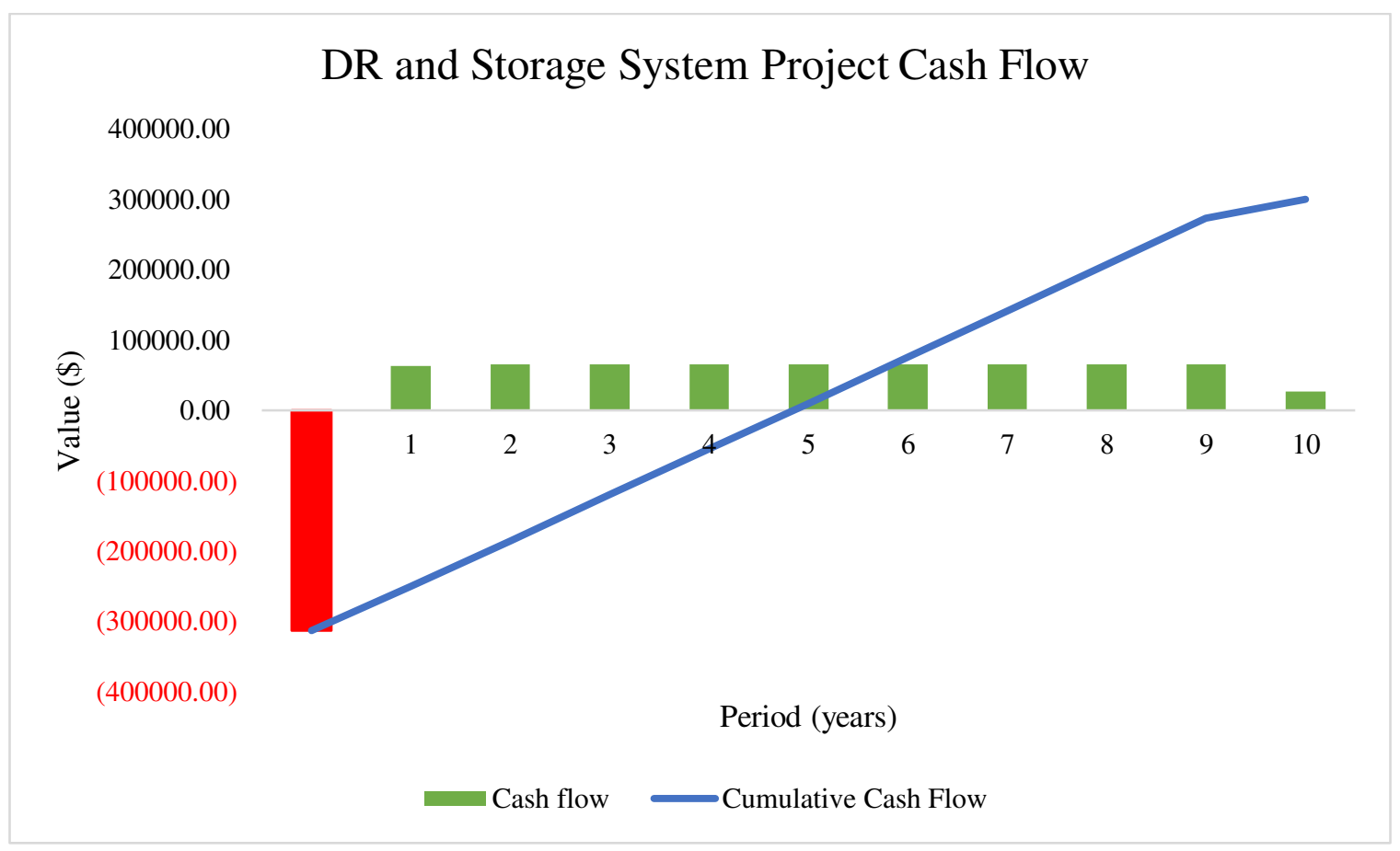

Figure 7-9: Cash flow for residential DR and ESS project 


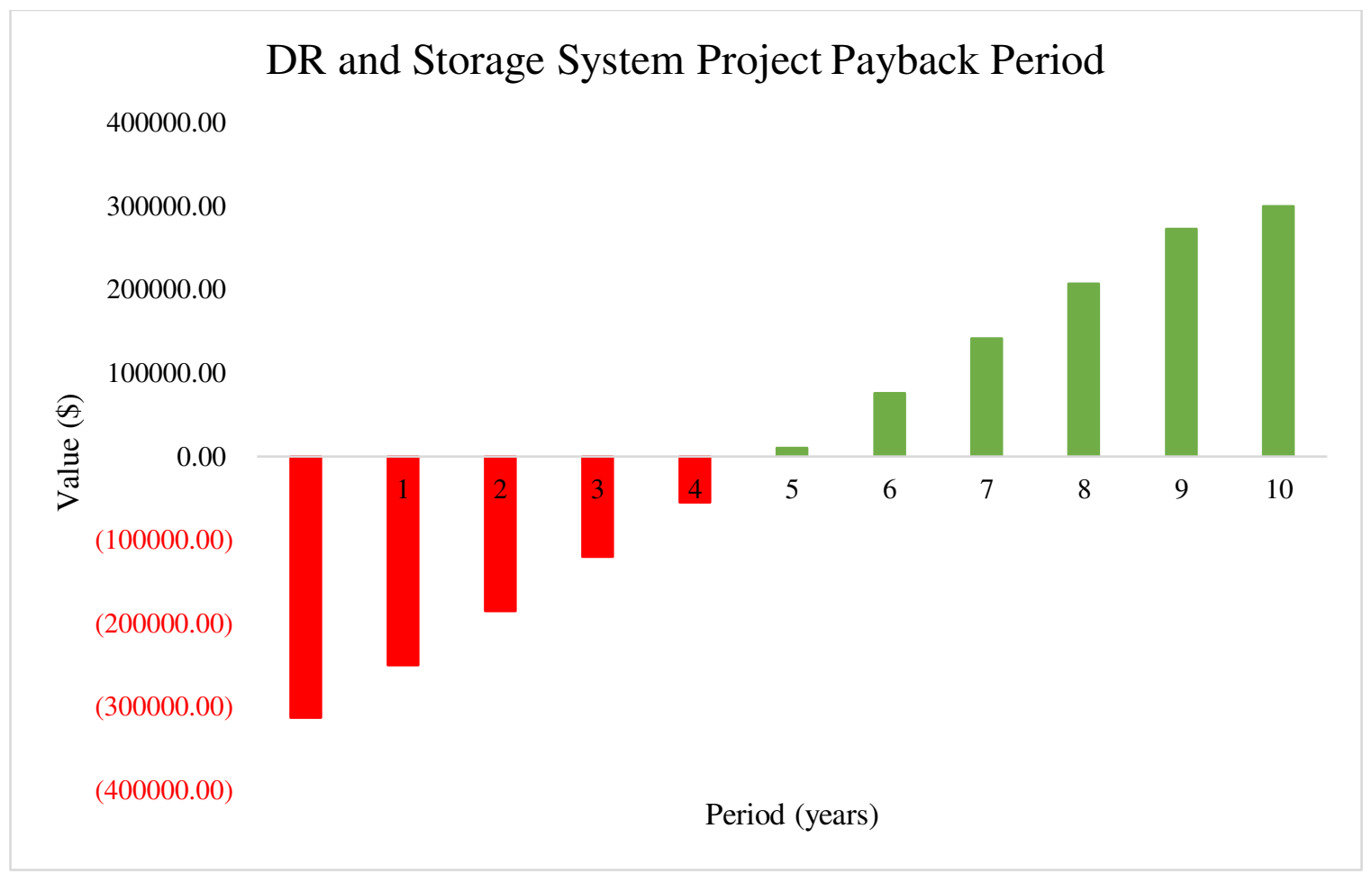

Figure 7-10: Payback period for residential DR and ESS project

\subsubsection{Communication and intelligence with energy conservation}

This scenario assumes applying conservation programs along with the residential DR. Conservation program uses the same model in subsection 7.3.2. The cost of implementing such a scenario might be higher since there is an effect on the convenience of the participants. After the first year, the residential DR increased the energy sales and reduced the costs of purchasing electricity as shown in Table 7-20. However, the total cost increases with incorporating energy conservation programs as stated in table 7-21.

Table 7-20: The First Year Financial Impact after incorporating Energy Conservation with Residential DR Project

\begin{tabular}{|c|c|c|c|c|}
\hline & $\begin{array}{c}\text { Energy Sales } \\
(\$)\end{array}$ & Energy Cost (\$) & Demand Charge (\$) & DR Cost (\$) \\
\hline Base case & 492,378 & 224,074 & 105,930 & \\
\hline $\begin{array}{c}\text { DR with } \\
\text { energy } \\
\text { conservation }\end{array}$ & 565,262 & 210,368 & 98,509 & 67,018 \\
\hline
\end{tabular}


Table 7-21: Costs of applying Residential DR with Energy Conservation Project

\begin{tabular}{|c|c|c|c|c|c|c|}
\hline & $\begin{array}{c}\text { Capital } \\
\text { Cost }(\$)\end{array}$ & $\begin{array}{c}\text { Program } \\
\text { Cost }(\$)\end{array}$ & $\begin{array}{c}\text { Socioeconomic } \\
\text { Cost }(\$)\end{array}$ & $\begin{array}{c}\text { Variable } \\
\text { Cost }(\$)\end{array}$ & $\begin{array}{c}\text { Recycling } \\
(\$)\end{array}$ & $\begin{array}{c}\text { Total Cost } \\
(\$)\end{array}$ \\
\hline Investment & 134,036 & & & & & 134,036 \\
\hline $1 \mathrm{Y}$ & & 10,205 & 54,232 & 100,156 & & 164,593 \\
\hline $2 \mathrm{Y}$ & & 10,225 & 54,340 & 100,356 & & 164,922 \\
\hline $3 \mathrm{Y}$ & & 10,246 & 54,449 & 100,557 & & 165,252 \\
\hline $4 \mathrm{Y}$ & & 10,266 & 54,558 & 100,758 & & 165,582 \\
\hline $5 \mathrm{Y}$ & & 10,287 & 54,667 & 100,960 & & 165,913 \\
\hline $6 \mathrm{Y}$ & & 10,307 & 54,776 & 101,162 & & 166,245 \\
\hline $7 \mathrm{Y}$ & & 10,328 & 54,886 & 101,364 & & 166,578 \\
\hline $8 \mathrm{Y}$ & & 10,349 & 54,996 & 101,567 & & 166,911 \\
\hline $9 \mathrm{Y}$ & & 10,369 & 55,106 & 101,770 & & 167,245 \\
\hline $10 \mathrm{Y}$ & & 10,390 & 55,216 & 101,973 & 1,222 & 167,579 \\
\hline Total & 134,036 & 102,973 & 547,225 & $1,010,622$ & 1,222 & $1,794,856$ \\
\hline
\end{tabular}

The benefit pertaining to this scenario ranges from reducing electricity bills and decreasing dependency on fossil-fueled generators. Table 7-22 illustrates the potential outcomes of using energy conservation with the residential DR. 
Table 7-22: Expected Benefit of merging Energy Conservation with Residential DR

\begin{tabular}{|c|c|c|c|c|c|c|c|c|}
\hline & $\begin{array}{c}\text { Sold } \\
\text { Electricity } \\
(\$)\end{array}$ & $\begin{array}{c}\text { Fuel } \\
\text { Saving }(\$)\end{array}$ & $\begin{array}{c}\text { Reduced } \\
\text { O\&M } \\
\text { Cost }(\$) \\
\end{array}$ & $\begin{array}{c}\text { Environmental } \\
\text { Benefit }(\$)\end{array}$ & $\begin{array}{c}\text { Deferred } \\
\text { Investment } \\
(\$)\end{array}$ & $\begin{array}{c}\text { Network } \\
\text { Support } \\
(\$)\end{array}$ & $\begin{array}{c}\text { Socioeconomic } \\
\text { Benefit }(\$)\end{array}$ & $\begin{array}{c}\text { Total } \\
\text { Benefit }(\$)\end{array}$ \\
\hline $1 \mathrm{Y}$ & 74,343 & 36,267 & 2,983 & 2,509 & 1,008 & 1,344 & 64,145 & 182,598 \\
\hline $2 Y$ & 76,029 & 36,339 & 2,989 & 2,514 & 1,010 & 1,347 & 64,273 & 184,502 \\
\hline $3 \mathrm{Y}$ & 76,181 & 36,412 & 2,995 & 2,519 & 1,012 & 1,349 & 64,402 & 184,871 \\
\hline $4 Y$ & 76,334 & 36,485 & 3,001 & 2,524 & 1,014 & 1,352 & 64,531 & 185,240 \\
\hline $5 Y$ & 76,486 & 36,558 & 3,007 & 2,529 & 1,016 & 1,355 & 64,660 & 185,611 \\
\hline $6 \mathrm{Y}$ & 76,639 & 36,631 & 3,013 & 2,534 & 1,018 & 1,358 & 64,789 & 185,982 \\
\hline $7 Y$ & 76,793 & 36,704 & 3,019 & 2,539 & 1,020 & 1,360 & 64,919 & 186,354 \\
\hline $8 Y$ & 76,946 & 36,777 & 3,025 & 2,544 & 1,022 & 1,363 & 65,049 & 186,727 \\
\hline $9 \mathrm{Y}$ & 77,100 & 36,851 & 3,031 & 2,550 & 1,024 & 1,366 & 65,179 & 187,100 \\
\hline $10 \mathrm{Y}$ & 77,254 & 36,925 & 3,037 & 2,555 & 1,026 & 1,368 & 65,309 & 187,474 \\
\hline Total & 764,105 & 365,947 & 30,099 & 25,318 & 10,172 & 13,562 & 647,256 & $1,856,458$ \\
\hline
\end{tabular}


After specifying all the utility costs and benefits obtained from this partnership between conservation programs and DR, the findings demonstrate this project has the longest time among others to recover the cost and starts receiving profit. Also, Table 7-23 indicates that this project is accepted based on its BCR value with less benefit when compared to other alternatives. Figure 7-11 explains the incurred cash for each year while Figure 7-12 illustrates the payback period during the life of the project

Table 7-23: Economic Results for Residential DR with Energy Conservation Project

\begin{tabular}{|c|c|}
\hline NPV (\$) & 14,746 \\
\hline IRR & $7.26 \%$ \\
\hline Payback (years) & 6.96 \\
\hline BCR & 1.010 \\
\hline
\end{tabular}




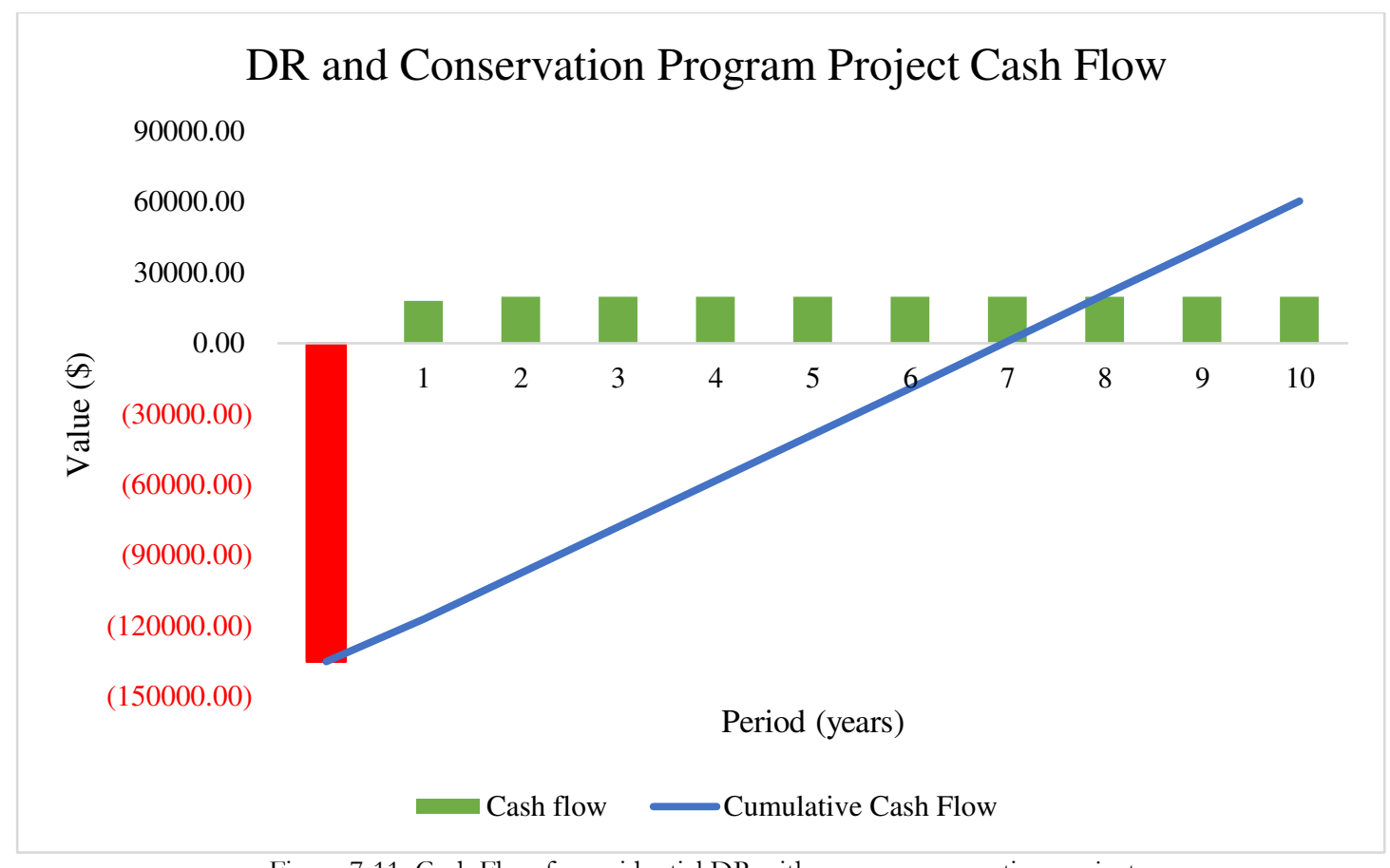

Figure 7-11: Cash Flow for residential DR with energy conservation project

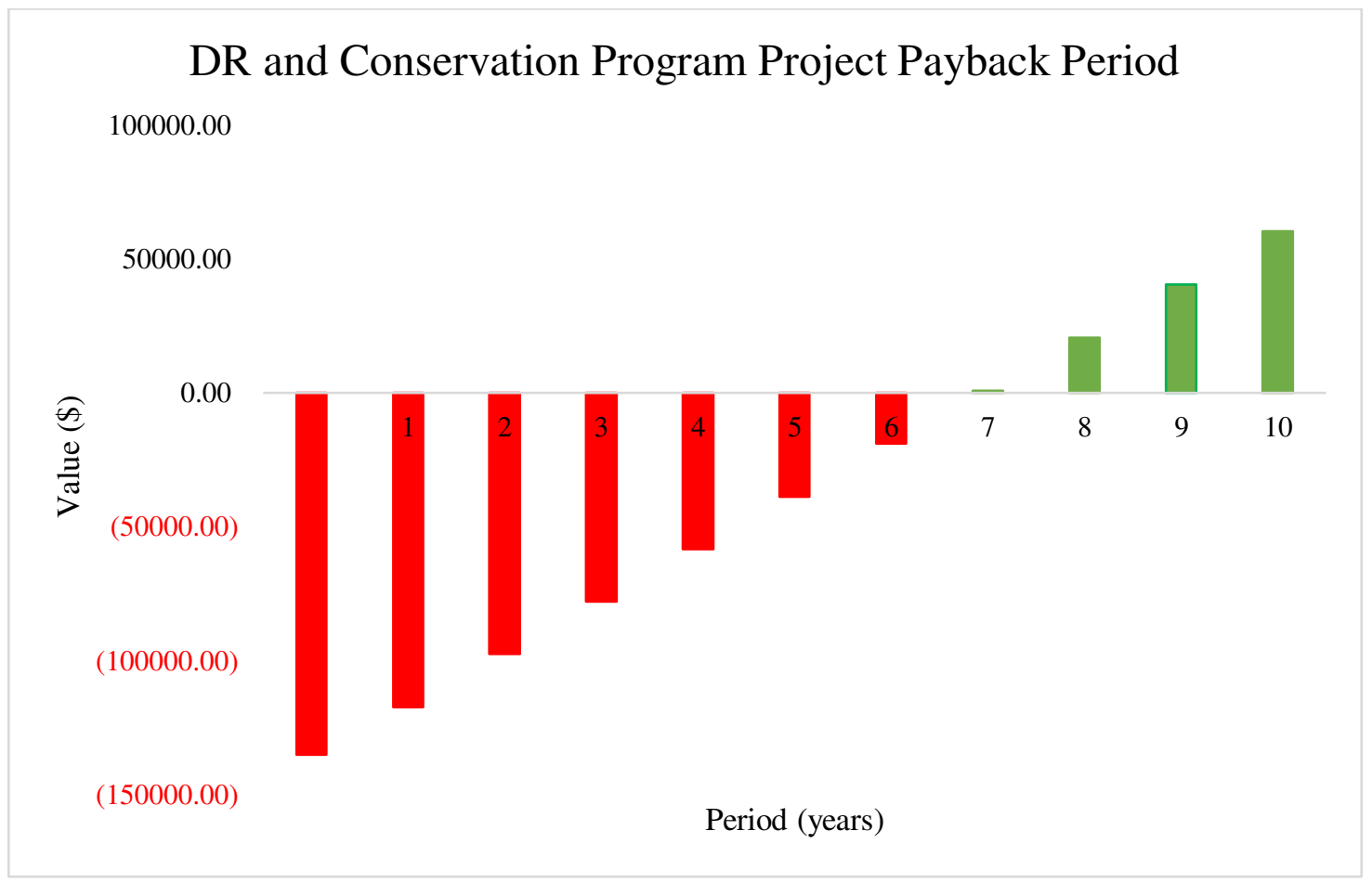

Figure 7-12: Payback period from residential DR with energy conservation project 
7.3.7 Communication and intelligence with ESS and energy conservation

Last scenario is to investigate the economic approach of combining all the proposed alternatives on the electricity residential sector. Environmentally, this option successfully achieved about $20 \%$ reduction in total emissions from the electricity residential sector. However, this subsection studies the utility economic viability of this approach. In that regard, the analysis takes into consideration the methodologies in subsections 7.3.4, 7.3.5, and 7.3.6. The results demonstrate that this scenario performs better than the base case. Table 7-24 shows the first financial year for the DR program with ESS and energy conservation. The costs needed to perform such a project is explained in Table 7-25.

Table 7-24: The First Year Financial Impact after combining All MCDM Alternatives

\begin{tabular}{|l|c|c|c|c|}
\hline & Energy Sales (\$) & Energy Cost $(\$)$ & Demand Charge (\$) & DR Cost (\$) \\
\hline Base case & 492,378 & 224,074 & 105,930 & \\
\hline $\begin{array}{l}\text { DR with ESS and } \\
\text { energy conservation }\end{array}$ & 549,903 & 206,560 & 91,105 & 67,018 \\
\hline
\end{tabular}

Including ESS with DR and energy conservation increased the predicted benefits since ESS discharge the stored energy during peaking demand and in turn increased the convenience level for the participants. Table 7-26 described all the expected benefits 
Table 7-25: Costs of combining All MCDM Alternatives

\begin{tabular}{|c|c|c|c|c|c|c|c|c|c|c|c|c|}
\hline & $\begin{array}{c}\text { DR \& } \\
\text { Con } \\
\text { Capital } \\
\text { Cost } \\
(\$)\end{array}$ & Battery (\$) & $\operatorname{PCS}(\$)$ & $\begin{array}{c}\text { Power } \\
\text { Control } \\
\text { System } \\
\text { Cost }(\$)\end{array}$ & $\begin{array}{c}\text { Balance } \\
\text { of Plant } \\
(\$)\end{array}$ & $\begin{array}{c}\mathrm{EPC} \\
(\$)\end{array}$ & $\begin{array}{c}\text { Program } \\
\text { Cost }(\$)\end{array}$ & $\begin{array}{c}\text { Socioeconomic } \\
\text { Cost }(\$)\end{array}$ & $\begin{array}{c}\text { Fixed } \\
\text { O\&M } \\
\text { Cost }(\$)\end{array}$ & $\begin{array}{l}\text { Variable } \\
\text { Cost }(\$)\end{array}$ & $\begin{array}{c}\text { Recycling } \\
(\$)\end{array}$ & $\begin{array}{c}\text { Total } \\
\text { Cost }(\$)\end{array}$ \\
\hline Investment & $\begin{array}{c}134,03 \\
6\end{array}$ & 143,649 & 27,932 & 9,577 & 38,306 & 14,365 & & & & & & 367,865 \\
\hline $1 \mathrm{Y}$ & & & & & & & 10,205 & 54,232 & 101,273 & 6,583 & & 172,293 \\
\hline $2 \mathrm{Y}$ & & & & & & & 10,225 & 54,340 & 101,476 & 6,596 & & 172,637 \\
\hline $3 Y$ & & & & & & & 10,246 & 54,449 & 101,679 & 6,609 & & 172,983 \\
\hline $4 Y$ & & & & & & & 10,266 & 54,558 & 101,882 & 6,622 & & 173,328 \\
\hline $5 Y$ & & & & & & & 10,287 & 54,667 & 102,086 & 6,636 & & 173,675 \\
\hline $6 Y$ & & & & & & & 10,307 & 54,776 & 102,290 & 6,649 & & 174,022 \\
\hline $7 Y$ & & & & & & & 10,328 & 54,886 & 102,495 & 6,662 & & 174,371 \\
\hline $8 Y$ & & & & & & & 10,349 & 54,996 & 102,700 & 6,675 & & 174,719 \\
\hline $9 Y$ & & & & & & & 10,369 & 55,106 & 102,905 & 6,689 & & 175,069 \\
\hline $10 \mathrm{Y}$ & & & & & & & 10,390 & 55,216 & 103,111 & 6,702 & 1,222 & 175,419 \\
\hline Total & $\begin{array}{c}134,03 \\
6\end{array}$ & 143,649 & 27,932 & 9,577 & 38,306 & 14,365 & 102,973 & 547,225 & $1,021,895$ & 66,423 & 1,222 & $2,106,381$ \\
\hline
\end{tabular}


Table 7-26: Benefits of combining All MCDM Alternatives

\begin{tabular}{|c|c|c|c|c|c|c|c|c|c|}
\hline & $\begin{array}{c}\text { Sold } \\
\text { Electricity } \\
(\$)\end{array}$ & $\begin{array}{c}\text { Fuel } \\
\text { Saving (\$) }\end{array}$ & $\begin{array}{c}\text { Reduced } \\
\text { O\&M } \\
\text { Cost }(\$)\end{array}$ & $\begin{array}{c}\text { Environmental } \\
\text { Benefit }(\$)\end{array}$ & $\begin{array}{c}\text { Deferred } \\
\text { Investment } \\
(\$)\end{array}$ & $\begin{array}{c}\mathrm{DG} \\
\text { Integration } \\
(\$)\end{array}$ & $\begin{array}{c}\text { Network } \\
\text { Support } \\
(\$)\end{array}$ & $\begin{array}{c}\text { Socioeconomic } \\
\text { Benefit }(\$)\end{array}$ & $\begin{array}{c}\text { Total } \\
\text { Benefit (\$) }\end{array}$ \\
\hline $1 \mathrm{Y}$ & 58,805 & 51,625 & 2,983 & 3,453 & 1,008 & 51,530 & 5,940 & 64,145 & 239,489 \\
\hline $2 Y$ & 60,111 & 51,728 & 2,989 & 3,460 & 1,010 & 51,633 & 5,952 & 64,273 & 241,156 \\
\hline $3 \mathrm{Y}$ & 60,231 & 51,831 & 2,995 & 3,467 & 1,012 & 51,736 & 5,963 & 64,402 & 241,638 \\
\hline $4 Y$ & 60,352 & 51,935 & 3,001 & 3,474 & 1,014 & 51,840 & 5,975 & 64,531 & 242,122 \\
\hline $5 Y$ & 60,473 & 52,039 & 3,007 & 3,481 & 1,016 & 51,944 & 5,987 & 64,660 & 242,606 \\
\hline $6 Y$ & 60,594 & 52,143 & 3,013 & 3,488 & 1,018 & 52,048 & 5,999 & 64,789 & 243,091 \\
\hline $7 Y$ & 60,715 & 52,247 & 3,019 & 3,495 & 1,020 & 52,152 & 6,011 & 64,919 & 243,577 \\
\hline $8 Y$ & 60,836 & 52,352 & 3,025 & 3,502 & 1,022 & 52,256 & 6,023 & 65,049 & 244,065 \\
\hline $9 Y$ & 60,958 & 52,456 & 3,031 & 3,509 & 1,024 & 52,360 & 6,035 & 65,179 & 244,553 \\
\hline $10 Y$ & 61,080 & 52,561 & 3,037 & 3,516 & 1,026 & 52,465 & 6,047 & 65,309 & 245,042 \\
\hline Total & 604,154 & 520,918 & 30,099 & 34,841 & 10,172 & 519,964 & 59,934 & 647,256 & $2,427,338$ \\
\hline
\end{tabular}


The economic results show the improvement after integrating ESS with the two remaining alternatives. The NPV has been increased as well as BCR while the payback period decreased as stated in Table 7-27. Figure 7-13 explains the cash flow for each year, and Figure 7-14 illustrates the required years for the project to pay its capital cost.

Table 7-27: Economic Results for combining All MCDM Alternatives

\begin{tabular}{|c|c|}
\hline NPV $(\$)$ & 160,315 \\
\hline IRR & $13.30 \%$ \\
\hline Payback (years) & 5.37 \\
\hline BCR & 1.094 \\
\hline
\end{tabular}

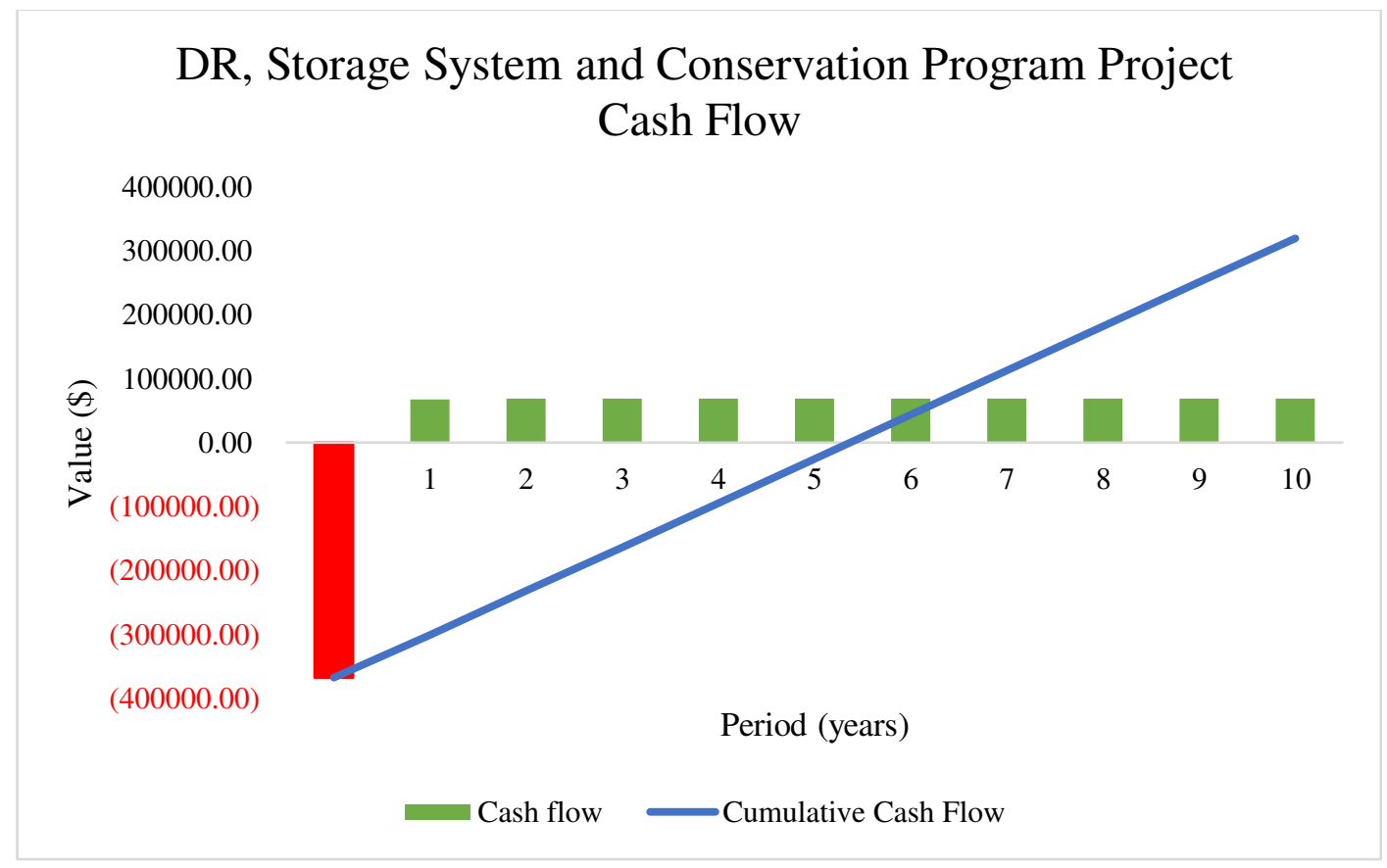

Figure 7-13: Cash flow after combining all MCDM alternatives 


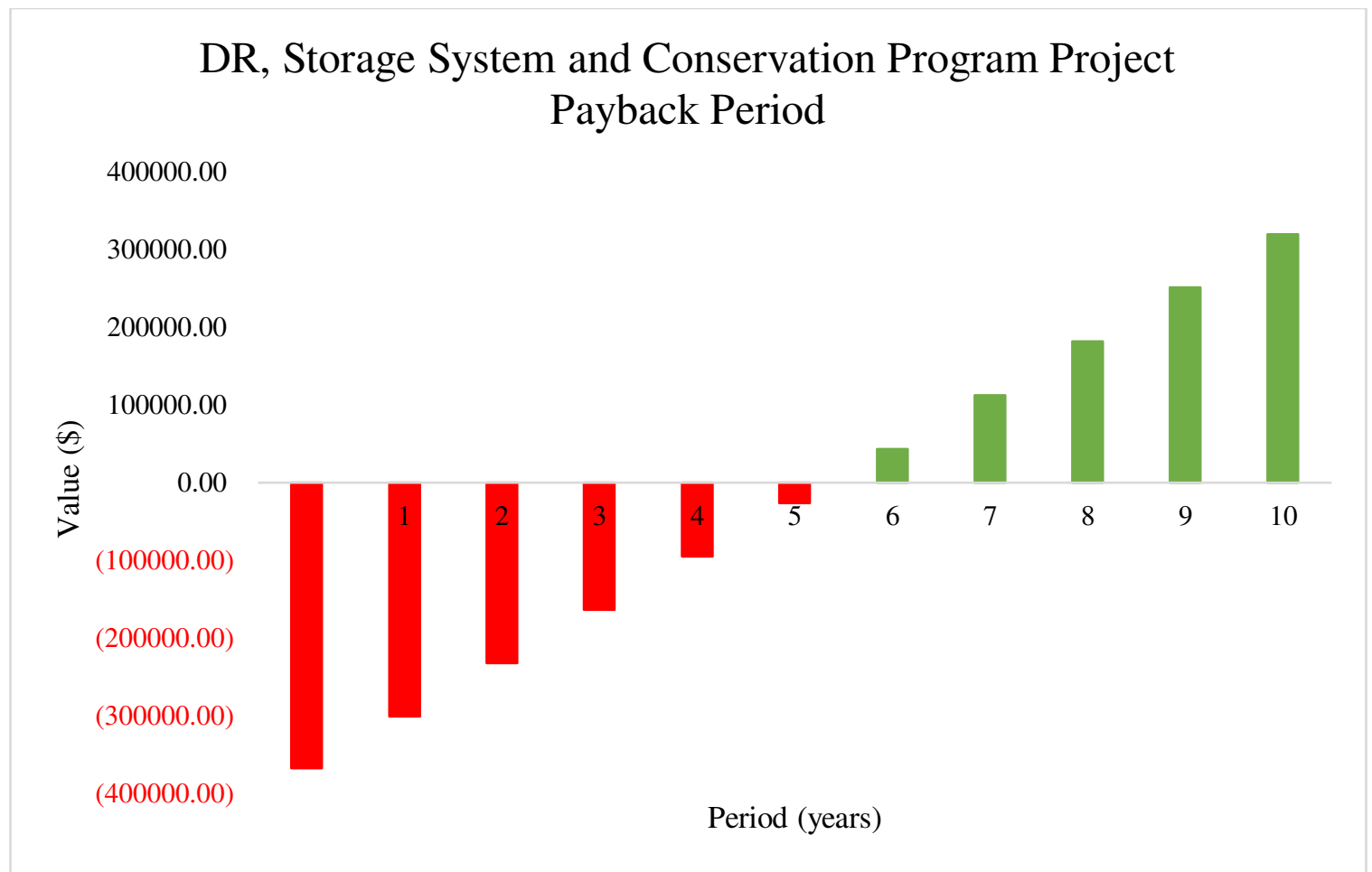

Figure 7-14: Payback period after combining all MCDM alternatives

7.4 Results

This section discusses the final economic evaluation among the proposed alternatives. The pertinent results to the above studied scenarios show that all the projects are economically accepted. They provide a positive NPVs, pay their costs during the life of the project, and their BCRs are greater than one. Table 7-28 illustrates the cash flow for each project for 10 years. Further, Table 7-29 explains the cumulative cash flow of the projects. To clearly justify all alternatives, we compare all the projects by obtaining the NPVs, the IRRs, the payback period, the BCRs, and the total expected emissions reduction for each alternative. Table 7-30 makes a comparison between all available options. 
Table 7-28: Cash Flow for All Projects

\begin{tabular}{|c|c|c|c|c|c|c|c|}
\hline Year & $\operatorname{ESS}(\$)$ & $\begin{array}{c}\text { Energy } \\
\text { Conservation } \\
(\$)\end{array}$ & $\begin{array}{l}\text { ESS and Energy } \\
\text { Conservation }(\$)\end{array}$ & $\begin{array}{c}\text { Residential } \\
\text { DR (\$) }\end{array}$ & $\begin{array}{c}\text { Residential DR } \\
\text { and ESS }(\$)\end{array}$ & $\begin{array}{c}\text { Residential DR } \\
\text { and Energy } \\
\text { Conversation } \\
(\$)\end{array}$ & $\begin{array}{l}\text { Residential DR, } \\
\text { ESS and Energy } \\
\text { Conversation }(\$)\end{array}$ \\
\hline Investment & $(793,986)$ & $(217,532)$ & $(932,089)$ & $(67,018)$ & $(313,154)$ & $(135,258)$ & $(367,865)$ \\
\hline 1 & 195,595 & 40,349 & 140,887 & 13,462 & 62,952 & 18,006 & 67,196 \\
\hline 2 & 195,952 & 40,430 & 141,134 & 15,717 & 64,925 & 19,580 & 68,519 \\
\hline 3 & 196,310 & 40,511 & 141,417 & 15,748 & 65,055 & 19,619 & 68,656 \\
\hline 4 & 196,668 & 40,592 & 141,699 & 15,780 & 65,185 & 19,658 & 68,793 \\
\hline 5 & 197,028 & 40,673 & 141,983 & 15,811 & 65,316 & 19,697 & 68,931 \\
\hline 6 & 197,388 & 40,754 & 142,267 & 15,843 & 65,446 & 19,737 & 69,069 \\
\hline 7 & 197,749 & 40,836 & 142,551 & 15,875 & 65,577 & 19,776 & 69,207 \\
\hline 8 & 198,110 & 40,918 & 142,836 & 15,907 & 65,708 & 19,816 & 69,345 \\
\hline 9 & 198,472 & 40,999 & 143,122 & 15,938 & 65,840 & 19,855 & 69,484 \\
\hline 10 & 73,835 & 41,081 & 17,064 & 15,970 & 27,221 & 19,895 & 68,401 \\
\hline
\end{tabular}




\begin{tabular}{|c|c|c|c|c|c|c|c|}
\hline Year & ESS (\$) & $\begin{array}{c}\text { Energy } \\
\text { Conservation } \\
(\$)\end{array}$ & $\begin{array}{l}\text { ESS and Energy } \\
\text { Conservation }(\$)\end{array}$ & $\begin{array}{l}\text { Residential } \\
\text { DR }(\$)\end{array}$ & $\begin{array}{c}\text { Residential DR } \\
\text { and ESS }(\$)\end{array}$ & $\begin{array}{c}\text { Residential DR } \\
\text { and Energy } \\
\text { Conversation }(\$)\end{array}$ & $\begin{array}{l}\text { Residential DR, } \\
\text { ESS and Energy } \\
\text { Conversation (\$) }\end{array}$ \\
\hline & $(793,986)$ & $(217,532)$ & $(932,089)$ & $(67,018)$ & $(313,154)$ & $(135,258)$ & $(367,865)$ \\
\hline 1 & $(598,391)$ & $(177,183)$ & $(791,202)$ & $(53,556)$ & $(250,202)$ & $(117,253)$ & $(300,669)$ \\
\hline 2 & $(402,439)$ & $(136,753)$ & $(650,068)$ & $(37,839)$ & $(185,277)$ & $(97,673)$ & $(232,150)$ \\
\hline 3 & $(206,130)$ & $(96,242)$ & $(508,651)$ & $(22,091)$ & $(120,221)$ & $(78,054)$ & $(163,494)$ \\
\hline 4 & $(9,461)$ & $(55,650)$ & $(366,951)$ & $(6,311)$ & $(55,036)$ & $(58,396)$ & $(94,701)$ \\
\hline 5 & 187,566 & $(14,977)$ & $(224,969)$ & 9,501 & 10,280 & $(38,699)$ & $(25,770)$ \\
\hline 6 & 384,954 & 25,778 & $(82,702)$ & 25,344 & 75,726 & $(18,962)$ & 43,299 \\
\hline 7 & 582,703 & 66,614 & 59,850 & 41,218 & 141,303 & 814 & 112,505 \\
\hline 8 & 780,813 & 107,531 & 202,686 & 57,125 & 207,012 & 20,629 & 181,851 \\
\hline 9 & 979,285 & 148,531 & 345,808 & 73,063 & 272,851 & 40,485 & 251,335 \\
\hline 10 & $1,053,120$ & 189,612 & 362,872 & 89,034 & 300,073 & 60,380 & 319,735 \\
\hline
\end{tabular}

Table 7-30: Comparison between All Projects

\begin{tabular}{|c|c|c|c|c|c|c|c|}
\hline & $\mathrm{ESS}(\$)$ & $\begin{array}{c}\text { Energy } \\
\text { Conservation } \\
(\$)\end{array}$ & $\begin{array}{l}\text { ESS and Energy } \\
\text { Conservation }(\$)\end{array}$ & $\begin{array}{l}\text { Residential } \\
\text { DR }(\$)\end{array}$ & $\begin{array}{c}\text { Residential DR } \\
\text { and ESS (\$) }\end{array}$ & $\begin{array}{c}\text { Residential DR } \\
\text { and Energy } \\
\text { Conversation } \\
(\$)\end{array}$ & $\begin{array}{l}\text { Residential DR, } \\
\text { ESS and Energy } \\
\text { Conversation }(\$)\end{array}$ \\
\hline NPV (\$) & 644,975 & 95,229 & 82,838 & 52,450 & 163,759 & 14,746 & 160,316 \\
\hline IRR & $20.40 \%$ & $13.34 \%$ & $7.02 \%$ & $18.83 \%$ & $15.27 \%$ & $7.26 \%$ & $13.30 \%$ \\
\hline Payback (years) & 4.05 & 5.37 & 6.58 & 4.40 & 4.84 & 6.96 & 5.37 \\
\hline BCR & 1.600 & 1.051 & 1.027 & 1.062 & 1.139 & 1.010 & 1.094 \\
\hline $\begin{array}{l}\text { Emissions } \\
\text { Reduction }\end{array}$ & $18.13 \%$ & $20.39 \%$ & $22.17 \%$ & $13.91 \%$ & $15.68 \%$ & $18.04 \%$ & $19.72 \%$ \\
\hline
\end{tabular}


Figure 7-15 presents the combination between the environmental impact and the economic outputs for the alternatives. The findings show that ESS has the highest rank among other alternatives. This is reasonable since ESS charges during lower electricity prices and discharge during peaking demand. Thus, the customers can avoid the high electricity charges, and the utility is not required to run more generating units. The second option is residential DR combined with ESS. This alternative comes after ESS due to its flexibility in shifting the loads to off-peak periods. Combining all the MCDM alternatives in one option is the third ranked scenario. This alternative provides more emissions reduction than the previous ones. While energy conservation project and ESS with energy conservation project provide less economic impact than residential DR, they take the fourth and fifth place, respectively, due to their environmental impact. The penultimate alternative is residential DR because it is designed to shift the peak load, and it has socioeconomic cost. The last alternative is combining residential DR with energy conservation. Although the option performs environmentally better than residential DR, its socioeconomic cost plays a major role in selecting this alternative.

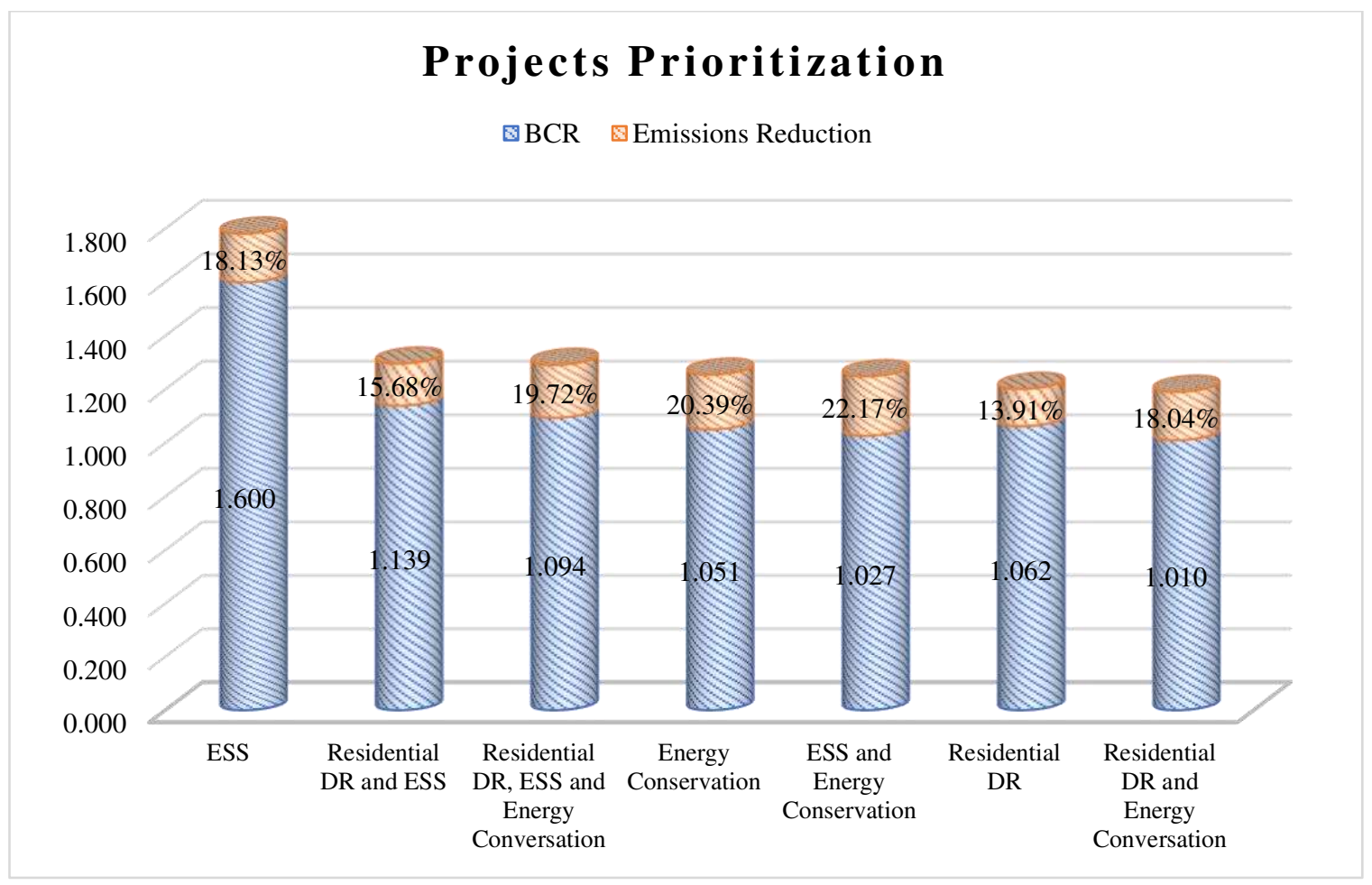

Figure 7-15: Projects ranking after combining environmental and economic impact 
The finding in Figure 7-15 are weighted based on environmental and economic impact of each project. However, priorities might change according to the preference. One can prefer environmental impact over economic output and vice versa. Therefore, a trade-off between the options is a strategic decision that takes into consideration the advantages and disadvantages of each project. In this analysis, there are two factors that can affect the prioritization: environment impact and economic output. Thus, the final result is presented in Figure 7-16 in a trade-off setup, so the decision-makers can tradeoff between the alternatives to select the most suitable option.

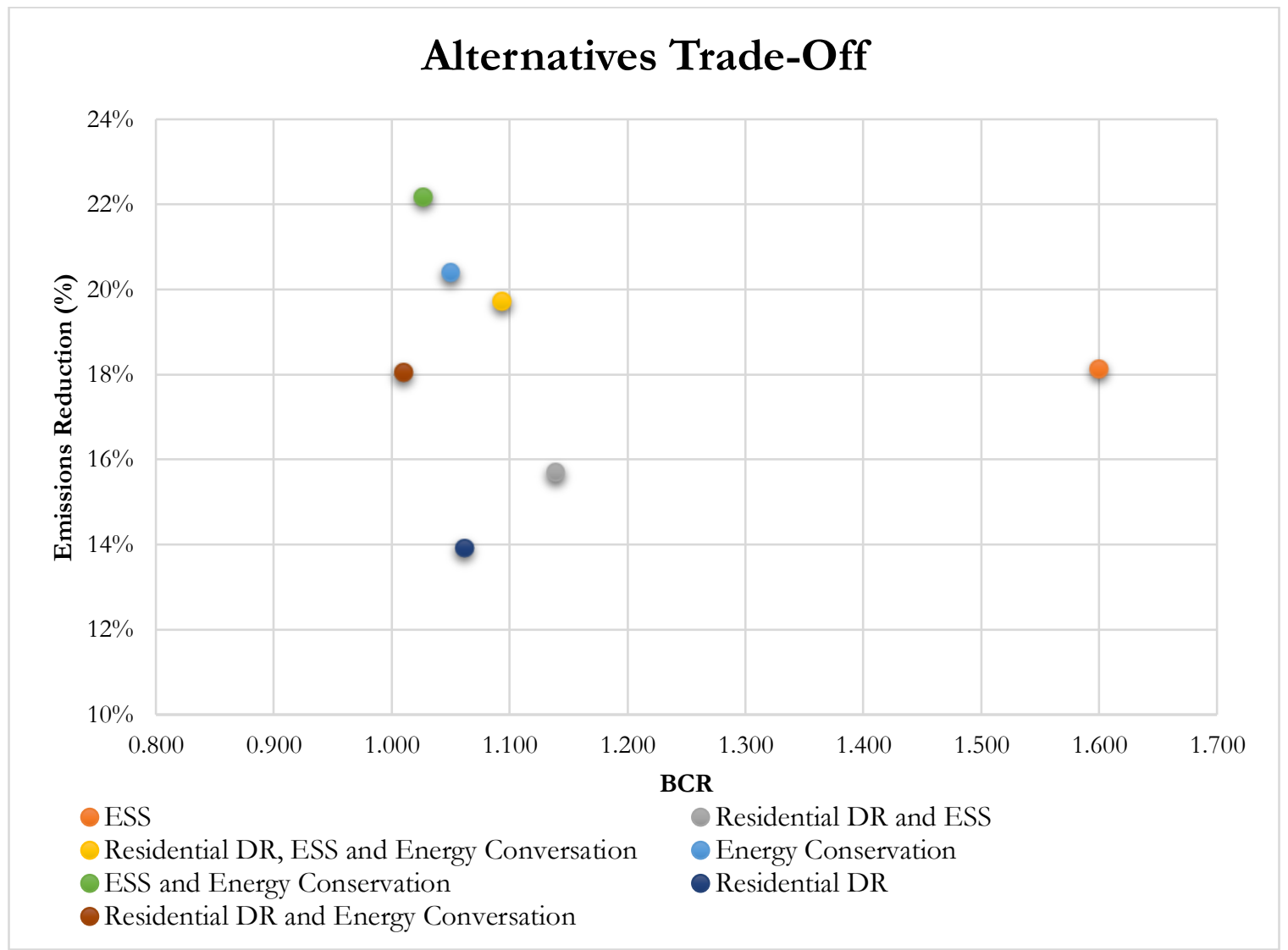

Figure 7-16: A trade-off between the alternatives

\subsection{Conclusion}

This chapter investigated the economic consequences of the MCDM options. It studied each alternative based on its associated costs and the expected benefits. The economic evaluation obtains the NPV, the IRR, the payback period, and the BCR for every scenario. Since this work examines the 
potential emissions reduction from the proposed alternatives, it ensured those solutions are economically accepted. The preliminary result shows that investing in ESS is the best option followed by combining residential DR with ESS. The third choice is merging all the MCDM options since they provide high emissions reduction. The remaining choices are energy conservation project, ESS with energy conservation, residential DR, and residential DR with energy conservation. Further, this chapter presents a trade-off chart to allow the participant to select the alternatives based on their environmental or economic preference. However, this analysis is particularly based on Fort Collins distribution system data. The result might change based on the location, data, or the distribution system structure.

From the previous analysis, we notice that the ranking on DSM options has changed. The AHP findings show that communication and intelligence (residential DR) is on the top of the list followed by ESS and energy conservation, respectively. The result from the ANP model explains the effect of alternatives on criteria. The ANP approach ranks the DSM options as follows: communication and intelligence (residential DR), energy conservation, and ESS, respectively. The simulation result based on the environmental impact shows the prioritization is different from the MCDM ranking as energy conservation provides the biggest emissions reduction in the distribution system. ESS comes in the second rank as it is integrated to the system for load shaving. Communication and intelligence (residential DR) alternative is in the third place based on the environmental simulation. Further, the simulation analysis allows us to merge several options in one scenario. This combination provides the flexibility of using the MCDM alternatives and helps in achieving cumulative emissions reduction. Economically, ESS is the best alternative as it has the highest BCR and requires less time to recover the investment cost. Communication and intelligence (residential DR) project is the second place followed by energy conservation project. However, this work presents a trade-off chart between the environmental impact and the economic outcomes of the DSM options. 


\section{CHAPTER 8}

\section{CONCLUSION AND FUTURE WORK ${ }^{7}$}

\subsection{Introduction}

This dissertation illustrated the impact of GHG emissions, especially of the electricity sector. This work discussed some climate action plans and their benefits and challenges in reducing the emissions from power plants. DSM is a technique that is used as an option to diminish the environmental footprints.

\subsection{Conclusion}

The increased use of energy leads to increased energy-related emissions. It is important to keep the produced emissions under control by regulating carbon footprints. Therefore, this work discussed some government-directed plans that can mitigate GHG. The CPP is the most comprehensive and largest climate protection plan in the U.S. until its proposed repeal in 2017. The plan provides several approaches and options to meet the targeted reduction of emissions from power plants. The CPP includes several scenarios that can lead to achieving the goal with less impact on electricity generation. Another plan in the CAP of Fort Collins. It is a climate plan in Fort Collins, Colorado, U.S. that aims to mitigate the emissions in the city by $20 \%$ in $2020,80 \%$ by 2030 , and carbon neutral by 2050 .

DSM was considered as a potential solution to mitigate the emissions from EGUs. In fact, DSM can make a significant impact in reducing the emissions and providing economic and reliability benefits. This work presented some DSM techniques such as loads shifting, energy conservation, and valley filing. Further, the work explained the most common DSM programs such as DR, energy management, and DG.

\footnotetext{
7 This chapter is verbatim reproduced from [37], and it is submitted to the Journal of Energy Transitions at the time of writing this dissertation
} 
In order to prioritize the DSM options based on their impact on reducing the environmental footprints, the research deployed a MCDM model, AHP, to calculate the final ranking of the DSM alternatives. In fact, AHP uses a framework for problem solving that organizes judgments into a hierarchy of criteria that influence decisions. Therefore, the fourth chapter of this dissertation established a problem framework corresponding to the goal of the CAP of Fort Collins, Colorado, U.S. to study the importance of each alternative in achieving the target. The results show that "communication and intelligence" has the highest priority in meeting the goal followed by "electric stationary storage" and "energy conservation". However, AHP evaluates the decision elements in a hierarchical way while ignoring the impact of alternatives on the weight of criteria and this can affect the final ranking.

ANP in another model in MCDM that allows interdependencies, outerdependencies and feedback connections among decision elements in the network structure to effectively rank alternatives. Hence, Chapter 5 constructed an ANP DSM-based framework to precisely calculate the important available options in reducing carbon footprint. The results pertaining to Fort Collins' electric distribution system indicate the final ranking changes when interdependence relationships are taken into consideration. The results show "communication and intelligence" is the most preferred alternative followed by "energy conservation". Also, "electric stationary storage" moved back to the third option while it was the second alternative in AHP. Indeed, "solar PV" and "combustion generation" are flipped while "load side management" and "electric water heater" maintain the same rank.

After prioritizing the most suitable options, from the DSM alternatives, in reducing the produced emissions from power plants, Chapter 6 presented environmental analysis by creating several scenarios based on the first-three options from the MCDM alternatives. The simulation in this chapter considers studying each alternative individually and then merge an alternative with another alternative. The IEEE 13-node test system was used through the OpenDSS simulation tool to analyze year 2017 hourly load data, corresponding to Fort Collins, Colorado area. Each scenario shows different $\mathrm{CO}_{2}$ 
curves based on the change in supply and demand. The base case simulation for the 2017 data indicates the emissions were reduced by $16.26 \%$ from 2005 level and this comply with the results released by the city. The results obtained for the 2017 load profile demonstrated that "electric stationary storage" can contribute a more than $18 \%$ emission reduction from the 2005 level. While "energy conservation" can meet the city's goal by achieving a $20.39 \%$ reduction in emissions, merging both alternatives in one scenario could increase the emissions mitigation up to $22.17 \%$. "communication and intelligence" in applied only to the residential sector and shows about a 14\% emission reduction from the 2005 level. Integrating "electric stationary storage" with "communication and intelligence" can provide a more than $15 \%$ decrease while combining "communication and intelligence" with "energy conservation" may diminish the environmental footprint by $18.04 \%$. The last scenario examined combines all MCDM alternatives into one option. The result finds that this option can reach a $19.72 \%$ emissions reduction.

The previous results are obtained based on environmental assessment while other factors can affect this ranking. CBA is conducted to study economic, technical, and environmental costs and benefits associated with each alternative. After evaluation all the costs and benefits of each scenario, the preliminary results rank the alternatives according to their environmental impact and the economic outputs. The results show that "electric stationary storage" is on the top of the list followed by "communication and intelligence" combined with "electric stationary storage". The scenario that includes all the MCDM options came in third place since it provides almost 20\% emissions reduction and the BCR is 1.094. The rest of the list is; "energy conservation", "electric stationary storage" with "energy conservation", "communication and intelligence", and "communication and intelligence" with "energy conservation", respectively. However, the ranking might change according to the participant's choice. One can prefer environmental impact over economic output and vice versa. Therefore, this work presented a trade-off chart, so the decision maker can select the alternative based on their preference. 
This analysis is mainly based on Fort Collins distribution system data and is not a general assessment. There are several factors that might affect the result such as the location, data, or the distribution system structure.

\subsection{Future work}

The results presented in this dissertation rank the alternatives based on the simulation from the IEEE 13-node distribution system. But, studying this case from a test system would not be sufficient in ranking the potential solutions for minimizing environmental footprints through DSM. Future path should consider the real electric distribution system of Fort Collins. As the city has a plan to reduce its dependence on conventional generation and to increase the penetration of renewable energy, analyzing the real system can obtain results that are more accurate. The future use of the test system doesn't constrain the results of the current studies as the future work will investigate reliability, and power quality, sizing and siting of ESS in the electric distribution system. This can increase the benefits of ESS by decreasing the system loss and increasing reliability and power quality. Our future path is also considering coordinated energy storage charging with available renewable energy generation. This dispatch will increase the utility utilization by smoothing energy output from intermittent resources and increase reliability and resilience of the system. It can also reduce the electricity bill, defer investment, and offset the emissions from dirty generating units. 


\section{REFERENCES}

[1] G. May, B. Stahl, M. Taisch, and D. Kiritsis, "Energy management in manufacturing: From literature review to a conceptual framework," Journal of Cleaner Production, 2016.

[2] (Sept. 16, 2018). Where Greenhouse Gases Come From [Online]. Available: https://goo.gl/vcHtyz

[3] (Sept. 16, 2018). How Much of U.S. Carbon Dioxide Emissions are Associated with Electricity Generation? [Online]. Available: https://goo.gl/rFseHN

[4] M. S. F. Stern, M. Tanner, and D. Violette, "Greenhouse Gas Reductions from Demand Response: Impacts in Three U.S. Markets," 2016 International Energy Policies \& Programmes Evaluation Conference, Amsterdam, 2016.

[5] L. M. Beard et al., "Key technical challenges for the electric power industry and climate change," IEEE Transactions on Energy Conversion, vol. 25, no. 2, pp. 465-473, 2010.

[6] (2017, November 23). Ontario's Climate Change Update 2014 [Online]. Available: https://goo.gl/73adQ8

[7] B. Finamore et al., "Demand-Side Management in China: Benefits Barriers and Policy Recommendations," Natural Resources Defense Council, 2003.

[8] S. Schiller, "EPA's Clean Power Plan With a Focus on Energy Efficiency and EM\&V," Lawrence Berkeley National Laboratory2015, Available: https://goo.gl/fFdXA7.

[9] C. W. Gellings and J. H. Chamberlin, "Demand-side management: concepts and methods," 1987.

[10] A. B. Haney, T. Jamasb, L. M. Platchkov, and M. G. Pollitt, "Demand-side management strategies and the residential sector: lessons from international experience," The Future of Electricity Demand: Customers, Citizens and Loads, 2010.

[11] P. Palensky and D. Dietrich, "Demand side management: Demand response, intelligent energy systems, and smart loads," IEEE transactions on industrial informatics, vol. 7, no. 3, pp. 381-388, 2011.

[12] C. W. Gellings and K. E. Parmenter, "Demand-side management," in Energy Efficiency and Renewable Energy Handbook, vol. 289no. 310): ROUTLEDGE in association with GSE Research, 2016, pp. 289310.

[13] O. M. Babatunde, P. O. Oluseyi, T. O. Akinbulire, H. I. Denwigwe, and T. J. Akin-Adeniyi, "Chapter 12 - The Role of Demand-Side Management in Carbon Footprint Reduction in Modern Energy Services for Rural Health Clinics A2 - Muthu, Subramanian Senthilkannan," in Environmental Carbon Footprints: Butterworth-Heinemann, 2018, pp. 317-363.

[14] D. L. Summerbell, D. Khripko, C. Barlow, and J. Hesselbach, "Cost and carbon reductions from industrial demand-side management: Study of potential savings at a cement plant," Applied Energy, vol. 197, pp. 100-113, 2017/07/01/ 2017.

[15] G. Strbac, "Demand side management: Benefits and challenges," Energy Policy, vol. 36, no. 12, pp. 44194426, 2008/12/01/ 2008.

[16] P. Samadi, H. Mohsenian-Rad, R. Schober, and V. W. S. Wong, "Advanced Demand Side Management for the Future Smart Grid Using Mechanism Design," IEEE Transactions on Smart Grid, vol. 3, no. 3, pp. 1170-1180, 2012.

[17] E. H. Forman and S. I. Gass, "The Analytic Hierarchy Process-An Exposition," Operations research, vol. 49, no. 4, pp. 469-486, 2001.

[18] O. S. Vaidya and S. Kumar, "Analytic Hierarchy Process: An Overview of Applications," European Journal of operational research, vol. 169, no. 1, pp. 1-29, 2006.

[19] T. L. Saaty, "Decision Making with The Analytic Hierarchy Process," International journal of services sciences, vol. 1, no. 1, pp. 83-98, 2008.

[20] S. Suryanarayanan, "Analysis of the Impact of Hidden Failures Using the Analytical Hierarchy Process," Arizona State University, 2001.

[21] R. Rietz and S. Suryanarayanan, "A Review of the Application of Analytic Hierarchy Process to the Planning and Operation of Electric Power Microgrids," in Power Symposium, 2008. NAPS'08. 40th North American, 2008, pp. 1-6: IEEE. 
[22] T. L. Saaty, Theory and Applications of the Analytic Network Process: Decision Making with Benefits, Opportunities, Costs, and Risks. RWS publications, 2005.

[23] E. W. Cheng, H. Li, and L. Yu, "The Analytic Network Process (ANP) Approach to Location Selection: A Shopping Mall Illustration," Construction Innovation, vol. 5, no. 2, pp. 83-97, 2005.

[24] T. L. Saaty, "Fundamentals of the analytic network process-Dependence and feedback in decisionmaking with a single network," Journal of Systems science and Systems engineering, vol. 13, no. 2, pp. 129-157, 2004.

[25] T. Saaty, Fundamentals of Decision Making and Priority Theory with the Analytic Hierarchy Process. RWS Publications, 2000.

[26] D. T. Feeders, "IEEE PES Distribution System Analysis Subcommittee's, Distribution Test Feeder Working Group," ed, 2013.

[27] A. Elmitwally, "A new algorithm for allocating multiple distributed generation units based on load centroid concept," Alexandria Engineering Journal, vol. 52, no. 4, pp. 655-663, 2013.

[28] S. Abate, "Distribution System Modeling for Assessing Impact of Smart Inverter Capabilities," University of Pittsburgh, 2015.

[29] A. E. Boardman, D. H. Greenberg, A. R. Vining, and D. L. Weimer, Cost-benefit analysis: concepts and practice. Cambridge University Press, 2017.

[30] P. Siano, "Demand response and smart grids-A survey," Renewable and Sustainable Energy Reviews, vol. 30, pp. 461-478, 2014/02/01/ 2014.

[31] J. Torriti, M. G. Hassan, and M. Leach, "Demand response experience in Europe: Policies, programmes and implementation," Energy, vol. 35, no. 4, pp. 1575-1583, 2010/04/01/ 2010.

[32] A. Nottrott, J. Kleissl, and B. Washom, "Energy dispatch schedule optimization and cost benefit analysis for grid-connected, photovoltaic-battery storage systems," Renewable Energy, vol. 55, pp. 230240, 2013.

[33] L. D. A. Garcia, F. Beaune, M. Pitard, and L. Karsenti, "Cost-benefit analysis of MV reactive power management and active power curtailment," CIRED - Open Access Proceedings Journal, vol. 2017, no. 1, pp. 1660-1663, 2017.

[34] O. Vilppo, J. Markkula, P. Järventausta, S. Repo, and T. Hakala, "Cost-benefit analysis for using the Li-ion batteries in low-voltage network for decreasing the outage time experienced by customers," CIRED - Open Access Proceedings Journal, vol. 2017, no. 1, pp. 2201-2204, 2017.

[35] T. Alaqeel and S. Suryanarayanan, "Ex Ante Cost-Benefit Analysis for optimal deregulation of electricity markets," in 2016 IEEE Power and Energy Society General Meeting (PESGM), 2016, pp. 1-5: IEEE.

[36] S. Almohaimeed, S. Suryanarayanan, and P. O’Neill, "Reducing Carbon Dioxide Emissions from Electricity Sector Using Demand Side Management," Utilities Policy, 2019/03/06 [under review] 2019.

[37] S. Almohaimeed, S. Suryanarayanan, and P. O’Neill, "Simulation Studies to Quantify the Impact of Demand Side Management on Environmental Footprints," Journal of Energy Transitions [submitted], April 092019.

[38] "Annual Energy Outlook 2016," U.S. Environmental Information Administration, Washington, DC2016, Available: https://goo.gl/RKM5vf.

[39] (Jul. 20, 2018). Overview of the Clean Air Act and Air Pollution [Online]. Available: https://goo.gl/4MyHs5

[40] "The Legal Foundation for Strong, Flexible \& Cost-Effective Carbon Pollution Standards for Existing Power Plants," Environmental Defense Fund 2014, Available: https://goo.gl/L1S13T.

[41] (Oct. 2, 2017). Analysis of the Impacts of the Clean Power Plan [Online]. Available: https://goo.gl/jcNREs [42] (Nov. 10, 2017). The Clean Air Act [Online]. Available: https://goo.gl/cy7hrw

[43] (Nov. 10, 2017). Progress Cleaning the Air and Improving People's Health [Online]. Available: https://goo.gl/ucXgN8

[44] "Energy Consumption by Sector and Source," Annual Energy Outlook 20172017, Available: https://www.eia.gov.

[45] "Clean Air Act Section 111," U.S. Environmental Protection Agency2013, Available: https://goo.gl/2oNr7B. 
[46] "Structuring Power Plant Emissions Standards Under Section 111(d) of the Clean Air Act-Standards for Existing Power Plants," The Clean Energy Group's Clean Air Policy Initiative 2013, Available: http://www.mjbradley.com/node/237.

[47] "Standards of Performance for Greenhouse Gas Emissions from Existing Sources: Electric Utility Generating Units," Environmental Protection Agency2014, Available: https://goo.gl/Fod16Q.

[48] "Potential Reliability Impacts of EPA's Proposed Clean Power Plan - Phase I," North American Electric Reliability Corporation2015, Available: https://goo.gl/PJWTsa.

[49] I. M. Hoffman, M. A. Billingsley, S. R. Schiller, C. A. Goldman, and E. Stuart, "Energy Efficiency Program Typology and Data Metrics: Enabling Multi-State Analyses Through the Use of Common Terminology," Ernest Orlando Lawrence Berkeley National Laboratory, Berkeley, CA (US)2013.

[50] "Energy-Related Carbon Dioxide Emissions by Sector and Source," Annual Energy Outlook 20172017, Available: https://www.eia.gov.

[51] (Sept. 25, 2017). Clean Power Plan implementation decisions affect CO2 emissions and electricity prices [Online]. Available: https://goo.gl/SyQc5v

[52] (Oct. 20, 2017). Proposal to Repeal the Clean Power Plan [Online]. Available: https://goo.gl/KHKUx9

[53] "2016 Community Carbon Inventory," City of Fort Collins2016, Available: https://goo.gl/JPeciS.

[54] "Climate Action Plan Framework," City of Fort Collins2015, Available: https://goo.gl/4zW2V2.

[55] "A Report to Our Community," City of Fort Collins2016, Available: https://goo.gl/heDkL1.

[56] N. S. Rau, P. Eng, K. Rose, K. W. Costello, and Y. Hegazy, "Methods to quantify energy savings from demand-side management programs: a technical review," The National Regulatory Research Institute, Columbus, OH, 1991.

[57] F. Shariatzadeh, P. Mandal, and A. K. Srivastava, "Demand response for sustainable energy systems: A review, application and implementation strategy," Renewable and Sustainable Energy Reviews, vol. 45, pp. 343-350, 2015.

[58] "INDEEP Analysis Report," Energy Information Administration2004, Available: https://goo.gl/eWh68W.

[59] J. Hong, "The development, implementation, and application of Demand Side Management and control (DSM+c) algorithm for integrating micro-generation system within built environment," University of Strathclyde, 2009.

[60] M. H. Alham, M. Elshahed, D. K. Ibrahim, and E. E. D. A. El Zahab, "Optimal operation of power system incorporating wind energy with demand side management," Ain Shams Engineering Journal, vol. 8, no. 1, pp. 1-7, 2017/03/01/ 2017.

[61] (Aug. 26, 2018). Total Energy [Online]. Available: https://goo.gl/vKLtzf

[62] "Demand-side management," sustainable energy regulation and policymaking for africa, Available: https://goo.gl/BCho9V.

[63] M. Lee et al., "Assessment of demand response and advanced metering," Federal Energy Regulatory Commission, Tech. Rep, 2013.

[64] "Carbon Dioxide Reductions from Demand Response: Impacts in Three Markets," Navigant Consulting, Inc.2014, Available: https://goo.gl/JLu9bg.

[65] F. Eldali, T. Hardy, C. Corbin, D. Pinney, and M. Javid, "Cost-benefit analysis of Demand Response programs incorporated in Open Modeling Framework," in Power and Energy Society General Meeting (PESGM), 2016, 2016, pp. 1-5: IEEE.

[66] J. Han and M. A. Piette, "Solutions for summer electric power shortages: Demand response and its applications in air conditioning and refrigerating systems," Lawrence Berkeley National Laboratory, 2008.

[67] B. Shen, G. Ghatikar, C. C. Ni, J. Dudley, P. Martin, and G. Wikler, "Addressing Energy Demand through Demand Response. International Experiences and Practices," Ernest Orlando Lawrence Berkeley National Laboratory, Berkeley, CA (United States)2012.

[68] M. Gottstein and S. Skillings, "Beyond capacity markets-Delivering capability resources to Europe's decarbonised power system," in European Energy Market (EEM), 2012 9th International Conference on the, 2012, pp. 1-8: IEEE.

[69] P. Alto, "The Green Grid: Energy Savings and Carbon Emissions Reductions Enabled by a Smart Grid," California: EPRI, 2008. 
[70] S. Sharma et al., "Metrics-Based Assessment of Sustainability in Demand Response," in 2017 IEEE 19th International Conference on High Performance Computing and Communications; IEEE 15th International Conference on Smart City; IEEE 3rd International Conference on Data Science and Systems (HPCC/SmartCity/DSS), 2017, pp. 130-137.

[71] "Implementing EPA's Clean Power Plan: A Menu of Options," National Association of Clean Air Agencies2015, Available: https://goo.gl/D2mBhm.

[72] M. DiMascio, J. Amann, and S. Nadel, "The Efficiency Boom: Cashing In on the Savings from Appliance Standards," 2012.

[73] S. Mazur-Stommen and K. Farley, "ACEEE field guide to utility-run behavior programs," American Council for an Energy-Efficient Economy 2013.

[74] R. Kadavil, S. Lurbé, S. Suryanarayanan, P. A. Aloise-Young, S. Isley, and D. Christensen, "An application of the Analytic Hierarchy Process for prioritizing user preferences in the design of a Home Energy Management System," Sustainable Energy, Grids and Networks, 2018.

[75] Y. Levron, J. M. Guerrero, and Y. Beck, "Optimal power flow in microgrids with energy storage," IEEE Transactions on Power Systems, vol. 28, no. 3, pp. 3226-3234, 2013.

[76] "Encourage Clean Distributed Generation," National Association of Clean Air Agencies2015, Available: https://goo.gl/ymkmFb.

[77] M. Mashayekhi, M. Meskin, and A. Farahbakhsh, "Impact of size and location of distributed generation on overcurrent relays in active distribution networks," in Power Symposium (NAPS), 2017 North American, 2017, pp. 1-6: IEEE.

[78] T. Saaty, "The Analytic Hierarchy Process, New York: McGrew Hill," International, Translated to Russian, Portuguesses and Chinese, Revised edition, Paperback (1996, 2000), Pittsburgh: RWS Publications, 1980.

[79] S. A. Mian and C. X. Dai, "Decision-making over the project life cycle: An analytical hierarchy approach," 1999: Project Management Institute.

[80] B. L. Golden, E. A. Wasil, and D. E. Levy, "Applications of the Analytic Hierarchy Process: A Categorized, Annotated Bibliography," in The analytic bierarchy process 1 st ed.: Springer, 1989, pp. 37-58.

[81] "IEEE Guide for Electric Power Distribution Reliability Indices - Redline," IEEE Std 1366-2012 (Revision of IEEE Std 1366-2003) - Redline, pp. 1-92, 2012.

[82] S. Suryanarayanan, M. A. Devadass, and T. M. Hansen, "A Load Scheduling Algorithm for the Smart Home Using Customer Preferences and Real Time Residential Prices," IFAC-PapersOnLine, vol. 48, no. 30, pp. 126-131, 2015/01/01/ 2015.

[83] T. L. Saaty, "Decision making with dependence and feedback," The analytic network process, 2001.

[84] T. L. Saaty, "Multicriteria Decision Making: The Analytic Hierarchy Process: Planning, Priority Setting," Resource Allocation, vol. 2, pp. 1-20, 1990.

[85] T. L. Saaty and L. G. Vargas, "Criteria for evaluating group decision-making methods," in Decision Making with the Analytic Network Process: Springer, 2013, pp. 295-318.

[86] N. Kadoić, N. B. Ređep, and B. Divjak, "Decision Making with the Analytic Network Process," in The 14th International Symposium on Operational Research in Slovenia, 2017.

[87] Z. Baharlouei and M. Hashemi, "Demand Side Management challenges in smart grid: A review," in 2013 Smart Grid Conference (SGC), 2013, pp. 96-101.

[88] Platte River Power Authority hourly load and generation data. Personal communication by Bradley J Decker, Resource Planning Manager, Platte River Power Authority, Ft Collins, CO.

[89] Platte River Power Authority emissions rate data. Personal communication by Bradley J Decker, Resource Planning Manager, Platte River Power Authority, Ft Collins, CO.

[90] A. M. Stanisavljević, V. A. Katić, B. P. Dumnić, and B. P. Popadić, "A Brief Overview of the Distribution Test Grids with a Distributed Generation Inclusion Case Study," Serbian Journal of Electrical Engineering, vol. 15, no. 1, pp. 115-129, 2018.

[91] (Sep. 28, 2018). Greenhouse Gas Equivalencies Calculator [Online]. Available: https://goo.gl/jS4v8o

[92] (Mar. 10, 2019). Energy Emissions [Online]. Available: https://bit.ly/2YMjHPi

[93] M. R. T. Aquino, C Baker, and L. Rowland, "Battery Energy Storage Technology Assessment " 2017.

[94] (Nov. 3, 2018). Coincident Peak [Online]. Available: https://bit.ly/2YMjZ8Q

[95] (Jan. 5, 2019). Residential Rates [Online]. Available: https://bit.ly/2Ud1yf1 
[96] (Dec. 15, 2018). Residential Electric Rates [Online]. Available: https://bit.ly/2K0jCUS

[97] D. S. Kirschen, G. Strbac, P. Cumperayot, and D. de Paiva Mendes, "Factoring the elasticity of demand in electricity prices," IEEE Transactions on Power Systems, vol. 15, no. 2, pp. 612-617, 2000.

[98] P. B. B. Janonis, J. Phelan, L. D’Audney, B. Switzer, and S. Catanach, "Residential Electric Rate Options," 2011, Available: https://bit.ly/2VfIMju.

[99] K. E. Newcomer, H. P. Hatry, and J. S. Wholey, Handbook of practical program evaluation. John Wiley \& Sons, 2015.

[100] P. G. Sassone and W. A. Schaffer, Cost-benefit analysis: A bandbook. Academic Press New York, 1978.

[101] (Feb. 27, 2019). An Introduction to cost Benefit Analysis [Online]. Available: https://bit.ly/2JZ2dfk

[102] E. Quah and J. Haldane, Cost-benefit analysis. Routledge, 2007.

[103] M. D. Adler and E. A. Posner, "Cost-benefit analysis: Legal, economic and philosophical perspectives," 2001.

[104] X. Li, K. Chalvatzis, and P. Stephanides, "Innovative Energy Islands: Life-Cycle Cost-Benefit Analysis for Battery Energy Storage," Sustainability, vol. 10, no. 10, p. 3371, 2018.

[105] A. S. Sidhu, M. G. Pollitt, and K. L. Anaya, "A social cost benefit analysis of grid-scale electrical energy storage projects: A case study," Applied Energy, vol. 212, pp. 881-894, 2018/02/15/ 2018.

[106] (Mar. 2, 2019). Annual Energy Outlook 2019 [Online]. Available: https://bit.ly/2HXqxwr

[107] (Mar 7, 2019). Levelized Cost and Levelized Avoided Cost of New Generation Resources in the Annual Energy Outlook 2017 [Online]. Available: https://bit.ly/2NDZODx

[108] (Feb. 26, 2019). The Social Cost of Carbon [Online]. Available: https://bit.ly/2rs4khX

[109] "City of Fort Collins Utilities: Front Range Smart Grid Cities," US Department of Energy2015, Available: https://bit.ly/2HWkIiI.

[110] "How Much Does Energy Efficiency Cost?," The American Council for an Energy-Efficient Economy2016, Available: https://bit.ly/2CQZL4y.

[111] "Understanding Cost-Effectiveness of Energy Efficiency Programs: Best Practices, Technical Methods, and Emerging Issues for Policy-Makers," U.S. Environmental Protection Agency2008, Available: https://bit.ly/2CTtnOZ.

[112] S. P. M. Quaid, and H. Geller, "Energy Efficiency at Fort Collins utilities: A Role Model for a PubliclyOwned Utilities," Southwest Energy Efficiency Project2013, Available: https://bit.ly/2YMcuiw.

[113] "2018 Proposed Rate Tariff," Platte River Power Authority2017, Available: https://bit.ly/2FXZD5j.

[114] "2018 Residential Rates," City of Fort Collins Utilities, Available: https://bit.ly/2K7brGu.

[115] M. A. Piette, O. Schetrit, S. Kiliccote, I. Cheung, and B. Z. Li, "Costs to automate demand responsetaxonomy and results from field studies and programs," Lawrence Berkeley National Lab.(LBNL), Berkeley, CA (United States)2017. 


\section{APPENDIX}

AHP questions for reducing GHG emissions with an electric distribution system

The answers are provided by the former chair of the city energy advisory board who served from 2011 through 2017. He chaired the board for the last three years of this period and led the extensive five-year revision of the city's energy policy document that was adopted by City Council in early 2016. During his period of service on the Energy Board, Fort Collins developed and adopted an aggressive Climate Action plan that seeks to reduce net city GHG emissions from a 2005 baseline by 20\% by 2020 (achieved in 2018), 80\% by 2030, and $100 \%$ by 2050 . The Energy Board worked closely with the municipal electric distribution utility, environmental service department, other city staff, and outside experts like Rocky Mountain Institute to develop and evaluate plans to implement the Climate Action Plan and to meet other city goals related to energy production and consumption. Among those plans are a time-of-use electric rate that went into effect in October 2018; WiFi thermostat and electric water heater demand-response programs; and a major shift in the city's bulk generation supplier, Platte River Power Authority, from coal to wind, solar, and even battery storage.

Though Mr. O'Neill's entire professional career has been spent in the semiconductor industry, he has been interested in energy technology and policy for decades, following the development of both and experimenting on his own house. He has built two very energy-efficient houses, installed two PV systems, and built an extensive home automation system a major objective of which is energy optimization.

Mr. O'Neill was awarded the MSEE degree in 1978 and the BSEE in 1977, both from Purdue University.

\section{Objective: reduce GHG emissions with an electric distribution system}

Which criterion do you think is more significant in achieving the objective?

1- Cost includes the following: fixed cost, operating and maintenance cost, and avoided cost

2- Reliability is quantified by indices: SAIFI, SAIDI, and CAIDI

3- Power quality includes acceptable levels of the following: harmonics, flicker, voltage deviations, and frequency variations 
Note: slider scale includes 17 steps. Equal means the options are equally important, and the closer the slider to the option the more important

1. 1

Cost

2. 1

Cost

3. 1

Cost

Equal

4. 1

Cost

5. 1

Reliability

Equal

6. 1

Reliability

Equal

Equal

Socio-economic equity

8. 1

Power quality

Equal

Equal

Power quality

10. 1

Environmental collateral

Equal

Reliability

Equal

Power quality

Equal

Socio-economic equity

Environmental collateral

Power quality

Environmental

collateral

7. 1

Reliability

equal

Socio-economic equity

9. 1

Equal

Equal
Environmental collateral

Socio-economic equity

Socio-economic equity 
Which of the following alternatives is more important in achieving the goal WRT?

Note:

1- The closer to the option, the better in achieving the goal with lower cost

2- The closer to the option, the better in achieving the goal with high reliability

3- The closer to the option, the better in achieving the goal with acceptable levels of power quality

4- The closer to the option, the better in achieving the goal with lower environmental impact

5- The closer to the option, the better in achieving the goal with equal socio-economic status

11. Cost

Energy consumption

Equal

12. Cost
Equal

Energy consumption

Equal

Energy consumption

13. Cost

14. Cost

Communication

\&

intelligence

15. Cost

Communication

$\&$

intelligence

16. Cost

Electrification

of

Equal

Equal

Distributed generation

heating \& transportation

17. Reliability

Energy consumption

Equal

Communication \&

intelligence

18. Reliability 
19. Reliability

20. Reliability

Communication \&

intelligence

21. Reliability

intelligence

22. Reliability

Electrification

of

Equal

Distributed generation

heating \& transportation

23. Power quality

Energy consumption

Equal

Communication \& intelligence

24. Power quality

Energy consumption

Equal

Electrification of

heating $\&$ transportation

25. Power quality

Energy consumption

Equal

Distributed generation

26. Power quality

Communication

\&

Equal

Electrification of

intelligence

heating \& transportation 
Communication \&

intelligence

28. Power quality

Electrification

of

Equal

heating \& transportation

29. Environmental collateral

Energy consumption

Equal

Equal

Electrification of

Energy consumption

31. Environmental collateral

Energy consumption

32. Environmental collateral

Communication

\&

Equal

Electrification of

intelligence

33. Environmental collateral

Communication

\&

Equal

Distributed generation

intelligence

34. Environmental collateral

Electrification

of

Equal

heating \& transportation

35. Socio-economic equity

Energy consumption

Equal

Communication \&

intelligence

36. Socio-economic equity 
Energy consumption

Equal

Equal

Energy consumption

38. Socio-economic equity

Communication

\&

Equal

intelligence

39. Socio-economic equity

Communication

\&

Equal

Distributed generation

intelligence

40. Socio-economic equity

Electrification

of

Equal

Distributed generation

heating \& transportation

Distributed generation

heating $\&$ transportation

Electrification of

$$
\text { heating \& transportation }
$$

Distibuted generation

heating \& transportation

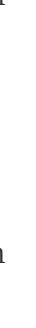


Energy conservation

42. Cost

Energy conservation

Equal

Equal

Load side management

43. Cost

44. Reliability

Energy conservation

Equal

45. Reliability

Energy conservation

Equal

Equal

Load side management

46. Reliability

47. Power quality

Energy conservation

48. Power quality

Energy conservation

Equal

Equal

Load side management

49. Power quality

Load side management

Equal

Equal

50. Environmental collateral

Energy conservation
Load side management

Stationary electric

energy storage

Stationary electric

energy storage

Load side management

Stationary electric

energy storage

Stationary electric

energy storage

51. Environmental collateral 
Energy conservation

Equal

Equal

Load side management

52. Environmental collateral

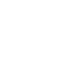

53. Socio-economic equity

Energy conservation

Equal

Load side management

54. Socio-economic equity

Energy conservation

Equal

55. Socio-economic equity

Load side management

Equal
Stationary electric

energy storage

Stationary electric

energy storage

Stationary electric

energy storage

-

Stationary electric

energy storage

Which of the following alternatives is more important in achieving the goal WRT?

Communication and intelligence infrastructure is an alternative to achieve the goal, and it consists of four investment options; Internet of Things (IoT), smart meters and Advanced Metering Infrastructure (AMI), real-time pricing and smart appliances. In this page, we make a comparison between the four options of communication and intelligence with respect to each criterion. . Note: 1- The closer to the option, the better in achieving the goal with lower cost

2- The closer to the option, the better in achieving the goal with high reliability

3- The closer to the option, the better in achieving the goal with acceptable levels of power quality

4- The closer to the option, the better in achieving the goal with lower environmental impact

5- The closer to the option, the better in achieving the goal with equal socio-economic status

Question Title

56. Cost 
IoT

57. Cost

Io'

58. Cost

Io'T

59. Cost

Smart meters

60. Cost

Smart meters

Equal

Smart appliances

61. Cost

Real-time pricing

Equal

Smart appliances

62. Reliability

IoT

63. Reliability

IoT

Equal

Equal

Smart meters and AMI

64. Reliability

IoT

Equal

Smart appliances

65. Reliability

Smart meters

Equal

Real-time pricing

66. Reliability

Smart meters

67. Reliability

Real-time pricing

68. Power quality

IoT
Equal

Smart appliances

Equal

Smart appliances

Equal

Smart meters and AMI 
69. Power quality

IoT

70. Power quality

Io'T

71. Power quality

Smart meters

72. Power quality

Smart meters and AMI

Equal

Smart appliances

73. Power quality

Real-time pricing

Equal

Smart appliances

74. Environmental collateral

IoT

75. Environmental collateral

IoT

76. Environmental collateral

IoT

77. Environmental collateral

Smart meters and AMI

78. Environmental collateral

Smart meters and AMI

79. Environmental collateral

Real-time pricing

80. Socio-economic equity

IoT

81. Socio-economic equity

Io'T
Equal

Smart appliances

Equal

Equal

Real-time pricing

Equal

Real-time pricing

Equal

Smart appliances

Equal

Smart appliances

Equal

Smart meters and AMI

Equal
Real-time pricing 
82. Socio-economic equity
Io'T
Equal
Smart appliances

83. Socio-economic equity

Smart meters and AMI

Equal

Real-time pricing

84. Socio-economic equity

Smart meters and AMI

Equal

Smart appliances

85. Socio-economic equity

Real-time pricing

Equal

Smart appliances

Which of the following alternatives is more important in achieving the goal WRT

Electrification of heating and transportation is an alternative to achieve the goal, and it consists of three options: geo-exchange heat pump, electric water heater, and electric vehicles. In this page, we make a comparison between the three options of electrification of heating and transportation with respect to each criterion

Note:

1- The closer to the option, the better in achieving the goal with lower cost

2- The closer to the option, the better in achieving the goal with high reliability

3- The closer to the option, the better in achieving the goal with acceptable levels of power quality

4- The closer to the option, the better in achieving the goal with lower environmental impact

5- The closer to the option, the better in achieving the goal with equal socio-economic status

86. Cost
Geo-exchange
heat
Equal
Electric water heater

pump

87. Cost 
Geo-exchange heat

pump

88. Cost

Electric water heater

Equal

Electric vehicles

89. Reliability

Geo-exchange heat

Equal

Electric water heater

pump

90. Reliability

Geo-exchange heat

Equal

Electric vehicles

pump

91. Reliability

Electric water heater

Equal

Electric vehicles

92. Power quality

Geo-exchange heat

Equal

Electric water heater

pump

93. Power quality

Geo-exchange heat

Equal

Electric vehicles

pump

94. Power quality

Electric water heater

Equal

Electric vehicles

95. Environmental collateral

Geo-exchange heat

Equal

Electric water heater

pump

96. Environmental collateral

Geo-exchange heat

Equal

Electric vehicles

pump 
97. Environmental collateral

Electric water heater

98. Socio-economic equity

Geo-exchange heat

pump

99. Socio-economic equity

Geo-exchange heat

pump

100. Socio-economic equity

Electric water heater
Equal

Electric vehicles

Equal

Electric water heater

Electric vehicles

Equal

Electric vehicles 
Solar PV

104. Environmental collateral

Solar PV

105. Socio-economic equity

Solar PV
Equal

Equal

Equal
Combustion generation

Combustion generation

Combustion generation 
AHP questions for applying energy conservation to reduce GHG emissions with an electric distribution system Objective: applying energy conservation to reduce GHG emissions with an electric distribution system

Which energy conservation option is more important in achieving the goal WRT

Applying energy conservation is one alternative, under energy consumption, to achieve the goal, and it consists of three investment options: efficient appliances, efficient buildings and behavior (educational programs). In this page, we make a comparison between the three options of energy conservation with respect to each criterion

Note:

1- The closer to the option, the better in achieving the goal with lower cost

2- The closer to the option, the better in achieving the goal with high reliability

3- The closer to the option, the better in achieving the goal with acceptable levels of power quality

4- The closer to the option, the better in achieving the goal with lower environmental impact

5- The closer to the option, the better in achieving the goal with equal socio-economic status

Question Title

1. Cost

Efficient appliances

2. Cost

Efficient appliances

3. Cost

Efficient buildings

4. Reliability

Efficient appliances

5. Reliability
Equal

Efficient buildings

Equal

Behavior

Equal

Behavior

Equal

Efficient buildings 
6. Reliability

Efficient buildings

7. Power quality

Efficient appliances

8. Power quality

Efficient appliances

9. Power quality

Efficient buildings

10. Environmental collateral

Efficient appliances

11. Environmental collateral

Efficient appliances

12. Environmental collateral

Efficient buildings

13. Socio-economic equity

Efficient appliances

14. Socio-economic equity

Efficient appliances

15. Socio-economic equity

Efficient buildings
Equal

Behavior

Equal

Behavior

Equal

Efficient buildings

Equal

Behavior

Equal

Efficient buildings

Equal

Behavior

Equal

Behavior

Equal

Efficient buildings

Equal

Behavior

Equal

Behavior 
ANP questions for reducing GHG emissions with an electric distribution system

Objective: reduce GHG emissions with an electric distribution system using Analytic Network

\section{Process}

For energy conservation, which criterion do you think is more important?

1- Cost includes the following: fixed cost, operating and maintenance cost, and avoided cost

2- Reliability is quantified by indices: SAIFI, SAIDI, CAIDI, CAIFI, and ASAI

3- Power quality includes acceptable levels of the following: harmonics, flicker, voltage deviations, and frequency variations

4- Environmental collateral considers the footprint of the whole system, e.g. fuel extraction in addition to fuel consumption

5- Socio-economic equity means the fairness in the access to and the benefit from the alternatives among social and economic groups

Note: slider scale includes 17 steps. Equal means the options are equally important, and the closer the slider to the option the more important

Question Title

1. 1

Cost

2. 1

Cost

3. 1

Cost

4. 1

Cost

Reliability

6. 1
5. 1

Equal

Reliability

Equal

Power quality

Equal

Environmental collateral

Equal

Socio-economic equity

Equal

Power quality 
Reliability

Equal

Equal

Socio-economic equity

8. 1

Power quality

Equal

Environmental collateral

9. 1

Power quality

10. 1

For load side management (DR), which criterion do you think is more important?

1- Cost includes the following: fixed cost, operating and maintenance cost, and avoided cost

2- Reliability is quantified by indices: SAIFI, SAIDI, CAIDI, CAIFI, and ASAI

3- Power quality includes acceptable levels of the following: harmonics, flicker, voltage deviations, and frequency variations

4- Environmental collateral considers the footprint of the whole system, e.g. fuel extraction in addition to fuel consumption

5- Socio-economic equity means the fairness in the access to and the benefit from the alternatives among social and economic groups

Note: slider scale includes 17 steps. Equal means the options are equally important, and the closer the slider to the option the more important

Question Title

11. 1

Cost

Equal

Reliability

12. 1

Cost

Equal

Power quality

13. 1 
Cost

14. 1

Environmental collateral

Cost

Equal

Socio-economic equity

15. 1

Reliability

Equal

Power quality

16. 1

Reliability

Equal

Environmental

collateral

17. 1

Reliability

Equal

Socio-economic equity

18. 1

Power quality

Equal

Environmental collateral

19. 1

Power quality

Equal

Socio-economic equity

20. 1

Environmental collateral

Equal

Socio-economic equity

For electric stationary storage, which criterion do you think is more important?

1- Cost includes the following: fixed cost, operating and maintenance cost, and avoided cost

2- Reliability is quantified by indices: SAIFI, SAIDI, CAIDI, CAIFI, and ASAI

3- Power quality includes acceptable levels of the following: harmonics, flicker, voltage deviations, and frequency variations

4- Environmental collateral considers the footprint of the whole system, e.g. fuel extraction in addition to fuel consumption

5- Socio-economic equity means the fairness in the access to and the benefit from the alternatives among social and economic groups

Note: slider scale includes 17 steps. Equal means the options are equally important, and the closer the slider to the option the more important 
21. 1

Cost

Equal

Reliability

22. 1

Cost

Equal

Power quality

23. 1

Cost

Equal

Environmental collateral

24. 1

Cost

Equal

Socio-economic equity

25. 1

Reliability

Equal

Power quality

26. 1

Reliability

Equal

Environmental

collateral

27. 1

Reliability

Equal

Socio-economic equity

28. 1

Power quality

Equal

Environmental collateral

29. 1

Power quality

Equal

Socio-economic equity

30. 1

Environmental collateral

Equal
Socio-economic equity

For communication and intelligence, which criterion do you think is more important?

1- Cost includes the following: fixed cost, operating and maintenance cost, and avoided cost

2- Reliability is quantified by indices: SAIFI, SAIDI, CAIDI, CAIFI, and ASAI

3- Power quality includes acceptable levels of the following: harmonics, flicker, voltage deviations, and frequency variations 
4- Environmental collateral considers the footprint of the whole system, e.g. fuel extraction in addition to fuel consumption

5- Socio-economic equity means the fairness in the access to and the benefit from the alternatives among social and economic groups

Note: slider scale includes 17 steps. Equal means the options are equally important, and the closer the slider to the option the more important

31. 1

Cost

32. 1

Cost

33. 1

Cost

34. 1

Cost

35. 1

Reliability

Equal

Power quality

36. 1

Reliability

Equal

Environmental

collateral

37. 1

Reliability

Equal

Socio-economic equity

38. 1

Power quality

Equal

Environmental collateral

39. 1

Power quality

Equal

Socio-economic equity

40. 1 
For geo-exchange heat pump space heat, which criterion do you think is more important?

1- Cost includes the following: fixed cost, operating and maintenance cost, and avoided cost

2- Reliability is quantified by indices: SAIFI, SAIDI, CAIDI, CAIFI, and ASAI

3- Power quality includes acceptable levels of the following: harmonics, flicker, voltage deviations, and frequency variations

4- Environmental collateral considers the footprint of the whole system, e.g. fuel extraction in addition to fuel consumption

5- Socio-economic equity means the fairness in the access to and the benefit from the alternatives among social and economic groups

Note: slider scale includes 17 steps. Equal means the options are equally important, and the closer the slider to the option the more important

41.1

Cost

42. 1

Cost Equal Power quality

43. 1

Cost Equal Environmental collateral

44. 1

Cost Equal Socio-economic equity

45. 1

Reliability Equal Power quality

46. 1

Reliability

Equal

Environmental

collateral

47. 1 
Reliability Equal Socio-economic equity

48. 1

$\begin{array}{lll}\text { Power quality Equal Environmental collateral } & \text { Equal }\end{array}$

49. 1

$\begin{array}{lll}\text { Power quality } & \text { Equal Socio-economic equity }\end{array}$

50. 1

Environmental collateral Equal Socio-economic equity

For electric water heater, which criterion do you think is more important?

1- Cost includes the following: fixed cost, operating and maintenance cost, and avoided cost

2- Reliability is quantified by indices: SAIFI, SAIDI, CAIDI, CAIFI, and ASAI

3- Power quality includes acceptable levels of the following: harmonics, flicker, voltage deviations, and frequency variations

4- Environmental collateral considers the footprint of the whole system, e.g. fuel extraction in addition to fuel consumption

5- Socio-economic equity means the fairness in the access to and the benefit from the alternatives among social and economic groups

Note: slider scale includes 17 steps. Equal means the options are equally important, and the closer the slider to the option the more important

51.1

Cost

52. 1

Cost

Equal

Power quality

53. 1

Cost

Equal

Environmental collateral

54. 1 
Cost

Equal

Socio-economic equity

55. 1

Reliability

Equal

Power quality

56. 1

Reliability

Equal

Environmental

collateral

57. 1

Reliability

Equal

Socio-economic equity

58. 1

Power quality

Equal

Environmental collateral

59. 1

Power quality

Equal

Socio-economic equity

60. 1

Environmental collateral

Equal

Socio-economic equity

For electric vehicles, which criterion do you think is more important?

1- Cost includes the following: fixed cost, operating and maintenance cost, and avoided cost

2- Reliability is quantified by indices: SAIFI, SAIDI, CAIDI, CAIFI, and ASAI

3- Power quality includes acceptable levels of the following: harmonics, flicker, voltage deviations, and frequency variations

4- Environmental collateral considers the footprint of the whole system, e.g. fuel extraction in addition to fuel consumption

5- Socio-economic equity means the fairness in the access to and the benefit from the alternatives among social and economic groups

Note: slider scale includes 17 steps. Equal means the options are equally important, and the closer the slider to the option the more important 
61.1

Cost

Equal

Reliability

62. 1

Cost

Equal

Power quality

63. 1

Cost

Equal

Environmental collateral

64. 1

Cost

Equal

Socio-economic equity

65. 1

Reliability

Equal

Power quality

66. 1

Reliability

Equal

Environmental

collateral

67. 1

Reliability

Equal

Socio-economic equity

68. 1

Power quality

Equal

Environmental collateral

69. 1

Power quality

Equal

Socio-economic equity

70. 1

Environmental collateral

Equal

Socio-economic equity

For solar PV, which criterion do you think is more important? 
1- Cost includes the following: fixed cost, operating and maintenance cost, and avoided cost

2- Reliability is quantified by indices: SAIFI, SAIDI, CAIDI, CAIFI, and ASAI

3- Power quality includes acceptable levels of the following: harmonics, flicker, voltage deviations, and frequency variations

4- Environmental collateral considers the footprint of the whole system, e.g. fuel extraction in addition to fuel consumption

5- Socio-economic equity means the fairness in the access to and the benefit from the alternatives among social and economic groups

Note: slider scale includes 17 steps. Equal means the options are equally important, and the closer the slider to the option the more important

71. 1

Cost

72. 1

Cost

73. 1

Cost

Equal

74. 1

Cost

Equal

75. 1

Reliability

Equal

76. 1

Reliability

Equal

Equal

Socio-economic equity

78. 1

Power quality

79. 1

Equal

Reliability

Equal

Power quality

Environmental collateral

Socio-economic equity

77. 1

Reliability

Equal

Environmental collateral 
Power quality

80. 1
Equal

Socio-economic equity

For combustion generation, which criterion do you think is more important?

1- Cost includes the following: fixed cost, operating and maintenance cost, and avoided cost

2- Reliability is quantified by indices: SAIFI, SAIDI, CAIDI, CAIFI, and ASAI

3- Power quality includes acceptable levels of the following: harmonics, flicker, voltage deviations, and frequency variations

4- Environmental collateral considers the footprint of the whole system, e.g. fuel extraction in addition to fuel consumption

5- Socio-economic equity means the fairness in the access to and the benefit from the alternatives among social and economic groups

Note: slider scale includes 17 steps. Equal means the options are equally important, and the closer the slider to the option the more important

81.1

Cost

82. 1
Equal

Reliability

83. 1

Cost

84. 1
Equal

Equal
Socio-economic equity

85. 1 
Reliability

86. 1

Reliability

Equal

Equal

Socio-economic equity

88. 1

Power quality

Equal

Environmental collateral

89. 1

Power quality

Equal

Socio-economic equity

90.1

Environmental collateral
Equal

Socio-economic equity

This test feeder includes data for lines, transformers, capacitors, spot loads, and distributed loads.

Transformer Data

\begin{tabular}{|c|c|c|c|c|c|}
\hline & $\mathrm{kVA}$ & $\mathrm{kV}$-high & $\mathrm{kV}$-low & $\mathrm{R}(\%)$ & $\mathrm{X}(\%)$ \\
\hline Substation: & 5,000 & $115(\Delta)$ & $4.16(\mathrm{Y})$ & 1 & 8 \\
\hline XFM -1 & 500 & $4.16-(\mathrm{Y})$ & $0.48-(\mathrm{Y})$ & 1.1 & 2 \\
\hline
\end{tabular}

Line Segment Data

\begin{tabular}{|c|c|c|}
\hline Node A & Node B & Length(ft.) \\
\hline 632 & 645 & 500 \\
\hline 632 & 633 & 500 \\
\hline 633 & 634 & 0 \\
\hline
\end{tabular}




\begin{tabular}{|c|c|c|}
\hline 645 & 646 & 300 \\
\hline 650 & 632 & 2000 \\
\hline 684 & 652 & 800 \\
\hline 632 & 671 & 3000 \\
\hline 671 & 684 & 1000 \\
\hline 671 & 680 & 0 \\
\hline 671 & 692 & 300 \\
\hline 684 & 611 & 500 \\
\hline 692 & 675 & \\
\hline
\end{tabular}

Capacitor Data (kVAr)

\begin{tabular}{|c|c|c|c|}
\hline Node & Ph-A & Ph-B & Ph-C \\
\hline 675 & 200 & 200 & 200 \\
\hline 611 & & & 100 \\
\hline Total & 200 & 200 & 300 \\
\hline
\end{tabular}

\begin{tabular}{|c|c|}
\multicolumn{2}{c}{ Regulator Data } \\
\hline Line Segment & $650-632$ \\
\hline Phases & A - B -C \\
\hline Connection & $3-P h$, LG \\
\hline Monitoring Phase & A-B-C \\
\hline Bandwidth & 2.0 volts \\
\hline PT Ratio & 20 \\
\hline Primary CT Rating & 700 \\
\hline
\end{tabular}




\begin{tabular}{|c|c|c|c|}
\hline Compensator Settings & Ph-A & Ph-B & Ph-C \\
\hline R - Setting & 3 & 3 & 3 \\
\hline X - Setting & 9 & 9 & 9 \\
\hline Voltage Level & 122 & 122 & 122 \\
\hline
\end{tabular}

Distributed Load Data

\begin{tabular}{|c|c|c|c|c|c|c|c|c|}
\hline Node A & Node B & Load & Ph-1 & Ph-1 & Ph-2 & Ph-2 & Ph-3 & Ph-3 \\
\hline & & Model & $\mathrm{kW}$ & $\mathrm{kVAr}$ & $\mathrm{kW}$ & $\mathrm{kVAr}$ & $\mathrm{kW}$ & $\mathrm{kVAr}$ \\
\hline 632 & 671 & Y-PQ & 17 & 10 & 66 & 38 & 117 & 68 \\
\hline
\end{tabular}

Spot Load Data

\begin{tabular}{|c|c|c|c|c|c|c|c|}
\hline Node & Load & Ph-1 & Ph-1 & Ph-2 & Ph-2 & Ph-3 & Ph-3 \\
\hline & Model & $\mathrm{kW}$ & $\mathrm{kVAr}$ & $\mathrm{kW}$ & $\mathrm{kVAr}$ & $\mathrm{kW}$ & $\mathrm{kVAr}$ \\
\hline 634 & Y-PQ & 160 & 110 & 120 & 90 & 120 & 90 \\
\hline 645 & Y-PQ & 0 & 0 & 170 & 125 & 0 & 0 \\
\hline 646 & D-Z & 0 & 0 & 230 & 132 & 0 & 0 \\
\hline 652 & Y-Z & 128 & 86 & 0 & 0 & 0 & 0 \\
\hline 671 & D-PQ & 385 & 220 & 385 & 220 & 385 & 220 \\
\hline 675 & Y-PQ & 485 & 190 & 68 & 60 & 290 & 212 \\
\hline 692 & D-I & 0 & 0 & & 0 & 170 & 151 \\
\hline 611 & Y-I & 0 & 0 & 0 & 0 & 170 & 80 \\
\hline & Total & 1158 & 606 & 973 & 627 & 1135 & 753 \\
\hline
\end{tabular}

